Florida International University FIU Digital Commons

\title{
Education for Democracy: Mixed Methods Case Studies of Teachers' Critical Thinking Dispositions and Their Teaching Styles
}

Maram Behairy

mbeha002@fiu.edu

DOI: 10.25148 /etd.FIDC004060

Follow this and additional works at: https://digitalcommons.fiu.edu/etd

Part of the Curriculum and Instruction Commons, Curriculum and Social Inquiry Commons, Educational Psychology Commons, Elementary Education and Teaching Commons, $\underline{\text { Humane }}$ Education Commons, Junior High, Intermediate, Middle School Education and Teaching Commons, Other Teacher Education and Professional Development Commons, and the Social and Philosophical Foundations of Education Commons

\section{Recommended Citation}

Behairy, Maram, "Education for Democracy: Mixed Methods Case Studies of Teachers' Critical Thinking Dispositions and Their Teaching Styles" (2017). FIU Electronic Theses and Dissertations. 3497.

https://digitalcommons.fiu.edu/etd/3497 


\section{FLORIDA INTERNATIONAL UNIVERSITY}

Miami, Florida

EDUCATION FOR DEMOCRACY:

MIXED METHODS CASE STUDIES OF TEACHERS' CRITICAL THINKING

DISPOSITIONS AND THEIR TEACHING STYLES

A dissertation submitted in partial fulfillment of

the requirements for the degree of

DOCTOR OF PHILOSOPHY

in

CURRICULUM AND INSTRUCTION

by

Maram Behairy 
To: Dean Michael R. Heithaus

College of Arts, Sciences and Education

This dissertation, written by Maram Behairy, and entitled Education for Democracy: Mixed Methods Case Studies of Teachers' Critical Thinking Dispositions and Their Teaching Styles, having been approved in respect to style and intellectual content, is referred to you for judgment.

We have read this dissertation and recommend that it be approved.

Linda Spears-Bunton

$\begin{array}{r}\text { Maria Lovett } \\ \hline \text { Isadore Newman } \\ \hline \text { Clement Fatovic, Co-Major Professor } \\ \hline \text { Thomas Reio, Co-Major Professor }\end{array}$

Date of Defense: November 6, 2017

The dissertation of Maram Behairy is approved.

Dean Michael R. Heithaus College of Arts, Sciences and Education

Andrés G. Gil Vice President for Research and Economic Development and Dean of the University Graduate School

Florida International University, 2017 


\section{DEDICATION}

I dedicate this dissertation to my family and friends. My parents raised me with the values that led me to pursue this degree and eventually created the foundation of this work. I grew up knowing that my voice matters and I am capable of dreaming and materializing those dreams. My father taught me to take life in stride, work hard, and stay committed to solid values. My mother is humanity's heart. She modeled what it means to care about others in the way she stands for anyone in need and her support for me in my weakest moments. I would also like to thank my beautiful sister who has modeled determination as I watch in awe as she pursues her dreams. My brother shows me the excitement in learning with his ever-growing list of passions that he masters. I am blessed to have married a man who supported me in every way to grow as an individual. He has been wisdom, stability, and unconditional love. We have been blessed with our incredibly vibrant children. Navigating the terrain of motherhood has allowed me to grow in new ways and appreciate the beauty in struggling through life's winding roads. My hope for my children is the same for all children, to be strong inside and out with a clarity of purpose that their life be a dedication for the betterment of humanity.

I have been blessed with dear friends who have supported me when I break and celebrate me when I grow. Along the way, there have been many and there is really no way to mention every person who has contributed to this work or my life because every conversation or interaction has changed me and helped me grow in different ways. Thank you. 


\section{ACKNOWLEDGMENTS}

I would like to thank the members of my committee and the faculty I have worked with for their guidance, patience, and support throughout this process. Dr. Mohammed Farouk, who started as my major professor, was there throughout the infancy of this work and my start as a doctoral student. I learned so much from him and am eternally grateful for his gentle guidance and wisdom. My coursework with Dr. Spears-Bunton was the impetus of this work, and I am grateful for her valuable feedback on my first graduate papers that revealed my immature understanding of democracy. This led me to Dr.

Fatovic, who guided me to a more sophisticated understanding of political philosophy maintaining high standards and expectations throughout. I admire very much Dr. Lovett's stance for social justice and her creative and vibrant spirit, which has inspired me greatly. Dr. Linda Bliss taught me how to be a qualitative researcher and has been an invaluable resource for me throughout this entire process. She has listened like a true qualitative researcher and gently guided me to growth and greater understanding. Dr. Newman is an accomplished academician who has been so incredibly generous with his knowledge and time. I appreciate his constant support, always remembering me and gently pushing me along throughout the years. Finally, I would like to thank Dr. Reio, who has adopted me and this work and guided us to completion. He has been incredibly encouraging and supportive throughout. I appreciate the contribution every faculty member and peer has made to my growth as a student and as a human being. 


\begin{abstract}
OF THE DISSERTATION
EDUCATION FOR DEMOCRACY:

MIXED METHODS CASE STUDIES OF TEACHERS' CRITICAL THINKING

DISPOSITIONS AND THEIR TEACHING STYLES
\end{abstract}

\author{
by \\ Maram Behairy \\ Florida International University, 2017 \\ Miami, Florida \\ Professor Thomas Reio, Co-Major Professor \\ Professor Clement Fatovic, Co-Major Professor
}

Democracy does not automatically maintain itself by prescribed constitutions and procedural codes (Dewey, 1939), but rather its citizens must have certain dispositions to protect and strengthen it (Biesta, 2006). According to John Stuart Mill (1859/1991), people can tyrannize one another within the structures of a democracy, a concept he phrased "tyranny of the majority" (p. 7). To safeguard against such tyranny and to maintain a democratic way of life conducive to progress, I contend that our schools must be tasked with developing critical thinking dispositions in our future adults. The literature on education for democracy was reviewed and aligned with the critical thinking dispositions defined in the present study.

Critical thinking dispositions are taught through interactions that promote them, not only limited to methods of direct instruction, such that they are infused throughout all academic subjects at all grade levels (Facione, 1990). Therefore, the present study explored the relationship between teachers' critical thinking dispositions and their 
teaching styles. The main research question was: How do critical thinking dispositions differentiate between teaching styles?

To best answer this question 10 mixed methods case studies were conducted of the teachers at one private pre-kindergarten through eighth grade school. The data were collected through a quantitative questionnaire, the California Critical Thinking Dispositions Inventory (CCTDI), and through qualitative observations and interviews. Subsequently, each strand, qualitative and quantitative, was analyzed individually and sequentially. Finally, through cross-case analyses, 10 distinctions in teaching styles were found for teachers who scored high on the critical thinking dispositions: truth-seeking to teacher explorer, truth-seeking to student teaching, open-mindedness to student teaching, inquisitiveness to fallibility, analyticity to emotional adaptability, analyticity to fallibility, analyticity to observational listening, systematicity to nurturing, confidence in reasoning to curriculum expansion, and confidence in reasoning to self-actualization.

Understanding these relationships is the start of possibly being able to use teachers' CCTDI profiles to predict teaching styles and to guide teacher education. Implications for future research include more focused studies around the consistent relationships emerging from the present study and research about students' development of critical thinking dispositions in relation to teaching styles. 


\section{TABLE OF CONTENTS}

CHAPTER

PAGE

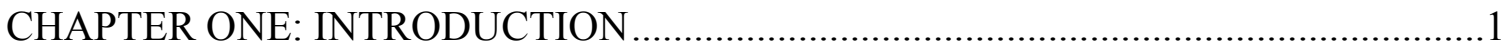

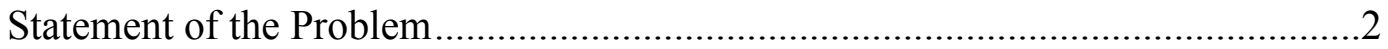

Background of the Problem ..............................................................................

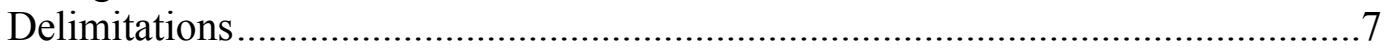

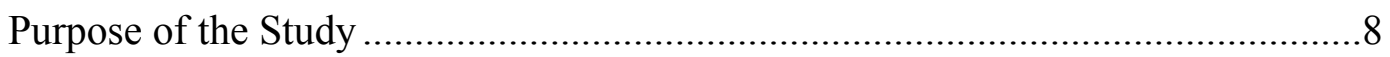

Research Questions …….......................................................................

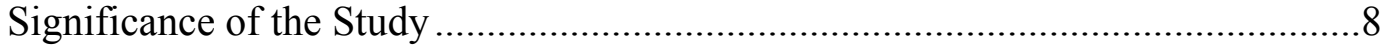

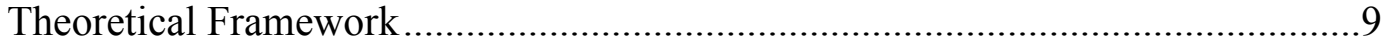

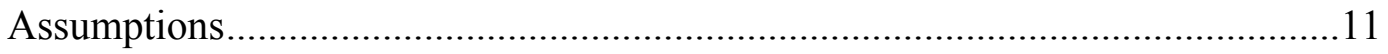

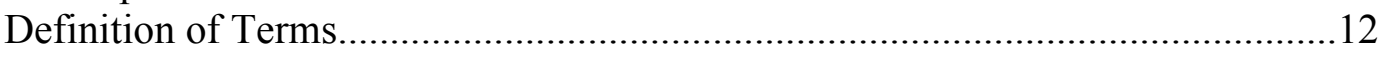

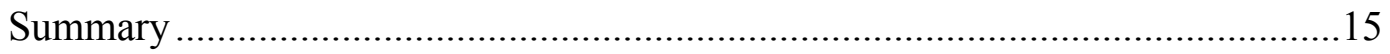

CHAPTER TWO: REVIEW OF THE LITERATURE ..................................................

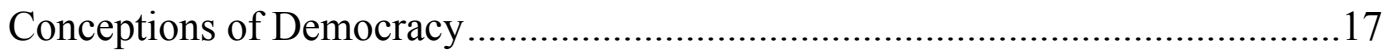

Critical Thinking Dispositions and Education for Democracy..............................25

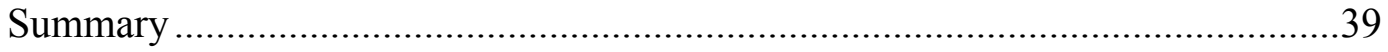

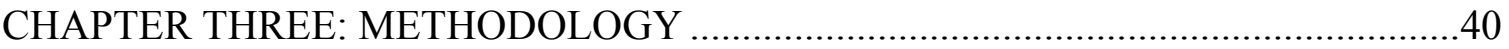

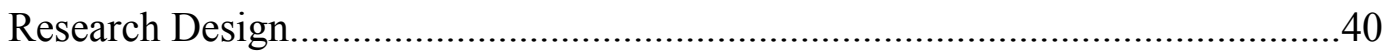

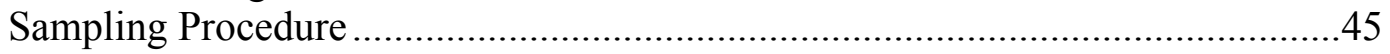

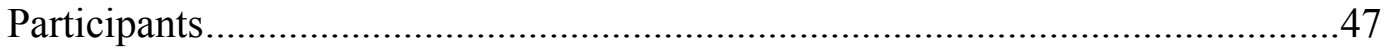

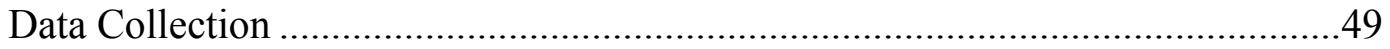

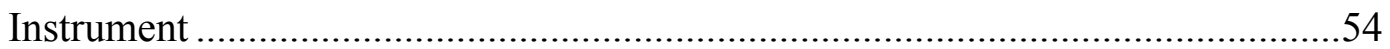

Measures for Quality and Trustworthiness ........................................................57

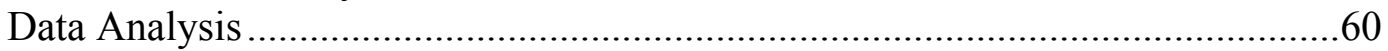

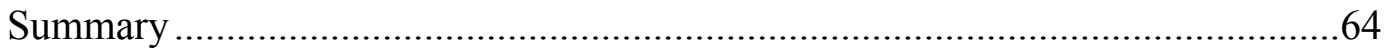

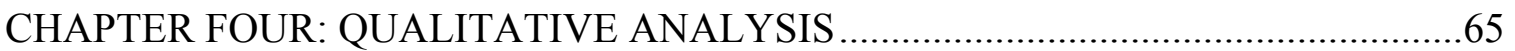

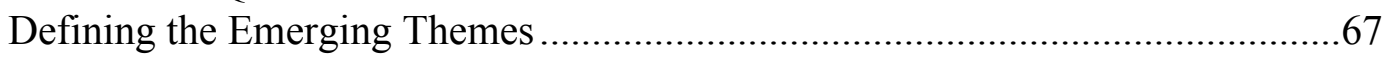

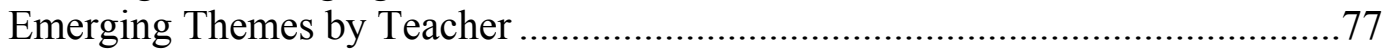

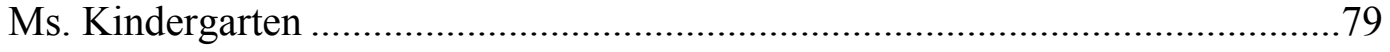

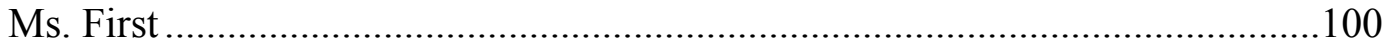

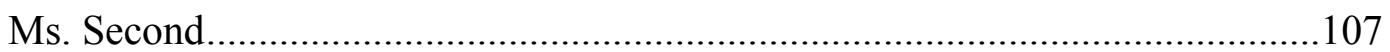

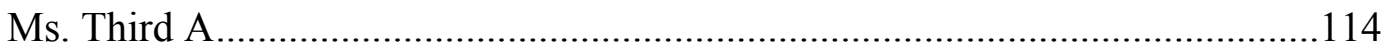

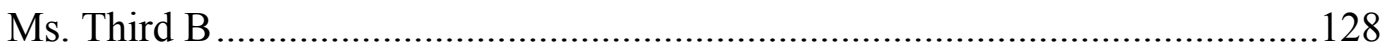

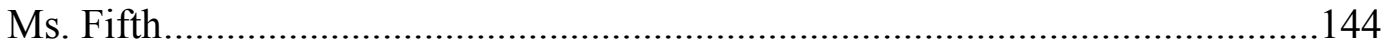

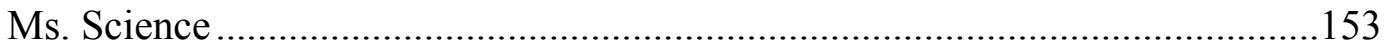

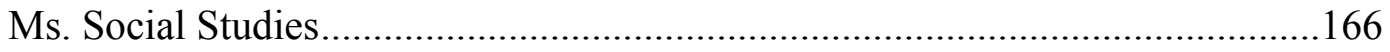

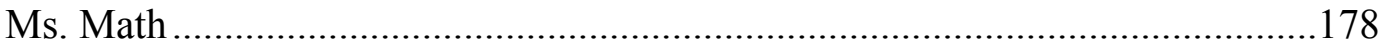




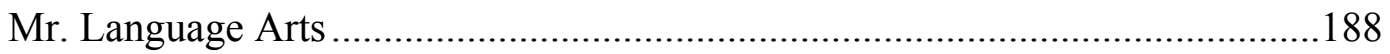

Connecting Themes Through Teachers .......................................................199

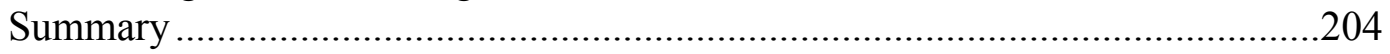

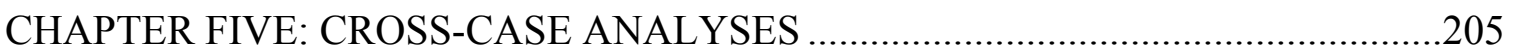

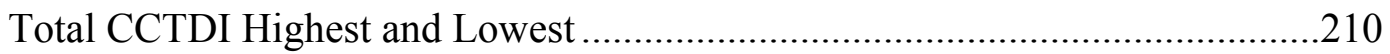

Disposition \#1: Truth-seeking Highest and Lowest..........................................212

Disposition \#2: Open-mindedness Highest and Lowest .....................................217

Disposition \#3: Inquisitiveness Highest and Lowest......................................223

Disposition \#4: Analyticity Highest and Lowest ................................................227

Disposition \#5: Systematicity Highest and Lowest .............................................233

Disposition \#6: Confidence in Reasoning Highest and Lowest...........................238

Disposition \#7: Maturity of Judgment Highest and Lowest ..................................242

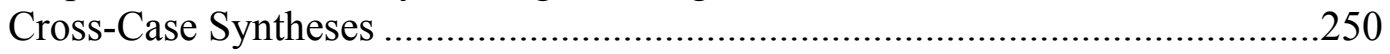

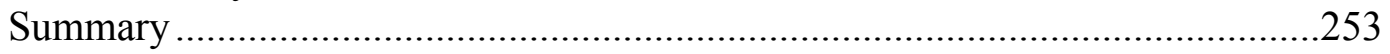

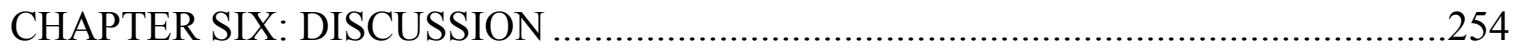

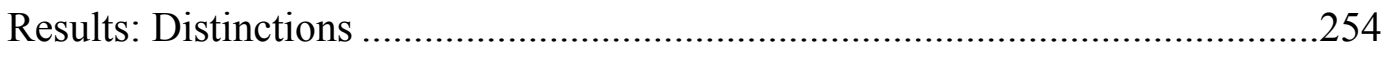

Results: Absent Teaching Styles.................................................................22

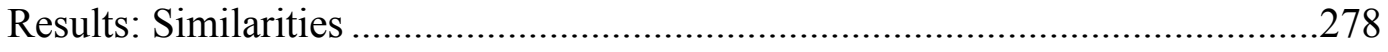

Limitations and Recommendations for Future Research..................................28

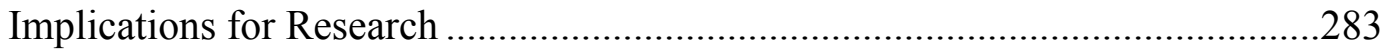

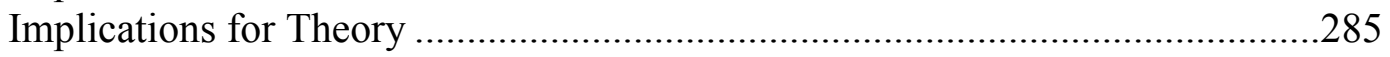

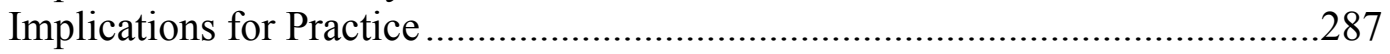

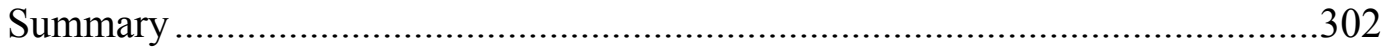

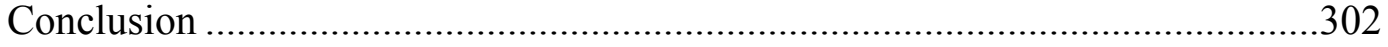

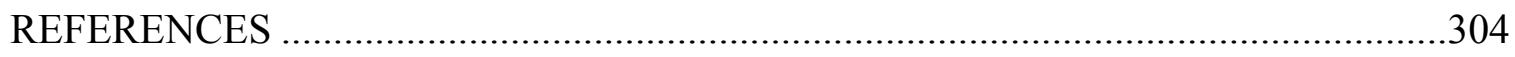

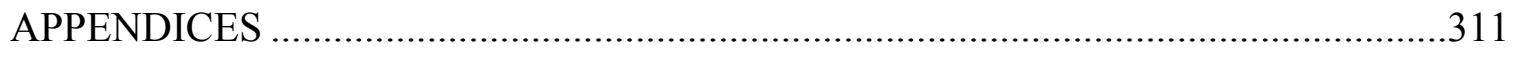

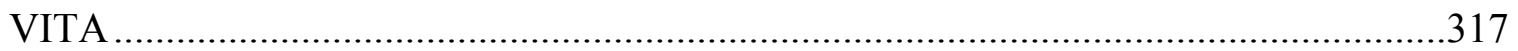




\section{LIST OF TABLES}

TABLE

PAGE

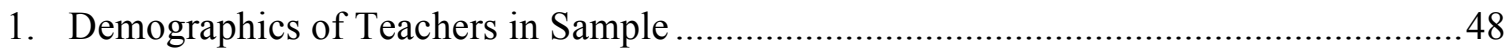

2. CCTDI Internal Consistency Reliability Coefficients ........................................................56

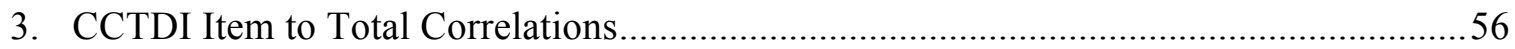

4. Research Questions, Data Collection, and Data Analyses ...............................................60

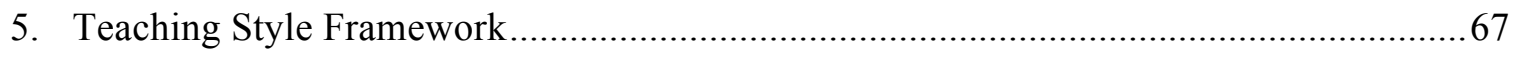

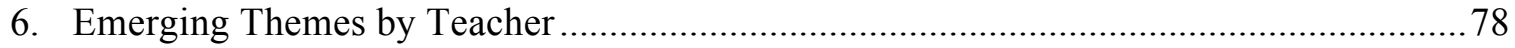

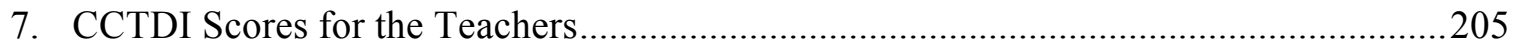

8. Highest and Lowest Scores, Mean, and Median for Critical Thinking Dispositions ......206

9. Highest 5\% and Lowest 5\% of Each Critical Thinking Disposition ................................208

10. Highest 5\% and Lowest 5\% of Each Teacher's CCTDI Scores ......................................2209

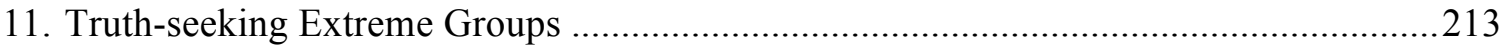

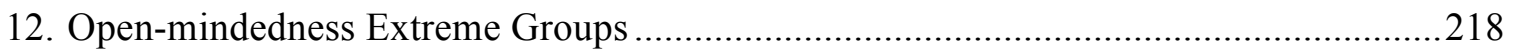

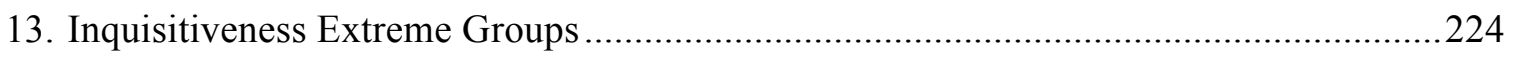

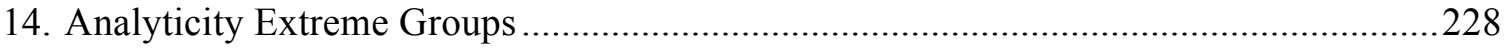

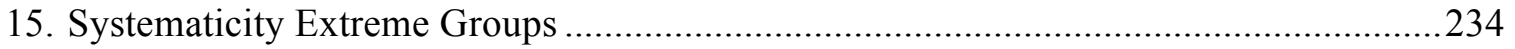

16. Confidence in Reasoning Extreme Groups .............................................................229

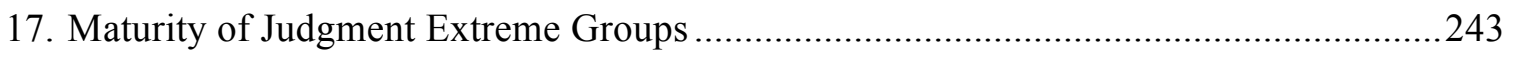

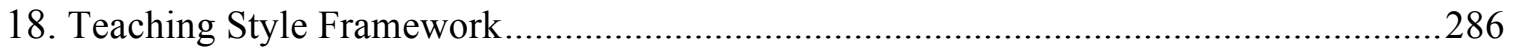




\section{LIST OF FIGURES}

FIGURE

PAGE

1. Theoretical Framework .........................................................................................

2. Multiple-Case Studies Sequential Mixed Methods Research Design........................44

3. The Highest and Lowest Scores for Each CCTDI Subscale..................................207

4. Total CCTDI Score for Each Teacher ...........................................................210

5. Total CCTDI Cross-Case Synthesis of Teaching Styles......................................211

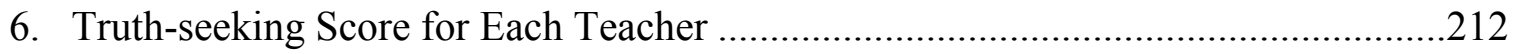

7. Truth-seeking Cross-Case Synthesis of Teaching Styles......................................214

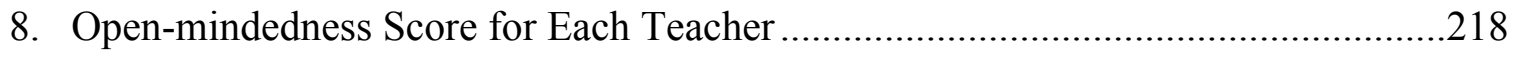

9. Open-mindedness Cross-Case Synthesis of Teaching Styles ................................220

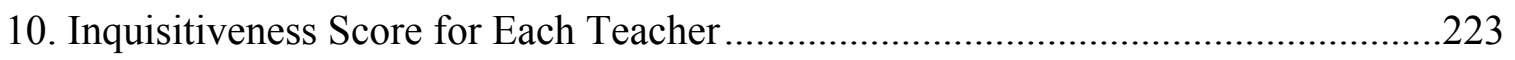

11. Inquisitiveness Cross-Case Synthesis of Teaching Styles …................................225

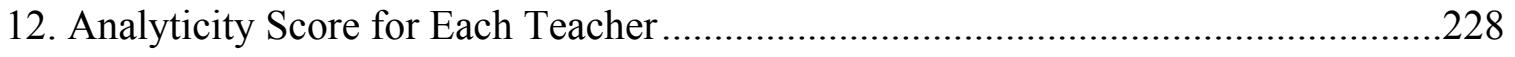

13. Analyticity Cross-Case Synthesis of Teaching Styles ..........................................229

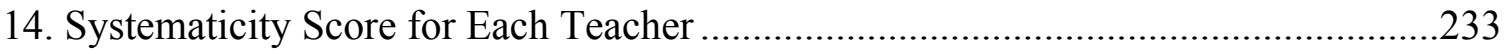

15. Systematicity Cross-Case Synthesis of Teaching Styles .....................................235

16. Confidence in Reasoning Score for Each Teacher .................................................238

17. Confidence in Reasoning Cross-Case Synthesis of Teaching Styles.......................240

18. Maturity of Judgment Score for Each Teacher ..................................................242

19. Maturity of Judgment Cross-Case Synthesis of Teaching Styles ............................244

20. Relationships of Critical Thinking Dispositions to Teaching Styles .......................250

21. Absent Styles Between Critical Thinking Dispositions and Teaching Styles ..........252 


\section{ABBREVIATIONS AND ACRONYMS}

CCTDI

Ms. K

SAT

USA PATRIOT Act

\section{California Critical Thinking Dispositions Inventory}

Ms. Kindergarten

Stanford Achievement Test

Uniting and Strengthening America by Providing

Appropriate Tools Required to Intercept and Obstruct

Terrorism 


\section{CHAPTER ONE}

\section{INTRODUCTION}

"Democracy cannot succeed unless those who express their choice are prepared to choose wisely. The real safeguard of democracy, therefore, is education."

\section{Franklin D. Roosevelt \\ "Message for American Education Week," 1938}

Remember Seuss' Sneetches for a moment. The star-bellied yellow creatures are allowed to fully engage in society while the plain-bellied folk are excluded. Dr. Seuss so beautifully illustrated the absurdity in exclusionary practices when Sylvester McMonkey McBean, the Fix-It-Up Chappie, makes a killing with his machine that initially put green stars on the plain-bellied Sneetches to grant them access to society, but later transformed into a machine to remove stars from the elite Sneetches who wanted to maintain the status quo. The addition and removal of green stars, while profitable for Mr. McBean, became so confusing that the Sneetches were forced to examine their ridiculous class structure. They eventually realized that all Sneetches can fully engage in society no matter their belly decorations. To not only tolerate difference, but to appreciate it, seek it, and defend it requires a totally different understanding of ourselves as human beings and our society at large. The theoretical foundation of the present study was that democracy is the best form of governance because it allows for freedom and free expression, which leads to the best societal outcomes-progress (Mill 1859/1991).

While democracy initially formed as a safeguard against tyrannical rule of a few over the many, Mill (1859/1991) argues that there is another more potent evil that can emerge within a democratic society where people can tyrannize one another, a concept he phrased "tyranny of the majority" (p. 7). Critical thinking is not only a necessary tool for 
fully engaging in democratic discourse, but it is a safeguard against any level of exclusionary practices, or the "tyranny of the majority." Developing critical thinking dispositions in our future citizenry would provide all members of our society access to the dialogue. First, everyone would have full access when they can understand and effectively engage in the discourse. Second, critical thinking serves as a system of checks and balances for any breech on freedom by creating an openness and willingness to engage with new ideas and different people and, also, because those who think critically will not allow others to so freely infringe on anyone's individual liberties. The result, hopefully, will be people who have full access to the dialogue (Gutmann \& Thompson, 2004), and thus a society that will have a greater capacity for progress (Mill 1859/1991). The present study seeks to understand the type of education that will develop students to live by and defend democracy so that we will be not only capable, but also free to have effective, progress-creating discourse.

\section{Statement of the Problem}

Mill (1859/1991) paints the following picture. In the world before democracy existed, when it was merely an outrageous idea, there were kings who saw their power as a God-given right. People knew that their interests were at odds with their government's interests. First attempts at safeguarding individual liberty generally took the form of restrictions placed on rulers' powers. However, a new idea emerged, an expectation that the governing power should align with the people's interests. The governing power should not be feared, but rather should be subordinate to the people. In that way, it would no longer be necessary to limit the government's power because that would be limiting the people's power. Democracy was born out of these ideas (Mill, 1859/1991). 
Democracy does not automatically maintain itself by prescribed constitutions and procedural codes, however (Dewey, 1939). History has shown us how dictators can emerge out of democratic institutions, as occurred with Germany's Hitler and Italy's Mussolini (Goodlad, Mantle-Bromley, \& Goodlad, 2004). Current affairs present many examples of majority votes or powerful votes that undermine individual liberty as Mill (1859/1991) warned, such as the USA PATRIOT Act allowing government unprecedented power to spy on its own citizens without proper checks (American Civil Liberties Union; Chaddock, 2011; Benjamin, 2011). For a democracy to flourish, it must be a way of life ingrained in all societal interactions (Tocqueville, 2002). Therefore, the maintenance of a democracy depends on the people (Plattner, 1998), just as the creation of democracy depended on the people (Mill 1859/1991).

If one sees a society as a collection of individuals, then it follows that the qualities of those individuals are directly related to the qualities of the society at large. If a democratic society requires a people with particular sets of qualities, then the question arises as to how to cultivate these qualities. Scholars agree that schooling is the primary institution in a society that can effectively take on this role of producing a desired citizenry (Barber, 1997; Westbrook, 1996). Westbrook (1996) goes as far as arguing that a measure of a democracy's strength is directly related to the public schools' devotion to the task of cultivating democratic citizens. Thus, the premise of the present study was that schools should educate for democracy by developing important and necessary dispositions in the future adults for the preservation and growth of our democratic society. 


\section{Background of the Problem}

There have been a number of seminal theoretical works that speak to the link between education and democracy such as John Dewey's (1916) Democracy and Education, Gutmann's (1987) Democratic Education, Soder's (1996) Democracy, Education and the Schools, Soder, Goodlad, and McMannon's (2001) Developing Democratic Character in the Young. As a result, there are various important perspectives one can take on an education for democracy.

First, education for democracy may be seen as providing equal educational opportunities for all citizens, as opposed to the injustice of the "savage inequalities" in school conditions based on economic class structures within society (Apple \& Beane, 2007, Greene, 1993; Kozol, 2005). On the most superficial level, schools are not all created equally. The disparity in resources creates a disparity in educational quality. Kozol (2005) describes situations in New York City where the discrepancy between neighboring schools is $\$ 40,000$ in teacher salaries and $\$ 10,000$ per child, with the higher

income school having a majority White student population while the other school having a majority Black and Hispanic population. In a democracy, all people should have access to the decision-making process (Gutmann \& Thompson, 2004) and an education system that does not prepare all of its future citizens to participate in the decision-making process, but instead provides different types of schooling determined by class or race undermines the primary tenet of democracy_empowering the people to govern themselves.

However, on a deeper level, the established curriculum gives the Western voice more authority over other perspectives, which creates racial class structures not 
necessarily parallel to the economic class structures (Aronowitz \& Giroux, 1991). Aronowitz and Giroux (1991) argue that schools must be viewed as both "instructional and cultural sites...places where knowledge and learning are deeply related to the different social and cultural forms that shape how students understand and respond to classroom work" (p. 88). Antithetical to democracy is a curriculum that restricts knowledge to the one designated voice of authority, in American schooling this voice has been Western Civilization and generally White (Aronowitz \& Giroux, 1991). By so doing, the result is a racially and ethnically diverse student population that does not feel appreciated or heard. This student population grows up to either rebel against unjust class structures or apathetically submit to the obstacles they face in a society that shames and shuns them. The wealth of contributions possible from America's pluralistic society are lost in the subliminal racism of a restricted curriculum. Every member of society, even those who are empowered and heard by the curriculum, loses. Every member loses the potential that is portrayed by Mill (1959/1991) of a diverse people interacting and creating better outcomes for society. Implementing a curriculum that integrates and empowers all voices and experiences as valid shows an appreciation for diversity and is a prime way for schools to preserve and cultivate diverse ways of living in a liberal democracy. The structures within society that maintain and perpetuate inequality and injustice create immense obstacles to equal education.

The latter perspective merges the equality of education conversation with the democratic schooling conversation, where students and teachers have a voice in the education in which they engage (Apple \& Beane, 2007; Campbell, 2005; Dewey, 1916; Foster, 2005; Rogan, 2006). Many critical theorists and social justice advocates argue 
that the curriculum materials often marginalize or completely omit multicultural perspectives (Spears-Bunton \& Powell, 2009). There are formative scholars, such as Dewey (1916), who argue that a school must be a model for democracy to cultivate democratic citizens. Therefore, not allowing students the freedom to learn in their own way, the freedom to select topics of interest to them, and the freedom to think independently about the selected topics is a complete contradiction to an education for democracy. Democratic education can also be viewed from the functional perspective of administrators, teachers, and students engaging in the sort of deliberation expected in a democratic society. Actually, Biesta (2007) argues that democratic education can be categorized as one method of developing the necessary qualities of a democratic citizen, the fourth perspective detailed below.

Third, there is the popular perspective of schools developing civic engagement, often called civic education. Civic education programs are more concerned with procedural elements of democracy such as teaching students to vote and participate in institutional democracy (IEA Civic Education Study; McDevitt \& Kiousis, 2006; TorneyPurta \& Barber, 2007). Civic education is an important perspective because citizens who do not know how to engage in the structures of democracy will not be effective. Consequently, knowledge of the democratic institutions and the process of engagement is one element of access. However, while procedural knowledge is an important and necessary prerequisite for action, it does not always translate accordingly and it does not provide the necessary intellectual capacity to engage in an informed and effective manner that the equal educational opportunities emphasizes. 
Finally, there is the perspective of the present study, namely that an education for democracy will develop important and necessary qualities for a democratic society (Soder, Goodlad, \& McMannon, 2001; Westheimer \& Kahne, 2004). Unlike civic education which is concerned with teaching knowledge of democratic institutions and procedures, education for democracy aims to develop qualities needed for selfgovernance. Different conceptions of democracy will necessitate very different important qualities. A liberal and deliberative conception of democracy, discussed in detail later, emphasizes qualities necessary for deliberation and discussion as well as qualities needed for living in a pluralistic society. Therefore, in approaching the connection between education and democracy from this educating "for" democracy point of view, two important questions must be answered. First, what conception of democracy forms our filter? Second and most significant for the present study, what exactly are the important and necessary qualities of a democratic people? These two questions formed the basis of the review of the literature.

\section{Delimitations}

To understand the purpose of the study, it is important to first clarify the delimitations here even though a more detailed discussion follows. While there are various qualities discussed in the literature that are necessary for a democratic citizenry, the present study delimited the scope to critical thinking dispositions as necessary for democratic living, not other types of thinking that are also important for freedom and progress such as creative or innovative thinking or meditative thinking (Facione, 2011). In the review of the literature, the delimitation to critical thinking dispositions was clarified and the various conceptions of the ideal democratic citizen, often coined "the 
good citizen," was aligned with the present study's conception of critical thinking. In researching education, there are numerous possible perspectives—students, environment, administration, teachers, etc. It is important to clarify that the present study was teachercentered, meaning that the focus was the teacher's dispositions and behavior within the classroom as opposed to the students or the school environment.

\section{Purpose of the Study}

The purpose of the present study was to explore the relationship between a teacher's critical thinking dispositions and his/her teaching styles.

\section{Research Questions}

Because this was a mixed methods study, there were two research questions, one for each phase - qualitative and mixed methods. The first research question guiding the qualitative portion of the present study was: How does each teacher interact with the students and the content? The teaching styles emerging from the qualitative data analysis were used along with the quantitative critical thinking disposition scores to answer the main research question: How do the teachers' critical thinking dispositions differentiate between teaching styles?

The critical thinking disposition scores were cross-referenced with the teaching styles emerging from the qualitative data analysis resulting in 10 consistent distinctions, 6 absent styles, and 6 similarities.

\section{Significance of the Study}

There are numerous implications for research, theory, and practice from the results of the present study that are discussed in detail in the final chapter. First, the comprehensive framework of teaching styles emerging from the qualitative phase can be 
used for future research and has implications for theory and practice. Second, the 10 consistent relationships emerging from the cross-case analyses are catalysts for future research studies around teachers' expressed behaviors in relation to personal dispositions as well as student development in relation to teachers' styles. While statistical generalizations to teacher populations were not possible in the present study, analytic generalizations to similar contexts can be useful in guiding teacher education programs (Yin, 2013).

An underlying assumption of the present study was that the critical thinking dispositions of a teacher will transfer to students. Therefore, possible implications of the present study are future studies that explore and test methods to develop critical thinking dispositions in students. More specifically, using the hypotheses that emerged from the present study's results, future research can test how well specific teaching styles are correlated to students' critical thinking dispositions. Critical thinking dispositions would benefit students personally in terms of academic performance, job performance, and personal decision-making throughout life. If more people have greater dispositions towards critical thinking, society as a whole will benefit in areas such as stronger families and stronger businesses (Facione \& Facione, 2007). However, the focus of the present study was developing a citizen population that defends democracy, seeks diversity, and values freedom, and as is elaborated further in the following chapter, critical thinking dispositions are important qualities that serve that purpose.

\section{Theoretical Framework}

The theoretical framework of the present study can be summarized in one statement derived from John Stuart Mill's (1859/1991) conception of democracy: 
democracy is the best means of governance to preserve freedom, freedom is a necessary condition to nurture diversity, and diversity is essential for human progress (Figure 1).

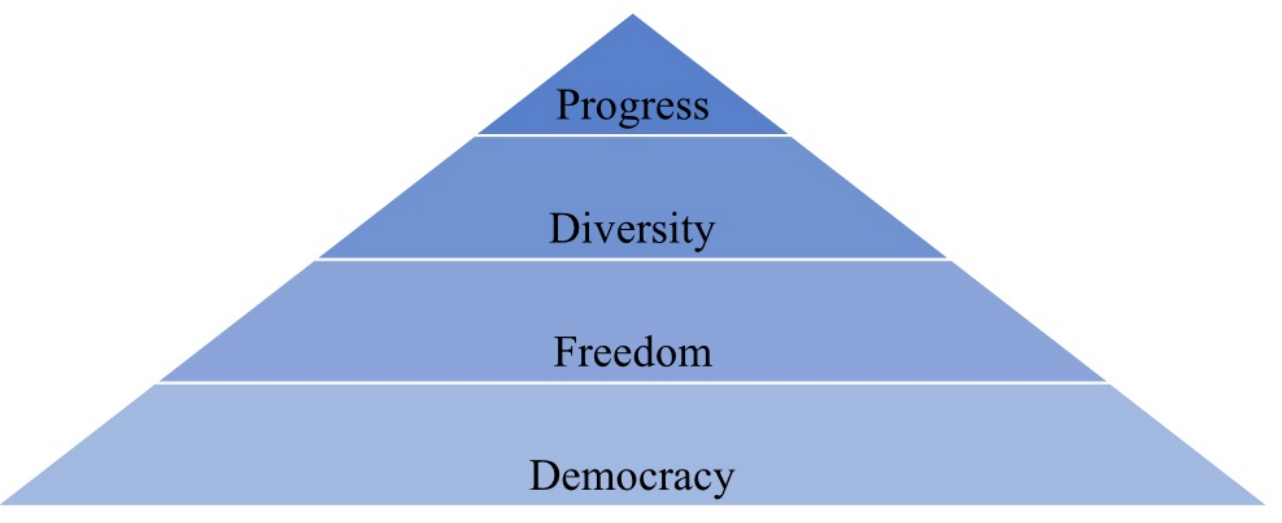

Figure 1

\section{Theoretical Framework}

There are various conceptions of democracy, the present study was conducted in and is based on American democracy. American society by definition is pluralisticreligiously, politically, ideologically, ethnically, racially, etc. All of these differences pose challenges to solidarity and to the assumption that democratic citizens are the same. Therefore, a democratic framework that accounts for and values diversity is fitting. Furthermore, there has been a great emphasis throughout American history on the preservation of individual liberties, as indicated by the Bill of Rights. While republican democratic ideals such as solidarity and homogeneity have foundations in American democracy as well, the US is generally considered a liberal democracy (Plattner, 1998; Tocqueville, 2002; Smith, 1993). However, authors such as Roger Smith (1993) argue that this is a false label that does not account for the lack of egalitarianism in America's history such as slavery and women's rights. He argues for a multiple-tradition approach in defining America's identity. However, even though Smith is right about America not 
living up to stated ideals, he clearly states that the US defines itself as a liberal democracy and, whether it is true or not, this is reason enough our education system must work towards developing the citizens necessary to create the ideal liberal democracy. Smith's argument is one of accurately labeling America on the basis of its history. However, the purpose of the present study was to work towards America's stated ideal, a true liberal democracy. Consequently, Mill's (1859/1991) conception of democracy formed the theoretical framework of this work. Deliberative democracy (Gutmann \& Thompson, 2004; Habermas, 1998) is a supplement to Mill's (1859/1991) ideas, providing a framework to fulfill on the vision of a liberal democracy. Nurturing diversity is only beneficial if those diverse entities can effectively interact and create meaningful outcomes for progress. That effective interaction of diversity is the role of deliberative democracy. The following chapter includes a discussion of the various conceptions of democracy in comparison to Mill's conception.

\section{Assumptions}

There are several concepts that laid a foundation for the present study and were not tested here. The literature supporting these assumptions was provided in the review of the literature. The first string of assumptions was related to the theoretical framework concerning democracy. Firstly, there was an assumption that progress is important and that democracy is the best means towards progress (Mill, 1859/1991). There was an assumption that democracy is the best way to ensure freedom, which will in turn allow for diversity (Mill, 1859/1991). There was an assumption that a successful democracy must have citizens who not only accept, but appreciate diversity (Mill, 1859/1991). There was an assumption that critical thinking dispositions are important and necessary 
qualities for citizens of a democracy to preserve freedom and engage in effective progress-creating democratic life. Therefore, critical thinking will not only improve the personal lives of students, but also improve society at large (Facione \& Facione, 2007).

The second set of assumptions was related to education for democracy. Namely, there was an assumption that teaching style will influence students' learning.

Specifically, the assumption was that certain teaching styles are more likely to develop critical thinking dispositions in students. There was also the assumption that critical thinking dispositions can be learned if students are in a classroom environment that promotes them.

\section{Definitions of Terms}

\section{Critical Thinking}

Critical thinking is "purposeful, self-regulatory judgment which results in interpretation, analysis, evaluation, and inference, as well as explanation of the evidential, conceptual, methodological, criteriological, or contextual inquiry" (Facione, 1990, p. 2). Critical thinking is a commonly mentioned and often heard concept that may seem obvious, but has been defined differently by various scholars. For the purposes of the present study, "critical thinking" was defined according to the California Critical Thinking Dispositions Inventory (CCTDI), which emerged from a two-year study on critical thinking using the Delphi Method. The Delphi Method is a form of qualitative research initially developed by the RAND Corporation in the 1950s for a government inquiry on technology's impact on warfare. It requires an interactive panel of experts anonymously working towards agreement on matters of opinion (RAND Corporation, "Delphi Method"). 
History. In 1987, the Pre-College Philosophy Committee of the American Philosophical Association asked Professor Peter Facione at Santa Clara University to investigate the meaning of critical thinking. As a result, he gathered 46 widely recognized scholars with special experience and expertise in critical thinking instruction, assessment or theory to participate in this Delphi Project. The resulting Delphi Report outlines the core cognitive skills and the dispositions of critical thinking (Facione, 1990). Rather than filter through all of the experts' individual definitions, the CCTDI is an integrated summary developed in much the same way the present study contends that citizens of a strong, progress-oriented democratic society should function.

Critical thinking skills. The experts determined that there are six core cognitive skills of critical thinking: analysis, evaluation, inference, interpretation, explanation, and self-regulation. More than $95 \%$ of the experts agreed on including the first three (analysis, evaluation, and inference) and more than $87 \%$ of the experts agreed on including the last three (interpretation, explanation, and self-regulation) as core cognitive skills. They asserted that a person does not have to be proficient at all six skills to have critical thinking ability; however, to successfully utilize these cognitive skills in certain contexts, one must have "domain-specific knowledge" (Facione, 1990, Delphi Report, p.5).

Critical thinking dispositions. The experts of the Delphi Project differentiated between critical thinking skills and critical thinking dispositions. As indicated on the CCTDI publisher's website, Insight Assessment: 
The CCTDI measures seven attributes that influence an individual's capacity to learn and to effectively apply critical thinking skills: the disposition toward truthseeking or bias, toward open-mindedness or intolerance, toward anticipating possible consequences or being heedless of them [analyticity], toward proceeding in a systematic or unsystematic way, toward being confident in the powers of reasoning or mistrustful of thinking, toward being inquisitive or resistant to learning, and toward mature and nuanced judgment or toward rigid simplistic thinking.

\section{Disposition}

While skills are an ability to perform certain tasks, dispositions reflect the willingness to do so (Facione, 1990; Facione \& Facione, 2007). Because the present study was concerned with educating for democratic life, dispositions are more relevant than abilities that may never be implemented in students' lives. For the purposes of the present study, the term "disposition" was used to refer to the seven critical thinking dispositions outlined by the CCTDI.

\section{Teaching Style}

For the purposes of the present study, teaching style is a general term used to describe the way a teacher interacts with the content and the students. It is a way of being in the classroom. It is the teacher's self-expression as was seen through observations and understood through personal interviews. Thus, teaching style was not measured in a quantitative sense using an established instrument. Teaching style was not predefined using established frameworks because the intent was to allow the teachers' natural expression to emerge without limits. As the Delphi Report asserts, critical thinking should not be seen as a body of knowledge that should be delivered to students as an additional school subject, but rather as a holistic conceptualization that should be infused throughout all subject matters (Facione, 1990, p. 4). This is a fundamental principle that 
guided the development of the teaching style concept of holistically infusing critical thinking in all subject areas at all grade levels.

\section{The Good Citizen}

In the literature, scholars refer to the ideal citizen of a democracy as "the good citizen" (Westheimer \& Kahne, 2004). Clearly, each definition of "the good citizen" varies based on the various conceptions of democracy. These differences are discussed in the review of the literature.

\section{Democracy}

As mentioned briefly and discussed in more detail in the next chapter, there are various conceptions of democracy. The present study utilized the definition of democracy expressed by John Stuart Mill (1859/1991) in On Liberty, where democracy is considered the best system of governance to ensure citizens' individual liberties to nurture diversity for the purpose of societal progress.

\section{Summary}

The present research study sought to understand how a teacher's personal critical thinking dispositions are related to his/her teaching style in the classroom. Foundational to the work is a desire to improve school's education for democratic living. If schools develop certain dispositions in our future adults, the hope is a society of people that are appreciative of difference and open to new ideas, a society of people willing to listen and excited to grow together, a society of free people working together to create a better world - progress. Two major assumptions were that critical thinking dispositions are necessary and important for democratic living and that a teacher can knowingly or unknowingly transfer his/her own personal dispositions through classroom interactions. 
The present research was interested in how teachers' critical thinking dispositions can be expressed in their teaching.

Through a sequential research design of multiple mixed methods case studies, the present study hoped to gain a more holistic understanding of this very important relationship between personal dispositions and expressed teaching styles. Teachers' critical thinking dispositions were quantitatively measured through the CCTDI—an instrument that was developed through an extensive qualitative process (The Delphi Method) integrating the ideas of 46 critical thinking experts. Teaching style, or the teacher's interaction with the students and the content, were explored through observations and interviews. While each strand, quantitative and qualitative, provided valuable information and understanding, the cross-case syntheses best answered the research question, ultimately resulting in 10 consistent relationships between critical thinking dispositions and teaching style. 


\section{CHAPTER TWO}

\section{REVIEW OF THE LITERATURE}

"It is through the cultivation of these (strong impulses) that society both does its duty and protects its interests: not by rejecting the stuff of which heroes are made, because it knows not how to make them" (p. 112).

John Stuart Mill, On Liberty, 1859

The chapter reviews two areas of the literature that were at the foundation of the present study. First, the theoretical framework was "educating for democracy." Therefore, clarifying different conceptions of democracy and specifying the specific conception of democracy underlying the present study is important. Second, one assumption of the present study was that critical thinking dispositions are important and necessary for citizens of a democracy. Each of the seven critical thinking dispositions is defined and discussed in relation to three areas: the present study's conception of democracy, the literature on the good citizen, and the implications for developing the dispositions through education.

\section{Conceptions of Democracy}

The word "democracy" is imprecise and very ambiguous. People with wide variations in beliefs and practices utilize the word quite differently. For this reason, it is crucial to clarify the use of this word for the present study. At the most basic level, democracy is a form of governance or regime type. Other regime types are "autocratic, authoritarian, despotic, dictatorial, tyrannical, totalitarian, absolutist, traditional, monarchic, oligarchic, plutocratic, aristocratic, and sultanistic" (Greenstein \& Polsby, 1975 as cited in Schmitter \& Karl, 1991, p. 76). What makes democracy different is how the ruler comes to power and mechanisms that hold them accountable (Schmitter \& Karl, 
1991). American social scientists tend to use Joseph Schumpeter's definition of democracy: "that institutional arrangement for arriving at political decisions in which individuals acquire the power to decide by means of a competitive struggle for the people's vote" (1943, p. 269). However, for the purposes of the present study, Schmitter and Karl's (1991) modified version is more fitting because it incorporates other mechanisms of citizen competition besides elections and emphasizes the public realm, which is the intent of the present study — to develop citizens who are capable and willing to engage in the public realm in a way that protects and strengthens the democracy. They state that:

Modern political democracy is a system of governance in which rulers are held accountable for their actions in the public realm by citizens, acting indirectly through the competition and cooperation of their elected representative (p. 76).

Accordingly, they define the public realm as the space where collective norms and choices are made, become binding on the society, and are enforced by state coercion. One significant distinction in various conceptions of democracy arises around the scope of the public realm. Liberal conceptions of democracy promote a limitation of the public realm by granting citizens the greatest amount of individual freedoms. On the other hand, while republican conceptions of democracy also value individual freedom, the emphasis is on the collective wellbeing of the society at large.

Examining liberal versus republican democracy is one way of classifying these various conceptions and should not to be confused with the current political understanding of these terms, "liberal" and "republican." While in our current political arena liberal is associated with the Democratic Party and republican with the Republican Party, the present study utilizes these terms (liberal and republican) differently in 
accordance with political philosophers. From a political philosophy perspective, liberal democratic thought values individual liberty above all (Mill 1859/1991). Republican democratic thought, on the other hand, focuses more on the collective (Rousseau, 1762/1978). Schmitter and Karl (1991) contend that applying either conception to the extreme could undermine democracy. The liberal conception could destroy "the basis for satisfying collective needs and exercising legitimate authority" and the republican conception (what the authors term "socialist," not always interchangeable) could destroy "the basis for satisfying individual preferences and controlling illegitimate government actions" (p. 77). Finding the balance between individual independence and social control is a fundamental challenge in society (Mill, 1859/1991).

A prime representation of the liberal conception of democracy, John Stuart Mill's (1859/1991) discussion in On Liberty echoes the underpinnings of the present study. Mill (1859/1991) contends that a society's ultimate goal is progress and diversity is the means to progress. As Wilhelm von Humboldt, who influenced Mill's thinking on individual development, asserts, "The end of man...is the highest and most harmonious development of his powers to a complete and consistent whole" and therefore, every human being must direct his efforts on "the individuality of power and development"; and there are two requirements for this_- "freedom and variety of situations," which will lead to "individual vigour and manifold diversity" (as cited in Mill, 1859/1991, p. 61). Mill (1859/1991) takes von Humboldt's argument of individuality and diversity further, asserting that the end is not the individual, but rather the society progressing. Every opinion, every idea, and every way of life may contain a portion of that truth. If all these opinions, ideas, and ways of life interact, the result would be an outcome that probably 
contains more portions of the truth. Therefore, by allowing diversity in all forms (religious, social, political, cultural, etc.) to develop and by promoting an interaction of these diverse perspectives, human beings are more likely to come closer to the truth and thus progress.

How is freedom and diversity linked to progress according to Mill? To create is the essence of progress - synthesizing new ideas from parts of existing ideas (Mill, 1859/1991). How do you create fertile minds that will generate new thoughts? Freedom. The ability to synthesize or create new structures is a higher order level of human thinking, as Bloom's Taxonomy (1984) reflects. Therefore, people must be free to develop themselves along diverse paths to contribute new ideas. Mill (1859/1991) refers to people's unique ways of living as different life experiments. How do you allow for people's thoughts to come together to create new ideas? Freedom. Consequently, freedom of speech is an integral part of free society, because it is not enough that people are free to think privately. If the knowledge is likened to a building, each new thinker and each generation of thinkers that follows adds to and improves upon the knowledge building. Without the basic tenet of freedom of speech, how will knowledge-builders communicate their thoughts, their innovations, their improvements, their additions? Any seeker of knowledge, any thinker will attest to the painful experience of unexpressed ideas and this is because progress is an essential human phenomenon.

If one looks at each individual, there are people whose judgment is deserving of more confidence than others and that is because they have done more internal "building." Mill contends that it is because these individuals have been open-minded and accepting of criticism. The individuals deserving of more confidence have made a habit of listening 
to whatever others with various opinions have said against them and made a habit of "correcting and completing" their own opinions. "No wise man ever acquired his wisdom in any mode but this; nor is it in the nature of human intellect to become wise in any other manner" (Mill, 1859/1991, p. 25). The individual is the building block of progress for society. Great ideas that led to societal progress originated from individuals. And improving the quality and value of an individual's opinions and ideas requires certain habits of mind, openness to diverse opinions, and openness to criticism of oneself.

The question then becomes what type of society will best ensure human progress by allowing for the development and interaction of diversity. Liberalism allows individuals the freedom to decide their own ways of life, thereby encouraging human beings to develop in unique ways. Therefore, liberalism is an ideal philosophy for the development of maximum diversity among a group of people. A monarchy can theoretically be a liberal society if the sovereign decides to allow citizens the freedom to live in any way they see fit. However, a democracy is more stable, consistent, and sustainable for several reasons. First, a democracy provides a greater guarantee of liberal freedoms. Individuals are less likely to pass laws to infringe on their own freedoms, whereas a monarch may decide that liberal rights for all citizens are not worth the trouble, especially if the citizens' freedoms begin to infringe on the monarch's desires. However, even in a democracy, there are still threats to individual liberty. Mill discusses a concept called "tyranny of the majority" where the majority or the more powerful can infringe on the rights of the minority, all while using the democratic institutions. Therefore, it is not enough for a liberal democracy to set up institutions and constitutions (Dewey, 1939), but rather the ideals of liberalism must permeate the interactions of citizens (Tocqueville, 
2002). Each citizen of a democracy must hold dear the value of individual liberty so much so that he will defend another person's rights even when disagreeing with a particular position.

Second, a democracy is a better political system for the interaction of the diverse perspectives within a society. In a democracy, people must interact and discuss their opinions to create policy. On the other hand, a monarchy has no such requirement. The sovereign may decide to hear the opinion of some people, but the ultimate decision is his alone. However, another threat to liberal democracy is the possibility that laws originate out of people's likes and opinions rather than reason (Mill, 1859/1991). Even if an opinion has popular support, absent of reason, it is still an opinion. Rawls (1996) argues that citizens of a democracy should have discussions and make decisions behind a "veil of ignorance" (p. 12). In this way, people completely ignore their own opinions, biases, or personal interests, and instead utilize legitimate reasons and principles that others would accept to justify their position on any given issue. Therefore, a person could not use religion to justify a decision because not all people will agree with the validity of religious texts. However, that same person could use reason to justify that stance, even if religion is the true motive. The intent is for each person to consider how a decision would impact all members of society, the best off and the worst off. On the other hand, if each person came into the discussion with their own personal interests, those with more persuasive abilities or those with an economic advantage could influence the majority at the expense of the minority (Mill, 1859/1991). Even if such decisions or ideas are not legally implemented in a society, the informal and social objection to specific ways of life can permeate a nation and lead to the tyranny of the majority (Mill, 1859/1991). A 
quick glance at current affairs confirms Mill's (1859/1991) case-for example, the French law that passed majority vote in March 2004 banning religious symbols in public spaces is viewed as a restriction on the individual liberty of many people living in France, especially the liberty of the minority Muslim population (Human Rights Watch, 2004).

Then if a democracy is not enough to safeguard freedom, how can a democratic society ensure liberty? Deliberative democracy has emerged as a normative mode of democracy that privileges specific forms of communication, a supplement to liberalism rather than a stand-alone theory. Unlike views that minimize democratic participation to voting, deliberative democratic theory (also known as discursive democracy) argues that legitimate lawmaking can only occur after public deliberation among citizens. In Millian $(1859 / 1991)$ notions of democracy, discussion among citizens is an essential component of any society. However, Mill (1859/1991) does not detail the process of deliberation although he does briefly touch on the problems that arise when decisions are based on opinions and likes. Deliberative democratic theories such as those proposed by Habermas (1998), as well as Gutmann and Thompson (2004) provide a framework for legitimate deliberation that is an extension of Mill's (1859/1991) ideas and necessary to realize Mill's goals.

Gutmann and Thompson (2004) outline four characteristics of deliberative democracy. First, much like Mill (1859/1991) and Rawls (1996), one must give reasons that appeal to others principles for their position on an issue. These reasons have two goals: to justify decisions and to express mutual respect. Consequently, Habermas (1998) provides four criteria for assessing the validity of an argument: intelligibility, truthfulness, justifiability, and sincerity. The second characteristic of deliberative 
democracy is the necessity of access; there must be equal access to the deliberation process and the arguments made. On the surface, access can be seen as primarily physical. However, a more substantial view, accessibility to the deliberation must consider a people's intellectual ability to understand and contribute to discursive processes. An education for a liberal democratic society requires the cultivation of the skills and dispositions necessary to engage in the democratic processes. The third characteristic is that decisions are binding for some time period. Because deliberation has an intended practical outcome, ongoing discussion with no end is not productive. Deliberative democracy dictates that at some point, deliberation must stop and citizens must take action. However, the fourth characteristic, similar to Mill's (1859/1991) dynamic view of democracy, is the provisional nature of decisions. Every decision can be revisited and revised later, thus supporting Mill's (1859/1991) notion that nobody can ever know with certainty the validity of an idea.

In summary, the term "democracy" is not easily defined and holds many meanings. At the most basic level, it is a form of governance. However, there is much discussion about the limits of government and the balance between individual liberty and collective wellbeing. One common classification of democracy is liberal conceptions and republican conceptions. As stated in the Introduction, political philosophers define the United States as a liberal democracy (Plattner, 1998; Tocqueville, 2002; Smith, 1993). Because Mill's (1859/1991) discussion in On Liberty is a classical work representing liberal democratic thought, it formed the theoretical framework and was the source of defining democracy for the present study. Consequently, deliberative democratic thought (Gutmann \& Thompson, 2004; Habermas, 1998) is an extension of Mill's (1859/1991) 
work and provides the necessary framework that can enable Millian (1859/1991)

democracy to achieve its goals. The following is a discussion of the relationship between critical thinking dispositions, various conceptions of "the good citizen," and education for a liberal deliberative democracy.

\section{Critical Thinking Dispositions and Education for Democracy}

Ultimately concerned with understanding the impact of education on the development of democracy's future citizenry, it was important to clearly define the conception of the "good citizen" that informed the work. Framing the inquiry in terms of extremes as a sort of mental experiment, consider the "good citizen" of a democracy and an authoritarian regime. Unlike an authoritarian government where one supreme decision-maker essentially creates the path of a society, the ruling power in a democracy is the people. Therefore, the people impacted by the decisions have a voice in those decisions. It is reasonable to assume that an authoritarian government would want an education system that develops obedient citizens who never question the powerful, yet a democracy would aim to develop a more critical people who can make informed decisions (Westheimer, 2008). Although basic skills may require didactic instruction, young students should be encouraged to think critically, rather than blindly accept authority (Gutmann, 1987). Ultimately, a democracy requires creators of knowledge, not just passive receivers of knowledge.

While there are numerous conceptions of the good citizen and many ways to classify the qualities of a good citizen, the present study was delimited to critical thinking dispositions as important and necessary for the good citizen of a liberal deliberative democracy. The first section of the review of the literature was therefore organized 
around the seven critical thinking dispositions of the CCTDI, integrating the various definitions of the good citizen along the way_truth-seeking, open-mindedness, inquisitiveness, analyticity, systematicity, confidence in reasoning, and maturity of judgment. Each of the seven dispositions was followed by the corresponding CCTDI definition, the alignment with liberal deliberative democratic thought, the alignment with the relevant literature on the good citizen, and the implications for an education for democracy, which formulated the hypotheses for associated teaching styles.

\section{Truth-seeking}

Truth-seeking $[\mathrm{sic}]$ is the habit of always desiring the best possible understanding of any given situation; it is following reasons and evidence where ever they may lead, even if they lead one to question cherished beliefs. Truth-seekers ask hard, sometimes even frightening questions; they do not ignore relevant details; they strive not to let bias or preconception color their search for knowledge and truth. The opposite of truth-seeking [sic] is bias which ignores good reasons and relevant evidence in order not to have to face difficult ideas (Insight Assessment website).

Liberal deliberative democracy. A truth-seeking disposition acts as a safeguard

for freedom. History has shown how powerful groups within even a democratic society can undermine freedom with the use of propaganda. If citizens are not truth-seekers, it is easier to believe without question an overwhelming storyline propagated as truth. For example, as many military takeovers have done throughout history, the Egyptian military has utilized their allied media outlets to exaggerate and fabricate popular support for the military coup that took place July 3, 2013 (Blumenthal, 2013). Dictatorships use propaganda tactics to effectively brainwash their population into obedience or choosing the "right" side. On an individual level, truth-seeking is the foundation of discourse that creates progress. Mill (1859/1991) says that every opinion can have a part of the truth and 
if we gather the truths from each into one new idea, we progress as a society. Therefore, to be a truth-seeker is to seek alternate viewpoints and to listen openly for possible truths. It is the willingness to acknowledge one's own biases and listen beyond personal filters.

Good citizen. In a seminal work, Westheimer and Kahne (2004) evaluated 10 education programs over 2 years aimed at developing citizens of a democracy. Through their work, three classifications of citizens emerged that seem to encompass many definitions of the "good citizen" found in the literature: personally responsible, participatory, and justice-oriented. To clarify the distinction between these three types, the authors give an example of a food drive. While the personally responsible citizen will contribute to the food drive and the participatory citizen will help organize the food drive, the justice-oriented citizen will explore why people are hungry and act to solve the root causes. Their contention is that an education for democracy should aim to develop the justice-oriented citizen, which is lacking in current programs, while also teaching the skills for participatory citizenship. The concern they expressed is that programs working to develop the justice-oriented citizens lack in developing the skills necessary to fulfill on their social justice agendas.

Westheimer and Kahne (2004) say that to be effective the justice-oriented citizen must consider "the evidence of experts," rather than following their own biases and opinions (p. 243). This clearly aligns with this disposition of truth-seeking because they argue that a justice-oriented citizen must follow the evidence against their own biases if necessary. Therefore, truth-seeking is a necessary disposition for this citizen to be committed to the motivation of social justice and to be effective in the solution. 
Similarly, two of Habermas' (1998) criteria for judging the validity of arguments align with this truth-seeking disposition—-truthfulness and sincerity. Truthfulness is important from both angles, as the creator and assessor of arguments. As the creator of an argument, one must not just be a seeker of truth, but also a creator of truthful statements. As the critic of an argument, the truth-seeker will have a "validity claim" on a statement that is not truthful even if that statement supports his own position. In terms of sincerity, the same logic applies. The lack of sincerity means that an ulterior motive is the driving force behind an argument, a clear bias. Therefore, sincerity is a tenet of a truth-seeking disposition, to not allow personal bias obscure good reason whether you are the creator of an argument or the critic of others' arguments (Soder, 2001).

Education for democracy. If one were to imagine a teaching style that would develop truth-seeking, it would be reasonable to expect a few characteristics. Firstly, a teacher developing truth-seeking may possibly expose students to competing points of view on a specific topic (Loewen, 2007; Zinn, 2003) or various methods of reaching a solution. Consequently, one could reasonably expect this teacher to ask discussionpromoting questions and allow lively debates between competing viewpoints. However, this teacher would also expect students to uphold certain criteria for creating valid arguments, similar to Habermas' (1998) validity claims, such that students cannot be dishonest or make claims without supporting evidence. This may, thus, require the teacher to guide students to research a topic. Consequently, a teacher who models selfreflective practices would theoretically be teaching students to examine one's own biases, not unlike quality qualitative research (Merriam, 2002), and uphold a standard of relying on facts rather than opinions. 


\section{Open-mindedness}

Open-mindedness is the tendency to allow others to voice views with which one may not agree. Open-minded people act with tolerance toward the opinions of others, knowing that often we all hold beliefs which make sense only from our own perspectives. Open-mindedness, as used here, is important for harmony in a pluralistic and complex society where people approach issues from different religious, political, social, family, cultural, and personal backgrounds. The opposite of open-mindedness is intolerance (Insight Assessment website).

Liberal deliberative democracy. To listen from the standpoint of truth-seeking, one must first be open to hearing other people, thus be open-minded. Therefore, in a way, open-mindedness is a prerequisite to truth-seeking. If the goal is a progress-creating society of people who have free and open discourse, open-mindedness is paramount. As Mill (1859/1991) contends, even an outrageous opinion is valuable to a society because it challenges others to strengthen their arguments and, as a result, their convictions and resolve. In order for someone to be willing to even hear an outrageous opinion, let alone a valid different opinion, he/she must possess this disposition towards open-mindedness.

Good citizen. Westheimer and Kahne (2004) describe the justice-oriented citizen as "weighing varied opinions" and argue that they "must develop the ability to communicate with and learn from those who hold different perspectives" (p. 243). This is the essence of open-mindedness. Yet another perspective on the good citizen, the Character Counts! Coalition advocates six pillars of character, two of which align with this CCTDI definition of open-mindedness: respect is to "be tolerant and accepting of differences," and fairness is to "be open-minded and listen to others" (Josephson Institute).

Interestingly, Westheimer and Kahne (2004) subtly criticize the Character Counts! Coalition as developing their first category of the good citizen, the personally 
responsible, in which they argue that even though it may be a desirable outcome for our students, it is not exclusive to democratic living. In other words, an authoritarian regime would not be opposed to having citizens of good character, per se. Westheimer (2008) argues that character development programs promoted by many policymakers advocate for volunteerism and charity work as alternatives to "social policy and organized government action" (p. 10). On the other hand, however, I argue that it would be hard to have a truth-seeking disposition, for example, without a guiding code of ethics to be honest even against ones' own self-interests, similar to Habermas' (1998) truthfulness and sincerity validity claims. Therefore, while Westheimer (2008) may be right that character development is not enough for an education for democracy, it is certainly important and may even be a necessary condition to have effective deliberations.

Education for democracy. What can be reasonably expected of a teaching style that promotes open-mindedness? Firstly, a teacher would model open-mindedness by listening and allowing all opinions and ideas generated by the students. Therefore, if either the text or a student expresses an uncommon perspective or an idea in which the teacher disagrees, the teacher would allow it to be expressed. Similarly, if a student shows intolerance towards an idea in the text or expressed by another student, the teacher would address the intolerance directly. Consequently, the classroom environment would have either implicit or explicit rules for civil discourse such as listening carefully as others speak and disagreeing using validity claims rather than intolerant opinions. 


\section{Inquisitiveness}

Inquisitiveness is intellectual curiosity. It is the tendency to want to know things, even if they are not immediately or obviously useful. It is being curious and eager to acquire new knowledge and to learn the explanations for things even when the applications of that new learning are not immediately apparent. The opposite of inquisitiveness is indifference (Insight Assessment website).

Liberal deliberative democracy. Inquisitiveness is the drive for open and free

discourse. It is what keeps people talking and seeking new ideas, thoughts, opinions, and knowledge. Imagine a society of indifferent people: why would they ever talk to each other about ideas? Communication would probably be limited to functional commands such as "Pass the peas please." Although a total lack of an inquisitive disposition may mean not even trying the peas. Inquisitiveness is the fertilizer that allows individuals to come up with new ideas, ask new questions, try new experiences, and seek better ways of living.

Good citizen. The foundation of the justice-oriented citizen is a question: "Why is this happening?" (Westheimer \& Kahne, 2004). From that question, the justice-oriented citizen seeks the root cause of societal ills with a desire to find a solution, rather than just a temporary fix. This question is indicative of an inquisitive disposition, an intellectual curiosity to discover the cause of a problem. As the definition states, it is the opposite of indifference.

Education for democracy. How can a teacher develop an inquisitive disposition in students? It would be reasonable to assume that it would require a teacher making students feel comfortable and safe to ask any questions that come to mind. Creating that safe environment entails a teacher never demeaning or insulting a student for asking an "irrelevant" question and always responding positively to behaviors that exhibit 
inquisitiveness. It may be challenging to keep students focused on a topic if they ask unrelated questions. However, it may be extremely beneficial to follow the trail that students lead, at least once in a while. Even if time does not permit exploring a tangent question, the teacher can still respond positively and encourage the students by possibly replying along the lines of: "Wow, that is a really intriguing thought. Why not research it tonight and share our findings tomorrow? Thank you so much for adding to our class discussion."

\section{Analyticity}

Analyticity is the tendency to be alert to what happens next. This is the habit of striving to anticipate both the good and the bad potential consequences or outcomes of situations, choices, proposals, and plans. The opposite of analyticity is being heedless of consequences, not attending to what happens next when one makes choices or accepts ideas uncritically (Insight Assessment website).

Liberal deliberative democracy. Because Mill's (1859/1991) goal is societal change or progress, analyticity is important. Free discourse is a means to developing ideas and plans for future possibilities. Therefore, the potential consequences of ideas must always be considered. Free discourse without analyticity is incomplete because it would mean passing around ideas without considering the real-life practical impact of implementing these ideas. Therefore, analyticity should guide discussions and while people may disagree about possible outcomes of decisions, a consideration of outcomes is necessary.

Good citizen. Westheimer and Kahne's (2004) characterization of the justiceoriented citizen would need a disposition towards analyticity. Unlike the personally responsible citizen who engages in community activities designed by others, the justiceoriented citizen is concerned with resolving social problems at the source. This means 
thinking about the cause of a problem and creating solutions that would change it.

Therefore, to be effective, the justice-oriented citizens must first understand the impact of past decisions and anticipate the impact of their proposed solutions. Similarly, Character Counts! also advocates developing responsibility in students, defined as "think before you act—consider the consequences" (Josephson Institute).

Education for democracy. What teaching style would theoretically promote analyticity? Even though history has already revealed the consequences to specific decisions, a teacher could discuss the connection between the policy and the result. This could lead to an intriguing discussion about possible alternative outcomes based on alternative policy decisions. In a math class, entertaining the solution outcomes based on different methods would also theoretically develop analyticity. Even in literature, a teacher could potentially develop this disposition by asking students to anticipate the outcome of a story, imagine various endings to the same story, or even produce their own story. In younger students, even following through on classroom rules and consequences could theoretically teach students analyticity, anticipating the potential consequences of one's actions.

\section{Systematicity}

Systematicity is the tendency or habit of striving to approach problems in a disciplined, orderly, and systematic way. The habit of being disorganized is the opposite tendency. The person who is strong in systematicity may not know of a given approach, or may not be skilled at using a given strategy of problem solving, but that person has the desire and tendency to try to approach questions and issues in an organized and orderly way (Insight Assessment website).

Liberal deliberative democracy. Systematicity is a functional disposition for progress that would greatly increase effectiveness. If we have free and open discourse 
without any systematicity, there is a high likelihood that the thoughts would evaporate without ever materializing into a created outcome. Systematicity forms a structure by which effective discourse can proceed and an effective action plan can emerge. Therefore, while systematicity may not be exclusively important for democracy, I contend it is important to achieve effective results for any desired outcome — democracy or otherwise. However, in a pluralistic liberal democracy with so many competing points of view, a disposition towards systematicity is especially beneficial to aid in the deliberation process and eventually achieve a productive result.

Good citizen. It seems as though the disposition of systematicity would fill the gap that Westheimer and Kahne (2004) point out in education programs aimed at solely developing the justice-oriented citizen. They discuss the skill set taught in programs aimed at developing the participatory citizen, which tends to align with this disposition. The participatory citizen is the one that organizes and executes programs that alleviate social problems without actually solving them at the core, such as the food drive example provided earlier. Therefore, to organize and execute, this citizen has developed effective, action-oriented skills that Westheimer and Kahne (2004) found lacking in the justiceoriented citizen's education. While the justice-oriented citizen has great intentions and a broad and deep understanding of social problems, they will not be effective in changing these problems without the planning, organizing, and executing skills. It also seems that Habermas' (1998) intelligibility validity claim aligns well with systematicity. Systematicity allows one to organize thoughts clearly, which enhances intelligibility. Therefore, it may not be the only factor of an intelligible argument; however, it is a disposition that is important in forming an intelligible argument. 
Education for democracy. As mentioned earlier, systematicity is an important disposition for effectiveness, not an exclusive quality for democratic living. It would be reasonable to expect that structured classroom processes teach students the skills and value of systematicity. By having a schedule for the class such as circle time, reading time, recess, etc. or processes such as homework completion, students become accustomed to orderliness and discipline. This can also be more explicitly taught when teachers expect students to approach questions in an orderly way, for example providing clear steps for writing an essay and providing clear criteria for quality. However, without clearly explaining to students these benefits of having an orderly classroom, would the students be able to transfer the discipline to other areas of life and thought? There is also a question if too much focus on systematicity can hinder creativity, which is also important for democracy. This is the core of the problem with standardizing the curriculum and testing (Au, 2007; Madaus, 1988; No Child Left Behind Act, 2002; Vogler, 2003).

\section{Confidence in Reasoning}

Confidence in reasoning is the habitual tendency to trust reflective thinking to solve problems and to make decisions. As with the other attributes measured here, confidence in reasoning applies to individuals and to groups. A family, team, office, community, or society can be trustful of reasoned judgment as the means of solving problems and reaching goals. The opposite habit is mistrust of reasoning, often manifested as aversion to the use of careful reason and reflection when making decisions or deciding what to believe or do (Insight Assessment website).

Liberal deliberative democracy. In a free society where power is in the hands of the people, confidence in reasoning is essential. Mill (1859/1991) argues that free discourse allows for people to combine their good ideas and develop better possibilities. 
He also contends that even the outrageous ideas are valuable because it drives the holders of truth to strengthen their own positions. This is a reflection of confidence in reasoning, that the process will produce the best outcome. Mill (1859/1991) warns about the dangers of basing decisions on opinions and whims and the potential for the pitfall of the tyranny of the majority as a result. Therefore, I contend that reason is one safeguard against tyranny of the majority.

Good citizen. Westheimer and Kahne (2004) describe the justice-oriented citizen as "considering the evidence of experts, the analysis of government leaders... with the varied opinions and arguments" (p. 243). This description is reflective of the confidence in reasoning disposition because they believe seeking these varied opinions and thinking about them openly will yield the best outcome. McDevitt and Kiousis (2006) contend that having a truly open discourse that will produce new ideas requires citizens to have a confidence in the process, because in the process they must be willing to take risks and potentially be wrong. Those with a confidence in reasoning disposition will trust the process even if a short-term result may not prove successful. This is supported by Gutmann and Thompson's (2004) assertion that decisions in a deliberative democracy are provisional, thus allowing for revision of incorrect actions. This provisional nature is conducive to progress; when the people understand that wrongs can be righted later, there is a willingness to take risks and make binding decisions. Aligning with a confidence in reasoning disposition is Biesta's (2006) stance that citizens of a democracy must have a deep appreciation and understanding of democratic values. Therefore, the people will not abandon reflective thinking and reasoned judgments because it is difficult or time- 
consuming. Rather, the people know the value of this process and trust the outcome as the best means to solving societal problems and achieving goals.

Education for democracy. How would a teacher develop a disposition towards confidence in reasoning? Theoretically, a teacher who encourages students to think through a problem would be developing this disposition. In a math class, this would look like a teacher allowing and guiding students as they work through a problem using logic. This could also be expressed in the teachers' interaction with the students; for example, does the teacher provide reasoning for decisions or just provide the final verdict without explanation? This may even look like a teacher never providing answers at all, but rather offering students information and guiding them with questions.

\section{Maturity of Judgment}

Maturity of judgment is the habit of seeing the complexity of issues and yet striving to make timely decisions. A person with maturity of judgment understands that multiple solutions may be acceptable while yet appreciating the need to reach closure at times even in the absence of complete knowledge. The opposite, cognitive immaturity, is imprudent, black-and-white thinking, failing to make timely decisions, stubbornly refusing to change when reasons and evidence would indicate one is mistaken, or revising opinions willy-nilly without good reason for doing so (Insight Assessment website).

Liberal deliberative democracy. Maturity of judgment is relevant to democracy

because its underlying premise is that there is a discussion of opposing viewpoints. If people have open and free discourse, an end does not always present itself because new knowledge is infinitely available and there are usually several possible paths of action. Therefore, the willingness to make a decision that can be revised thoughtfully is an important habit of progress-creating people. Actually, unlike some republican democratic thought, which argues that citizens have the same "general will" and therefore ought to 
come to the same decisions (Rousseau, 1762/1978), liberal democratic thought does not necessarily expect consensus (Mill, 1859/1991). Maturity of judgment aligns with Mill's $(1859 / 1991)$ assertion to base ideas on reason rather than whims.

Good citizen. The maturity of judgment disposition is aligned with one aspect of Gutmann and Thompson's (2004) characteristics of deliberative democracy, that decisions are binding for some time and can be revisited. As Westheimer and Kahne (2004) contend, the justice-oriented citizen must be prepared to "effectively promote their goals as individuals and groups in sometimes contentious political arenas” (p. 243). However, after effectively promoting one's goals, there should be an agreement among citizens of a democracy that a decision must be made even if unanimity is not achieved.

Education for democracy. How can a teacher develop maturity of judgment in students? Much the same way a teacher would promote truth-seeking by requiring evidence to support positions, maturity of judgment requires justifying an opinion. This aligns well with Habermas' (1998) justifiability claim. Consequently, students can be exposed to the complexity of problems and the imperfection of policy decisions. If a history lesson is studied from this complex point of view, with all the positive and negative outcomes of a decision outlined, students could begin to understand that it is unrealistic in the real world to always expect a perfect solution. This can easily be transferred to literature, exposing students to complex storylines and discussing how the main character deals with a problem. This can also be modeled in classroom processes. If students are asked to decide on the title of a group project, for example, how long does the teacher allow the discussion to continue? What parameters for reaching a decision does the teacher implement? Is the final decision binding for some time? Are there 
provisions for changing a group decision? Maturity of judgment would require that the teacher does stop discussions at some point and make a binding decision that may have provisions for changing it later.

\section{Summary}

Because my research was delimited to critical thinking dispositions as important and necessary qualities of a democratic people, the seven dispositions of the CCTDI were reviewed in relation to the theoretical framework (liberal deliberative democracy) and the literature on the good citizen. In addition, each section ended with a discussion of possible expressions of the dispositions within the classroom. All seven dispositions except for systematicity closely align with an education for democracy. However, even though systematicity is not exclusive to democracy, it is an important disposition for effectiveness and success of any goal. Therefore, it fills a gap often found in programs aimed at educating for democracy without providing the necessary skills to actually execute on ideas and plans (Westheimer \& Kahne, 2004). Furthermore, while there are numerous ways each disposition can be integrated into all the subject matters, there are subtle ways the dispositions may be expressed through classroom processes and environment as well. Consequently, there may be instances that the same teacher behavior can develop more than one disposition simultaneously. 


\section{CHAPTER THREE}

\section{METHODOLOGY}

"He who lets the world, or his own portion of it, choose his plan of life for him, has no need of any other faculty than the ape-like one of imitation" (p. 110).

John Stuart Mill, On Liberty, 1859

Using multiple case studies and a sequential mixed method research design as outlined by Tashakkori and Newman (2010), qualitative data were collected through interviews and observations of 11 teachers at one pre-kindergarten to eighth grade private school. Quantitative data were collected through the CCTDI. The CCTDI provided scores in each of seven dispositions and a total score. Interviews and observations aimed to show how teachers interact with the students and content. After coding categories describing teaching style were developed from the qualitative data (Bogden \& Biklen, 2007; Rubin \& Rubin, 2005), the scores from the CCTDI were analyzed descriptively. Through cross-case analysis for each disposition, teaching styles were compared and contrasted based on CCTDI scores. Thus, the end products of the present study are a teaching style framework and cross-case syntheses detailing relationships between critical thinking dispositions and teaching styles.

\section{Research Design}

\section{Multiple-Case Studies}

In deciding the research design of the present study, I considered three conditions in accordance with Yin's (2013) recommendations: the research question posed, the researcher's control over behavioral events, and whether the focus is on contemporary as opposed to historical events. Case study research is a favorable option for "how" and 
"why" research questions, when there is less researcher control over behavioral events, and when the focus of the study is on contemporary events (Yin, 2013). The current study asked the following main research question: How do teacher's critical thinking dispositions differentiate between teaching styles? Therefore, the first condition for case study research of a "how" question was met. Second, because the present study was looking to understand the relationship between teachers' personal dispositions and their teaching styles, the researcher could not manipulate the variables as in changing the teachers' dispositions or teaching style. Rather, the study examined already existing phenomena. Finally, the events that were studied are current and happening now, and therefore, the final condition was also met.

Yin (2013) defines case study research in two parts: the scope and the features.

He states:

1. A case study is an empirical inquiry that investigates a contemporary phenomenon (the "case") in depth and within real-world context, especially when the boundaries between phenomenon and context may not be clearly evident.

2. A case study inquiry copes with the technically distinctive situation in which there will be many more variables of interest than data points, and as one result relies on multiple sources of evidence, with data needing to converge in a triangulating fashion, and as another result benefits from the prior development of theoretical propositions to guide data collection and analysis (p. 17).

As indicated by the first part of Yin's (2013) definition, in doing case study research, two of the most fundamental problems are clearly defining and bounding the case to be studied. The research question is the starting point in defining the case (Yin, 2013). For the purposes of the present study, the units of analysis were the teachers. Because the focus was teachers at one particular school, it may seem that the school was the unit of analysis; however, only the teachers' personal dispositions and their teaching style were 
observed and analyzed as opposed to looking at other components of the school such as culture, administration, processes, etc. These other areas of the school were only considered in relation to the research question at hand. For example, one teacher was eventually removed from the present study because her strained relationship with the administration impacted her teaching style to a degree that her data were no longer valid in answering the research question. Therefore, each teacher was a case and the boundary of inclusion of cases was the school. The rationale for bounding the cases to one school touches on Yin's (2013) second part of his definition which intended to minimize the impact of different administrative constraints, cultural influences, and other variables in which each school most certainly differs. Rather than study several teachers at various schools, focusing on all the teachers at one school helped minimize the external impact of school environment, a major spurious variable. Because the culture at various schools most definitely varies, and the culture impacts the teaching within classrooms, minimizing these variables allowed for more focus and clarity in the findings. One would theoretically expect these variables to have a link to the way a teacher interacts with her students and the content. By bounding the cases to one school, the research focus was the teacher while holding other school variables somewhat constant. Obviously, the administration could theoretically and sometimes did interact with each teacher differently, thus adding an element of impact; however, these findings were incorporated into the analysis and added depth and nuance to the findings. Important though, all the teachers were working in the same school culture with the same explicit guidelines. 


\section{Sequential Mixed Methods}

In addition to being multiple case studies, the present study also utilized a sequential mixed methods approach (Tashakkori \& Newman, 2010). Because the aim was to understand teachers' critical thinking dispositions in relation to their actual classroom behaviors as teachers, it was very important to gather more in-depth qualitative data along with the quantitative disposition scores. Teddlie and Tashakkori $(2010,2011)$ contend that contemporary mixed methods research is methodological eclectic where "practitioners select and creatively integrate the most appropriate techniques from a wide variety of QUAL, QUAN, and mixed strategies in order to thoroughly investigate the phenomena of interest" (as cited in Teddlie \& Tashakkori, 2012, p. 776). Yin (2013) states, "Mixed methods research forces the methods to share the same research questions, to collect complementary data, and to conduct counterpart analyses" (p. 65). Yin (2013) distinguishes between two types of nesting arrangements where either a case study is embedded as a qualitative data collection method under a larger mixed methods design or "other research methods are embedded within case study research" (p. 66). The present study is the latter, for each of the 11 cases (10 eventually remaining), data were collected using mixed methods. The meta-inferences are a result of cross-case syntheses discussed in the analysis section of this chapter (Yin, 2013).

To minimize researcher bias in the observations, the CCTDI scores were not known before collecting and analyzing the qualitative data. The research design is sequential because the qualitative observations and interviews were conducted and analyzed first before looking at the quantitative CCTDI data (Tashakkori \& Newman, 2010). The CCTDI scores were then described in detail and emerging patterns were 
discussed. The teaching style themes that emerged from the qualitative data analysis were then integrated with the patterns that emerged from the CCTDI scores to produce the meta-inferences, more specifically the cross-case syntheses. In this way, the present study relied on mixed methods. Figure 2 below shows the multiple case studies sequential mixed methods research design utilized for the present study.

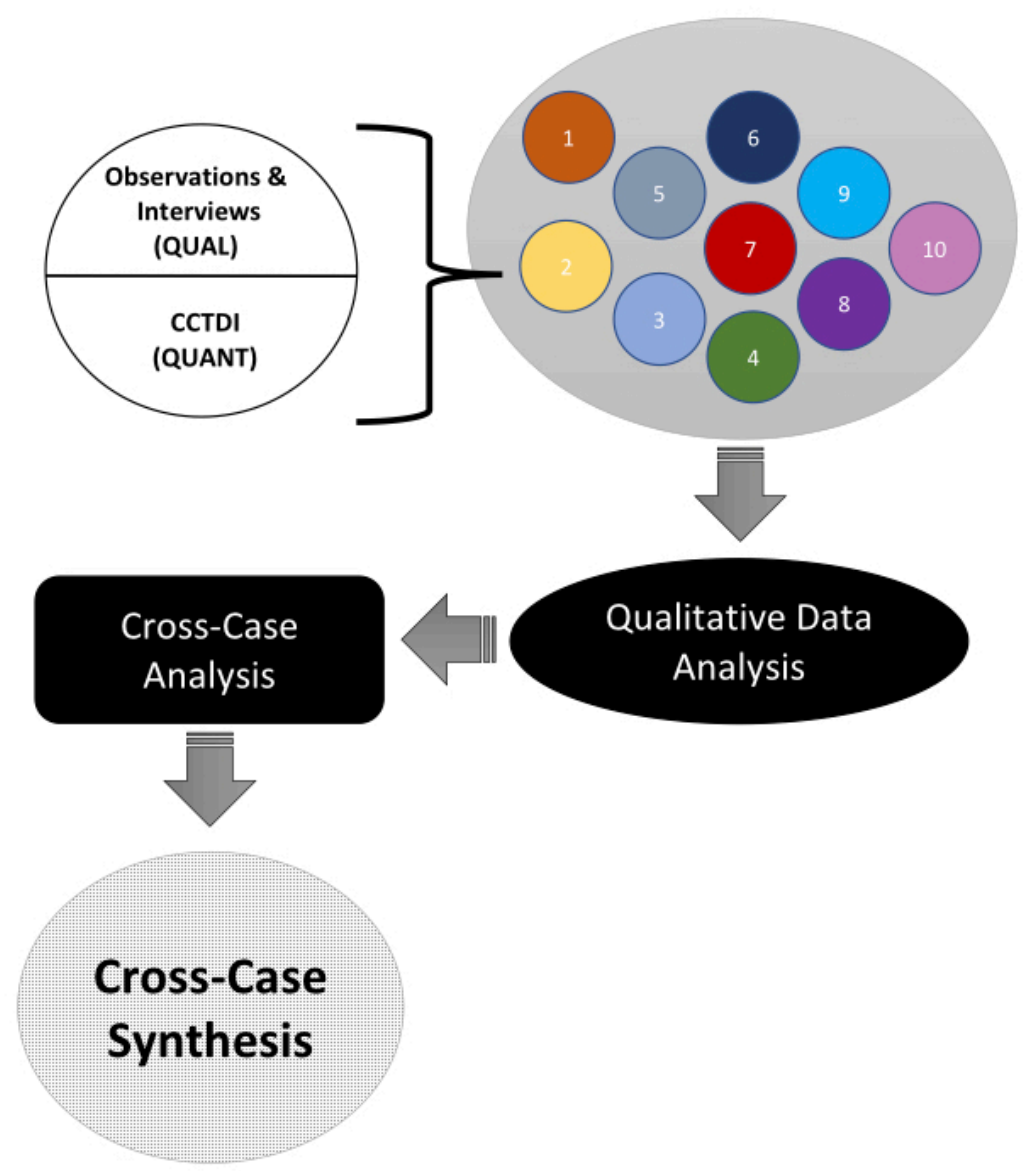

Figure 2

Multiple-Case Studies Sequential Mixed Methods Research Design

To summarize, first both the qualitative and quantitative data collection for each case study occurred. Second, the qualitative data analysis of all the case studies was completed, resulting in a teaching styles profile for each teacher case. Third, the CCTDI 
quantitative data were analyzed and described in detail. Finally, a cross-case analysis of all the teachers was conducted, comparing and contrasting teaching styles using the quantitative CCTDI scores. The resulting cross-case synthesis provided multiple inferences around the relationships between teaching styles and critical thinking dispositions, thus answering the research question: How do critical thinking dispositions differentiate between teaching styles?

\section{Sampling Procedures}

The school for the present study was purposively selected "to yield the most information about the phenomenon of interest" (Merriam, 2002, p. 20; Newman \& McNeil, 1998). It is a small private school from pre-kindergarten to eighth grade in Broward County, Florida. It is important to note my relationship to this school. My son attended pre-kindergarten at this school. My mother was also previously the middle school math teacher. Finally, my father is currently on the board of the school. All of these factors facilitated my entry into the school and allowed me to gain an insider perspective on the administrative practices discussed below. As a result, there may be a concern that the administration would not be able to decline participation in the present study. However, I had previously requested to pass out politically-oriented flyers at the school and was denied by the same principal, indicating her comfort in denying my request irrespective of my father's influence. Therefore, I am confident that the administration would have felt comfortable declining participation without fear of repercussion. The reflective practices discussed below under "Measures of for Quality and Trustworthiness" mitigated possible bias that may have presented itself. 
There were several reasons this school setting was ideal for the present study. First, its size made it suitable for a more in-depth case study that can included all the cases (teachers) at the school. Second, because it is a private school, natural teaching style was more likely observed by avoiding the constraints of standardized testing placed on public school teachers (Au, 2007). Third, this particular private school allows teachers a great level of freedom in selecting textbooks, designing their curriculum, and selecting their instructional methods. The expectation was a greater level of naturally arising diversity in teaching styles. For the present research, I expected a more accurate representation of the relationship between teachers' personal dispositions and their teaching style because the teachers did not have a specific curriculum and instructional method imposed on them from above.

The sample was delimited to include only the kindergarten through eighth grade teachers of the main subject areas - main teacher for elementary grades and middle school math, science, social studies, and language arts. While one can argue that prekindergarten teachers can also interact with the students and content in ways that promote critical thinking or not, the researcher decided that including the younger ages would possibly require different research methods because of the differences in toddlers. Beginning with kindergarten, the teachers and the school take on a more structured classroom approach and the research methods were suitable. The extra-curricular teachers were also not asked to participate for similar reasons. While extra-curricular teachers can theoretically teach in different ways to reflect and promote critical thinking, a different research design may be needed to explore and capture that relationship for those teachers. First, they are not always in a classroom setting, such as the physical education teacher. 
Meanwhile, the extra-curricular teachers often provide other administrative duties such as study hall or transitions between classes. These duties would have been obstacles to the observation component in the research design. Finally, there is only one teacher for the entire school in each extra-curricular subject and the cross-case analysis may not be the best analytic technique to account for the influence of the subject matter on teaching styles. In casual observations while at the school, I did notice the unique conversations the physical education teacher would engage with the older students. Therefore, not including the extra-curricular teachers is a possible limitation and an area for future research that is discussed in the final chapter.

\section{Participants}

\section{Teachers}

The school begins at pre-kindergarten and ends at eighth grade. As discussed previously, the participants have been delimited to the teachers of kindergarten to eighth grade of only the main subject areas. There was one class with one teacher for each grade level between kindergarten and fifth grade, except for third grade which had two separate classrooms with their own teachers. Middle school grades six through eight had four teachers, one for each subject area-Math, Science, Social Studies, and Language Arts. Although data were collected and analyzed for the grade four teacher, she was not included in the results due to fidelity concerns. As mentioned previously, the teacher's strained relationship with the administration adversely impacted her relationship with the students. The entire interview was a catharsis of the unhealthy dynamic that had developed. While her contribution was important in understanding how a teacher's emotions can impact her teaching styles, it was not a valid representation of her critical 
thinking dispositions relationship to her teaching styles. Therefore, after removing the fourth grade teacher from the present study, the total number of cases was 10 .

\section{Demographics}

A demographic survey was administered at the beginning of the online CCTDI obtaining the following information for each teacher: gender, age, education level, education track, and years of teaching experience. It was gathered to provide context to the results, providing nuance to further understanding the teaching styles of the participants. The table below (Table 1) summarizes the demographic data.

Table 1

Demographics of Teachers in Sample

\begin{tabular}{lllll}
\hline Teacher & Gender & Age & Degree & Experience \\
\hline Kindergarten & F & 49 & BA, Alternative & 10 years \\
First & F & 35 & BA Elementary & 9 years \\
Second & F & --- & BA Elementary & 4 years \\
Third A & F & 47 & BA Elementary & 14 years \\
Third B & F & 33 & BA, Alternative & 10 years \\
Fifth & F & 31 & BA Middle School Math \& Science & 4 years \\
Math & F & 36 & BA Math Education, MS Education & 6 years \\
Science & F & 37 & BA Education, MS Middle School & 14 years \\
Social Studies & F & 47 & Non-US Law Degree, Alternative & 9 years \\
Language Arts & M & 64 & BA Science, MS Elementary Education & 30+ years \\
\hline
\end{tabular}




\section{Confidentiality}

The teachers were not promised confidentiality. It is a small school and dissertations are published works. Therefore, anyone with knowledge of the present study can find this work. The subject and grade level are important factors that were considered and stated in the data analysis phase. They offer a perspective on inferences made and therefore could not be hidden in the report. Even though the researcher did not use the names of the teachers and maintains confidentiality with the name of the school, it would be easy to identify the person based on subject and grade level taught. The letter that was given to the participants can be found in Appendix A.

Even though confidentiality was not promised and the teachers still agreed to participate in the study, I did abide by certain rules in the way I handled the data. First, my laptop is password protected and the observation data recorded on it is inaccessible to anyone. Second, I did not share any information obtained from the teachers with the administration or other teachers. Third, the device containing the recorded interviews was in my possession at all times. Finally, I will not be providing the administration or the teachers a copy of the present study.

\section{Data Collection}

Data were collected in three ways. The CCTDI provided quantitative scores for teachers' critical thinking dispositions. The observations and interviews provided qualitative data to understand teaching styles.

\section{CCTDI}

The CCTDI was administered electronically to all teachers individually through an online module provided by the publisher, Insight Assessment. The researcher provided 
the website and log-in information to the teachers and asked them to complete it at their convenience within a two-week period. As described in the "Instrument" section below, the CCTDI is a quantitative measure of a person's critical thinking dispositions. The results of the questionnaire are numerical scores in each of seven dispositions categories and one total score. The maximum score in each disposition category is 60 and the maximum total score is 420 .

\section{Observations}

The observations have provided the main source of qualitative data from the researcher's perspective of how the teachers interact with the students and content. As Bogdan and Biklen (2007) say about an organizational case study, the researcher picks areas to focus on; therefore, the foci in this case study were the teaching style and critical thinking dispositions. While the observations were more open-ended without the use of an instrument, I was looking through the lens of the critical thinking dispositions. Because the purpose of the present study was to explore how a teacher's personal critical thinking dispositions are reflected in his/her teaching, the seven dispositions of the CCTDI formed a backdrop to the observations and interviews. Even though the dispositions formed a backdrop, the classroom actions associated with these dispositions were not known. However, I did have preconceived expectations of teaching that may theoretically be associated with each critical thinking disposition, as was described in the previous chapter. To improve the validity of the observations, I did not look at or analyze the CCTDI scores before collecting and analyzing the qualitative data. With this approach, I increased the likelihood that the observed phenomena were not a result of my preconceived expectations based on CCTDI profiles for each teacher. 
The initial question I kept in mind was: "How does the teacher interact with the students and the content?" The observation guide created prior to the present study merely served as a thinking tool in analyzing observation data, but was not used during the observation (Appendix B). The observation protocol reflects my prior expectations of possible indicators of the teachers' expressions of personal critical thinking dispositions before beginning the study, thus serving a dual purpose — assist in analysis and identify personal researcher biases, as Merriam (2002) recommends.

Each teacher was observed between three and six times, with the majority being observed four times or more. Each session lasted a range of half an hour to an hour and one half, with the majority lasting roughly an hour. The number of observations was not predetermined. The decisive factors in determining the number of visits were whether or not the teacher had different classrooms, as was the case for the four middle school teachers, and whether or not I felt saturation was reached. Saturation is described by Merriam (2002) as beginning "to see or hear the same things over and over again, and no new information surfaces as you collect more data" (p. 26). Therefore, for the middle school teachers who taught three grade levels, I intentionally selected from the different classes. This allowed for a more holistic view of the teacher and allowed for a nuanced perspective on an important spurious variable, the chemistry between the students and the teacher. For the elementary school teachers, I attempted to select varying times of day and varying days of the week as to capture different subjects and different student and teacher energy levels. Moreover, circumstances of selected observation days often dictated further observations needed, such as test days or special activity days. Finally, each teacher is different, and if I felt that the teaching style was not sufficiently 
expressed, further observation days were added. The number of observation sessions per teacher was between three and six.

I recorded the observations in field notes in a notebook and on a laptop. The field notes were labeled with the date, time, teacher, subject, and grade level. Following Bogden and Biklen's (2007) suggestion of maintaining observer comments, the field notes were divided into two columns: descriptive fieldnotes and reflective fieldnotes. Descriptive field notes included descriptions of the subjects, setting, events, activities, behaviors, and dialogue. Reflective fieldnotes were noted across from the description of an event and included my reflections on analysis, methods, ethical dilemmas, and biases. Some reflections were noted during the observation, while other reflections were noted during the various stages of analysis. These reflections served as a check on my own biases and a guide for member checking with the participants to check the accuracy of my interpretations.

\section{Interviews}

All the teachers were formally interviewed one time between 40 minutes to 90 minutes. Bogdan and Biklen (2007) discuss observational case studies, where observations are "the major data-gathering technique" and are supplemented by informal and formal interviews. The interviews supplemented and served to support the observation data. Throughout the process, informal interviews were also utilized whenever needed. This took the form of brief clarification conversations with teachers in passing or text messages during analysis (Bogdan \& Biklen, 2007).

Formal interviews were scheduled according to the teachers' schedules to provide qualitative data expressing their self-perception of their teaching style, namely their 
interactions with their students and the content. As Merriam (2002) contends, a characteristic of qualitative research is that "researchers strive to understand the meaning people have constructed about their world and their experiences" (pp. 4-5). Following Rubin and Rubin's (2005) responsive interview model, an interview guide with possible probing questions was created prior to collecting data, yet is quite different than the actual questions that emerged in the interviews (Appendix C). At first, the interviews began with small talk in an effort to build rapport (Bogden \& Biklen, 2007). The interviews were open-ended, often starting with a question about how the teacher came into the profession. Because no two people are alike, the interviews all evolved differently. As a result, I responded with the appropriate follow-up and probing questions to gain a deeper understanding of the teacher's perspective on his/her teaching while trying to maintain focus on the research question. A different focus emerged through each interview and thus provided valuable information about the unique experience of each teacher.

I requested permission to audio record the interviews so that they may be transcribed for the data analysis phase. In this way, I was able to fully listen and concentrate on the words of the participant. As Bogden and Biklen (2007) state, "Good listening usually stimulates good talking" (p. 107). When transcribing the interviews, headings indicating the participant, date, and time were utilized to help organize the data. Each segment of speech was labeled with the speaker and began on a separate line. Space in the margins allowed for easier coding and note-taking. 


\section{Instrument}

The CCTDI is a 75-item test with 7 subscales, one subscale for each of the respective seven dispositions published by Insight Assessment (2010). The items are clearly not evenly distributed over the seven subscales. Unfortunately, because Insight Assessment scores the instrument, I did not have knowledge of which items measure which disposition. This information may have been helpful in gaining deeper understanding during the analysis of teacher scores. The CCTDI is a 6-point Likert scale ranging from "strongly agree" to "strongly disagree," with no neutral option. The test prompts are in standard English with no technical vocabulary or jargon. The information needed to answer the questions is present within each prompt. It is available in written or electronic format. As stated earlier, the teachers completed the electronic form available through a sign-in portal on the publisher's website. The scores for each teacher are reported on each subscale out of 60 and an aggregate score for the entire CCTDI out of 420.

\section{Face Validity}

The CCTDI has been determined to have face validity. College level educators and researchers skilled in survey and instrument development screened the original 250 prompts to identify ambiguity. The resulting 150 selected prompts were tested at several universities and reduced to the final 75 items based on their ability to discriminate well between test takers in pilot samples (CCTDI Test Manual, 2010).

\section{Construct Validity}

In examining the relationship between the CCTDI and other cognitive and psychological constructs, significant correlations were observed between four of the 
subscales of the CCTDI and "openness to experience," one of the Big-Five factors of human personality defined as "a broad dimension of personality manifested in a rich fantasy life, aesthetic sensitivity, awareness of inner feelings, need for variety in actions, intellectual curiosity, and liberal value systems" (CCTDI Test Manual, 2010, p. 29). The four correlates with $n=200$ are: truth-seeking $(0.27, p<.001)$, open-mindedness $(0.33$, $p<.001)$, critical thinking confidence $(0.25, p<.004)$, and inquisitiveness $(0.37, p$ $<.001)$. In addition, all seven of the CCTDI subscales were positively correlated with "ego resiliency," which refers to "a person's ability to alter his/her modal perceptual and behavioral functioning to adapt to situational constraints, that is, being a flexible and adaptable person" (CCTDI Test Manual, 2010, p. 29). With $n=200$, the three largest correlations to ego resiliency are: truth seeking $(.41, p<.001)$, systematicity $(0.47, p<$ $.001)$, inquisitiveness $(0.39, p<.001)$. Positive correlations were also found between the CCTDI and measures of biculturalism and modernity in a study of 365 Latino high school students. In the same study, a negative correlation was seen between the CCTDI and males' level of traditional sex-role beliefs. Finally, the CCTDI has been shown to significantly correlate with American College Test and Scholastic Assessment Test Verbal scores (CCTDI Test Manual, 2010).

\section{Internal Reliability}

Internal consistency reliability measures for the seven subscales of the initial pilot CCTDI ranged from Cronbach's alpha values of 0.71 to 0.80 , with the alpha for the overall instrument reaching 0.91 . Consistently over the past 15 years, the alpha has ranged from 0.60 to 0.78 on the subscales, with a 0.90 on the total CCTDI score. These values indicate a strong internal consistency reliability of the CCTDI. However, lower 
values have been seen when there is a smaller variance of scores. Table 2 and Table 3 below present the Cronbach's alpha range reported by the authors and the item to total correlation for each of the seven subscales (CCTDI Test Manual, 2010).

Table 2

CCTDI Internal Consistency Reliability Coefficients

\begin{tabular}{ll}
\hline CCTDI Subscale & Cronbach's Alpha \\
\hline Truth-seeking & $0.70-0.78$ \\
Open-mindedness & $0.67-0.74$ \\
Analyticity & $0.70-0.73$ \\
Systematicity & $0.72-0.74$ \\
Confidence in Reasoning & $0.75-0.78$ \\
Inquisitiveness & $0.78-0.82$ \\
Maturity of Judgment & $0.73-0.76$ \\
\hline
\end{tabular}

Table 3

CCTDI Item to Total Correlations

\begin{tabular}{ll}
\hline CCTDI Subscale & Item to Total Correlation \\
\hline Truth-seeking & $0.167-0.467$ \\
Open-mindedness & $0.205-0.573$ \\
Analyticity & $0.272-0.510$ \\
Systematicity & $0.269-0.568$ \\
Confidence in Reasoning & $0.393-0.569$ \\
Inquisitiveness & $0.317-0.627$ \\
Maturity of Judgment & $0.175-0.597$ \\
\hline
\end{tabular}




\section{Measures for Quality and Trustworthiness}

\section{Human Instrument}

Unlike in quantitative research, which utilizes instruments to collect data, in qualitative research the researcher is the instrument (Merriam, 2002). This is an advantage in many ways. Merriam (2002) points out that the researcher can be adaptive and responsive to real-life situations, "expand his or her understanding through nonverbal as well as verbal communication, process information (data) immediately, clarify and summarize material, check with respondents for accuracy of interpretation, and explore unusual or unanticipated responses" (p. 5). However, it is impossible to approach research without bias and judgment. Therefore, Merriam (2002) argues that researchers should identify and monitor their own biases. One way I have done so is through selfreflection throughout the process. Before beginning data collection, I documented my personal relationship to the present study (Appendix D). I also notated my thoughts during observations in the column for reflective fieldnotes. Finally, I discussed my preliminary inferences with peers throughout the data collection and analysis phases of the present study. This usually resulted in a widening of my perspective that has been incorporated in the results.

\section{Member Checks}

Member checks is a common strategy used to increase internal validity where the researcher asks the participant to comment on researcher interpretations of collected data (Merriam, 2002). In the present study, the informal and formal interviews served as an outlet for member checks to occur. After the observations, the researcher often asked the teachers about preliminary interpretations of findings. These comments were then used to 
determine if the researcher's interpretation made the participants feel understood. The findings of member checks guided and were integrated into the qualitative data analysis.

\section{Peer Review}

The peer review process is where another trained researcher reviews the data analysis of the observations and interviews (Merriam, 2002). In this way, confirmation increases the internal validity of findings and differences in researcher interpretation increase the nuance and complexity of findings. Either way, the results of peer review have guided and were integrated into the qualitative data analysis.

Dr. Patricia Salahuddin has graciously assisted in several levels of peer review throughout the present study. Dr. Salahuddin has an Ed.D. in Curriculum and Instruction and is experienced and skilled in qualitative research. She has extensive experience as a teacher as well, having taught for 30 years. She serves on the board of a private school in Miami as well as several boards for various educational organizations. Therefore, her contribution to the present study has been valuable from the methods perspective as well as providing an insider point of view as a teacher. She provided her perspective on the researcher's interpretations of data throughout the project. She also conducted several observations independently and the data she collected was cross-referenced with the researcher's data of the same teacher.

\section{Triangulation}

Triangulation is a widely used term that has become ambiguous in its meaning. It is intended to describe multiple sources of information confirming findings (Bogdan \& Biklen, 2007; Merriam, 2002). Because of its wide usage and ambiguity, it is important to clarify what was triangulated (Bogden \& Biklen, 2007). As Yin's (2013) definition of 
case study research states, it is important to triangulate data to gain a better understanding of the numerous variables of a case. Denzin (1970) identifies four types of triangulation: multiple investigators, multiple theories, multiple sources of data, and multiple methods (as cited in Merriam, 2002). For the present study, three of these four types of triangulation have been employed. First, this is a mixed methods research design; therefore, multiple methods triangulation intended to improve the validity of the findings. In other words, integrating both quantitative CCTDI data and qualitative data allowed the present study to better answer the research question: How do critical thinking dispositions differentiate between teaching styles? Second, multiple data sources also improved the validity of the findings in two ways. The observations and interviews have served to deepen the results of the CCTDI by providing a physical expression of the teachers' critical thinking dispositions. And the interviews were used to clarify observation data. Similarly, the 10 cases were also considered multiple data sources. Finally, multiple investigators, namely Dr. Salahuddin conducting some of the observations, served as a form of peer review to increase the validity of the observed phenomena and the interpretation. While not integrated initially, multiple theories were discussed in the final chapter to better understand the findings.

\section{External Validity}

There is a concern that case study research results cannot be generalized. Yin (2013) addresses this concern with a simple argument that researchers do not generalize results of one experiment, but rather from a series of experiments replicating the same phenomenon throughout various conditions. He further argues that case studies are generalizable to theoretical propositions as opposed to "populations or universes" (p. 21). 
Therefore, the goal of case study research is to "expand and generalize theories (analytic generalizations) and not to extrapolate probabilities (statistical generalizations)" (p. 21).

The current research aimed to gain an understanding of teachers' internal critical thinking dispositions as they are expressed in behaviors in teaching and ideas about teaching. The intention of looking at teachers stated in Chapter One was based on the assumption that the teacher's impact on student education is critical. The intention of focusing on critical thinking is the impact such dispositions within a population have on the maintenance and strength of a democracy.

\section{Data Analysis}

To present the phases of the present study in a simple way, Table 4 below summarizes the data analysis based on the data collection method and the research question.

Table 4

Research Questions, Data Collection, and Data Analyses

\begin{tabular}{ccc}
\hline Research Questions & Data Collection & Data Analyses \\
\hline $\begin{array}{c}\text { How does the teacher } \\
\text { interact with the students } \\
\text { and the content? }\end{array}$ & Observations and Interviews & $\begin{array}{c}\text { Qualitative thematic } \\
\text { analysis }\end{array}$ \\
$\begin{array}{c}\text { How do the teachers } \\
\text { critical thinking }\end{array}$ & CCTDI + Emerging Themes & Cross-Case Analysis \\
$\begin{array}{c}\text { dispositions differentiate } \\
\text { between teaching styles? }\end{array}$ & from Qualitative Strand & \\
\hline
\end{tabular}

\section{Qualitative Data Analysis}

Qualitative data analysis "involves working with the data, organizing them, breaking them into manageable units, coding them, synthesizing them, and searching for 
patterns" (Bogden \& Biklen, 2007, p. 159). The qualitative data analysis phase, unlike quantitative data analysis, begins during the data collection phase (Bogden \& Biklen, 2007; Rubin \& Rubin, 2005). For example, Bogden and Biklen (2007) suggest planning future data collection sessions in response to the data found in previous observations. Consequently, the exact number of observations was not predetermined for the present study. They also suggest writing down "observer comments" in one's fieldnotes about ideas or feelings that may arise during observations, for example, making a note of mental connections when events recur and speculations about meanings arise. Such notetaking has helped in forming coding categories in the phases of the data analysis that followed.

After the data were collected and fieldnotes and interviews were typed, I began to develop a coding system. Coding categories were created based on an initial read of the data and emerging patterns or regularities. The research question guided the development of these coding categories (Bogden \& Biklen, 2007; Rubin \& Rubin, 2005). Therefore, the goal was to create a thematic framework of teaching styles that emerged from the data. Because the present study was not intended to be a validity study of the CCTDI, labeling the teachers' expressions with dispositions from the CCTDI would not serve the purpose. Rather, the intent was to explore the relationship between the critical thinking dispositions and the teaching style expressed in the classroom and interviews. The teaching styles could not have been predetermined before data collection and analysis, and for that reason the qualitative research question was left as one general question, allowing for the flexibility of including sub questions about the critical thinking 
dispositions when appropriate. The result of qualitative data analysis phase was a framework for teaching style.

\section{Cross-Case Analysis}

Yin (2013) describes five analytic techniques one can implement for case study research. While the first four can apply to one or multiple cases, the final technique is designed to analyze multiple case studies. Similar to a meta-analysis, the result of a crosscase analysis is a cross-case synthesis. To begin a cross-case analysis, one possibility is to create a word table that displays the data from individual cases according to relevant and determined categories. Because the purpose of the present study was to explore distinctions in teaching style based on teachers' critical thinking dispositions, the tables created in the results chapters display the 10 cases according to both teaching styles and CCTDI scores.

Because the sample was only 10 teachers for the present study, it was not helpful to statistically analyze the CCTDI scores in relation to the teaching styles that emerged. Rather, this was an exploratory study and the CCTDI scores were described and emerging patterns discussed. Following that thorough description of each teacher's scores and the scores of all teachers for each of the seven dispositions, I created extreme groups among the cases for each of the seven disposition subscales of the CCTDI. Each case study was seen as its own research study, as Yin (2013) describes for cross-case analysis. Therefore, for the present study, each teacher was a case study and each case study could be seen as its own stand-alone research study. In conducting a cross-case analysis for each disposition, therefore, I purposefully sampled the extreme cases within these 10 
studies. Using the CCTDI scores on each of the seven subscales, I selected the highest and lowest score disposition scores to compare the teaching styles.

The methods utilized in creating the extreme subgroups consisted of looking within each teacher's scores and across teachers within each disposition. First, the highest and lowest scores for each disposition were designated as anchors for comparison. Next, to gain supporting evidence for the differences in teaching styles, the scores that lie within $5 \%$ of those highest and lowest were added to the extreme group. Finally, the highest $5 \%$ and lowest $5 \%$ of each teacher's scores were also placed into the extreme groups. The teachers within $5 \%$ of the mean for each disposition were removed from the extreme groups. Similarly, the teachers who may have been placed in the high group but scored below the mean or placed in the low group but above the mean were also removed. After the process of extreme sampling for each disposition, there was an extreme high group and extreme low group for each of the seven dispositions. These extreme groups were used to compare teaching styles during the cross-case analyses.

Possible relationships between teaching styles and critical thinking dispositions were noted based on the anchors. Ten relationships were unanimously corroborated by all the teachers of the extreme group. A qualitative description of the teachers' styles was also incorporated in the cross-case analysis. In some instances, a teacher who had an extreme score on a critical thinking disposition was qualitatively known for a specific teaching style. However, because the teaching style categories were generalized, more teachers carried the same teaching style code for various reasons. Therefore, through a qualitative description, an additional nuance of teaching style may be added to the list of possible relationships for that disposition. The result of this mixed methods cross-case 
analysis is a framework of possible relationships between teaching styles and critical thinking dispositions. While the results of the present study did not produce statistical generalizations, they did produce analytic generalizations beneficial to future studies that can explore these concepts further (Yin, 2013).

\section{Summary}

The purpose of the present study was to explore the relationship between teachers' critical thinking dispositions and their teaching styles. To answer the main research question, a multiple-case studies sequential mixed methods research design was employed (Tashakkori \& Newman, 2010; Yin, 2013). It was multiple-case studies research because each of the main teachers at one private school was one case in exploring the relationship between teaching style and critical thinking dispositions, resulting in 10 total cases. Next, the research design was mixed methods because both quantitative data, namely the CCTDI, and qualitative data, namely observations and interviews, were collected. Finally, it was sequential because the qualitative data were intentionally collected and analyzed prior to the analysis of the CCTDI to mitigate possible bias. Several other measures to improve the trustworthiness of the present study were employed, including: member checks, peer review, researcher reflections, and triangulation (Merriam, 2002). The qualitative results of the present study produced a teaching style framework, while the cross-case syntheses produced a framework of possible relationships between teaching styles and critical thinking dispositions. 


\section{CHAPTER FOUR}

\section{QUALITATIVE ANALYSIS}

"Human nature is not a machine to be built after a model, and set to do exactly the work prescribed for it, but a tree, which requires to grow and develop itself on all sides, according to the tendency of the inward forces which make it a living thing” (p. 111).

John Stuart Mill, On Liberty, 1859

While the theoretical framework of the present study is an education for democracy, which ultimately means a goal of understanding these teaching styles in relation to developing important qualities for democracy, the purpose of the qualitative phase was to gain an understanding of each teacher's style, irrespective of whether or not those teaching styles develop democratic qualities. Therefore, while relevant connections to democracy were integrated throughout the analysis, this was not always evident. The relationship between teaching styles and democratic qualities was not tested in the present study and is an important area for future research. Teaching styles relationship to critical thinking dispositions was, however, the purpose of the present study and was explored in the next phase of analysis.

The term "style" was loosely defined intentionally as the teacher's self-expression in the classroom in terms of her interactions with the students and the content. The intent was to allow whatever existed to emerge naturally rather than enter the present study with preconceived boundaries that may have limited the data. For this reason, teaching style frameworks that already exist in the literature were not utilized. This section is simply a detailed description of each teacher's style organized according to the emerging themes that formed an important contribution to the field — a comprehensive teaching style framework. 
Through observations and interviews with each of the 10 teachers, 5 themes comprising of 25 teaching styles emerged: the teachers' ways of adapting to the students' needs, the teaching methods, the teachers' ways of connecting to students, the teachers' growth-oriented styles, and the teachers' highest hopes for their students. Each teacher reflected the themes differently and the 25 styles reflect how each teacher uniquely reflected that theme. During the next phase of analysis detailed in the subsequent chapter, three additional teaching styles emerged as significant: curriculum expansion, teacher explorer, and observational listening. To accurately reflect the analytic process, I chose not to retroactively adjust the teaching styles throughout the chapter. Rather, I made the distinctions clear in the text. Such methodology is in line with Teddlie and Tashakkori's (2012) assertion that contemporary mixed methods research "is an iterative, cyclical approach to research" (p. 781).

While confidentiality was not promised to the teachers because the research occurred in a small school and this is a published work, the real names were not used throughout the analysis. Rather, the grade level was used in place of the elementary teachers' names and the subject was used in place of the middle school teachers' names to allow the reader a perspective on the classroom and interaction style. The age of the students and the subject matter may provide contextual clues to teaching styles and seeing the teachers through that lens is important.

To better capture the emerging data, the first section in this chapter describes and defines each of the themes and sub-themes. Because the present study was a multi-case study research design, I chose to present the data as 10 case studies as opposed to integrated themes. Therefore, the second section is a thorough description of each teacher 
following the same theme and sub-theme headings, in the same order. The teachers are in order by grade, youngest to oldest. While there was a clear overlap in the way the teachers reflected the themes, each teacher was unique and hopefully the broad themes allowed for the nuance of each teacher's style to be reflected here. To improve the trustworthiness of these interpretations, as mentioned in the previous chapter, an iterative process of member checking and peer review occurred alongside data analysis.

\section{Defining the Emerging Themes}

Table 5 below displays the teaching style framework that emerged from the qualitative analysis phase of the present study discussed in this chapter. Each column lists the teaching styles within its theme. Following the table is a detailed explanation of each teaching style.

Table 5

\section{Teaching Style Framework}

\begin{tabular}{|c|c|c|c|c|}
\hline Adaptability & Methods & Connecting & Growth-Oriented & Highest Hopes \\
\hline Curriculum & Experiential & Nurturing & Self-reflective & Effectiveness \\
\hline $\begin{array}{c}\text { Curriculum } \\
\text { Expansion }\end{array}$ & Teacher Guide & Humor & Fallibility & Character \\
\hline Instruction & Teacher Explorer & Reward & Assessment & Connection \\
\hline Emotional & Lecture & Respect & Holistic View & Self-Actualization \\
\hline Physical & $\begin{array}{c}\text { Student Teacher } \\
\text { Group Size } \\
\text { (Whole, Small, } \\
\text { Teams })\end{array}$ & $\begin{array}{c}\text { Conversational } \\
\text { Listening }\end{array}$ & High Standards & \\
\hline & $\begin{array}{c}\text { Free Movement } \\
\text { Trust }\end{array}$ & Trual & & \\
\hline
\end{tabular}




\section{Adaptability to Student Needs}

Emerging from the data, teachers adapted to various student needs in different ways. Sometimes these adaptations occurred in the curriculum or instruction. Other times teachers adapted to student's emotional or physical needs.

Curriculum. The adaptations to curriculum fell into four categories: expectations of quality, the difficulty level of work, the quantity of work given, or the curriculum content. Curriculum content refers to unexpected questions leading to integrating new content not originally part of the curriculum plan. Many teachers were observed integrating outside sources to answer student questions or unexpected discussion tangents that arose. This is an example of democratic education because students are encouraged to think freely about and their interests are incorporated into the curriculum (Dewey, 1916). The final characteristic of integrating outside sources eventually became its own teaching style called "curriculum expansion." The reasoning was that it was distinct from the other forms of curriculum adaptation ideologically and it reflected an important distinction in the relationships with critical thinking dispositions in the next phase of analysis. Some teachers had either the basic curriculum adaptability or the curriculum expansion style. One teacher (Ms. First) had both the basic and expansion styles.

Instruction. Adaptations to instruction occurred in four categories: methods, time on work, thinking time, or connection to real life. When needed, the teachers would adapt their instructional methods to help students understand. Dewey (1916) argued that a school must be a model for democracy to cultivate democratic citizens, and allowing student the freedom to learn in their own way is one example of democratic education. 
Emotional. Often teachers discussed the emotional obstacles their students may have that prevent learning, referring to their personality or their personal stories at home. This prompted some teachers to adapt to these emotional needs in different ways such as spending personal time to connect with the student or even avoiding established discipline methods that would cause some students to shut down and stop learning.

Physical. Physical adaptations occurred when teachers adjusted the environment or their rules to the learning needs of students. One example of a physical adaptation occurred when teachers allowed a student to draw during lessons because doing so helps him/her focus and concentrate. Another example was moving certain students' desks closer to the board or away from others.

\section{Teaching Methods}

This theme refers to various ways in which the teacher provides instruction. Teaching methods is divided into six categories: experiential, teacher as guide, lecture, student as teacher, group size, and free movement.

Experiential. Experiential teaching methods refer to lessons that have students manipulating objects, moving around, experimenting, or creating art. These can be handson experiences with the intention of teaching.

Teacher guide. Teachers are guides when they do not readily provide answers to students' questions, but rather asks questions that guide them to find the answers themselves. Teachers may provide the resources and allow students time to seek the answers. During discussions, they may ask questions that guide students to the curriculum objectives. During demonstrations, teachers may ask students to guide their writing or actions. Teacher explorer is the second of three teaching style categories that 
emerged in the next phase of data analysis. Teacher explorers also guides student learning; however, they do so without having a predetermined outcome. Therefore, every teacher explorer is also a teacher guide, but not every teacher guide is a teacher explorer. Teacher explorers and students embark on an intellectual journey and co-create the learning.

Lecture. Lecturing is when the teacher stands in the front of the room or walks around the class while students sit at their individual desks primarily listening and taking notes. Even if they ask questions, the primary source of knowledge is the teacher and she answers their questions. This is different than a discussion guided by the teacher in that students are not producing knowledge.

Student teacher. This code refers to assigning students research projects to prepare and present to the class.

Group size. While whole group instruction occurs at some points in every class, many teachers adjust the group size during the same lesson or on different days for different reasons. Teams working independently, for example, is one group size, sometimes with small groups or one-one-one working with the teacher occurring simultaneously. On some occasions, teachers ask their students to work independently as well. For the purpose of the present study, group size was divided in three sub-categories: whole group/individual configurations, small group teacher-led instruction, or teamwork.

Free Movement. While free movement could theoretically be placed under experiential teaching methods, there was a clear distinction in the classroom between teachers who promoted free movement and those that did not. Free movement means students are allowed to freely move around. This looked like students walking around to 
attend to their needs or actual lessons requiring movement. It also looked like students standing to work or sitting on the floor. Some teachers viewed physical movement as a way to reenergize students during lessons, and as a result allowed and encouraged free movement as an integrated part of the environment, while other classrooms had a palpable tension when students moved away from their desks where teachers were heard frequently telling kids to sit down and only get up with permission.

\section{Ways of Connecting to Students}

For learning to occur from the teacher to the students, there must be a personal connection that forms. Some teachers were more consciously aware of this relationship and discussed its importance during the interviews. Connection can be thought of as interactions that lower any barriers between teacher and student. Through the data, there seemed to be six ways that teachers connected to their students: nurturing, humor, reward, respect, listening, and trust.

Nurturing. Nurturing behaviors presented like caring for their physical needs and calling them sweet names - a sort of parental demeanor with the students. For example, some teachers were witnessed frequently noticing students' discomforts such as coughing or visible pain and asking, "Are you ok?” or offering water. Further, some teachers used endearing terms such as "honey" or "sweetie" to refer to students.

Humor. Another tendency was a sense of humor with the students, and different teachers did humor differently. Some teachers gently smiled and laughed at students' spontaneous jokes, this was seen as more nurturing and not necessarily labeled humor. Silliness during class interactions was considered humor, such as funny voices. Other teachers used humor to offer praise or knowledge in non-threatening ways to older kids. 
It was seen as an attention-grabber by some. All of these reasons are ways to use humor to connect with the students for the purpose of removing barriers to learning.

Reward. Third, teachers connected to students through reward, whether tangible, verbal, or non-verbal. Letting someone know that you see them is a powerful connection tool—it validates them as individuals. While all teachers used this to some degree, some teachers focused on specific praise as most powerful. Teachers often used tangible rewards such as stickers and candy for younger students or homework leeway and free time for older students.

Respect. Some teachers talked about the importance of respecting students and speaking to them in respectful ways. Through developing such respect, students are more likely to open up to learn from the teacher.

Listening. This presented itself so strongly for some teachers that it required its own category. While it may seem obvious that a teacher would listen to student communication, some teachers make a conscious effort to listen intently and respond to form connections with their students. In some instances, this presented as a broader and deeper way of listening for all clues, not just verbal communication. Some teachers intentionally observed students to gain an understanding of their lives, their thinking, or their emotions. This last type of listening, while initially placed in the same category, eventually became its own teaching style entitled observational listening. Observational listening is a teacher's data collection of student experiences with the intention of adapting teaching practices. Some teachers exhibited only the basic conversational listening, while others had both conversational and observational listening. Observational 
listening seemed to include conversational listening in all presentations of these styles in the present study.

Trust. For some teachers, they used trust as a way to connect to their students. This presented itself as allowing students to go to the restroom or attend to their nonacademic needs without direct supervision. Trust means that the teacher assumes the best intention when communicating with her students. If they are late coming back from the bathroom, the teacher who trusts her students may question them out of concern, but not accusatory in tone.

\section{Growth-Oriented Teaching}

The teacher's growth-oriented style refers to the way in which the teacher views growth in general and how this impacts teaching specifically. Is growth linear-take students from point $\mathrm{A}$ to point $\mathrm{B}$ ? Is the primary focus knowledge acquisition? Is the curriculum the end goal or is it merely a vehicle for growth? What is growth? Some teachers really see their students as whole and view growth as multi-directionalintellectual, physical, emotional, and spiritual. Mistakes are encouraged in some classrooms while in others students may be more reserved and avoid trying due to a fear of being shamed. It was evident that some teachers were more self-reflective and accountable than others. This relationship with fallibility was really intriguing and presented in various ways throughout the data. Some teachers talked about student egos blocking learning and took actions to make the class a safe space for errors. Others talked about the ego as well but shamed students when they erred. The way teachers used assessments was also of interest here. Some teachers allowed students to keep correcting errors while others used assessment as an evaluation of that student's knowledge. Yet 
others saw the assessment grade as a consequence of effort, whether good or bad. To capture these constructs, this theme looks at five perspectives: self-reflective, fallibility, assessment for growth, holistic view of students, and high standards.

Self-reflective. Self-reflection is a way toward growth. A person who seeks improvement thinks about their own practices and results, understand the "why" behind their actions, look for weaknesses, and find solutions. There was a distinction among teachers who exhibited self-reflective practices. Self-awareness is a prerequisite for reflection. Therefore, a teacher who knows herself is self-aware. Then a teacher who uses that self-knowledge to understand "why" and/or look at the impact of those behaviors or qualities is exhibiting self-reflection.

Fallibility. The relationship the teachers have with fallibility is intriguing and reflective of their perceptions of learning and growth. This sub-theme was evident in the teachers' openness in sharing their own mistakes with students. It was also evident in the intentionality in creating a safe space for student mistakes and an emphasis on effort over results.

Assessment for growth. While some teachers view assessment as a way of categorizing students, high-achievers vs low-achievers, other teachers clearly used assessments as a learning tool. All teachers need to submit grades, but the data revealed how some teachers allow their students multiple chances to correct wrong answers. Some teachers' intention for homework or classwork is more a means to student growth. Some teachers are constantly assessing their students informally. These are practices reflective of a growth-oriented mindset. 
Holistic view. There was a distinction between teachers who focused only on intellectual gains, physical well-being, and social skills, which is customary, and teachers who considered other factors such as emotional and spiritual well-being. The teachers who looked at emotional and spiritual factors in their students were considered in the present study to have a holistic view of their students. In addition, teachers who viewed the curriculum as a vehicle towards student growth rather than the goal were also labeled as having a holistic view of the learning process.

High standards. High standards is a tricky category because sometimes it contradicts with some of the growth-oriented qualities mentioned here. Sometimes, a teacher who only focuses on high standards on academics may compromise on the holistic view or may unintentionally not promote a positive disposition towards fallibility for students. For example, if a teacher corrects student mistakes repeatedly and rewards students for correct answers, this may tell students that mistakes are not valued in this class, thereby compromising the goal of making students comfortable making mistakes. Finding that balance between being open and positive with mistakes while still pushing for higher standards can be challenging. Meanwhile, maintaining an eye on students' emotional well-being while simultaneously pushing for higher standards can be challenging. However, high standards are definitely an important factor for growth because having a holistic view of students without maintaining expectations lacks an important component of a growth-oriented mindset. Therefore, the high standards witnessed among the teachers is categorized here alongside the other growth-oriented qualities emerging from the data. It refers to teachers' adherence to curriculum standards and their insistence that students improve accordingly. 


\section{Highest Hopes for Students}

In understanding the "why" in teaching, an observer may begin to decipher the "what." By looking at teacher's highest hopes for their students at graduation from the "perfect school," it can clarify their teaching philosophy and help an observer see these ideals manifested in the teaching. Emerging from the data, teachers' highest hopes for students can be described in four categories: effectiveness skills, character, connection skills, and self-actualization.

Effectiveness skills. Some teachers responded to this question of highest hopes with statements about preparedness, either generally or with specific skills of preparedness. Such comments like creating a "functional student" or having students be ready for the upcoming challenges, or students being ready for later life challenges. Any descriptions that spoke of preparedness were categorized under effectiveness skillseffective at school or at life.

Character. Many teachers spoke about the importance of character development over knowledge. They may have emphasized different characters, but the concept was the same. Some teachers spoke of honesty, others respect or hard work. They generally said the word "character" and used the variations in describing it after being prompted. Any descriptions that spoke about constructs of internal and individual development were defined as character.

Connection skills. Many teachers talked about the need for students to work well with others or know how to share their talents. This category is separate from character because it is about the interaction between people rather than the development of the individual. For some teachers, the focus was interpersonal connection, and for others they 
incorporated a broader social theme such as community and multiculturalism. This correlates to the theoretical foundation of this work in that democracy depends on the exchange of diverse viewpoints in order for society to progress (Mill, 1859/1991).

Self-actualization. Some teachers talk about students developing their own unique talent or skill. Others were more general and talked about students knowing themselves and becoming their own unique person. These all fit under this concept of selfactualization, a term first coined by Kurt Goldstein yet strongly associated with Abraham Maslow (1943/2013). Maslow asserted in "A Theory of Human Motivation" that even if all of an individual's basic needs are met, there is often a void until he/she reaches his potential, or as he said, "for him to become actualized in what he is potentially" (p. 7). Among the preconditions for self-actualization, Maslow listed liberal freedoms, aligning with Mill's (1859/1991) notions of freedom as a means to progress, and cognitive capacities, aligning with Gutmann and Thompson's (2004) tenet of access.

\section{Emerging Themes by Teacher}

Most teachers exhibited six teaching styles: instructional adaptation, experiential methods, group size whole, group size teams, conversational listening, high standards. Only one teacher lectured, Ms. Social Studies, and only one teacher had students teach, Ms. Fifth. To aid in organizing the massive amount of information while reading through the data on each teacher, Table 6 below lists the emerging teaching styles for each teacher. 
Table 6

Emerging Themes by Teacher

\begin{tabular}{|c|c|c|c|c|c|}
\hline Teacher & Adaptability & Methods & Connecting & Growth & Hopes \\
\hline K & $\begin{array}{l}\text { Curr. Expansion* } \\
\text { Instruction } \\
\text { Emotional } \\
\text { Physical }\end{array}$ & $\begin{array}{l}\text { Experiential } \\
\text { Guide } \\
\text { Explorer* } \\
\text { GS: W, S, T } \\
\text { Free Mvmt }\end{array}$ & $\begin{array}{l}\text { Humor } \\
\text { Reward } \\
\text { Conv. listening } \\
\text { Obs. listening* }\end{array}$ & $\begin{array}{l}\text { Self-reflect } \\
\text { Fallibility } \\
\text { Assessment } \\
\text { Holistic } \\
\text { Standards }\end{array}$ & $\begin{array}{l}\text { Effectiveness } \\
\text { Character } \\
\text { Connection }\end{array}$ \\
\hline First & $\begin{array}{l}\text { Curriculum } \\
\text { Curr. Expansion* } \\
\text { Instruction }\end{array}$ & $\begin{array}{l}\text { Experiential } \\
\text { Guide } \\
\text { GS: W, S }\end{array}$ & $\begin{array}{l}\text { Nurturing } \\
\text { Reward } \\
\text { Conv. listening }\end{array}$ & $\begin{array}{l}\text { Fallibility } \\
\text { Holistic } \\
\text { Standards }\end{array}$ & $\begin{array}{l}\text { Effectiveness } \\
\text { Character } \\
\text { Connection } \\
\text { Actualization }\end{array}$ \\
\hline Second & $\begin{array}{l}\text { Curriculum } \\
\text { Instruction }\end{array}$ & $\begin{array}{l}\text { Experiential } \\
\text { Guide } \\
\text { GS: W, S, T }\end{array}$ & $\begin{array}{l}\text { Reward } \\
\text { Respect } \\
\text { Conv. listening }\end{array}$ & Standards & $\begin{array}{l}\text { Effectiveness } \\
\text { Character } \\
\text { Connection }\end{array}$ \\
\hline Third A & $\begin{array}{l}\text { Instruction } \\
\text { Emotional } \\
\text { Physical }\end{array}$ & $\begin{array}{l}\text { Experiential } \\
\text { Guide } \\
\text { GS: W, S, T } \\
\text { Free Mvmnt }\end{array}$ & $\begin{array}{l}\text { Nurturing } \\
\text { Reward } \\
\text { Respect } \\
\text { Conv. listening } \\
\text { Trust } \\
\end{array}$ & $\begin{array}{l}\text { Self-reflect } \\
\text { Fallibility } \\
\text { Assessment } \\
\text { Holistic } \\
\text { Standards } \\
\end{array}$ & $\begin{array}{l}\text { Character } \\
\text { Connection }\end{array}$ \\
\hline Third B & $\begin{array}{l}\text { Curr. Expansion* } \\
\text { Emotional } \\
\text { Physical }\end{array}$ & $\begin{array}{l}\text { Experiential } \\
\text { Guide } \\
\text { GS: W, T } \\
\text { Free Mvmt }\end{array}$ & $\begin{array}{l}\text { Respect } \\
\text { Conv. listening } \\
\text { Obs. listening* }\end{array}$ & $\begin{array}{l}\text { Fallibility } \\
\text { Holistic }\end{array}$ & Effectiveness \\
\hline Fifth & $\begin{array}{l}\text { Instruction } \\
\text { Physical }\end{array}$ & $\begin{array}{l}\text { Experiential } \\
\text { Guide } \\
\text { Explorer* } \\
\text { St. Teaching } \\
\text { GS: W, T } \\
\text { Free Mvmt }\end{array}$ & $\begin{array}{l}\text { Reward } \\
\text { Conv. listening } \\
\text { Obs. listening* }\end{array}$ & $\begin{array}{l}\text { Fallibility } \\
\text { Standards }\end{array}$ & Effectiveness \\
\hline Science & $\begin{array}{l}\text { Curr. Expansion* } \\
\text { Instruction } \\
\text { Emotional } \\
\text { Physical }\end{array}$ & $\begin{array}{l}\text { Experiential } \\
\text { Guide } \\
\text { GS: W, S, T }\end{array}$ & $\begin{array}{l}\text { Nurturing } \\
\text { Respect } \\
\text { Conv. listening } \\
\text { Obs. listening* }\end{array}$ & $\begin{array}{l}\text { Self-reflect } \\
\text { Fallibility } \\
\text { Assessment } \\
\text { Holistic } \\
\text { Standards }\end{array}$ & $\begin{array}{l}\text { Effectiveness } \\
\text { Character } \\
\text { Connection } \\
\text { Actualization }\end{array}$ \\
\hline $\begin{array}{l}\text { Social } \\
\text { Studies }\end{array}$ & $\begin{array}{l}\text { Curr. Expansion* } \\
\text { Instruction } \\
\text { Emotional }\end{array}$ & $\begin{array}{l}\text { Experiential } \\
\text { Lecture } \\
\text { GS: W, S, T }\end{array}$ & $\begin{array}{l}\text { Humor } \\
\text { Reward } \\
\text { Conv. listening }\end{array}$ & $\begin{array}{l}\text { Self-reflect } \\
\text { Fallibility } \\
\text { Assessment } \\
\text { Standards } \\
\end{array}$ & Actualization \\
\hline Math & $\begin{array}{l}\text { Instruction } \\
\text { Emotional }\end{array}$ & $\begin{array}{l}\text { Experiential } \\
\text { Guide } \\
\text { GS: W, T } \\
\text { Free Mvmnt }\end{array}$ & $\begin{array}{l}\text { Nurturing } \\
\text { Humor } \\
\text { Reward } \\
\text { Conv. listening } \\
\text { Obs. listening* } \\
\text { Trust }\end{array}$ & $\begin{array}{l}\text { Fallibility } \\
\text { Standards }\end{array}$ & $\begin{array}{l}\text { Effectiveness } \\
\text { Character } \\
\text { Connection } \\
\text { Actualization }\end{array}$ \\
\hline $\begin{array}{l}\text { Language } \\
\text { Arts }\end{array}$ & $\begin{array}{l}\text { Curr. Expansion* } \\
\text { Instruction } \\
\text { Emotional } \\
\text { Physical }\end{array}$ & $\begin{array}{l}\text { Experiential } \\
\text { Guide } \\
\text { GS: W, T }\end{array}$ & $\begin{array}{l}\text { Humor } \\
\text { Conv. listening } \\
\text { Obs. listening* }\end{array}$ & $\begin{array}{l}\text { Self-reflect } \\
\text { Fallibility } \\
\text { Holistic } \\
\text { Standards }\end{array}$ & Actualization \\
\hline
\end{tabular}




\section{Ms. Kindergarten}

\section{Introduction}

Since high school Ms. Kindergarten (Ms. K) switched between wanting to become a teacher or a doctor. During middle and high school, Ms. K participated in a special program for the students who scored high on an IQ test where they tailored a portion of the school day dedicated to their desired profession. Initially interested in teaching, the school allowed Ms. K to leave her school early and walk $3 / 4$ of a mile to the local elementary school to assist with a reading program. Dropping out of this special program in $9^{\text {th }}$ grade, Ms. $\mathrm{K}$ decided she would focus more on science and become a doctor. Finally, in college, she settled on becoming a teacher. Going to a Presbyterianaffiliated university, she earned a degree in Christian Education, which was half education and half religion. She also has a minor in psychology because she thought about becoming a youth director at one point, but moved past this idea after one job in Massachusetts.

She laughs when people ask her why she chose teaching because she never liked little children. After having her first child, Ms. K started a home daycare out of necessity. She received so much positive feedback from parents that she decided to get her teaching certification and took her first teaching job at a Christian preschool. That was close to 20 years ago today. She has taught upper elementary throughout the years, but now teaches kindergarten.

Ms. K has a sarcastic sense of humor, which she is proud of but admits the South does not appreciate it as much as New England (Interview, p. 29). She does not like baby 
talk and approaches her students with honest and direct dialogue. Ms. K goes beyond the scripted curriculum and appreciates unique ideas from her students.

\section{Adaptability to the Student Needs}

Curriculum. Ms. K adapts the curriculum to meet the immediate functional need of the lesson. For example, during the second observation, Ms. K changed the directions on a workbook page by coming up with new words that had the letter "u" in it that still matched the pictures provided. Therefore, the picture of a dog became "pup" and the apple became "fruit." She was teaching the letter "u" and she reconfigured the script to match her lesson's current needs. She explained the new directions to the students and told them, "Remember, I don't always follow the directions" (Observation \#2, pp. 5-6).

Ms. K also adjusted the curriculum to challenge her students, saying, "I don't always follow the curriculum. Because if I did, sometimes I feel like it dummies down a lot of stuff. And so while that's good on some level, the ones that are already higher need something else thrown in there" (Interview, p. 13). For example, she spoke about teaching her students the difference between fiction and non-fiction, or the meaning of a legend. While she does not expect them all to grasp these higher concepts, she believes that exposing them will be beneficial. This is an example of the curriculum expansion style that emerged in the next phase of the analysis. Ms. K even asks her students questions during discussions to which she does not have the answer. For example, during a lesson on national parks, they learned about black-footed birds. She asked them why they think all these animals have black feet and patiently listened to the students' responses. Then she said, "I don't know. Just wanted to hear your good guesses. Maybe we can do research on it. Maybe you should research it." Some students screamed, 'Ya! 
Google it!" and she agreed that she would do that during break (Observation \#5, pp. 4-5). This is an example of the teacher explorer style that emerged in the next phase of analysis.

During this same national park lesson, one conversation was different. When Ms. K spoke about the Everglades, she talked about Marjorie Stoneman Douglas' battle to create the Everglades National Park. She told them about the courts and that in her honor a high school was named after her (Observation \#5, p. 3). During the interview, I asked her if that was scripted. She told me that it was not and she chose to incorporate it because "it's something that is right here, right now, more of a reality" and some of these kids actually live in Parkland, Florida next to the high school named after Marjorie (Interview, p. 13). I was interested in the underlying lesson in social activism given the purpose of the present study in educating for democracy; however, Ms. K did not link her conversation to that intention during our interview so I did not offer it. She also discussed safety from alligators, which is highly relevant in South Florida, yet is not a part of the national park curriculum (Observation \#5, p. 3). This reflects how Ms. K also adapts the curriculum to incorporate life experiences and the needs of her students because they live in this area where alligators are a major safety concern for small children. Both of these examples provide further evidence to support the curriculum expansion style. After reanalyzing the data with the new curriculum expansion style in mind, it was evident that Ms. K did not adapt the curriculum in the other ways of varying the difficulty level, varying the amount of work, or varying her expectations. Rather, I witnessed her pushing students to complete the work even when they were behind and challenging all her students to meet expectations. 
Instruction. Ms. K assesses the needs of her students and adjusts accordingly. She said during the interview that if her students are not understanding a lesson, she will reteach it one-on-one and monitor their progress (Interview, p. 6). She will also incorporate specific real-life context to capture the attention and to aid in understanding of specific students not grasping the lesson. She said during the interview, she can tell who understood something and who did not based on their facial expressions. Immediately, she will target the three students, for example, that did not understand and think, "Okay, what do I know about those three that I can try and pull them in" (Interview, p. 16). This is a teacher adapting her instruction to the specific needs of her students, using their personal context to reteach lessons as needed. She is continuously assessing their understanding and adjusting accordingly. She also makes a clear effort to know her students. Often, she sees their challenges as more an emotional self-concept obstacle and will work on affirmations and praise (Interview, p. 6).

Emotional. Early in the interview, Ms. K spoke about the emotional barriers to learning that a teacher must first overcome. She mentioned a previous year teaching $4^{\text {th }}$ graders and having to stop the regular curriculum to deal with some anger management problems. She said, "I learned how to help them talk through their issues so we could get some education going" (Interview, p. 5). This is an example of how Ms. K adapts to the emotional needs of her students. From this experience, she has learned skills that she transferred to other classes to teach her students how to talk through their problems.

She asserted during the interview that if students do not have that sense of security and self-worth, they will not learn anything. She is conscious of the way students feel about themselves and is very cautious in words spoken, even as simple as banning 
the word "done" because it sounds like "dumb" (Interview, p. 5). She asks her students to instead say, "I'm finished" (p. 6). When she sees a child discouraged from the difficulty of the work, she gives powerful pep talks to get them going again, saying to them, "Show the world the truth, you can do this" (Interview, p. 7). These are all examples of how Ms. K's awareness of students' emotional state and adjusts her actions to address her students' emotional needs.

Later, in discussing Ms. K as a teacher guide, it is evident that she does so for a number of reasons, one of which is more emotional. On one occasion, she said that if she responds to students' incorrect answers with a "no," they will shut down and stop thinking (Interview, p. 9). This shut down is an emotional response to being wrong. In guiding them with questions and acknowledging their answers, she is adapting her instructional methods once again to their emotional needs. She displayed this once again when discussing one experiential lesson where students created class flags and voted on the winner, Ms. K said that giving them choice "allows them to feel more in control" (Interview, p. 20). This is an example of how her awareness of student emotions, namely feeling in control, guides her teaching methods. There seems to be a link between this emotional adaptation, her teaching methods, and fallibility. She pays attention to the emotional well-being of her students and the impact of the teaching methods on their emotions. In so doing, she is fostering a positive relationship with fallibility.

Ms. K said during the interview that she individualized her reward system to meet the emotional needs of some students who had difficulty adjusting to school. Specifically, she would reward the students who generally cried at the beginning of the year with extra stickers when they did not cry. The other students who were adjusting well began to feel 
badly about unequal treatment. Ms. K discussed how she would talk to the well-adjusted students alone and explain, "See this is what she's struggling with. But you guys are over that already, you don't need that kind of support. But maybe if you support her, she'll get over it faster and catch up with us" (Interview, p. 11). Not only is Ms. K adapting her strategies to the emotional needs of the struggling child, but she is also paying attention to the emotional needs of the other students as well.

Ms. K also spoke extensively about a strategy she tried in her class this year. With the consent of the parent, Ms. K asked one student to become a buddy to a struggling student and keep her focused and on-task. She coached the buddy on how to help while also coaching the struggling student on opening up to a new friend. She talked about how this arrangement was good for the buddy and for the struggling student. The buddy needed to build her confidence because she was going through a tough time at home with a custody battle beginning. Both Ms. $\mathrm{K}$ and her mother felt that being the helper was good for her emotional well-being. The struggling student did not have any friends and Ms. K ascertained that she was not receiving appropriate home support, possibly living in poverty. She felt that this student needed the extra encouragement and academic support. Our interview was 3 months after this arrangement began and Ms. K was pleased with the results (Interview, p. 11).

Physical. During the interview, Ms. K discussed how she would sometimes ask students to relocate in the classroom to get them to focus again. She said students would still be included in the activity, but were no longer disruptive (Interview, p. 23). This is an example of adapting to the physical needs of the student to help them focus. During 
one observation, she asked one student to make an island because he was screaming. The student pulled his desk apart from the group and sat independently (Observation \#6, p. 4).

\section{Teaching Methods}

Experiential. During one observation, Ms. K had the students stand up and follow her instructions as she gave detailed directions such as, "Stand under the flower next to Mr. Jaber" (Observation \#1, p. 3). This is an example of experiential learning because the students are using their entire body movement to complete the lesson. Ms. K used this same strategy in a subsequent lesson to teach shapes, having the students move around the classroom finding the requested shape. During the interview, Ms. K shared a lesson where students created a class flag and voted on the final winner. She used this to explain the voting process and political elections (p. 19).

Teacher guide. During the lesson finding shapes, Ms. K stopped the activity to ask the students why they have not found many triangle-shaped objects in the classroom. She asked them how many sides are on a triangle. The students answered that there are 3 sides, but no one responded to why there are not many triangles around the class. She finally said, "Well, it's hard to stack triangles in a class and that base with the pointy part" (Observation \#1, p. 5). This reflects the curriculum expansion style once again. Ms. K mentioned repeatedly during the interview that she likes to guide students to critical thinking, saying, "It's more of how you guide the questions and pull out that thought" (Interview, p. 21). One boy eventually responded to her questions and said, "Your nose" (Observation \#1, p. 5). Ms. K was not exactly looking for that, but she enthusiastically acknowledged his response and said, "Did you all hear what Issa is saying? I like that. Yes, your nose is sort of like a triangle" (p. 5). In being a teacher guide, students have the 
opportunity to bring new ideas into the conversation. Even though she did not get them to where she intended, namely thinking about the functionality of triangular shaped objects, she appreciated her student's unique perspective and input.

During the interview, Ms. K discussed a lesson where she was teaching students about main ideas of a story. The students kept giving details, so she would respond, "Well, that definitely was a really good detail, but let's see if we can make the whole story in one sentence" (p. 9). As they continued along, she would repeat this strategy and guide them along. She said that if you just say, "no" to their incorrect answers, they "shut down and don't think about it” (p. 9). Her guiding technique is intentional. Ms. K wants her students to learn to think, not just know information. She wants them also to feel safe in sharing. She appreciates their input, saying, "If they can come up with a different way to think about it, and then there's even times when they just amaze me," recalling one instance where a student caught her off guard with his usage of a difficult word (p. 9).

During the observations, Ms. K would guide students to discover the answers to her questions on their own. For example, she asked them what "variety" means as she read a story to them. She then reread the sentence to them. One student answered incorrectly and she said, "That's a good guess" and waited for more responses. After one more incorrect answer and responding the same way, she reread the sentence and then said, "If you opened your crayon box and found 24 purple ones, would you be happy?" The students said in unison, "No." She then responded, "You like a variety of colors" (Observation \#2, p. 2). She did not define the word for them, like a lecturing teacher may, rather she guided them to understanding through a couple of methods. First, contextual clues through the sentence in the story. Then relating it to their own 
experience. Finally, using the word in a different sentence related to that experience. The example discussed previously about the black-footed bird shows how Ms. K even guides students to seek information when she does not actually have the answer (Observation \#5, pp. 4-5).

In discussing the voting strategies she uses in class, Ms. K explained how she deals with a tie when time allows. Rather than be the tie-breaker, she has the students on opposing sides speak and provide reasons for their choices. Then, she allows the class to vote once again and see if the results change. While she admits that they are only five years old and their arguments are weak, this exercise is developing a habit of discourse, clearly a valuable method aligned with the theoretical framework of the present studyliberal and deliberative democracy - discussed in earlier chapters. Sometimes she actually gets a real reason and full sentences, which Ms. K appreciates (Interview, p. 20).

Ms. K emphasizes throughout the interview the value of dialogue and talking to your children. She believes, "You can't teach critical thinking, you just kind of need to encourage it" (Interview, p. 20). In discussing her oldest daughter's high critical thinking abilities, she cited her frequent dialoguing with her as she grew up, different than her youngest child who received more commands. Even as a baby before her eldest could speak, Ms. K would take on both voices in a mock conversation (Interview, p. 21-22). Also throughout the interview, Ms. K mentioned talking through conflict in her classroom and using the same voice over technique when students gave her blank stares (p. 22).

Dialogue is an important theme emerging from this teacher's data and it is closely aligned with her methods as a teacher guide as well as listening to connect to her students 
and her highest hopes of having them connect to others by listening. In trying to understand how she connects dialogue to critical thinking, Ms. K explained that the goal is to "have them really think through it and go 'okay, what was the wrong thing that I did there and what was the right thing that I can do?"' (Interview, p. 23). She linked this discussion to classroom rule number four which states, "Make smart choices" (Interview, p. 23). I asked her "How do students know if their choice is smart?"” and she said very quickly, "They think about what the outcome is" (Interview, p. 23). This is the definition of analyticity, one of the seven critical thinking dispositions from the CCTDI, and it was not surprising to see her high score (51 out of 60 ) on the analyticity subscale in the subsequent stage of analysis. Therefore, Ms. K believes that dialogue is a way to develop analyticity in students, previously defined as:

Analyticity is the tendency to be alert to what happens next. This is the habit of striving to anticipate both the good and the bad potential consequences or outcomes of situations, choices, proposals, and plans. The opposite of analyticity is being heedless of consequences, not attending to what happens next when one makes choices or accepts ideas uncritically (Insight Assessment website).

Group size. Ms. K does a lot of whole group lessons where she guides students through work, reads a story, and asks questions to guide learning (Observation \#2). She mentioned in the interviews that she will work one-on-one as necessary to reteach a concept (p. 6). She also mentioned in the interview that she had small group discussions to explain why some students were receiving additional rewards for not crying when others felt it was not fair (p. 11). During the observations, Ms. K had the students' desks arranged in small teams and mentioned her buddy system during the interview.

Free Movement. Ms. K has a rule that students are not allowed to speak or get out of their chair without permission. It is understandable that kindergarteners may not yet 
have the self-regulation skills needed to allow for free movement in the class while maintaining focus on learning. However, Ms. K incorporates a lot of body movement learning activities. For example, finding the shapes in the class or playing out the instructions with prepositions mentioned earlier under "experiential" are all body movement lessons (Observation \#1). During the interview, Ms. K discussed how she uses "body movement voting" when taking a vote in her class. The students express their vote with their body position such as hands on shoulders versus hands on table. She does it this way as to avoid them all raising their hands for all options (Interview, p. 19). During the second observation, they voted in this way to answer a question about the letter "u" being a consonant or a vowel (p. 5).

\section{Ways of Connecting to Students}

Humor. Ms. K uses humor all the time to communicate. She does voice imitations and tells jokes to her students. She has a sarcastic sense of humor at times. During the interview, she was proud of her sarcasm and pleased that it was appreciated in New England, but sad that in Tallahassee it was considered extremely rude (p. 29). As she stands up after a carpet activity with her students, she said to them, "Watch the old lady get off the floor" (Interview, p. 15). During one observation, she was discussing a main lesson from a story about finding beauty in everything. She pointed to one boy and said he has beautiful eyes even if his behavior drives her crazy (Observation \#2, p. 4). This is an example of her humor and the children seemed to take it in stride. When one student snickers about a word Ms. K spoke, she responded by imitating the student and snickering back (Observation \#2, p. 4). When teaching how to write the letter " $\mathrm{u}$," Ms. K writes on the board a skinny "u," a fat "u," a little "u" with a tail, and a regular "u." She 
then tells them using a funny voice that one " $u$ " is not eating, the other " $u$ " is eating too much, and the final incorrect " $u$ " should not have a tail (Observation \#2, p. 5). When the word "tulips" came up during a lesson, she took a tangent to tell the students a joke her father used to tell her, "What flower do you always carry with you? Two lips" (Observation \#3, p. 2). The kids laughed and she wrote the variation in spelling on the board so the students would understand. Then she told them to go home and tell their family to make them all laugh and to be sure and tell her how their dad sprayed his drink everywhere because of how hard he laughed. During the last observation of this class, Ms. K told her students that they all look like jack-o-lanterns because they lost so many teeth during the break, saying, "You didn't have these funky smiles 10 days ago" as they all laughed and showed off their new smiles (Observation \#6, p. 3). There are so many examples of her humor with the student and it has clearly emerged as a theme for this teacher.

Reward. Ms. K says that in the beginning of the year, she maintained sticker charts and constant rewards to teach her students what was expected of them. As these behaviors became more habitual, she tapered off the reward system. She believes in rewarding positive behaviors as opposed to handing out consequences, citing the class she took on teaching students anger management to help her deal with that $4^{\text {th }}$ grade class she taught previously (Interview, p. 9). She said that eventually, praising students is enough for them to feel rewarded or to expect a reward later on, therefore she does not need to spend so much extra time and energy on the sticker charts in the second half of the year. During the observations, Ms. K frequently praised her students. Even when incorrect, she repeatedly responded, "Good guess" (Observation \#2, Observation \#3). For 
example, she said to one boy, "Oh, Jad, you are rocking it today. Wow after I made that comment about your journal you are stepping it up" (Observation \#3, p. 3). Directed at another student, Ms. K said, 'Issa, you can do a lot better today. Start over. The 'p' shouldn't hang all the way down below the line" (Observation \#3, p. 3). Similar to Ms. Second, Ms. K provides direct and honest feedback that is not always positive. In this way, the positive seems more powerful and the negative feedback helps develop in students an acceptance of fallibility.

Listening. Ms. K listens to her students in the most obvious sense in hearing their conversations and responding appropriately, but also on the deeper, broader sense in being open and receiving any clues about her students. In terms of the basic listening, which was eventually labeled conversational listening, she would allow her students to speak freely during lessons and respond no matter the value of the comment. She did not ignore her students' speech. For example, as she was reading a story about a princess who liked dandelions and an apple branch who thought he was better, she asked the students to predict what would happen. Students made various predictions such as the Princess killed the dandelions, the Princess agreed with the apple branch, or one student said, "he wanted him back," which made no sense given the portion of the story read so far. Ms. K responded to all the comments asking why the Princess would kill the dandelions that she liked and asking for clarification, "Who wanted them back?" (Observation \#2, p. 2). She said to the students, "I want to see how you are thinking" and then said before continuing with the story, "Okay, we got some nice predictions, that's what you were doing" (p. 3). This is not an isolated example of Ms. K's listening. She frequently exhibited listening throughout all observations. The triangle nose example 
cited earlier under "teacher guide" also reflects her listening nature (Observation \#1, p. 5). During the third observation, for example, she walked around as the students worked independently and had a few random conversations. One boy was saying, "U-K-U-K" over and over again. She said, “UK? That's a country. The United Kingdom. They're really good at soccer." Another girl was saying that she is going to Orlando in 3 days. The teacher asked her, "You're not going to be here on career day?" The girl responded that she would. Then the teacher said, "So you're going in 4 days" (pp. 3-4). These are seemingly insignificant conversations, but I would guess that her students felt heard when she responded to them in this way.

Ms. $\mathrm{K}$ also listened in that deeper, broader sense of seeking information about her students, which I defined as its own teaching style in the next phase of analysisobservational listening. Emerging from Ms. K's interview data, she believes in learning about her students, saying, "You gotta know about your family" (Interview, p. 16). She begins the year with an "All About Me" book where the students work with their family to create this story about themselves. While it is not very in depth, Ms. K says that this project begins revealing important information that helps her understand her students' context. Knowing how many siblings a child has, knowing the birth order, or knowing the age of other siblings provides valuable clues for her. She says this basic information may provide clues to the student's behavior in the class. She also learns about the student's cultural background, stating that "knowing where they've been helps me too because I've never had so many international-type students as I do here" (Interview, p. 17). However, this little book does not provide her more substantial information about the type of support each student receives at home. 
Ms. K spoke about the personal context of some of her students and how that impacted their learning. For example, in the conversation about the two girls she paired up, Ms. K cited the custody battle for the buddy and the poverty of the struggling student's family (Interview, p. 11). When I followed up with questioning how she learned these personal details, she explained that at the beginning of the year, the student who was struggling drew her family as cockroaches. It was very strange for Ms. K to see that and when she asked the brother's teacher, she found the same drawing. She remembered that she had this occur once before when they discovered that the students had a major infestation due to the poor living conditions. She also mentioned that her student also had problems with hygiene (Interview, pp. 17-18). Ms. K clearly seeks information about each of her students to aid in her teaching. She adapts to their academic and emotional needs as shown earlier. While listening can mean a basic hearing of words spoken, in a general sense, listening means being open to receiving information as a way to connect to students. Ms. K is clearly always listening for any clues to provide insight into the personal context of her students. Ms. K argues, “People don't realize as a teacher you are a social worker, a psychologist, a family guidance" (Interview, p. 18). This type of deeper and broader definition for listening is similar to Ms. Science's portrayal of this theme discussed later. Likewise, just as she listens carefully for clues from her students, Ms. K also teaches them to listen to each other, which is closely linked to the highest hopes of connection skills discussed later as well.

\section{Growth-Oriented Mindset}

Self-reflective. In discussing how Ms. K plans out her lessons, she said, "My mind works very quickly, if I had to write out everything I was going to say, I can't do it" 
(Interview, p. 16). She realized early on that if she tries to write out and follow a detailed plan, she fails and becomes very discouraged. Rather, she creates a broad outline with the goals and adapts her actual teaching methods during the lesson based on how the students are responding. Knowing herself and creating a structure that works is a sign of a selfreflective person. Just as clearly stating early in the interview that she did not like little kids is another example of Ms. K knowing herself and being honest about it (p. 2). Another example of her self-awareness is the comment about her sarcasm being appreciated in New England and considered rude when she moved to Tallahassee (Interview, p. 29).

Fallibility. Ms. K worried that some of her students fear being labeled "lazy" or "stupid" and would prefer to not try at all so they can avoid the criticism. She said that some have this idea that "if I try something, somebody's going to criticize me" (Interview, p. 7). She acknowledges that parents have life stressors that may create that sort of environment at home, but it is her job to make the classroom a safe space for the students. Creating that safe space to try new ideas without being criticized is essential to developing a healthy relationship with fallibility. This is similar to Mr. Language Arts' outlook, which is discussed later, where he intentionally creates that culture in his classroom so students will not hold back. When Ms. K had that discussion with her students about triangles in the classroom, her acknowledgement of the student's comment about noses is significant. Rather than dismiss his observation, Ms. K's response further supports an environment where students feel comfortable to share (Observation \#1).

During the observations, Ms. K would openly share her own shortcomings with students. For example, in teaching the students the difference between fiction and non- 
fiction, she said, "Ms. K struggled with this so we're going to get out of kindergarten knowing the difference" (Observation \#2, p. 1). During another guided whole group lesson, Ms. K incorrectly read the directions and corrected herself, "Oh silly Ms. K, color the flower in the middle red" (Observation \#3, p. 1). On one occasion, she admitted that she should not have collected their glue sticks and scissors because they will need them again (Observation \#4, p. 3). She seems to use her own fallibility to make the students comfortable with their own. For instance, when explaining the plural of the word "dice," Ms. K said that she always makes that mistake and has to correct herself (Observation \#6, p. 3).

Fallibility has emerged as one of the most important concepts throughout the present study. Students at this school tend to be unwilling to admit their own faults and seem to hold themselves to a standard of perfection that is unattainable. As they get older, teachers start to see this translate into a lack of initiative or disrespectful attitude towards the teacher to avoid being called out. Ms. K interestingly addressed this perfection concept directly in one conversation with her students. During one lesson, she instructed them to color neatly and asked the students if she is asking for perfection. When they answered, “yes,” Ms. K said, “No, but I don't want scribble scrabble” and proceeded to explain that they should do it well, but not so meticulously that they take too long (Observation \#6, pp. 2-3). This is addressing that balance between fallibility and high standards that needs to occur in order for students to grow.

Assessment for growth. Ms. K spoke about how she is constantly assessing her students' understanding by looking at their faces as she speaks. When she sees a student not understanding, she quickly tries to pull them in using her knowledge of that particular 
student (Interview, p. 16). This is an example of her informally assessing her students for the purpose of growth. Through her guiding methods, she is able to see where the students are throughout a lesson and adjust accordingly. This is linked to her adaptability as a teacher as well.

Holistic view. Ms. K definitely considers the emotional well-being of her students. This is evident in her adaptations to the emotional needs of her students. When she paired the two girls, for example, she was not only considering the academic goals. She discussed the emotional benefit to both. Additionally, when the buddy student was having difficulty with the constant rejection from the struggling student at first, Ms. K coached her and cited the spiritual components of faith and helping others (Interview, p. 11). Ms. K repeatedly discussed her students' personal context and how that was important in the classroom to aid in learning and to explain observed challenges. She wants students to develop a positive self-concept and emphasized that during the interview. She has strong family values and discussed how incorporating her own nice family stories helps them appreciate their own families more (Interview, p. 15). These are all examples indicative of her holistic view of the students and the curriculum. She clearly showed in observations and confirmed in the interview how she goes beyond the curriculum all the time. She does not follow a scripted lesson plan, but follows the lead of the students with the curriculum goals as a guide.

High standards. Ms. K expects her students to do their work appropriately and holds them to a high standard. In her lesson on the letter "u," she demonstrated all the ways in which students can write the letter. Using her humorous techniques, she told them exactly what is expected of them (Observation \#2). When she commented on Issa's 
“p” formation, this also reflects Ms. K's high standards (Observation \#3). During one lesson, the class was counting by tens alone. When one boy was not participating, she asked him to do it alone saying, "Ms. K is getting tired of it so I'm calling you out today" (Observation \#5, p. 1). When he made a mistake and students laughed, she immediately stopped them and commanded they give him a chance. He said it correctly after that. So while putting the student on the spot may lead to emotional challenges, Ms. K seemed to address that right there and the student seemed to respond positively and continued. Maintaining high standards is important, but balancing it with maintaining that positive relationship with fallibility and a holistic view accounting for emotional well-being is difficult at times.

In her curriculum adaptations, it is evident that she expects more from her students than the limits of the script. She told them during one observation, "You guys know I give you more information than they ever ask you for. But I know you can handle it" (Observation \#6, p. 5). During that same lesson, she explains to students that a tomato is a sphere but the stem sticking up is not a vertex. She connects their lesson to real-life because she expects them to apply what they learn. She also keeps the conversation complex, using terminology such as "vertex" that is beyond their age. Later she read them a story about a boy dreaming of outer space and explained that it is a "science fiction" work because the boy is dreaming, which is fiction, and it is about space, which is science. In her acknowledgement of unique contributions from students, she is showing her high expectations for critical thinking. During the interview, she repeatedly talked about developing critical thinking through dialogue, which is discussed in detail under "teacher guide." 


\section{Highest Hopes for Students}

Effectiveness Skills. "I give them the behavior and the belief in themselves and then the rest of it follows real easy," asserted Ms. K during the interview (p. 8). This statement seems to address effectiveness skills and character. Behavior is about preparedness for learning. When students follow rules and behave according to guidelines, it clears the way for the teacher to teach. This is the commonly understood phenomenon that good classroom management is essential for learning to take place. Therefore, the behavior component in Ms. K's assertion points to effectiveness skills.

Character. The "belief in self" component seems to fit under character. It is similar to other teachers' focus on confidence-building, such as Ms. Second. Ms. K repeatedly spoke about how she monitors students' self-concept and is careful in the words she speaks. She wants them to try and not worry about making mistakes. She wants them to show the world how smart they are, which is about believing in their own abilities (Interview, pp. 5-7).

Connection skills. During the interview, Ms. K spoke a lot about teaching the students different cultures and exposing them to other ways people live. In discussing why she taught them about Marjorie Stoneman Douglas, she said that anything not reading or math-based is intended to raise their awareness of what is around them (Interview, p. 14). She does lessons on how birthdays are celebrated around the world and discusses the differences even within their own class. She validates the different ways people live. She teaches them about different holidays around the world also and from the conversations about Veteran's Day, she talks about conflict resolution. She touches upon the silly reasons World War I began and connects it to their own conflicts 
and why she insists on talking through their problems (Interview, p. 15). Early in the interview, she brought up the importance of conversations with the students and how she talks through everything with them. She also guides them to talk through their little arguments out on the playground by asking questions and repeating each student's point of view. She wants them to learn to listen to each other and care about the other's feelings (pp. 4-5). Ms. K consistently talks about being open to new ideas, accepting different cultures, and resolving interpersonal conflict with communication. These are all connection skills. Ms. K addresses interpersonal connection skills as well as the more broad social perspective of accepting diversity. She tells the students, "In the US, lots of different people come here. Does that mean we can't be friends if someone looks different? We live many cultures in this country, you don't want to be in your own bubble" (Interview, p. 29).

Both of these perspectives on connection skills - the interpersonal and the social - are essential to the theoretical framework of the present study. Liberal and deliberative democracy are about living in a pluralistic society and having effective, progress-creating discourse (Habermas, 1998; Gutmann and Thompson, 2004; Mill, 1859/1991). They are also closely linked to the critical thinking disposition of openmindedness, which states:

Open-mindedness is the tendency to allow others to voice views with which one may not agree. Open-minded people act with tolerance toward the opinions of others, knowing that often we all hold beliefs which make sense only from our own perspectives. Open-mindedness, as used here, is important for harmony in a pluralistic and complex society where people approach issues from different religious, political, social, family, cultural, and personal backgrounds. The opposite of open-mindedness is intolerance (Insight Assessment Website). 
Consequently, it was quite unexpected when I saw that open-mindedness was Ms. K's lowest score (33) on the CCTDI and her open-mindedness score was the lowest of all the teachers as well.

\section{Ms. First}

\section{Introduction}

At the time of data collection, Ms. First had been teaching for 8 years, 2 years at a public school and 6 years at this private school. She has taught kindergarten and first grade for her entire career. She has a bachelor degree in Elementary Education with ESOL endorsement.

Ms. First had a very positive and gentle demeanor. She was controlled and organized. Striking qualities about this teacher included her nurturing nature and patience with her students. She was constantly praising their efforts and responding to all their communications including irrelevant, tangent comments. She mentioned during the interview that she appreciates art and color, which validated what I witnessed during the observations. There appeared to be a tension between maintaining the organized, time efficient classroom and the creative, free-flowing, imaginative classroom. Ms. First seemed to be constantly balancing her approach between these two extremes in the classroom.

\section{Adaptability to the Student Needs}

Curriculum. Ms. First discusses during the interview how she skips around in the curriculum to connect students' experiences in the classroom to real life. For example, she mentions that she will do unit four of social studies before two and three because it correlates to Thanksgiving (Interview, p. 7). She integrates outside sources to simplify 
more difficult concepts for the students, using the television or YouTube videos in the classroom (Interview, p. 10). She also integrates outside sources when the students ask questions that require research on her part (Interview, p. 17). These are examples of expanding the curriculum, one of the additional teaching styles that emerged in the next phase of analysis.

Correspondingly, Ms. First indicated during the interview that her expectations vary based on the student's academic level. Therefore, while she may expect three sentences properly punctuated from one student, she will accept one sentence from another student because this is their current level (p. 15). Similarly, some students may be able to take the tests on their own, while others cannot. These examples reflect the general adaptations to the curriculum of varying difficulty of work and expectations. Therefore, Ms. First showed evidence of both curriculum adaptability and curriculum expansion styles.

Instruction. During the observations, Ms. First's efficiency was very apparent. She really kept a close watch on the time. This led to an interview question about time where she indicated that she adapts her time based on her students' ability level and makes sure to provide the appropriate time accordingly (p. 12). She gave their journal writing as an example, where in the beginning of the year she had to allot 30 minutes for this exercise, but by the end of the year the students can complete it in 15 minutes. This is a reflection of her instructional adaptations based on her students' needs.

\section{Teaching Methods}

Experiential. While it would be expected that an elementary teacher would be more experiential, unfortunately, that is not always the case. Pleasingly, Ms. First spoke 
about various experiential lessons such as the cycle of the butterfly, which she indicated was her favorite. She orders a caterpillar online and the students witness the whole process (Interview, p. 4). During the observations, the students did several art projects related to lessons such as a cloud book with cotton balls configured differently to show the various scientific classifications of clouds (Observation \#3). They also created a hermit crab to represent the story they read as a group, A House for Hermit Crab by Eric Carle (Observation \#2). The teacher also referred students to look at an ongoing experiment in the classroom possibly about evaporation, which was reflective of a previous experiential lesson (Observation \#2, p. 2).

Ms. First reflected a desire to be more creative in her classroom and an emphasis on art. She even mentioned that she has them color and draw on their tests after they finish because, she says, "All of our tests are black and white and I don't like that" (Interview, p. 7).

Teacher guide. During observations of various lessons, Ms. First asks students questions to guide the lesson and demonstrations on the board. For example, during the lesson on clouds, Ms. First guided the class to create a short paragraph that described each cloud type. After a discussion, she formulated a final draft on the board for everyone to copy (Observation \#3). Similarly, on another occasion while reading a book to the whole class, Ms. First would stop at certain words and ask students to define them, ask students questions to assess comprehension, or ask students for their opinions (Observation \#2). For example, she asked them to define the word "plain.” After a student defined it as "ordinary, no color," she followed up with, "So, 'simple.' Do you like a simple house with nothing in it?" (Observation \#2, p. 6). This is a representative 
example of Ms. First's lessons, guiding students through questions to probe for understanding and promote thinking.

Group size. Ms. First said during the interview that she loves doing small groups because "the reason I love it so much I feel I get more connected to them" (p. 12). During the observations, I did not witness the small groups, however, I did not probe for this comment during the interview either. On the other hand, the observations reflected Ms. First frequently led whole group discussion during the observations where she guided students through new information or experiential projects.

\section{Ways of Connecting to Students}

Nurturing. "I look at them I feel like they are my kids too...I try to think as if it was my daughter or my son what would I do. I think being a mother helps me being a teacher" (Interview, p. 13). Throughout observations, Ms. First referred to her students lovingly with terms such as "sweetheart" and was always kind to her students. When they came in from PE during one observation, she greeted them, "Come in, have a drink of water. How was PE?" When she saw their heads all wet, she asked them with a gentle smile if they put water on their head before instructing them to dry themselves with paper towels (Observation \#2, p. 1-2).

Reward. Ms. First uses praise as a way of connecting to students. She said in the interview, "I try to praise them for every little thing that is good that they do even if it is something as simple as picking up a piece of paper from the floor and throwing it in the garbage" (p. 5). She also has a sticker system where she gives them rewards every 10 stickers, then again at 20 stickers, and finally at 100 stickers they can order a milkshake 
and enjoy it during class. She said, "They actually feel very special with that" (Interview, p 5).

Listening. While discussing her love of small groups during the interview, Ms.

First cited it as a chance for her students to talk to her and for her to talk to them. She said that they have so much to say and it does not come through during whole group instruction. She also said, "I feel like they feel more important, their opinions matter" (p. 12). Ms. First sees listening to her students as a way of connecting. During observations, Ms. First frequently engaged in small talk with her students, listening and responding to them. For example, one student mentioned that it was hot and she responded, "Yes, it feels like summer already" (Observation \#2, p. 1). It may seem simple and obvious manners, but unfortunately, this conversational listening may not always be present in a teacher-student relationship. Plus, it is a conscious desire for Ms. First to make her students feel heard by her, as she indicated during the interview.

\section{Growth-Oriented Mindset}

Fallibility. During a demonstration on the board, Ms. First made a mistake. She corrected it and told the students that she had made her shape too big (Observation \#2, p. 3). Ms. First showed her students that it is alright to make a mistake and correct it. She modeled the struggle of getting it right and taking it lightly when it does not exactly turn out as desired. During the observations, Ms. First repeatedly made light of difficult questions. For example, she responded to a student question, "I can see why you are confused with number two, just move on and we will go over it together" (Observation $\# 4$, p. 5). She said, during the interview, that effort is more important than results saying, 
"I don't want them to feel getting a $70 \%$ is a failure as long as they put all their effort into it” (p. 15).

Holistic view. During the interview, Ms. First discussed her students' needs to talk to their friends and her accommodations for that by allowing some class time for talking (p. 6). This reflects her understanding of their emotional and social needs. She also discussed how she integrates moral conversations of equality of all human beings during the Martin Luther King, Jr lesson (p. 9). When asking her if it is sometimes hard to connect to all students, she responded that "every child has something to offer" (Interview, p. 12). She cited one student in particular who is academically challenged, but is so kind "that it makes you forget everything" (p. 12). This reflects her own personal philosophy towards others and she explicitly teaches her students that they are "like a big family, brothers and sisters" and they should be careful not to hurt each other's feelings (Interview, p. 13).

High standards. Ms. First values art and creativity, but not at the expense of accuracy and adherence to the prescribed directions. During a lesson where students were constructing creative images out of geometric shapes, Ms. First acknowledges a student's rocket ship and drew it on the board, but she also tells him that the directions stated to use only two not four shapes (Observation \#2, p. 3). On another observation day, there was a student falling behind and repeatedly asking Ms. First's assistant for help. Ms. First several times gave him guidance and finally asked the assistant to stop writing for him. She then came and stood by him to guide him to write the words himself (Observation $\# 4$, p. 8). It may seem insignificant, however, one could see how a teacher directing 25 students could easily let the assistant take care of this one. However, Ms. First's actions 
indicated her high standards for all her students, expecting and working towards growth of each one.

During the lesson on clouds, Ms. First directed the students to create clouds out of cotton balls. She had them accurately depict each of the scientific types of clouds (Observation \#3). Her emphasis on the scientific classifications with the appropriate color for each is indicative of this adherence to a high standard for her students.

At times, however, a tension between creativity and high standards is evident. For example, Ms. First commented a few times about students staying within the lines. She also indicated this tension when discussing what color the students should select for the cloud on the cover. She started by saying, "Okay, this is your cloud book, so you decide how you want it, but obviously not red" (Observation \#3, p. 1). When a student asked if orange was alright, she responded, "Have you ever seen an orange cloud in the sky?" indicating "no" in her tone. Then she quickly said, "Okay, you are the author and the illustrator. This is your book. Go color it, if you want a colorful cloud, it's your book" (p. $1)$.

\section{Highest Hopes for Students}

Effectiveness skills. Ms. First said during the interview, “They may not remember the grammar or method I taught but I want them to have a habit of being organized and on time" (p. 13). These are clearly effectiveness skills. During the observations, she clearly modeled neatness, timeliness, and organization and she expected the students to do the same.

Character. Ms. First said that character is very important. When probed about the meaning of character, it became clear that she also referred to connection skills as well. 
For the character component, she mentioned work ethic and being honest, the two being connected. She mentioned that if you take a job, you have to put all your effort into it and this is honesty.

Connection skills. For connection skills, Ms. First emphasized the need for people to share their talents with others, be able to speak in front of other people, and work well with others even if they do not necessarily like them (Interview p. 14). It makes sense that she talked about the importance of kids talking to their friends during recess and that she even gives some class time for them to talk to one another (interview, p. 6). She wants to "teach them to be nice to each other and smile a lot... and say thank you" (p. 17). During the interview, she summarized the hope for her students as: "Just being a human" (p. 17).

Self-actualization. She did not directly mention the term self-actualization, but she discussed the need for people to "know about their life" and that a degree does not indicate a talent. That a person with a $\mathrm{PhD}$ may not be the best teacher and "someone with no experience that knows how to get to the level of the children and talk to them maybe a great teacher" (p. 14). These comments are reflective of self-actualization, developing one's unique talents not necessarily indicated with a degree.

\section{Ms. Second}

\section{Introduction}

Ms. Second began working as an assistant at this private school midway through her Bachelor's Degree in Elementary Education. Through marriage and having three children, Ms. Second continued her education and eventually earned her degree.

Ms. Second has a calm and controlled demeanor. She is very clear about her classroom goals and her students know exactly what is expected of them. She is efficient 
with time, yet allows students significant time to process and respond to her questions after providing them the resources and tools necessary. She values analysis and problem solving, therefore rarely provides directs answers to student questions.

\section{Adaptability to the Student Needs}

Curriculum. Because the high-achieving students complete their work rather quickly, Ms. Second has additional "beyond level” work for them in math and extra projects for science and social studies as well as an extra reading packet each week (Interview, pp. 4-5). Therefore, she adapts the amount of work and the level of difficulty depending on the needs of her students.

Instruction. The first response to a question asking her to describe her teaching style during the interview, Ms. Second said she tries to reach every learner and "everyone needs different amount of time" (p. 2). Ms. Second allows her struggling students the time they need to complete their tasks. She said that one of her most difficult challenges in the class is keeping the high-achieving student occupied during the free time because they complete "a half hour worth of work in 10 minutes" (Interview, p. 4).

During the observations, one of the most striking qualities about this teacher is the amount of thinking time she gave each student. It was not a surprise that this came up so quickly in the interview and repeated so many times throughout. After she brought it up, I followed with a comment about the thinking time and she revealed that her purpose is to allow them to analyze and come to inferences on their own.

\section{Teaching Methods}

Experiential. Although I did not observe any experiments, Ms. Second mentioned that the students do some science experiments at their desks. Additionally, during one 
observation, the students created 3-dimensional shapes out of paper (Observation \#3). Ms. Second frequently integrates real-life examples into discussions such as blinds as pulleys, butter melting, and Hi-C dissolving.

Teacher guide. Ms. Second does not lecture her students. She values developing their thinking in such ways to promote analysis and inference. To give one example, she mentioned giving her students a set of blocks without instructions, rather a goal—build a cube (Interview, p. 2). She believes in providing them the resources they need and then allowing them the space and time to put it all together. During one observation, she directed the students to reread a story, work in groups, and come up with the problem, the three steps to the solution, and the solution. She responded to requests for help in several ways — giving examples of another problem/solution set, asking a series of guiding questions to clarify understanding, advising the students to look at the resources provided, providing hints such as telling students that the steps are in order in the text, and providing specific feedback without giving the answers about incomplete or wrong answers (Observation \#1, pp. 1-2). During a subsequent lesson, Ms. Second asked the students to define a liquid. One student said that when you shake a liquid it moves. Ms. Second responded with a challenge rather than an answer, "A solid moves too when I shake it” (Observation \#1, p. 5). Rather than say, "No, wrong,” Ms. Second again demonstrated her style as a teacher guide. On another occasion, a student asked her if his answers should be the same as his group. She responded before walking away, "Generally, when you work in a group, you have the same answer because you discuss over it" (Observation \#2, pp. 5-6). Even with the simplest questions, it was hard for students to get direct answers from Ms. Second. 
Group size. During the observation, whole group and individual work was witnessed. Ms. Second also had the students frequently work in teams. During the interview, she mentioned how she engages some students while working one-on-one with the students that need extra attention (p. 5). Therefore, there is evidence in the data that Ms. Second utilizes all formulations of group size — whole group/individual, small group teacher-led instruction, and team.

\section{Ways of Connecting to Students}

Reward. During the interview, Ms. Second indirectly mentioned how she verbally praises students while she was giving examples of class lessons. On one occasion, she told a student who came up with a unique life example of a pulley that she never thought of that (p. 8). Such feedback validates student involvement and builds powerful connections with students, especially because Ms. Second does not offer empty praise. On several occasions, she was quite honest with students and directly told them when they made a mistake, such as one boy who answered incorrectly and she responded, "So we know (Name) didn’t pay attention in class yesterday" (Observation \#1, p. 5). In another instance she told a boy that his answer is not in the text and he was making it up (Observation \#1, p. 4). Therefore, when Ms. Second recognizes a student, it is authentic and more powerful, one could argue, than a teacher that is constantly saying, "Good job, Sweetie.” During the observations, Ms. Second repeats what students say and confirms their point with a simple "yes" or her tone of voice. Sometimes she would simply say, "good" (Observation \#2, p. 4). The validation was powerful because it was so simple.

Ms. Second has an elaborate rewards mechanism set up for her classroom. She has a team reward system and individual rewards, because "the whole row shouldn't have 
a consequence for something that one person did" (Interview, p. 9). Teams can earn points towards munchkins, candy, or salam bucks (a school-wide reward system). Individuals can earn M\&M's for right answers or lose recess points for misconduct. The students also have designated jobs that rotate weekly, with two students on vacation every week. They get paid with candy for their classroom job.

Respect. During the observations, Ms. Second did not raise her voice to any students. Even in providing feedback, she says it in a matter of fact way and quickly moves on. In the interview, Ms. Second discusses this intentionality in not pushing students too much because she does not want them to feel like "she's always taunting at us, she's always telling us what to do, so just ignore her" (p. 20). As a result, she intentionally gives instruction in a sentence or two to point out what they could do differently in "a polite way" (p. 20). She said about children, "They are worthy of respect, if anything I think kids are the most worthy of respect... haven't done harm to anyone" as opposed to adults who are "structures of sin by this time" (Interview, p. 21).

Listening. During the observations, Ms. Second listened and responded to most of student communication. There was an instance that she asked a student to put his hand down because she was not asking a question, but given time constraints in classroom settings, this can be expected. She indicated during the interview that it is very important for her to be approachable by her students. She says she tries to joke around to project this approachable image. She also gives them time to think so they do not feel rushed to answer. One of her highest hopes for her students is to be able to communicate all of their thoughts (Interview, p. 27). These are examples of Ms. Second's conversational listening style. 


\section{Growth-Oriented Mindset}

Ms. Second has high standards for her students with very specific academic goals and a clarity about the achievement level of each of her students. "I believe in pushing them," she said (Interview, p. 23). She discussed during the interview the challenges in dealing with the varying achievement levels within the class, specifically citing one of her ESOL students reaching approaching level by the end of the year and her hopes to get her to grade level (Interview, p. 4). She also spoke about keeping the high-achieving students challenged and busy. These are all behaviors that point to her high standards and expectations for student learning. During the observation, she provided resources for her students to solve challenges and was very specific about the response. One instance, a boy answered a question and she told him that what he said is not in the story, he is making it up, and he should reread the story (Observation \#1, p. 4). During the same lesson, she sarcastically told another group with incorrect answers, "We think we are too smart and can get the answers without reading?" (Observation \#1, p. 4). During one observation, Ms. Second asks a student who dropped the whiteboards as he was passing them out to go back to his seat because there is a reason the rule is to only carry four at a time. She has very clear rules and expectations, and enforces them consistently. In one statement during the interview summarizes her high standards: "I try to make sure every student is giving their best... and I think that's where the success lies” (p. 2).

\section{Highest Hopes for Students}

Effectiveness skills. When asked to describe an ideal graduate, Ms. Second opened a dialogue about people being able to make the right choice at the right time. She said that if you make a wrong choice, "that same scenario, that same time frame is never 
going to return even if you do want to go back and change it" and "they will not get a fix up time" (p. 12). This is reflective of effectiveness skills because the ability to make effective decisions is a preparation for life skill. Interestingly, Ms. Second scored the highest of all the teachers on maturity of judgment (50 out of 60), the critical thinking disposition defined as, “...the habit of seeing the complexity of issues and yet striving to make timely decisions" (Insight Assessment website). While her emphasis on timely decision-making aligns with maturity of judgment, the black-and-white thinking around not getting a "fix up time" contradicts both maturity of judgment and the tenet of deliberative democracy outlined by Gutmann and Thompson (2004) allowing for decisions to be revisited.

Character. When asked how a teacher would prepare her students to make the right decision at the right time, Ms. Second cited character defined as personality, confidence, and knowledge. She talked about building their courage and confidence when they see their achievements. She also briefly discussed the character development focus in the curriculum with monthly traits such as kindness, respect, and cooperation.

Connection skills. Ms. Second talked at length during the interview about getting the students to cooperate and include new students in activities. She spoke about a particular instance where a student was not being nice to a peer because she does not get good grades. One strategy Ms. Second utilizes to address conflict requires the dueling students to work together on class projects. She also speaks to them individually to resolve the errors in their thinking. For example, with this particular student, she had a conversation about how playing has nothing to do with good grades. She speculated that maybe her mother told her to pick good friends and the student misunderstood what her 
mother intended as "good." One of the other strategies she implemented was organized group activities such as soccer or girls against boys, telling the students, "You will only have organized play unless you all start getting along with each other" (Interview, p. 16). There was another instance where students would correct one another in unkind, commanding tones. She would direct her students to be kind to one another, providing examples as to how to correct one another respectfully. Another interesting example was how she coached two students to reframe a conflict and come together again (Interview, p. 25). Although the right and wrong conversation during the interview painted Ms. Second as having a sort of black-and-white view of the world, this scenario with the two students revealed her more nuanced view of human interaction. Ms. Second showed the student who was pushed that it could have been accidental and her peer may have not even realized what had occurred. She said that she wants her students "to be able to communicate and speak and say whatever it is on their mind and what happened" (Interview, p. 26).

\section{Ms. Third A}

\section{Introduction}

Ms. Third A never wanted to be a teacher. She was a science major until financial difficulties led her to a teaching assistant job in the preschool at her children's school. When the preschool teacher had to take a leave for a family emergency, Ms. Third A found herself the sole teacher for the rest of the year. She found it very easy and quite enjoyable, so decided to change her major to elementary education. At the time of this data collection, Ms. Third A had been teaching for over 14 years. She has taught preschool, kindergarten, second grade, third grade, and fourth grade throughout the years. 
She was principal at this school for 2 years, but she eventually decided to go back to her passion of teaching.

At first, the most striking quality of this experienced teacher is her nurturing nature. As you spend more time with Ms. Third A, it is evident that she is extremely selfreflective and personally responsible, meaning she looks for solutions she can implement rather than complain about and blame others for challenges. She deeply cares for her students and maintains high expectations for that reason. She has a growth-oriented view of human beings and, as a result, is open to her students', as well as her own, fallibility. She is constantly learning and implementing new strategies that are practical with an ultimate purpose of growth and progress for the students. The quiet student is a major concern for this teacher. She worries about the ones who go unnoticed and she encourages and nurtures free expression from all her students. She believes that the core of that teacher-student relationship is to develop a connection.

\section{Adaptability to Student Needs}

Ms. Third A views her students as having unique life circumstances that shape them with specific emotional and intellectual needs. She tries hard to understand each of her students and adapt to their particular needs to ensure a capacity for learning. Through the observation and interview data, Ms. Third A adapts to her students' needs by continuously assessing any obstacles to learning for each student and adjusting accordingly by adapting her methods of instruction, attending to students' emotional needs, and accommodating their physical needs.

Instruction. Ms. Third A is attentive to her students and continuously assesses their understanding. In the interview, she discussed one particular lesson that went 
"horrifyingly horrible" because the children did not understand it (Interview, p. 3). She said, "I blame myself because that means how I'm teaching it or the instruction, it means it's not good instruction" (Interview, p. 3). She reassessed and tried different instructional methods. Specifically she sat with them in small groups and realized that they lacked a pre-knowledge base that she assumed they had. She said she "used different strategies for different learners" (Interview, p. 4). More specifically, she discussed different learning styles such as the student that memorizes how to do something, the student that needs it broken down into steps, and the student that needs to see it and manipulate it. Ms. Third A repeatedly spoke about how some kids really need one-on-one attention because they get distracted in whole group settings. In the observations, Ms. Third A utilized several modes including whole class instruction, small group instruction, and one-on-one instruction as she directed other students to work individually or in small teams. She also provided thinking time as needed. During one observation session, she asked the class to "give him time" as she guided a student to the answer during a whole group lesson. To allow students the time to process is reflective of her trust in the learning process and the growth mindset she embodies as a teacher.

Emotional. Generally, assessments are considered to be a way of measuring knowledge or understanding of the curriculum content. With Ms. Third A, she assesses not only a student's understanding of material, but also their current capacity to acquire knowledge. That capacity is often impacted by their self-concept or their emotional state. Therefore, she not only adapts her methods of instruction, but also her discipline methods. For example, she created a discipline strategy with different color levels where each student has a clothespin. She moves clothespins to refocus students and they can 
always move back if behavior improves. Ms. Third A noticed that certain students respond well to this discipline system and become energized and motivated to improve, while others completely shut down if their clothespin is moved. Rather than take the mindset that these are the rules and students must accept consequences for their actions, Ms. Third A adapts her discipline strategies to each student depending on what produces the best outcome, meaning which method best motivates this particular student to learn and grow. Therefore, if it motivates one, she uses it and if it discourages another, she avoids the clothespin strategy. For one student, for example, Ms. Third A created an individualized sticker chart to help her address a weakness of not bringing home her work. The student was energized by the special reward for her, she loved it and loved the special green pen. Ms. Third A felt that she needed that special attention, it was an emotional need that was blocking this particular student's productivity.

Throughout the interview, Ms. Third A discussed various students' personal context as reasoning for adapting her interaction. For example, the student with the green pen, Ms. Third A mentioned that she is a middle child and maybe for that reason she sought out that special attention. For other students, she cited home life disputes or personality. One of the ways Ms. Third A adapts to her students' needs is through personally connecting. She discussed a strategy she learned from an ESE course where the teacher takes two minutes out of the day to talk to the child. The course teaches this strategy to address behavior, but Ms. Third A said that she "found it to be very helpful with people who have delays in learning, or maybe just need that little extra push" (Interview, p. 6). She spoke about using this strategy with one student who was very withdrawn and how he started "opening up more" as a result (Interview, p. 7). Ms. Third 
A has a special connection to the quiet students, mentioning that she was that quiet student as a young girl. She said during the interview that the loud students get what they need because they are loud about it, but the quiet students are often unintentionally neglected. The 2-minute strategy addresses emotional barriers to learning because, Ms. Third A said, "It becomes more of my feelings about this then how hard the problem is, 'well, how do I feel about something like this? I feel like a failure because I look at it and I don't know a thing"' (Interview, p. 8). She infers this from her students because all they really say is "I don't get it. I don't get it at all" (Interview, p. 8).

Physical. During the interview, Ms. Third A mentioned that drawing helps one boy focus on the lesson. While her innate reaction may be to stop him from doodling, she refrained from doing that and came to realize that it was not a distraction, but actually improved his attention (p. 16). Repeatedly throughout the data it is clear that Ms. Third A adapts anything if it is effective for student growth.

\section{Teaching Methods}

Experiential. One of the most exciting ideas in Ms. Third A's class was the interactive word wall. She noticed in previous years that students barely looked at this massive word wall. It was nothing more than a decorative piece. Because she is constantly seeking to grow and improve her craft, Ms. Third A came across this idea of an interactive word wall from a teacher relative at another school district. As students write, they are encouraged to use the words on the wall by making a dot on top of each word used. This serves many functions such as encouraging students to actually look at and use the word wall and incorporated physical movement during lessons as a refresher. The word wall is both kinesthetic and visual, appealing to different learning styles. 
Finally, it allows the teacher and students to visually assess the frequency of the class use of the words (Observation \#1, p. 10).

Teacher guide. Ms. Third A led whole group lesson through questions. The students produced the answers and she guided the conversation. For example, one observation was during a vocabulary lesson. Ms. Third A would ask the students to define the word in their own words, taking more than one definition for the same word. She also asked them to give examples from their life experiences. Another example of a whole group lesson was a demonstration where she created a frequency chart on the board. She asked the students questions to guide her actions on the board. She also frequently had them work in small groups as she walked around answering their questions or providing guidance when she saw mistakes. She frequently did not provide answers, but rather directed students to areas of the text where they would find the answer (Observation \#1, p. 2; Observation \#2, p. 6).

Group Size. During the observations, Ms. Third A used all configurations of group size. Sometimes she instructed the whole group, other times they worked in small teams or independently while she worked with small groups or one-on-one. During the interview, she discussed the benefits of small groups in connecting to students and being able to maintain their attention level easier (Interview, p. 5). She uses the one-on-one time also to assess the students and ensure "they are on the right track" because some students may continue to do the wrong thing without asking to just finish (Interview, p. 5). Ms. Third A believes that by spending that personal one-on-one time with particular students, it makes them more comfortable and less shy to ask for help in the future. This 
is an example of how Ms. Third A uses connection strategies to adapt to the emotional needs of her students as discussed earlier.

Free Movement. In Ms. Third A's class, students moved about freely, whether to get needed items such as pencils or tissues, or to approach the teacher with a question. Ms. Third A never once instructed a student to sit down, even when I witnessed a boy repeatedly go to get a sharpened pencil during one observation. She mentioned that movement refreshes them and, also, that this particular group self-regulates well. One unique learning experience that promotes free movement in this class was the interactive word wall, which was mentioned earlier.

\section{Ways of Connecting to Students}

Nurturing. One of the most striking qualities of Ms. Third A is her nurturing nature with the students. Repeatedly observed in the classroom, she would stop instruction to ask students if they were "okay" or offer a bottle of water to a coughing student. One observation day, she saw one boy visibly distressed and bent down to speak to him, then had another student take him to the office. Even her tone of voice is gentle and soothing. As she directs students in the classroom, she does so with gentleness, like a mother on a good day. She often uses words of endearment such as "sweetie" and "honey" when addressing her students. Interestingly, after the observation data revealed this nurturing nature, the teacher confirmed this classification of her style in the interview. When asked to describe her teaching style, she said, "I mean basically I try to be nurturing, I try to be caring, I am tough, and I'm silly sometimes, but I also like to balance that" (Interview, p. 16). She also described a teacher's role as: “...you are their psychologist, their counselor, their mommy, their teacher, you are everything to these 
kids" (p. 12). As discussed earlier in Ms. Third A's adaptability to student needs, in being nurturing and connecting to her students in this way, she is also cognizant of the benefits to their learning. Ms. Third A loves her students and the nurturing is a reflection of that love. The love is also evident in her high expectations of them. She reflected back during the interview on a conversation she had with her class where she told them that she is tough on them because she cares about them and if she did not care about what they are learning or about their success, they would get away with everything.

During the observations, Ms. Third A would smile and laugh with the students often. The classroom felt light and carefree. One boy that seemed to be a bit of a class clown raised his hand to answer a question. She smiled gently and called on him, rather than ignore him or respond abruptly like some teachers may do with the class clown. Another example of the lighthearted atmosphere, after reviewing vocabulary words, she asks them to take out their "reading response journals" and the students moaned in unison. One student called out, "Now everyone is wailing!" which was one of their vocabulary words. She smiled and said, "Yes, good job." While some of the teachers have a more overt or explicit sense of humor with intentionality, Ms. Third A has a lighthearted sense of humor that is more nurturing, laughing with her students and sometimes engaging in silliness with them as she indicated in the interview.

Reward. During the observations, Ms. Third A always celebrates her students' successes with tangible rewards and repeatedly praises her students. In the interview, she discusses the importance of specific praise in developing an ability to bounce back from a mistake. Parents who tell their children "you're the best, you're the fastest," she says, "when they are caught making a mistake, they just go down into, it's such a tragedy" 
(Interview, p. 12). This ability to face and learn from one's own mistakes is important for Ms. Third A and giving unspecific flattery prevents students from accepting their own missteps. Therefore, specific praise not only builds confidence, but allows students to look at themselves honestly. Along with the praise, Ms. Third A also provides honest feedback. In this way, it's authentic and balanced.

Respect. During the observations, her interactions with the kids were always respectful. One time, a group of children came in late as the rest of the class was reviewing homework. They silently waited to ask a question until the teacher paused. She spoke to them calmly and respectfully and said, "You guys took a long time in the bathroom, ask your classmates to review homework with you" (Observation \#1, p. 3). Although not the only example, her view of the students was evident from this one interaction, she trusted them and saw them as responsible. It was not accusatory or demeaning as is sometimes the case in the relationship between teacher and student. Rather, she made an observation and offered a solution to the consequence of their tardiness.

Another interesting indication of respect to students was the way in which the teacher introduced me to the class. Some teachers did not even acknowledge my presence to the students, while others took time to explain why I was in the classroom. While it may not be an indication of a teacher's lack of respect towards her students if she did not introduce me, it reflected respect towards them when she did. Ms. Third A introduced me by name on the first observation day and explained that I would be observing for some time. Each subsequent observation, she would greet me when I entered. On one occasion, she stopped the lesson and said, "I'm sorry, I didn't say hello" (Observation \#2, p. 1). 
Listening. The two-minute conversation mentioned earlier is an example of Ms. Third A using listening as a strategy to connect to her students. I saw Ms. Third A responding to student conversations regularly during observations. For example, when one boy humorously said, "You shouldn't step in wet concrete" during a vocabulary lesson on the word "sidewalk," many teachers may smile and move on, but Ms. Third A engaged him in a conversation and asked him, "Why?" (Observation \#1, p. 4). She exhibited the conversational listening style.

Trust. Ms. Third A repeatedly demonstrated a deep trust and positive image of her students. As the theory of the self-fulfilling prophecy reflects, when Ms. Third A treats her students with an expectation of responsible behavior, they will likely fulfill her expectations. This was not stated as her intention, but rather, she indicated in an informal conversation during the observation that this class self-regulates well and unlike last year's group, she does not need to provide intense structure for them to be productive. She said, "...this is a good class, they actually love to learn which is great and I love it" (Observation \#1, p. 10).

\section{Growth-Oriented Mindset}

Emerging from all the data, Ms. Third A embodies a growth-oriented mindset. Every single human being has some area they can improve upon. She sees her students as whole human beings and her role as much more than a knowledge-giver. She is keenly aware of hidden obstacles to human growth and various kinds of growth as well. As a person who is self-reflective and seeks ways to improve, Ms. Third A is someone who sees human beings as growing. Therefore, in looking at her own students, they are not 
absolutes—smart or not, good or not—-they are improving and growing and her role as teacher is to mitigate obstacles to growth and help them through.

Self-reflective. Ms. Third A is one of the most self-reflective teachers or maybe she is just the most open about it. She is constantly seeking to improve in her teaching. During the interview, she spoke about her growth as a teacher and how she never stops learning. She said, "Things I learned before, I am actually using this year and it makes a big difference" (p. 2). The interactive word wall is one example witnessed during the observations and mentioned in the interview as well, where she learned a new strategy and implemented it effectively. She discussed in detail one example of a lesson that went badly and how she took a step back and tried again differently (Interview, p. 3-4). When Ms. Third A discussed the two-minute connection strategy, she inferred that her students feel like failures when they do not understand something and the quiet ones do not express themselves. Her self-awareness was evident here as well when she said, "I mean maybe I came to this conclusion all to myself but as a child who was very bad at school, I know what it's like to say, 'what am I doing here?’” (p. 9).

Fallibility. Ms. Third A creates a safe space for her students to make mistakes and openly models in front of her students how to deal with her own mistakes. She said during the interview, "Who's perfect? I'm not perfect. I make mistakes every day. I feel like I'm a very flawed person. But at least I know I'm a flawed person and I try to improve myself" (p. 12). It is evident in seemingly insignificant interactions such as a student saying to her during one observation, "I wasn't done with that" after the teacher had changed the screen, and the teacher responding, "What is that, honey? Oh, sorry" as she turned it back for that student (Observation \#2, p. 1). During another observation, Ms. 
Third A moved two names to red as she gently said, "What did I say, guys, no talking, right?" Then another student defended his classmate and said he was not talking, but just counting with the teacher as she was creating a chart on the board. She immediately put the clips back and said, "Oh, I'm sorry, I thought you were talking" (Observation \#3, p. 3). In one instance the students witnessed her struggles to get the chart lines even as she erased and tried again and squeezed it in saying, "Even teachers do that" (Observation \#3, p. 3). She allows her students to see the messy processes, not just the clean and sterile results. In the interview, she spoke about her intentionality with her openness about making mistakes, "You have to think what's your purpose here, are you here to show how good you are or is it about these kids. It can't be about ego, if I make a mistake I'm going to tell them" (p. 31). She models what it looks like to make mistakes, acknowledge them, and improve.

Ms. Third A encourages her students to do the same with statements such as, "If you don't know it's okay" (Observation \#1, p. 1). One student had forgotten his sentence, for example, in a whole group discussion, and her response was respectful as usual, saying, "It's okay, we can come back to you" and she did come back (Observation \#1, p. 2). During the observation, for example, as the whole class was reviewing homework answers, Ms. Third A tells a student about his wrong answer, "It's okay. Correct it" (Observation \#1, p. 2). She said, during the interview, that she tells her students, "A mistake is only a mistake if you don't learn from it” (p. 10) Assessments for growth. Consistent with a growth-oriented philosophy, any questions, homework, or classwork were viewed as learning tools, not testing tools. One particular example from the observation data were especially striking. During a 
vocabulary lesson, one boy was snickering as he secretly held the book and asked if he can say one more definition. They were reviewing vocabulary that they had already learned. The teacher was asking the class to provide definitions in their own words. So, another student yelled out, "He's looking at the book!" implying that his classmate was cheating somehow. The teacher smiled, let the boy read it anyways, and then said, "It's okay, when we don't know the definition, what do we do? We look it up" (Observation $\# 1$, p. 4). This reflects the teacher's growth-mindset as well. Rather than view her questions as a test on the student's current knowledge, she modeled for students that it was alright to acquire knowledge. Observing this exchange, one could imagine a teacher coming down hard on the student secretly looking in the book, but Ms. Third A's actions nurtured a positive relationship with seeking knowledge and research. As stated earlier, she has them correct wrong answers on homework assignments.

Holistic view. As mentioned repeatedly for Ms. Third A, her focus is not only on the intellectual growth of her students or developing their social skills, she is also conscious of their emotional and spiritual growth. This is evident in her adaptability to various student needs. It is evident in her 2-minute connection strategy and her nurturing demeanor. It was evident repeatedly during the interview when she speaks about various students' personal context. She said that the education will come, but the problem is "when they don't have the self-esteem, or the character, or even the humbleness" (Interview, p. 14).

High standards. One of the frequent observations about Ms. Third A is her commitment to high standards for her students. One conversation she had with them, Ms. Third A explained that she is tough on them because she loves them and cares about their 
success. "I'm expecting more from you than you want to give me" (Interview, p. 13). While her class feels carefree and easygoing, she pushes her students to excel. During the interview, Ms. Third A discussed how some students will rush through their work and get all the answers wrong because "they think it's not important that I learned anything, it's important that I got it done. I don't want to see that" (Interview, p. 6). She reflected in the interview, "Maybe I have a little higher expectations than I should because I want them to be the top, you know. But that's okay, because I feel like if I have high expectations I will get them there eventually" (p. 15).

\section{Highest Hopes for Students}

Character. During the interview, Ms. Third A argued that while the education comes either way, her purpose is to build character. To her, character means humbleness, honesty, self-esteem, and love for people. A prevalent thread throughout is Ms. Third A's relationship with fallibility, which is discussed in detail later. She frequently brought up the importance of acknowledging mistakes and the difficulty that some students have saying, "Okay, I made a mistake" (p. 14) because of their ego. Interestingly, this was also a concern of Ms. Second and Mr. Middle Language Arts.

Connection skills. The foundation of connection skills is in character and Ms. Third A beautifully bridged the two categories in the interview when she discussed her desire to teach students good sportsmanship and encouraging others to be their best. She spoke a lot about respecting one another. During the interview, Ms. Third A discussed one unexpected lesson to her students about healthy competition and encouraging classmates' successes. One student was wishing her classmate would fail in a competition, which prompted a discussion of being supportive and working harder 
yourself if you want a different outcome. These are all qualities important for teamwork and cooperation.

Through her interpersonal connection to students, Ms. Third A models behaviors such as listening to feedback from the students, praising students for their responses, and generally connecting to each student uniquely. She also encourages students to speak to each other during the class. She admits that it can get loud at times, but she said in the interview, "I believe communication is very important between students, this is how they learn" (p. 17). During the observations, students worked in teams a few times. There was a chart on the board for the writing process, including a step for peer edit and she directed them to follow these steps during a writing session. Not only does this teacher create a non-threatening environment where the children can offer feedback freely, but she encourages them to seek and listen to feedback from their peers. During observations, Ms. Third A would ask the class to quiet down and listen to their classmate who is speaking. She modeled good listening herself by remaining attentive to all student conversations directed at her and responding appropriately, such as, "that's an interesting idea" (Observation \#1, p. 3).

\section{Ms. Third B}

\section{Introduction}

Ms. Third B had many majors in college and struggled in finding a path that balanced her passion for performing arts and her faith values. Eventually, her journey led her to teaching, saying, "I love being in front of a classroom and if you haven't noticed, it's a stage" (Interview, p. 1). She earned a degree in the Liberal Arts and obtained an alternative teacher certificate before graduating. She began teaching in 2006 in a public 
school for three years before coming to this private school. During her first year teaching, which she said "was like hazing," Ms. Third B was placed in a $4^{\text {th }}$ and $5^{\text {th }}$ grade ESE and ESOL class. After many tears were shed, she was well-equipped for her next year and earned the "Rookie Teacher of the Year" award. Her third year in that public school, however, was the most difficult class she ever had with a multitude of students with various tragic life circumstances and psychological problems. After her experiences in that school, Ms. Third B said that this private school is like "Disneyland" (Interview, p. 6). Being a young mom and a full-time teacher, Ms. Third B manages to find the time to write children's books as well. At the time of data collection, Ms. Third B had already published three books. Ms. Third B is an energetic and self-reflective teacher who seeks to reach every student in her class in whatever way possible.

One of the most intriguing facets of this teacher was this thread of respecting authority that continued throughout the interview and observations. Ms. Third B does not come down hard on her students, but instead engages them in conversations and guides them to discover knowledge. As a result, to hear her speak about respecting authority so many times was surprising at first. This interview exposed one of my own biases to me, namely that the concept of respecting authority can contradict with democracy. If respecting authority is seen as a sort of blind trust for any authority, then it is in opposition to the ideal of the critical thinking citizen who challenges the status quo in an effort to find the better or higher truths, as Mill's conception of democracy was described in earlier chapters. She wants them to accept their position in society as children, enjoy it, and respect its limits. In getting them to reach this place "to be responsible in the position they are in and to stop fighting it," she uses respectful and democratic methods. How 
does she balance between developing democratic dispositions, such as in the way she interacts with them, and developing a respect for authority, as she states repeatedly? It became evident to me that this respect of authority she seeks to develop in students is necessary for democratic living. If a student is constantly in "challenge-mode" and does not allow information from any valid source to seep into his or her mind, then there is no hope for an open discourse that yields progress. This is why she used various examples of authority, showing that authority refers to any valid source of information. In discussing how some students challenge authority, she not only cited challenges to her as a teacher, but also to displayed rules or instructions (e.g., museum pyramid exhibit discussed under "Ways of Connecting to Students"). How can she teach a child who is unwilling to listen to anything anyone else has to say? How can she teach a child who will not even believe her when she says there are carrots in carrot cake? Ms. Third B may not be consciously educating for democracy, but, she has definitely touched upon a very real obstacle to democratic living that seems to be a result of over-parenting our children. From this teacher, I gained a deeper perspective about the qualities necessary for democratic living and understood this very important connection between respecting authority and progress. It opened a door to future research questions around parenting for democratic living and this concept of fallibility necessary for democracy.

\section{Adaptability to the Student Needs}

Curriculum. Evident in the data, Ms. Third B adapts curriculum for academic or intellectual needs. For example, during one lesson at her current school, a student could not understand right angles. Ms. Third B took an unconventional approach and taught her a concept that was way beyond her curricular level. She drew a $360^{\circ}$ circle and explained 
right angles using that framework, which enabled that student to understand (Interview, p. 21). She said about this example, "I would rather give you more knowledge than less. Sometimes that means going past the curriculum to understand the curriculum" (Interview, p. 21). This is precisely the definition of curriculum expansion, one of the three new distinctions developed during the next phase of data analysis. After reanalyzing the data with this distinction, Ms. Third B did not show evidence of adapting the curriculum in the other ways - namely, varying the difficulty level, varying the quantity of work, or varying the expectations.

Emotional. Ms. Third B began the interview with a discussion of her first years teaching at a public school with a student population that had tremendous psychological challenges. Her achievements with her students were noticed across the school, not so much because of their academics, but their behavior and demeanor. They were emotionally improving. She said that she would start each day fresh with the kids and would have a quick "pep talk" with the students who were struggling the day before, saying, "This is a brand-new day, let's forget about whatever you did yesterday and let's focus on today. What are you going to do today to make today a good day for you?" (Interview, p. 4). She believed that this approach made the students more willing to work with her and make better choices. Ms. Third B adapted her approach based on the emotional needs of the students because she "would determine which children needed a little bit of something extra," as she described (Interview, p. 4).

Ms. Third B spoke about conversations that were not necessarily planned, but became necessary as she assessed the needs of her students. For example, when seeing the boys playing rough with the girls, she gave them an analogy that boys are like blocks 
and girls are like flowers. She would tell the boys to be more gentle with the girls because they are delicate, like a flower, whereas boys can tumble unharmed just like a block. The intent and the result was to change the boys' behaviors with girls and to change the girls' self-concept, where they expect to be treated better. Instilling in young girls an expectation of being treated well is appropriate for a democratic society; however, the stereotypes about the sexes outlined here create many questions around the equality of citizens in a democracy. How will these students grow to view boys that are like flowers and girls that are like blocks? Regardless of the implications for democracy, this was not a planned curricular discussion and Ms. Third B adapted to her students' current needs. This adaptation could be seen as curricular, but also as addressing an emotional need for her students.

Attuned to the internal state of her previous students, Ms. Third B realized that they rarely had the freedom to act like kids. They were worried about finding their next meal, so playing was really not a priority for them at all. In her class, she would tell them that "it's okay to be a kid" and put on some music and have them just dance (Interview, p. 5). This was an intentional adaptation to address their emotional needs, because she said, "It seemed like they were missing a childhood" (Interview, p. 6).

While her current students did not have the severe psychological circumstances like some of the students in her previous class, Ms. Third B still displayed adaptability to their emotional needs. One day, for example, Ms. Third B brought in carrot cake for her class, which started an entire discussion about whether or not there were carrots in carrot cake. Ms. Third B responded by telling the students that there are carrots in carrot cake. However, after one boy was adamant about his position that there are no carrots in carrot 
cake, Ms. Third B had the students vote and then research carrot cake recipes online. When Ms. Third B noticed the boy's demeanor changing, she decided to show him the results privately at her desk. She said that "because it looked like it was damaging his self-esteem, I did not publicly announce it because it does more harm than good" (Interview, p. 17). Her decision is an example of adapting to the emotional needs of one student.

Physical. In Ms. Third B's class, there is a student desk pushed up against the teacher desk. During observations, Ms. Third B explained that the students all want to sit in that desk to be close to her and she rotates them throughout the year to give everyone a chance (Observation \#4, p. 5). Before she explained the reason for the desk, I assumed it was a disciplinary solution for behavioral problems, which would still be an example of a physical adaptation for the needs of her students. However, it was a physical adaptation to motivate and connect to the students.

\section{Teaching Methods}

Experiential. Ms. Third B used experiential teaching methods in her class. During one observation, the students were working independently trying to solve a problem the teacher gave them: to make a diagonal rectangle with rubber bands on a geo board using only 5 squares (Observation \#2). The students created various figures and excitedly showed the teacher. She would acknowledge their creations and direct them to continue solving the assigned problem. When one student thought she solved it, Ms. Third B counted the squares and explained why it was wrong. The class was talking and moving around as they each work independently on this problem. Ms. Third B walked around checking their work. 
Teacher guide. Ms. Third B is a teacher guide. She does not give answers to student questions, but rather guides them to discover the answers themselves. She said during the interview, “I don't give them the answer because it doesn't teach you anything" (Interview, p. 16). If a student asks her what to do, she has him or her read the directions out loud to the class. For example, during one observation, a student asked the teacher what page they were on in their Stanford Achievement Test (SAT) practice book. Rather than tell him, she said, "You tell me," eventually pointing to the board and saying, "See how you were able to find it by reading?" (Observation \#4, p. 2). The carrot cake scenario mentioned earlier under "emotional adaptation" is also an example of how Ms. Third B guides students to find answers to their questions through research. Even though she told them, when one student still had doubt, she went through a process to show the class the truth instead of merely making an authoritative statement (Interview, p. 17). During the observations, Ms. Third B asks students guiding questions as they read a story out loud (Observation \#3, p. 2). When one student exaggerates the facts from the story, she directs him to find the information in the text to support his claims, which is aligned with Habermas' (1998) justifiability and truthfulness validity claims. Ms. Third B did not even define words for the students, but rather had them find the word in the text of the story and read the surrounding sentences to ascertain clues. She then asked them to tell her the words that hint to the meaning of the desired word (Observation \#3, p. 4). This example reflects Ms. Third B's tendency to guide students to answers and in the process, teaching them the skills to find answers on their own in the future, reflective of her highest hope of effectiveness skills explained below. 
Group size. During all the observations for this teacher, the class was configured either in a whole group setting or as individuals. Students were seen coming up to the teacher to check their work. The whole group, as indicated prior, was dynamic as the teacher guided the class to learning. As students worked independently, there was a lot of conversing and the class was always vibrant.

Free Movement. During observations, the class was always in motion and loud. The kids were moving around, talking to the teacher and to each other. There were times when Ms. Third B asked students to work quietly for a set amount of time on a specific task or took a bracelet from one student for playing with it during class (Observation \#1, p. 3). However, the general feel of the class is dynamic with students moving around. On one occasion, she directed a student to take her chair and sit. The girl said "no" to the teacher and explained that she was using the seat for her work. The teacher said, "Okay, whatever gets you working" (Observation\#2, p. 3). Later on during the same observation day, the teacher explained to me that she lets the students move around and talk because she wants them to be comfortable and not confined. One day, she tried having them sit and be quiet because she worried that they disturb the neighboring class. She hated it and made them get up and stretch it out. She told them, "When you're quiet, it doesn't mean that you're learning, it just means that you're quiet" (Observation \#2, p. 5).

\section{Ways of Connecting to Students}

Respect. Developing a good relationship with her students is important for Ms.

Third B. During the interview, she said that a teacher will inevitably develop some sort of relationship with her students because they are around each other for eight hours a day. She asserted: 
I would like it to be a healthy and respectful relationship because that is how you're going to get through the year and actually learn something and I'm going to get through the year and actually teach you something. And I'd like to learn something myself (Interview, p. 4).

Respect was an important theme for this teacher. She recalled an incident from her public school years where one first-grade student was placed in her class midyear because he punched his previous teacher. Physically, a first grader is not going to cause much damage, but she was more concerned with the "disrespect that has to go into your psychology to hit a teacher" (Interview, p. 4). Ms. Third B's class was noticed by the rest of the school for major improvements. When probing her during the interview to elaborate on the improvements, she said, "The kids were more respectful and more willing to listen and were not as hard and rigid as before" (Interview, p. 5). She gave one example that was especially prominent for her. While walking to the cafeteria, one boy got out of line. Surprising all bystanders, the boy responded to Ms. Third B simply gesturing for him to get back in line. This was a boy who had held scissors to another child's neck earlier in the year and to see him follow his teacher's guidance indicated his growth. She credits the respectful relationship she had developed with him over the course of the year. She said, "They are respecting boundaries, they are respecting authority, and they're changing as a person. It's the little things" (Interview, p. 6).

Ms. Third B spoke a lot about students respecting authority, but she believes that adults must respect children too. She said in the interview about how she would like her students to think:

Okay, this is my role and my responsibility and I have to respect adults and I have to know that I am a child and understand that and be comfortable with it and then when it's my time to be an adult, I will also be respectful to other adults, my peers, and to children (Interview, p. 8). 
Her respect towards the students was evident from the observations and the interview also. She was always conscious about how the students felt after an interaction with her. For example, in discussing issues some students have with boundaries, she talked about an uncomfortable conversation she had to have with a boy who was always physically too close. She would say, "Please back up a little bit." She told me that she would tell the students in a nice and polite way why they cannot do that and that she would "never want a child to walk away feeling guilty or shunned" (Interview, p. 8). She added that "any negative emotion they get out of it is bad" and that means her talk failed (Interview, p. 9).

Ms. Third B expects her students to respect others, but only because she herself respects them. Ms. Third B said, "I feel like if you respect the children and show them respect then you can demand it back" (Interview, p. 10). Respect for Ms. Third B is demonstrated in the students' responsiveness to her guidance and their interaction with others, but also by keeping their promises and holding themselves accountable (Interview, p. 10).

While she repeatedly spoke about respecting authority, Ms. Third B's definition of authority was not limited to adults. While on a field trip to the science museum, Ms. Third B spoke about an experience with a student who refused to try an exhibit. The directions were to build a pyramid out of two blocks. Minutes prior, she had done the exhibit herself and succeeded. Then, her student came up to it, looked at it, and said, "It's impossible. It can't be done" (Interview, p. 18). She urged him to try it, but he refused. He continued to argue that it cannot be done as he demonstrated his reasons. She told him, "Well, just try it," but he eventually walked away to another exhibit. She told this 
story as an example of a student not respecting authority. She said, "The authority is in the instructions, the authority is the display" (Interview, p. 19). She continued to speak about how logically the people at the museum would not create a display that was a lie and that these people are bigger, "not necessarily physically bigger," but to "have respect and just try it" (Interview, p. 19). Respect here seems to reflect her desire for students to be open to ideas from others and not be so arrogant as to think that their own thoughts are superior. In this sense, respect for Ms. Third B is linked to fallibility — being honest about your own place, knowing that you can be wrong, and accepting you can learn from others. This conception of authority and respect seems to fit in the liberal deliberative conception of democracy forming the theoretical foundation of the present study. In order for deliberation to be productive, citizens must be open to their own fallibility and to the ideas presented by others.

Listening. Along with respect, Ms. Third B spoke a lot about students listening and making sure her interactions with them created an environment where they were open to listening. For example, she spoke about the downfall of a more aggressive approach with children in that they will "just walk around on eggshells" and a healthier way to guide children is "to point it out to them, to hold it up, and say look what you did and here's the consequences" (Interview, p. 11). In so doing, they will be more comfortable in listening, respect you more, and willingly "jump on board to do it as opposed to being forced to do it" (Interview, p. 11).

Ms. Third B uses the word "listen" to refer to both following her guidance and allowing students to express themselves freely. During the interview, she spoke about one girl who never spoke. At the beginning of the year, her mother approached Ms. Third B 
with her concerns and hopes for her daughter. Ms. Third B worked with her all year until the gentle whisperer turned into a chatterbox who was yelling at the boys. She reflected, "I think that's a good thing when you can be comfortable enough to express yourself. I think that's important" (Interview, p. 22). This listening disposition was evident during the observations as well. On one occasion, for example, Ms. Third B gave one boy a consequence for throwing his book. When he began explaining himself, the teacher listened. After he finished speaking, she accepted his explanation and did not discipline him. This example reflects Ms. Third B's listening disposition with her students because she did not insist on her interpretation of what had happened, but rather she listened to the boy and changed her mind. This reflects the newly emerging teaching style of observational listening because the purpose was not merely connection or conversational. It was difficult to distinguish if Ms. Third B listened as observation to inform teaching only or also listened to connect, as in conversational listening. It seemed after reviewing the data with the new codes in mind, Ms. Third B engaged in both types of listening simultaneously.

An important question came to mind during the third observation, which I had notated in the reflection margin of my fieldnotes: "Is this too much freedom? Or is it okay to struggle through what it means to have freedom and choice?" Ms. Third B was engaged in this ongoing discussion with the students to select a team to go first. She began by asking them which team had never been selected first. The kids argued. She directed them to raise hands and challenged their assertions. She initially selected Team Four. After more argument from the students, she changed to Team Three declaring that it was her last decision before beginning the reading lesson. She clearly listens to her 
students and many times follows their suggestions, which is in line with a democratic discourse. Is this an example of democratic education preparing students for the type of dialogue expected in a democracy? She challenged student assertions, which is in line with Habermas' (1998) validity claims. Ms. Third B eventually made a decision, which is in line with timely decisions of maturity of judgment and in line with the tenet of deliberative democracy outlined by Gutmann and Thompson (2004) that decisions are binding for some time.

Listening was connected to this concept of respecting authority on several levels. Ms. Third B spoke about how her current students' problems with respecting authority likely stems from parents that actually listen to their children and value their input so much. In this interaction with their parents, they learn to value their own thoughts so highly that it can create a barrier for them to listen to others and be open to different points of view. A similar experience was echoed by Ms. Third A when she described her students' discomfort with making mistakes because their parents overly praise them. Is Ms. Third B guilty of the same behavior in the classroom as described in the previous paragraph? It was interesting to talk about the contrast in respect between her current student population that did not have emotional barriers to learning and her previous student population who had various challenges beyond their age. According to Ms. Third $\mathrm{B}$, her current students overvalued themselves and, as a result, were not open to learn from others. As Ms. Third B said in the interview, "It is good to ask why. It helps make them smarter. But when someone answers the why, it's not smart to say, 'I don't believe you!'” (Interview, p. 26). Her previous students, on the other hand, some of whom were mistreated or under-cared for would become rebellious against authority and become 
belligerent with teachers. Either extreme leads to a blockage to growth and learning. One student has parents who made him feel really big and now he is too big to learn from others. The other student's life circumstances make him feel really small and now he is too scared to learn from others.

\section{Growth-Oriented Mindset}

Fallibility. Already touching upon this theme of fallibility, Ms. Third B's conversations on respecting authority and listening are really central to understanding one's own short-comings and being open to growth. She recalled during the interview a moment with her students, "Man, you all think you know a lot now, but the older you get, you realize the less you knew and know and you realize the world is so big and you're just this one little person" (Interview, p. 21). The inability of some students to accept their own fallibility is what creates this obstacle Ms. Third B had been experiencing with her students. She called this obstacle a lack of respect for authority. It seems that there may also be a lack of humility or maybe it is perfectionism with a fear of failure. This inability to face one's own fallibility poses significant challenges to a healthy, vibrant democracy. If citizens lack the truth-seeking disposition to overcome their own biases and listen with an open-mind, then effective, progress-creating deliberation becomes impossible. Needless to say, Ms. Third B was concerned with some of her students' inability to accept their own mistakes. She mentioned one example of a student who was "so devastated and so heartbroken" when she made corrections on his paper. She told this student: 
You know you're in school to learn, right? You're not going to get everything right every single time and I don't even get everything right. You know how many mistakes I make. If I cry every time I make a mistake, my shirt would be dripping wet (Interview, p. 27-28).

When one parent asked Ms. Third B how to help her perfectionist daughter learn to accept her own mistakes, Ms. Third B told her, "She needs to be wrong more" (Interview, p. 28). Ms. Third B believes that this devastation associated with making mistakes is not healthy and "as long as you try your best; that is all that matters" (Interview, p. 28).

To address her students' inability to sit with their own fallibility, Ms. Third B directly addresses it with them, as shown in the above statement she made to her class. She also models it by accepting guidance from her students and rewarding them for correcting her, saying, "Kudos for you!” For example, during the observations, Ms. Third B directed her students to work on pages 35 to 38 , until one boy reminded her that it was to page 39. She repeated the correction to the class (Observation \#1, p. 3). On another occasion, she had directed a student to sit down, but when the girl explained that she is using her chair to hold her work, Ms. Third B approvingly said to do whatever helps her work (Observation \#2, p. 2-3). By listening to her students and following their suggestions when appropriate, she is modeling an openness to her own fallibility that she hopes will translate into them emulating this acceptance of their own fallibility as well.

Holistic view. During the entire interview, Ms. Third B's conversation was not about academic concerns for her students; rather her focus was the internal well-being of her students - their psychology, their emotions, and their character. She considers her students' emotional well-being in all interactions, such as when she chose to privately tell the student the results of the recipe research for carrot cake because she noticed his 
emotional hurt from being wrong (Interview, p. 17). Even the decision to go off on this tangent of researching carrot cake is in and of itself an example of her holistic view of the students and the curriculum. She assessed that one of the biggest challenges facing her students is their inability to accept guidance from authority. When this trait exposed itself as they ate cake, she turned it into a life lesson. It was not intended to address an academic concern to teach about research or a physical goal of healthy eating, it was purely an exercise to confront this internal psychological block in some of her students.

\section{Highest Hopes for Students}

When asked what her highest hopes for her students are, if she could imagine the ideal graduate from a perfect school, Ms. Third B said, "That they have learned that what they don't know they can learn, that their efforts can affect any outcome, and planning and execution are essential to success" (Text Message, 7/21/17). The three hopes she specified can be seen as effectiveness skills, and in their simplicity encompass most aspects of preparedness for whatever life circumstances may arise. First, if a person knows they can learn whatever knowledge they need and at any point they realize the need, this removes the impossible burden of teaching students all knowledge they will ever need for the rest of their lives. It is preparedness in the most efficient and effective way - teach children to be seekers of knowledge when needed. Second, if a person learns to put the effort into whatever goal they pursue, there will be some positive outcome correlated to the amount of effort. Finally, if students leave school with an ability to plan and execute those plans, they will be prepared to tackle any challenge.

These effectiveness skills are connected to Ms. Third B's greatest challenge with her students - the unwillingness to entertain different ideas, or what she labeled a 
"disrespect of authority." If a student is unwilling to accept his or her own fallibility, they will not even notice they lack knowledge, let alone seek it. Consequently, if a student is so caught up in being perfect and never making a mistake, he or she may eventually develop a fear of trying, which means no effort. This is again contradictory to the second effectiveness skill Ms. Third B values, as she stated in the interview, "Did you try hard? Did you work hard? Did you try?" (Interview, p. 28).

\section{Ms. Fifth}

\section{Introduction}

At the time of data collection, Ms. Fifth had been teaching for 4 years. She graduated with a bachelor's degree in Math and Science Education with a concentration in middle school. As a young girl, Ms. Fifth used to take her teachers' old textbooks and subject her friends to extra school. She jokes about how her passion for teaching was evident from those young days. However, one great teacher in her early college days prompted her to consider it seriously.

\section{Adaptability to the Student Needs}

Instruction. During the interview, Ms. Fifth discussed how she offers students who are not as artistic the option to write an essay instead of doing a project (Interview, p. 13). This is adapting the instructional methods to the needs of the students. During the class conversations, she often gave students a lot of thinking time. On one occasion, the students were correcting another student's errors as she read out loud and Ms. Fifth "shhh" them and allowed her time to self-correct. During the interview, Ms. Fifth mentioned that she intentionally does not write on the board, but rather prefers to speak information for students to write down. This is to prepare them for middle school. 
However, she circles the room to ensure that the students who struggle are writing down important information during this whole group instruction. She also tells them to look at their partner's work when they do not have the complete answer. She adapts partially to their needs, but not fully. One can argue that fully adapting to each student's needs may hinder adequately preparing them for future challenges where adaptations may not be available. Thus, for example, a teacher can fully adapt to a student who struggles to take notes by providing the notes or writing on the board for him to copy. However, this student will never learn to take notes if the teacher always adapts instruction for his needs. Therefore, Ms. Fifth only scaffolds by reviewing and guiding him as needed. As is discussed in the last theme, Ms. Fifth's highest hopes for her students were to prepare them for the coming stages of their schooling and their lives. Thus, it makes sense that she did not adapt fully because this would not prepare them for future challenges.

Physical. All the student desks were grouped, creating three groups, except for one boy's desk pushed up to the board. This student sat at his individual desk during whole group discussions, but joined a group for team projects. This is considered a physical adaptation to address a specific student's needs.

\section{Teaching Methods}

Experiential. Ms. Fifth is possibly the teacher with the most hands-on lessons in the school. When introducing the teachers to me, the principal commented about all of Ms. Fifth's great projects throughout the year. These experiential learning activities were evident during the observation and evident as decorations on the classroom walls and doors. During the observations, Ms. Fifth's class reviewed their homework which was an experiment conducted at home about the density of different liquids and objects placed in 
them (Observation \#1). On another observation day, they conducted an experiment in the class about milk and vinegar (Observation \#5). During the interview, Ms. Fifth told me of many experiential lessons such as the artistic rendition of Pompeii out of Legos and how the students used dirt from outside to show what happened after the volcanic eruption (Interview, p. 13). She tries to do something hands-on every day if not two to three times a day. The reasons, she mentioned during the interview, are to make learning fun (Interview, p. 12), promote interest in undesired subjects (Interview, p. 13), help students remember the lessons (Interview, p. 15), and reach all types of learners (Interview, p. 13).

Teacher guide. Ms. Fifth did not answer her students' questions directly. During one lesson observed, the class interactions generated the definitions they all used. She passed out seven index cards to each student to create study flash cards as a whole group. She allowed them to refer to the book. She listened to several student suggestions. She asked them to use their own words so it would be easier to understand. Finally, she went to the board and said she was going to take a little bit of what everyone said. She visibly thought through their responses, adjusted accordingly and finally said, "Okay, I think that's pretty good. Let's write that down" (Observation \#3, p. 2). This is an example reflective of a teacher explorer, not just a guide, because Ms. Fifth did not have a predetermined end result before engaging in the dialogue. During that same interactive lesson, the class deliberated about whether a basketball was a solid because it was filled with gas. They eventually decided that it was a solid filled with gas. Ms. Fifth did not guide them to a preset wording, but rather used the discussion as a tool to create definitions that felt authentic for all the students. 
During another class discussion about their density experiments at home, the students shared their findings and Ms. Fifth probed and challenged their comments. For example, one student mentioned that she tested the density of a cookie in the oil and water set up. The teacher asked her, "What kind of cookie? It makes a difference in the density" (Observation \#1, p. 1). Another student mentioned that he tested a ruler. She asked if he tried to push it down. After discussing their individual home experiments, Ms. Fifth had them work in groups to solve for the density of water and oil. She walked around the classroom observing their process and guiding them when needed. It was a contest between the teams and they were working hard to win. When one group announced they won, Ms. Fifth checked their work and told them their units were wrong. After repeatedly calling out random units, she finally told them to use their iPad to find the answer. When one group kept getting large numbers, she recommended they check their decimals. Ms. Fifth did not readily provide answers.

In her classroom, it was a constant give and take with no direct answers to any student questions. During the interview, Ms. Fifth said in response to a probe about how she pushes her students, "If I see they are really in a rut and can't figure it out on their own, I will give them a hint, but refuse to give them any answers" (p. 6). She says that these students prefer lecture-style teaching where the teacher gives them study guides with the test topics and all the answers, but that is not the way she teaches. She said, "We are going to figure it out together. I tell them you are going to find the answer" (Interview, p. 6). Unlike other teacher guides, such as Mr. Language Arts, Ms. Fifth does not always have rigid destinations. Rather, the answers are often co-created in the class 
and the purpose is the process, this is the distinction of teacher explorer that solidified in the subsequent analysis phase.

Student teacher. During one of the observations, the students were presenting their research projects about the industrial revolution. The assignment was to choose a topic, research it using three sources, and answer questions critiquing the sources. They worked in teams of two to three students and presented their findings to the class (Observation \#4). Ms. Fifth listened and asked questions to guide the student-led presentations. She gave honest feedback and praised stylistic factors that captured the audience's interest.

Group size. During observations, Ms. Fifth had the students in whole group as well as teams. They performed experiments in teams, worked on problem-solving in teams, and also presented research projects in teams. I did not witness dedicated one-onone or small-group instruction with the teacher, but, Ms. Fifth was walking around the class answering any questions the students had and guiding them to the answers. One student asked her during an observation if he could work alone, to which she responded, "If you think you can do it alone if you want, but there is a reason you are working in groups, more heads are better than one" (Observation \#1, p. 3).

Free Movement. The students in Ms. Fifth's class often worked in teams on various projects. There did not seem to be any restrictions on movement. During one observation when the students were working in teams, one boy picked up his chair and moved to the other side of the table (Observation \#4, p. 1). In classrooms where movement is restricted, I would often hear teachers directing their students to sit up straight or stay in their seats. This was not the case in Ms. Fifth's class. 


\section{Ways of Connecting to Students}

Reward. Similar to Ms. Second, Ms. Fifth did not praise students with empty encouragement, but rather with focused and not overly emotional validation. She often repeated correct responses with a simple nod. For example, when asking students how to change ounces to grams, she asked if they will multiply and divide. When a student correctly answered "multiply," she simply repeated with a nod, "We are going to multiply" and followed up with a specific example (Observation \#1, p. 3). She is unapologetic about negative feedback as well. During a lesson that required the students to draw, Ms. Fifth looked at one boy's work who had mentioned earlier that he cannot draw and she said, "That is pretty terrible" (Observation \#3, p. 3). The class, including the boy, laughed.

Listening. Ms. Fifth engaged in constant conversations with her students. During one observation where students were brainstorming the characteristics of a basketball, one boy said it tasted like a lizard. Ms. Fifth looked at him and asked if he tasted a lizard before. The class laughed and they moved on. Her communication style with students was honest and direct, not cushioned with overly emotional platitudes. The example above with the terrible drawing also reflects Ms. Fifth's listening to her students and remembering earlier comments, especially when unrelated to the actual learning activity. This is reflective of truly listening to her student's communications. After reviewing the data once again with the new code distinctions for listening, it was evident that Ms. Fifth listened conversationally as well as observationally. She engaged in tangent conversations regularly, but also engaged in dialogue to inform learning (teacher explorer). 


\section{Growth-Oriented Mindset}

Fallibility. Ms. Fifth repeatedly admitted her own mistakes to her students and the students felt very comfortable in pointing out her mistakes to her. During the observation, the class was reading a Time Magazine article and Ms. Fifth had stated that humans burn 90 calories while asleep. One of the students corrected the teacher and said it is actually 90 calories per hour. Ms. Fifth asked her where she saw that, the student showed her, and the teacher repeated the student's correction. It was easy and matter-of-fact. This is a reflection of making mistakes light and modeling truth-seeking behavior. During another observation, a student came up to Ms. Fifth during lunch break to discuss taking a test early because she was going on a family vacation. Ms. Fifth tells the student she cannot take it when she requested because of SAT week. The student said to the teacher, "Are you confused?" The teacher smiled and told the student, "I guess I was confused. Then of course you can take both tests on Monday" (Observation \#4, p. 5).

Ms. Fifth also models for the students repeatedly the messy process of thinking through ideas and coming up with solutions. This was evident during the whole group lesson creating flash cards mentioned earlier (Observation \#3). During that lesson, she drew a basketball on the board to help visual learners understand a concept, saying about her lop-sided drawing, "I don't know, it's the best I can do" (p. 2). During the same lesson, she made light of a student's terrible basketball drawing. This was also making imperfection acceptable, especially because the student had previously talked about his drawing deficiencies.

High standards. At the start of the interview, Ms. Fifth spoke about one of her mentors, the principal at her first job. She said, "From her I learned so much just how to 
keep the students accountable and the high standards" (Interview, p. 5). When asked how she specifically holds the students accountable, she said that she is strict with them and enforces consequences for their actions. This was evident throughout the data on this teacher. She not only expected them to work hard academically, but she wanted them to be responsible without the teacher holding their hand every step of the way. One of the problems she faced was students forgetting to return items from home. She mentioned that she has been working on this skill all year, giving silent lunches as a consequence, and has seen great improvement (Interview, p. 7; Observation \#2, pp. 5-6, Observation $\# 4$, p. 5).

Even though Ms. Fifth assigns a lot of artistic projects to students, she has expectations of accuracy. For example, when the students recreated Pompeii with Legos, she had them research the topography of the land beforehand (Interview, p. 13). The student presentations also reflected her high standards because she expected them not only to present the knowledge component, but also discuss the reliability of the sources they used. This seems to develop the habits of formulating and critiquing arguments according to Habermas' (1998) validity claims, specifically truthfulness and justifiability.

\section{Highest Hopes for Students}

One of the reasons Ms. Fifth has her students do so many art projects is because she felt unprepared for her college education where they expected her to do many posters, bulletin boards, and PowerPoints. She wished she had more art experience throughout her school years and was more artistic in general (Interview, p. 16). This sentiment is a reflection of a recurring theme for this teacher - to prepare her students for what is to come, namely effectiveness skills. She shared, "I feel like a goal is to give them like a 
purpose of being here and I'm trying to prepare you for something bigger. You're not just here to pass time" (Interview, p. 16). When students ask for the purpose of certain subjects or lessons, Ms. Fifth gives them life examples.

This is also the reason that Ms. Fifth never answers a question her students ask, she wants them to learn to problem solve "so whenever they reach a problem in life they have to figure out another way of doing things" (Interview, p. 6). She wants them to be self-sufficient in life and not have to rely on others. She wants them to move on to future grades capable. She mentioned the need for them to be independent and organized. For example, she expects them to remember to bring requested items or papers from home, often giving silent lunch as a consequence (Interview, p. 7; Observation \#2, p. 5-6). She also expects students to write down what she says, rather than writing information on the board for them to copy. This is because Middle School moves fast and she wants them to be prepared (Interview, p. 11). A moment that made her proud was hearing "really good feedback from the Middle School teachers that really see a difference with the fifth graders coming up this year" (Interview, p. 6). She said, "I would like to think that I had something to do with it" (Interview, p. 6).

All of these examples are a reflection of Ms. Fifth's highest hopes for her students - to be functional and effective students as they progress and adults after they graduate. This hope for her students is the core of her teaching methods as a guide and experiential teacher, as well as holding her students to high standards. 


\section{Ms. Science}

\section{Introduction}

Ms. Science initially wanted to be a doctor, but realized that the sight of blood was unbearable. Her family owned a school back home in India and as a result there was always an expectation that Ms. Science would grow up to take over. She first earned a Bachelor's degree in Science before earning another Bachelor's in Education. After getting married, Ms. Science completed a Master's in Middle School Education as well. She has been teaching since 2002, initially at a different local private school.

Ms. Science teaches middle school science at this school, grades six through eight. Ms. Science has a calm, friendly, and positive demeanor. She is self-reflective and observant of her students. Teaching is not merely a job to Ms. Science. Rather, she sees her role as "changing the life of an individual" (Interview, p. 2). Being a teacher, therefore, is molding the kind of community in which we live, because these individuals will grow up to live in and contribute to humanity. To be a teacher is "to be able to bring a sound and capable child to the community" (Interview, p. 2).

\section{Adaptability to the Student Needs}

Curriculum. "The thing is, my teaching style is a little different. I do not go by the book," said Ms. Science. Ms. Science observes her students as a scientist would and assesses her students' needs. Each class and each student within the class may need different approaches, and she tries to accommodate those needs. For $8^{\text {th }}$ grade, for example, she said that they are a more intellectual group and tend to challenge her with really high-level questions on the topic being studied. As a result, she often has to go beyond the book. For example, in chemistry, the book stops at bonds. Ms. Science 
teaches her $8^{\text {th }}$ graders electron configurations because, she says, "I know they can handle it" (Interview, p. 10). This is an example of expanding the curriculum, one of the new styles developed after the next analysis phase. After analyzing Ms. Science's data again with the new styles in mind, there was no evidence to support the other more general curriculum adaptability of varying the difficulty, expectations, or quantity of work based on student achievement. Rather, she varied her instruction to accommodate struggling students, which is discussed in the upcoming section.

Ms. Science focuses on the state and national standards in teaching her students. She uses the curriculum and textbook provided as a tool, not a guide. Therefore, she skips around chapters and integrates outside sources as needed. In terms of SAT preparation, Ms. Science does not dedicate specific time or material in her teaching. Rather, through experience, she has created her own sequence based on the timing of the test. Therefore, she may decide to cover a later chapter first to ensure the students are indirectly prepared for the test at the right time. When she began teaching, she would go in order from the first chapter onward. However, now she aims to hit the national and state standards while preparing students for the SAT. This means she goes in whatever order and uses whatever sources help that her achieve her goals. This is adapting the curriculum to the students' needs because she is preparing them for the SAT. This is also a prime example of systematicity, the critical thinking disposition that means approaching problems in an orderly manner. While I did not know during the qualitative analysis phase, Ms. Science scored the highest of all the participants on systematicity (54 out of 60).

Instruction. When Ms. Science noticed one of her students having trouble with problem solving, she guided her through the question, having the student underline and 
break up the smaller parts. This is an example of adapting instruction to a specific student's needs. She first observed her closely to assess which problems tend to be challenging for this one student. She then assessed what aspects of this type of question are difficult. Then, she taught her strategies to tackle this type of problem (Interview, pp. 2-3). Ms. Science worked one-on-one with one generally high-achieving student who was failing Chemistry. After going over the concepts, going one step at a time, Ms. Science created a new exam for the student (Interview, p. 13). This example reflects her instructional adaptation for this student in providing the extra one-on-one time after school and allowing her to retake the exam. Even during regular classroom instruction, Ms. Science was witnessed allowing a student extra time to answer a question, reassuring her to take her time and "look for it" (Observation \#2, p. 5).

Ms. Science mentioned during the interview how she modifies exams for certain students who are struggling. For example, if the test has an objective and subjective component, she makes the subjective part extra credit for certain students (Interview, p. 13). Ms. Science also discussed how she teaches some students to use a second piece of paper to cover tests and only expose one question at a time. It helps them focus and avoids unnecessary errors. This example is an instructional adaptation, but also cited as an emotional one below (Interview, pp. 4-5).

Ms. Science not only adapts instruction for individual students, but also for the needs of an entire class, such as the $7^{\text {th }}$ graders. She states in the interview that if this group is not busy enough, she notices the behavioral problems. Therefore, she makes sure to plan everything out for them and allows those that complete their work quickly to move on to future lessons. Otherwise, she said, they will sit idle and begin to bother the 
other students who are still working. She said that her teaching style changes in each class because "the same thing doesn't work in all places" (Interview, p. 9).

Emotional. Ms. Science's test-taking strategy mentioned earlier as an instructional adaptation to cover up the questions to improve focus is also addressing students' emotional needs. She mentioned that some of her students feel overwhelmed and scared when they see the entire test (Interview, p. 4). Therefore, Ms. Science is responding to an emotional need of her students as well as an academic need, because the emotional response eventually leads to poor performance.

Ms. Science also mentioned during the interview that even though she encourages her students to ask questions during class, some students feel embarrassed. Because she personally reviews all her students' work, she knows each student's challenges. She also pays attention to comments they write for her in the margins (Interview, p. 15). To overcome the emotional barrier to seeking guidance in front of their peers, Ms. Science invites students to stay after school to go over their questions privately (Interview, p. 16). She also support students who ask questions that trigger laughter among their peers. She validates the "silly question" by saying, "That is such a curious question that I wouldn't have thought about" (Interview, p. 16). Both responses to her students' embarrassment, staying after school and validating student questions, are examples of adapting to the emotional needs of her students. They are also good examples of developing inquisitiveness in students, which is one of the critical thinking dispositions relevant to the present research. Ms. Science's approach with student questions correlates to her high inquisitiveness score (58 out of 60), which was unknown at the time of the qualitative analysis phase. 
Physical. Ms. Science noticed that the problem-solving student mentioned above seemed physically slower than her peers. She mentioned that this student would take significantly longer to pack up her belongings. Ms. Science chose to approach her parents with her observations, which eventually led to a diagnosis and treatment that improved this student's performance and self-esteem (Interview, pp. 3-4).

\section{Teaching Methods}

Experiential. Ms. Science raised the lack of experiments as her most challenging situation at this school. She said that because of space constraints, it would be hazardous to do many of the labs she would like to do with the students. They have done projects, but she has only demonstrated experiments for them. She believes that the projects such as putting electron shells and making atom models are not enough for exposure. During the Science Fair, the students participating would stay after school. Because it was a small group in the small space, the students were able to do their own experiments. They even ordered additional equipment for the Science Fair (Interview, pp. 17-18).

Teacher guide. During the interview, Ms. Science gave an example of a student who had trouble with all problem-solving questions. After observing her, Ms. Science guided her to break down the problem and underline key information. The student was able to finally answer these questions and was ecstatic. Later, she admitted to Ms. Science that she never tried before because her previous teachers always gave her the answer when she repeatedly asked (Interview, pp. 2-3). Ms. Science did not do this with her; rather, Ms. Science stopped the cycle and guided this student to do the work.

During the observations, Ms. Science guided her students in classroom discussions by asking questions. During a review on drugs with the $8^{\text {th }}$ graders, Ms. 
Science asked the class to define hallucinogens. One girl said they can make you happy or sad. She asked, "So, they can make you happy?" and waited for a response. She continued to describe how they can make people see scary things. Rather than immediately rebuke the student's comment about making people happy, Ms. Science responded with a question. This is an example of guiding students to learning (Observation \#3). Even when students bring up tangent topics, she engages in them as she guides back to the subject matter.

Group size. During the interview, Ms. Science mentioned that her students work in groups and individually. She also discussed ways she provides one-on-one instruction after school. During the observation, she had whole group lessons. Therefore, Ms. Science utilizes all configurations of group size.

\section{Ways of Connecting to Students}

"Observing is key...I mean you really could just go in and teach and then step out, but you would never be successful that way, you would just be a regular teacher. You're not going to be able to connect or bond with the children" (Interview, p. 5).

Nurturing. During the observations, Ms. Science's nurturing nature became evident in her interactions with the students. On several occasions, she responded to students' coughing with a question if they were okay and offering them water (Observation \#1, Observation \#2). She maintains a calm demeanor with them and engages in playful banter, similar to Ms. Third A. She is smiling and kind to her students. Even in her discussion of the "silly question," Ms. Science's nurturing demeanor is clear when she supports the student being teased by the class by validating the question (Interview, p. 6). 
Respect. Respect was an important concept emerging from the data on this teacher. She said during the interview that when teachers get upset, "It makes the kids feel they are not respected" and "the teachers can lose their respect...that way in the long run" because the student "can turn back and say something to you one day" (Interview, p. 5). She continued, "Their parents bring them here to study, not to be screamed at and yelled at" (Interview, pp. 5-6). This does not mean that Ms. Science does not give consequences, but she does so calmly, and in that way, she believes she maintains her own respect.

Later in the interview, Ms. Science revealed an experience that contributed to her current beliefs about respecting the students and enforcing consequences calmly. At her first teaching job in a different private school, Ms. Science became frustrated with the students being distracted by a butterfly and not responding to her requests to sit down. She raised her voice a little bit just as the principal passed. He walked into her class, and in a very polite manner, told her to just give them detention, not to worry about it, and that she did not have to raise her voice. She thought about his guidance and realized it was much easier on her and more effective with the students. Correspondingly, they would in turn respect her more. She believes now that if a teacher avoids giving the consequence thinking she is being lenient and loving, she will lose the students' respect over time (Interview, pp. 13-14).

Listening. If we see listening in its broadest sense, it is intentionally acquiring information from students as a way to connect. This is observational listening. While initially placed in the same category, it became evident during the next phase of analysis that it needed to be its own teaching style category. Ms. Science repeatedly throughout 
the interview spoke about the importance of being observant of her students. She talked about reading through their work searching for comments they write in the margins that can give her clues about their challenges and understanding. When asked to describe herself as a teacher, she said that she feels the need to always learn more and do more. When I followed up asking if she meant with the content, she said it is more about her connection to the children. Then she said, "When you know more, you can help them more" (p. 17). Ms. Science is intentionally listening and looking for any information about her students that can help her be more effective. However, this comes across as conversational listening many times. For example, Ms. Science had a conversation with the eighth graders about college classes and grades where she responded to their comments and questions with guidance and advice. The two listening styles are merged from Ms. Science, conversational to connect and observational to inform teaching.

\section{Growth-Oriented Mindset}

Self-reflective. Throughout the interview, Ms. Science displayed her selfreflective nature. When discussing classroom management and discipline issues, she talked about how her enforcement of the rules varies based on her stress levels. She said, "There are some days that you're happy and you're okay with everything" (Interview, p. 7). This example shows a level of self-awareness many people may not have. She knows how her emotional state, as well as her teacher colleagues, impacts her teaching and acknowledges that it leads to unequal enforcement of rules.

In discussing the $7^{\text {th }}$ graders, which seems to be consistently thought of as the most difficult group, she discussed how some days are harder than others. However, she said: 
I see it's me, it's not them. They are already like that. There are some days that I'm very patient, but there are some days that I come in with a headache...And those days it is hard for me to calm down and thus it is hard to calm them down (Interview, p. 8).

Again this is an example of her self-reflection. She is able to see how her own state impacts her teaching and her students. She displayed this self-reflective nature in the conversation about her previous principal's guidance when he witnessed her raising her voice to the students. Instead of blaming him or defending her actions, she acknowledged his kind delivery, acknowledged her embarrassment, thought about his words, and adjusted her behavior accordingly (Interview, pp. 13-14). She also displayed selfreflection when she judges her effectiveness as a teacher by analyzing student assessments. She said during the interview that if too many students do poorly on her exam, she knows it is her teaching that needs adjusting and as a result, reteaches that material.

Fallibility. Ms. Science exhibits this acceptance of her own fallibility and the fallibility of students as well as an intention to make the classroom safe for students to make mistakes. In her validation of the "silly questions" mentioned earlier, Ms. Science displayed her openness and support of the imperfect - her intentional creation of a safe space for student learning. During one of the observations, a boy walked into class with a Band-Aid on his forehead. The nurturing and worried Ms. Science asked him what was wrong. When he told her it was a pimple, she smiled and said, "You should show it off" (Observation \#2, p. 3). It was Ms. Science telling her students to embrace the imperfection. 
She also willingly admits her own faults, rather than attempt to artificially cover them up. I observed her repeatedly misspell the word "hallucinogens" during an eighth grade lesson. The students laughed until she finally got it right with a smile (Observation \#3, p. 1). Ms. Science asserted that if a teacher does not admit her own mistakes, does not accept guidance from her students, and pretends to know what she does not know, then students will not respect this teacher and will feel that they know better (Interview, pp. 19-20). "A teacher should not try to answer a question that she does not know, especially when it is wrong," said Ms. Science (Interview, p. 18). If a student asks her a question that she does not know, she says, "Oh my God, that is such a nice question and you know what I'm going to do. I'm going to check it out myself and let you know tomorrow" or "You know what? Why don't you check it out for extra credit, two points, okay? Got it?" (Interview, pp. 18-19). Ms. Science believes that if a teacher knowingly answers incorrectly to save face with her students, they know. They may never confront her out of fear of repercussions, but they will no longer trust her or respect her. Ms. Science spoke about her daughter's teacher who did this and would have an authoritarian "I' $m$ the teacher" attitude when students attempted to correct her. She believes that such an attitude diminishes the teacher in the eyes of her students and admitting mistakes elevates the status of a teacher. She even referred to such an authoritarian attitude as the teacher trying to bully her students into being quiet.

It is intriguing to think that by admitting mistakes, students will not develop this feeling that they know better than the teacher, as Ms. Science asserts. It is obvious that they would trust the teacher who admits mistakes to be honest about his or her knowledge limits, and therefore, students will trust the knowledge that teacher does share. However, 
this may not be connected to them necessarily believing that their teacher knows more than they do. The validity of this claim is not relevant to the present study, but what is clear is that Ms. Science accepts her own fallibility. She asserted during the interview, "You are human, you tell them, 'I made a mistake"” (p. 20).

Assessment for growth. Ms. Science uses assessment for growth because she uses it as a tool for her own self-reflection. She allows students to retake one exam in the year, and she thoroughly reviews student notations in exams to understand their thought processes. First, if all of her students do poorly, it points to her teaching as the source of the problem. Therefore, she goes back and reteaches differently. This is using assessment for her own growth as a teacher and consequently student growth. Second, in allowing students an opportunity to retake a failed exam, she teaches them that there is always an opportunity for improvement. Finally, Ms. Science chooses to personally grade student work so that she can understand their thinking. She said during the interview that some students may write comments on the side of difficult problems such as "I was having a hard time with this" or others may show their work (Interview, p. 15). These clues allow her to be a better teacher, which is again a tool for her own growth. Her intentionality in discovering these clues reflect how she uses student work as a tool for their growth, not just a tool to level or label them.

Holistic view. In the same example stated earlier about the student who was having trouble with problem solving, Ms. Science spoke about how happy she was in the days after she learned how to solve the problems independently. She continued to share how she watched her student "completely change and transform" throughout the years (Interview, p. 3). Once she began treatment, this student academically soared. Ms. 
Science said, "She really was a quiet person, but I saw her grow and become more confident. Things add up" (Interview, p. 4). In this one example, Ms. Science displays her holistic view of her students. She not only observed an academic need, but also a physical need. She also appreciated the emotional aspect after resolving both of these needs.

High standards. Ms. Science is a teacher who maintains high standards for her students' learning. This is evident in how she goes beyond the curriculum to challenge her $8^{\text {th }}$ graders. This is also evident in how she only offers students one retake per year on failed exams. This is also evident in her insistence to grade all her students' work personally so she can understand each student's progress and challenges.

\section{Highest Hopes for Students}

Effectiveness skills. While not explicitly stating that effectiveness skills are among Ms. Science's highest hopes for her students, she discussed during the interview how she intentionally prepares her $8^{\text {th }}$ graders for high school and her joy when past graduates come back and thank her for such preparations. For example, during the observations, Ms. Science was reviewing a health unit on drugs with her $8^{\text {th }}$ graders (Observation \#3). During the interview, Ms. Science spoke about this particular unit and her intention in preparing them for high school away from their comfortable, small private school. She said, "They are going to be exposed to it next year, that's why I let them know ahead of time" (Interview, p. 21). She said that she does not rush through the topic and she gets resources online to teach them more "before they leave us" (p. 21).

This topic is more of a social preparation for high school, but Ms. Science also spoke extensively about preparing her students academically for the next stages in their education. For example, she gave a few examples of past students who came back with 
positive feedback on their current academic achievements and praised her for preparing them to succeed. She mentioned one student who was not one of the high-achieving students who was smart, but did not take school seriously. He told her, "What you taught me in class is still in my brain today and is helping me do really well in Chemistry" (Interview, p. 22). He told her current class that they need to pay attention to Ms. Science because they will remember it later and their high school teacher will love them. As mentioned previously, Ms. Science cited the Chemistry unit on electrons as an example of her going beyond the curriculum because her students could handle it. Another student came back and gave her the same feedback about Biology. She intentionally looks up the content for transition and teaches it. Therefore, Ms. Science was not surprised when this student told her that the first three chapters in high school were the same as what he learned in $8^{\text {th }}$ grade. She said, "The students were so happy because what they learned here and made it so easy for them in high school with transition and now they've said that many of them are choosing science for their field" (p. 22).

Character, connection skills, self-actualization. When asked to describe her perspective on the goal of schooling, Ms. Science addressed the other three themes under "Highest Hopes for Students." She said, "It's to be able to bring a sound and capable child to the community" (Interview, p. 2). "Sound" seems to refer to the character of the person. A sound person is someone who is well. While people can define the qualities of a "well" person differently, any definition falls under the theme of an individual's character. "Capable" sounds like self-actualization because it is referring to the development of a skill or an ability to function. It could also be effectiveness skills and this would depend on what Ms. Science means when she says "capable." Either way, she 
later indicated her hope for self-actualization when she responded to a question about the goal of school by saying, "Well it is actually to try and reach the potential of a child" (Interview, p. 2). Finally, her focus on developing individuals to be a part of the "community" brings in the social aspect and is more in line with connection skills.

\section{Ms. Social Studies}

\section{Introduction}

Ms. Social Studies completed a law degree from an international university, but when moving to the United States, its equivalent was assessed as either a teaching degree or a paralegal. She was more drawn to the education degree and took the subject area exam for social studies to get her teaching certificate. She began teaching in 2007 as a substitute teacher for elementary and middle public schools. When the middle school social studies teacher at this private school had to take a leave of absence for health reasons, Ms. Social Studies took over. The students scored high on SATs that year and the administration was very pleased with Ms. Social Studies' performance, eventually offering her a full-time position. She received an offer from the public school system the same year, but eventually decided to accept the offer at this private school to teach middle school social studies.

Ms. Social Studies teaches middle school social studies—World History for sixth grade, Civics for seventh grade, and American History for eighth grade. Ms. Social Studies is an organized and efficient teacher who knows her material well. She is mildtempered and easy-going with her students, often joking around, yet maintains high expectations for their performance. While she mainly lectures as students take notes, Ms. 
Social Studies always seeks new project ideas to integrate into her lessons. She believes in connecting the curriculum to students' real-life experiences.

\section{Adaptability to the Student Needs}

Curriculum. Ms. Social Studies reflected during the interview that she reads and frequently integrates outside sources into the curriculum (Interview, p. 2). One of the most obvious curriculum adaptations is SAT preparations. Because SATs are based on the national standards and their curriculum is based on Florida's standards, the subject areas for social studies do not match. Ms. Social Studies' sixth grade class is world history, but that is the subject of the eighth grade SAT. She creates flashcards for her students to study SAT materials. She stops her regular curriculum lessons a month before the exam and concentrates on each grades' exam topics (Interview, p. 15). While technically this is expanding the curriculum because the material is beyond the prescribed curriculum at this school, most educators view the preparation for standardized testing as a constriction of the curriculum ( $\mathrm{Au}, 2007)$. A simple example of integrating outside sources, during one observation of the $7^{\text {th }}$ grade Civics class, she asked the students if they knew the root of the word "plaintiff." When they were looking through their book, she told them it is not in the book and it is French, meaning "injured" (Observation \#2, p. 4). This is a small way Ms. Social Studies expanded the curriculum, which is one of the three new styles emerging from the next phase of analysis. Ms. Social Studies expands the curriculum in other ways as well, such as integrating teacher-made YouTube videos related to the current lessons.

When students ask unrelated questions, Ms. Social Studies first assesses the intention. If she feels that the student is genuinely interested in the information and not 
merely trying to waste class time, she engages in that conversation. If she suspects the student has ulterior motives, she does not close the door fully but instead asks him or her to come during break time to discuss the question. When they do not come, they confirm her suspicions (Interview, p. 16). After reviewing the analysis of Ms. Social Studies data with the new teaching styles in mind, there was no evidence that she adapted the curriculum in the more general way of varying difficulty, expectations, or quantity of work for struggling or advanced students. Rather, it seems that she mainly adapted instruction to assist students.

Instruction. Ms. Social Studies adapts her instruction to meet the needs of her students. During the interview, she reflected that the most challenging subject to teach has been world history because it is far beyond the current reality of her sixth-grade students. She frequently tries to find ways for students to connect to and remember the information about these ancient civilizations, such as telling students that the paper they use today is one of Ancient China's contributions to the world (Interview, p. 8). During one observation, Ms. Social Studies humorously connected the concept of "damages" in civics class to one boy's previous punishment from another teacher where he had to write a sentence 150 times for disturbing PE class. She was teaching them that damages do not have to be monetary (Observation \#2, p. 5).

As an effective instructional method, she found teacher-made videos on YouTube where the lyrics to famous rap songs have been changed to teach world history. As the students are studying the chapter over a two- to three-week period, she frequently plays the adapted rap song relevant to the content they are learning. By the end of the chapter, 
the students have learned the song and the content within the song (Interview, p. 3). This is an example of the teacher adapting instruction to meet the needs of her students.

In her seventh grade class, Ms. Social Studies reflected on the time around the presidential election and how exciting it was for her students to watch the news and connect it to their classroom conversations. She never asked for updates from her students, but because of their interest, Ms. Social Studies began allotting the first five minutes of class to election conversations (Interview, p. 3). It was fitting because the seventh grade social studies curriculum is Civics, yet it is an example of how she adapts instruction to the current needs of her students.

Ms. Social Studies also mentioned that one of her students who had recently stopped taking medication for ADHD needed some additional time one-on-one with her, so she frequently spent her lunch and snack-time reviewing material with him (Interview, p. 14). This is another example of an instructional adaptation to meet her student's needs.

Emotional. The example stated above is also an example of an emotional adaptation because Ms. Social Studies felt that this student did not necessarily need the academic support, but rather he was scared and needed a boost in confidence (Interview, p. 14).

\section{Teaching Methods}

Experiential. "Honestly, the kids learn from the project more than just a lecture style" (Interview, p. 2). Because the observations did not capture any experiential lessons, the interview provided insight here. Without being asked or prompted to talk about experiential activities, Ms. Social Studies mentioned projects as a major instructional tool that seeks and learns about from other teachers and workshops. She mentioned the music 
videos she integrates into world history lessons, but she also shared that the students researched and built models of homes in ancient Rome, following the same open concept designs. They also built the pyramid out of sugar cubes (Interview, p. 7). The older students created a television advertisement where they chose and dressed up as one candidate from the presidential election (Interview, p. 3).

During the course of the present study, Ms. Social Studies was tasked with organizing and executing a school-wide multicultural event on Ancient Rome. Every grade throughout the school was assigned a specific job and contributed to the megaperformance. Some students sang a rap song about Ancient Rome, while others performed a play about Julius Caesar. Some classes made clay coins to replicate money at the time. Everyone wore costumes. On the day of the event, classes were canceled. Teachers, students, and parents gathered to watch the performance and learn about Ancient Rome together. This event has become a school-wide tradition, selecting a different culture each year. Everyone was very impressed with the program and constantly praised Ms. Social Studies' efforts and results to me. This was the ultimate experiential learning event.

Lecture. Ms. Social Studies combines lectures with experiential projects. She uses the board to write down important information. The students are expected to take notes. The students are also expected to read the chapter and complete a worksheet requiring detailed facts from the chapter. Before the exam, Ms. Social Studies gives the students a study guide or study topics. Students are expected to sit and listen attentively during lessons and to ask questions for clarification when needed (Interview). During the observation, Ms. Social Studies asked knowledge-based questions to assess student 
learning. Thinking time did not emerge as an evident theme for this teacher. On one occasion, she asked a student a question and when he did not readily answer, she moved on to another student. This may be the way the class functions or it could be a specific adjustment for this student as to not put him on the spot, because he was sitting isolated near the desk (Observation \#3). Repeatedly during all observations, Ms. Social Studies answers relevant student questions directly. On one occasion, I witnessed her guiding a student through a series of questions to clarify her answer. However, this was not the norm over the course of the observations.

The lecturing style with knowledge-based questions emerging from the analysis of Ms. Social Studies' qualitative data seems to align with her low maturity of judgment score (32 out of 60). Because maturity of judgment is seeing the complexity of issues, I had expected a teacher with a strong disposition to expose students to varying points of view and initiate and guide lively discussions. Ms. Social Studies' lecturing style may also be aligned with her low truth-seeking score (35 out of 60 ). Because truth-seeking was defined as seeking the best possible understanding, a didactic, by-the-book lecturing style is reflective of a low score. This idea seems especially true for a subject like social studies where a teacher could theoretically expose students to the competing perspectives on the same historical event or ask students higher-order thinking questions like: Why do human beings make the decisions they do? And what circumstances can lead citizens to go against their own value structures and accept their government's unjust actions?

Group size. The configuration of Ms. Social Studies' classes during observations were whole group and individual. She mentioned during the interview that she works with students one-on-one during her breaks as needed. She also mentioned that the 
students did some group projects. Therefore, Ms. Social Studies utilizes all configurations of group size.

Free Movement. For some teachers, free movement emerged as an important theme. For others it did not emerge at all. For Ms. Social Studies, she explicitly mentioned that this was not desired in her classroom. Because the teachers in middle school rotate to the students' classroom, it was overwhelming for her to walk into a class and be bombarded by students making various requests. She said during the interview that "this is one of the things I hate because I can't deal with too many people at the same time, so settle down" (p. 9). She also mentioned that she does not like when they turn around to talk to the person behind them when she is lecturing. During the observations, the students were asked to do independent work at their desks and remain quiet. On occasion, Ms. Social Studies would remind them to be quiet and write some students' names on the board as a warning (Observation \#1, p. 2).

She mentioned during the interview that she does not prefer to give students silent lunch because it is not effective. Initially, I assumed she believed it was not effective because the students misbehavior may be a sign that they need to release physical energy. After probing for more information, Ms. Social Studies said that her students "have a privilege to go (outside) 15 minutes each day" unlike some public school students their age. She also said, "I understand they have the energy, but you should be able to control yourself" (Interview, p. 15). Interestingly, during the observation, a seventh-grade student joked with her that the class can sue her saying, "You treat us unfairly, you don't take us outside ever" (Observation \#2, p. 4). 


\section{Ways of Connecting to Students}

Ms. Social Studies, like many teachers, believes in connecting to her students to teach them most effectively. She said during the interview, "You have to be friends and you have to be close with them because you can't come with them and be strict and mean, you won't get anything out of them" (p. 4). However, the way in which each teacher connects to her students varies. Emerging from the data, Ms. Social Studies uses humor, reward, and listening to connect to her students.

Humor. Ms. Social Studies was seen using humor to connect to students.

Specifically during the second observation of the seventh grade Civics class, she bantered with them as they reviewed chapter questions. For example, for one question a student said he would ask his uncle Jalal who is a lawyer. The teacher asked the students, "Do you all have an uncle named Jalal?" (Observation \#2, p. 2). They laughed before moving on. They were discussing various family disputes that may occur and she joked, "like when mommy and daddy fight," and all the students laughed (Observation \#2, p 1). She asked them what would happen if they ate at a restaurant and left without paying the bill. When no one answered, she asked them to research it. One boy said, "We should try it." She said, jokingly, "No, don’t do it, just Google it” (Observation \#2, p. 2). A few moments later, they were discussing divorce law and how the home is split. The boys were riled up and complaining that it is not fair if she did not pay for it. The teacher smiled and told them, "Be careful, whatever you own will be split" (Observation \#2, p. 2). During another conversation they were talking about people who fake injuries and sue for money. The boys again start joking about where someone should stage their fake 
injury as to avoid cameras, such as the bathroom or the frozen section. Ms. Social Studies laughed, asking how they know this.

Reward. When asked specifically what she does to build that relationship, she said by allowing them "to do cool stuff in class" or giving them a break on their homework assignments (Interview, p. 4). She may give them additional chances to correct mistakes

on a test. These are all examples of tangible rewards. During the observations, Ms. Social Studies was seen also praising students, responding to students' correct answers with statements such as "Excellent job. I am so proud of you" (Observation \#3, p. 1).

Listening. Ms. Social Studies said in response to a follow-up question on building a relationship with her students, "I am always open with them and I tell them if they have a problem to come to me and I'll work it out because...I won't know what's inside them if they don't come and tell me" (Interview, p. 4). During the interview, she repeatedly spoke about being "friends" with her students and being close to them. In one instance, she commented on a student's emoji hat, saying it was cute and asking where he bought it (Observation \#1, p. 1). While this type of conversation is not immediately relevant to teaching, it develops a connection and rapport that opens the door for students to approach the teacher about academic deficiencies or personal obstacles to learning. She frequently tells them that her door is always open and she is available during all her breaks. Her conversational listening style is a means to connection.

\section{Growth-Oriented Mindset}

Self-reflective. When she first began teaching, Ms. Social Studies attended many workshops to meet other teachers and gain access to many resources to grow as a teacher. She would go on the weekends and summer, saying, "It didn't matter whenever it was 
available, I always wanted to go and see and learn different ways" (Interview, p. 2). She gained insight into the curriculum, ideas for instruction, and knowledge of changing rules.

Fallibility. Effort is an important concept that emerged throughout the data on Ms. Social Studies. She said during the interview, "If they are doing any assignment they have to show me that they tried and put effort. All I want is that they put effort" (p. 13). She did clarify and said she is not looking for two-page essays, but she is looking for their understanding. She wants to see that they are trying hard. She tries "not to be harsh on them" and gives them the credit for their work whenever she can without compromising on standards.

Similar to Ms. Third B's conversation about students' problems with respecting authority, Ms. Social Studies mentioned that a few students "do not know what respect means to teachers" (Interview, p. 8). When probed for more information, she defined disrespect as students not admitting their own mistakes and arguing that they are right when they are clearly not. For this reason, this concept fit well under fallibility. Ms. Social Studies wants her students to take the attitude "that I did something wrong and that I should say 'I'm sorry'” (Interview, p. 9). She believes that there is a feeling among the students that permeates the school culture, "I own this school, I can do whatever I want" (Interview, p. 12). It is not clear if this is the same obstacle Ms. Third B noticed in her younger students or if it is a different problem. It may be that if the problem with the younger students, to sit with their own fallibility, is not addressed that it transforms into a more brazen expression in older age. 
At an older age, Ms. Social Studies feels that the school should enforce more severe consequences such as detention and expulsion to send a message to all students that disrespect will not be tolerated (Interview, p. 11). She admits, however, that she is as much of the problem because the school culture is more loving and accepting, stating, "Even if we yell at the student, five minutes later we feel guilty. Why did we do that? The culture itself doesn't allow you to move forward with the punishment" (Interview, p. 11).

While implementing school-wide consequences is one approach she discussed, Ms. Social Studies also promotes this acceptance of fallibility with modeling. She mentioned during the interview that students often correct her spelling mistakes on the board and this was also witnessed during the first observation. She always responds with, "Thank you for correcting me" even when they taunt her and make comments such as "We caught you doing something wrong" (Interview, p. 16). Her reasoning, "Because I don't want them to fear that they can't correct the teacher. Anyone who makes a mistake needs to be corrected, even if I'm your teacher" (Interview, p. 16). She also modeled this by researching student questions about material that she was not sure about. While some teachers may feel insecure to say, "I don’t know," Ms. Social Studies said, "I would rather not answer if I'm not $100 \%$ sure about it so I will tell them I will read and I will answer tomorrow" (Interview, p. 17).

Assessment for growth. Ms. Social Studies allows her students to correct their answers on exams in which they performed poorly. This could be a reflection of how she uses assessments as a tool for growth rather than merely placing her students in a hierarchy of achievement levels. The composition of her self-created assessments are multiple choice, true/false, completion, and some essay questions. She said during the 
interview, "They know the material but they still get it wrong...These kids just want to rush and finish" (Interview, p. 6). She expects the students to pay attention to the details which they often miss such as slight changes to the year or a negating statement towards the end of true/false questions. Moreover, the completion questions are the most difficult for them because the answer is a specific word they have to generate. One of the takeaways from this conversation is that her exam essentially trains them to take their time and pay attention to minor changes in wording or facts. It is not only an assessment of knowledge, but also a training tool for effort.

High standards. While Ms. Social Studies allows students to correct exams and reward them with less homework on occasion, she is very strict with her homework policy. If homework is late, students lose $10 \%$ per day progressively. In addition, she actually grades the homework answers rather than giving students a grade for completion. Even though such a strict homework policy is cumbersome for her, she found that this has been the only effective method to ensure her students are reading the entire lesson because the questions are extremely detailed (Interview, pp. 4-5). This is a reflection of Ms. Social Studies' high standards for her students because she has created a structure in her class to make sure her students do the work necessary to succeed. The test structure mentioned earlier is another reflection of Ms. Social Studies' high expectations that her students pay attention to the details, which is an important skill for any life endeavor. Ms. Social Studies also demonstrated that her expectations are purposeful, not merely busywork. For the essay questions, for example, she is not looking for numbers of pages, but rather one statement that reflects key understanding (Interview, p. 7). One statement Ms. Social Studies made during the interview summarizes her high standards, "I am very 
serious about my teaching... with all of this, I expect the results of my students to be great" (p. 13).

\section{Highest Hopes for Students}

When asked about her highest hopes for her students, Ms. Social Studies'

response aligned with the emerging theme of "self-actualization." She said:

The highest hopes for my students to see them successful in the field of their choice and to proceed (in) higher education after their bachelor degree. I would also like to see my students in Ivy League schools (Text, 7/25/17).

When I followed up asking if she would say that she wants her students to reach their highest potential in their chosen path, she responded, "For sure" (Text). Her response was not about their personal dispositions or being prepared for life, as in effectiveness skills or character. It also was not related to their social interactions, as in connection skills. While different people define "potential" differently, for Ms. Social Studies higher degrees and Ivy League schools is a reflection that this person is doing well in their chosen field. Because she said, "a field of their choice," it seems that she believes in finding that unique calling or talent.

\section{Ms. Math}

\section{Introduction}

Ms. Math has wanted to be a teacher since she was in fifth grade, inspired by her smart math teacher who used body movements to keep the class alert. She attended a specialized high school for math and continued to earn a Bachelor's degree in Math Education and a Master's in Education. At the time of data collection, Ms. Math had six years teaching experience. She began teaching elementary students, but moved to middle school a couple of years ago. She now teaches grades six through eighth at this school. 


\section{Adaptability to the Student Needs}

Instruction. Ms. Math spoke about her love of the philosophers she learned about during her Master's program, specifically mentioning the theory that most students have similar abilities and it is practice that impacts learning. She said, "If the teacher changes her teaching style from one student to another, thy can get it, you know" (Interview, p. 2). She said she does not give up and she changes the way she gives them information or changes the metric. For example, she will remember that one student likes to solve problems mentally, so she teaches him strategies to do so. Another student has trouble with big numbers so she teaches him to solve with estimation. She said that she changes her way based on their learning styles and sometimes that means solving the same problem in five different ways (Interview, p. 14).

She also integrates real-life applications of math lessons to help them understand, such as looking at the taxes on receipts to teach percentages. The real-life application helps the students understand and Ms. Math said about these examples, "You just meet (their) needs to make it easier for them" (Interview, p. 5). Ms. Math reads through the curriculum materials thoroughly and the suggested instructional strategies, but she said during the interview that sometimes "you feel in my class, no I cannot do it that way" (p. $5)$.

Emotional. During the interview, Ms. Math discussed the importance of group work for students to learn from one another. This is a fairly common strategy. However, Ms. Math went on further to discuss how and why she selects the groups herself. She specifically noted the emotional compatibility of the students, not putting the "mean student with the weak student" (Interview, p. 8). She said that the mean student will pick 
on the weak student and tease him or her for not knowing something and this "will hurt him" (p. 8). She also considers the benefits to the high-achieving, kind student when she said, "It helps make them more confident and he feels that he is responsible...He feels the teacher trusts me, I'm smart and I did it" (Interview, p. 8). This is adapting teaching to the emotional needs of her students. Rather than only focus on grouping students based on intellectual compatibility, for example the high achieving student with the low achieving student, Ms. Math also intentionally considers the emotional well-being of her students. Out of curiosity, I asked who she puts the "mean" student with, and she said she always puts the mean student with someone who is very friendly, is not sensitive, and takes it easy.

\section{Teaching Methods}

Experiential. Ms. Math integrates real-life experiences to make the math lessons relevant, saying, "When they can actually touch it, it helps them understand" (Interview, p. 4). One time she had students bring in receipts from home so they could practice calculating percentages for discounts and taxes (Interview, p. 4). For another lesson, they were instructed to bring in items to sell, calculating final price after discounts. She said, "They did it without feeling like they were doing a hard problem" (Interview, p. 4). She also discussed that for geometry lessons in eighth grade, the students build the 3dimensial shapes from paper and as a result do not forget (Interview, pp. 5-6). One of the most powerful statements Ms. Math made was: "Because whenever they create their own problem, for sure they can solve a problem" (Interview, p. 5).

Teacher guide. Ms. Math guides her students to understanding through real-life examples, such as the receipts and selling home items. She also is a teacher guide by 
allowing them to experience failure. She provides the resources the students need to succeed, but if they repeatedly choose not to do the work, she allows them to fail. For her, math is all about practice. One " $\mathrm{A}$ " student kept talking during class and was not practicing. She felt he was not going to do well on the exam and he did not respond to her plea to focus. When he received a bad grade on the exam, she reminded him when he did not heed her warnings. The next chapter, he was focusing and asking good questions (Interview, p. 13). This is an example of a teacher guide because she allowed her student to make his own choices, she merely guided him without enforcing her will.

Ms. Math also guides students to the computational rules through solving actual problems and discussing the process. For example, when she started a new lesson about scales, she put a simple example on the board and guided the discussion to determine the answers, then ended by deriving the rules for solving similar problems (Observation \#1, p. 5). Rather than lecture students on the rules or simply demonstrate how to solve the problem, the students had to generate the rules. During a review of a previous lesson, she guided the students through a question about diameter as she drew a cone on the board. She asked them if they were given the diameter or radius and asked them to explain. She then asked a girl to come up to the board to solve the problem (Observation \#1, p. 1). Ms. Math frequently has students solve problems on the board. It is partly as a way to integrate movement, but also when students solve the problems themselves, they remember. She does not force students to solve problems one way, but rather allows them the freedom to try various methods. For example, during the same observation, one student asked if he could solve a problem his way. She responded, "Improper fraction. It's up to you. But I'm telling you this is easier" (p. 3). 
Group size. Ms. Math configures her class in various group sizes. She uses whole group when introducing a lesson. Sometimes the students work individually as well (Observations). However, she likes to have the students work together when practicing because she learned from her Master's degree that "sometimes the students they learn more when they sit together" (Interview, p. 8).

Free Movement. Probably the most prominent example of this theme, Ms. Math mentioned movement almost immediately in the interview. She cited the body language of her fifth-grade math teacher as the first characteristic that impressed her and inspired her to become a math teacher herself. She said, "When she is moving, it helps with the teaching" (Interview, p. 1). She later spoke about how she uses body language as a teaching method (Interview, p. 14). During the interview, I asked her to talk more about this theme of movement in her teaching. She spoke about her years as a bored student who was not even allowed to chew gum and how she would fall asleep in class. She said about herself that she is not hyperactive, but she is active and needs to be able to go to the board (p. 15). Therefore, from her response, it seems that her movement is a way to maintain the students' attention. She also mentioned that by moving around the class constantly, she can catch student mistakes during classwork before they do it on homework (Interview, p. 16). She also mentioned movement as showing her students she cares, possibly because it shows effort on her part.

Ms. Math was recalling a class activity calculating percentage tax from receipts. She mentioned that rather than have the students in small groups, they work as a whole group together for an entire hour, sitting together and sitting as they want (Interview, p. 5). One of the reason she prefers middle school students over elementary is that she does 
not have to micromanage who needs a tissue or go to the restroom. Ms. Math allows her students to freely move around the classroom to attend to their needs. She expects them to go to the restroom as needed and return in a timely fashion. If they ask her for simple needs, such as sharpening a pencil, she asks them if they need her to do it, otherwise she expects them to do it themselves. If a student cannot see the board, she expects him or her to move the chair. She begins by trusting her students and only changes the rules if they do not honor that trust. She said, "I dislike the student just sitting in one place all the time. It's not going to help them learn" (Interview, p. 16). She argues for doing the most appropriate thing for what they need. Sometimes that means having them do some physical activity before class or as a break during a lesson, such as walking around the school outside or doing some yoga exercises. "I like them to feel and move," she asserts. "Whenever the students move, they are ready to focus and they are ready to listen and it helps him to be productive" (Interview, p. 17).

\section{Ways of Connecting to Students}

Nurturing Humor. Ms. Math likes to laugh with her students; it is a nurturing humor. A combined code is used because separating the nurturing components from the humor proved very difficult for this teacher. On the first observation day of her eighthgrade class, she introduced me to them and told me, "See how cute the eighth graders are" (Observation \#1, p. 1). The kids joked that some of them are not so cute before finally settling down. During the interview, she talked about a funny class moment when they were discussing the practical application of increasing line graphs for their growth charts at the pediatrician. A shorter boy in the class said to her, "You are right, we need 
line graphs in our real-life because my line graph is like strictly the same because I'm not growing" (Interview, p. 5). She laughed and told him not to worry and it will increase.

Even in reprimanding a student who used a calculator against her rules, she smiled with a smirk telling him that his answer " 24.6 " means he used the calculator. In another reprimanding incident to a boy who forgot his book at home, she instructed him sarcastically to pay attention to the board and then leaned in close and said, calmly with a smile, “And I need it tomorrow, sir" (Observation \#1, p. 2).

Another example of Ms. Math using humor to talk to the students is when she told them "guys, whenever you want to answer anything in math, don't tell me a paragraph, I'm not Mr. Language Arts, tell it to me or show it to me in steps" (Interview, p. 7). She could have simply instructed them on how to answer a question or given them the format, but she communicates with them in this lighthearted way, using humor to connect to students.

Reward. Ms. Math says she likes to focus more on the positive than the negative because this is her personality. She acknowledges when they do something well by verbally telling them "good job" and "I'm so proud of you" (Interview, p. 11). For example, during an observation Ms. Math picked up one boy's book to show the class as she praised his work (Observation \#1, p. 1). Ms. Math also mentioned that she rewards her students with outside free time for completing their work early, even if there is merely 10 minutes left in class time.

Ms. Math not only praises students for academic achievements, but also for behavior. For example, she mentioned in the interview that she thanks students who have improved their behavior after a talk with her (p. 11). Even to avoid cheating on pretest 
preparations, she does not focus on removing points from those that copy answers, rather she incentivizes the students to show their work and receive extra points (Interview, p. 12). If she suspects someone of cheating on review work, she starts asking him or her to come to the board to show their work and gives them additional points.

Listening. "You have to listen to them sometimes they tell you what you're doing they dislike and there is another way" (Interview, p. 2). Ms. Math repeatedly spoke about listening to her students. She intentionally creates an atmosphere that feels easy-going, even though she says, "Really, I'm not that easy" (Interview, p. 9). The purpose, she says, is to "give them the space and ability to talk to me so I can hear from them" (p. 9). Even when a student misbehaves, Ms. Math says they come back, apologize, and adjust their behavior in the following class because she is not hard on them and lecturing them, but rather, she says, "I just listen” (Interview, p. 10). Ms. Math spoke about the time constraints during class time, but emphasized the importance of talking to her students when she said, "When there is free time I promise to take them outside and we can talk for 10 minutes or 15 minutes" (Interview, p. 11). To maintain that open communication, she makes sure to keep it private when students approach her as to not embarrass them in front of their peers. She is keenly aware of the middle school psyche and the fragile balance of maintaining a connection to the students without causing them the pain of being labeled a teacher's pet. She said during the interview, "I make them feel they are an important person for me and not only just like my student” (Interview, p. 15). Ms. Math's listening style is a combination of both conversational and observational.

Trust. Ms. Math spoke about trusting her students. She tells them in the beginning of the year that she trusts them and it is their responsibility to take care of that 
trust. So if they need to use the restroom during her class, she does not intervene.

However, if they misuse that trust repeatedly, they lose her trust. She spoke about a time when a student abused this trust and stayed out of the class for 15 minutes. When he returned to the class, she asked him to go to the office and get a tardy slip. When students slip up and come talk to her, she easily forgives them, telling them, "Okay, yes. I accept your apology, but next time this is what we are going to do" (Interview, p. 10).

\section{Growth-Oriented Mindset}

Fallibility. During the third observation of this teacher, she made a computational error and wrote an incorrect answer on the board. The students began calling out that they have a different answer. She looked over her work and agreed with them. Ms. Math showed that she can easily correct her own mistakes in front of students.

She also showed her ease with student errors as well, such as the example stated earlier with the boy who used the calculator. She laughed and called him out on it (Observation \#1, p. 3). Another boy during the same class leaned over his friend's paper and put a squared symbol to correct the answer before the teacher saw. When she approached, the student smiled and said, "I didn’t square it, he did" (Observation \#1, p. 5). She smiled and walked away. It is telling that the student was willing to so easily announce what his friend did, showing that the students feel safe in this classroom. They are not worried that she will come down hard on them or that she will perceive them as cheaters.

High standards. Ms. Math expects her students to do the work. She mentioned during the interview that she does her part and the students have to practice. For example, with the "A" student who slacked in preparation for one exam and eventually did poorly, 
she expected that outcome and warned him repeatedly. Finally, she had to let him experience the results himself. However, her high standards are reflective in her awareness of this student. If she did not have high standards for her students, she would not have noticed and remembered this one " $\mathrm{A}$ " student who got a " $\mathrm{C}$ " on one exam. Her high standards are evident also in her insistence that students do not use the calculator. They are allowed the calculator during SAT. If she only cared about SAT scores because they reflect back on her teaching, then she probably would not insist on the no calculator throughout the year. However, she wants her students to learn the process and develop a systematic thinking skill. She believes that they can all learn as long as she adjusts her teaching to their needs.

\section{Highest Hopes for Students}

Effectiveness skills. Ms. Math spoke about math developing systematic thinking in all students. She said that this thinking will help students face any problem logically and “step-by-step" (Interview, p. 7). This is considered an effectiveness skill because her intention is preparing students for future challenges.

Character. Ms. Math spoke about personal character development as well. She specifically cited gentleness, honesty, and helpfulness.

Connection skills. She clearly connected the personal character to the ability to connect to others. She said about the ideal student graduate, "She knows how to talk, not just a brain, but they have a full character, full personality" (Interview, p. 6).

Self-actualization. Ms. Math wants her students to move beyond basic knowledge, but to reach a level of mastery in whatever area. She repeated this twice during the 
interview (p. 7). This is considered self-actualization because it is about the student reaching his or her personal potential.

\section{Mr. Language Arts}

\section{Introduction}

Mr. Language Arts has been teaching for over 30 years, making him the most experienced teacher at the school. At the time of the data collection, he was 64 years old. He began teaching elementary grades, taught some high school, but is now a middle school teacher. He taught some science classes, which he does not prefer, but mostly taught social studies or language arts. Currently, he teaches middle school language arts. Mr. Language Arts completed an undergraduate degree in science before realizing he actually wanted to teach. He continued and received his Bachelor's degree in Elementary Education.

Mr. Language Arts teaches middle school language arts at this school. His style is fun and edgy, using humor to maintain student engagement while secretly having a deep purpose of life lessons. His ultimate goal as a teacher is to guide the students to find and be the best version of themselves. He views the curriculum as a tool to teach about life. He deeply trusts the process, the kids, and himself.

\section{Adaptability to the Student Needs}

Curriculum. Mr. Language Arts repeatedly incorporated outside sources, which later became its own category called curriculum expansion. He would go with the flow if new ideas emerged from the class interactions, which they frequently did. But he always seemed to tie it into necessary objectives. For example, he created a gum bank, a board on the wall where kids stuck their gum. It was his solution to the ongoing administrative 
problem of enforcing the "no gum rule" and the unwanted impact on the janitorial staff having to clean up gum from floors and desks. The creation of the gum bank was a physical adaptation; however, his use of the gum bank at the end of the year to teach a displacement lesson makes it also a curricular adaptation (Interview, pp. 6-7). After reviewing the data with the new styles in mind, there was no evidence that Mr. Language Arts adapted the curriculum in the general sense of varying the difficulty of work, quantity of work, or expectations based on student achievement. Therefore, his curriculum adaptation style was specifically an expansion of the curriculum.

Instruction. During the observations, Mr. Language Arts gave students extra time to complete a test. He asked one student why he had not finished even after being given three days, but eventually gave the student more time. Another student asked for more time and he initially refused, but reconsidered after the student explained that he was pulled out for a school-wide competition. This could be seen as a teacher who adapts to the needs of his students, or it could be seen as accommodation. Where is that line between adaptability for students' continued growth and accommodating student whims to their detriment?

Emotional. Mr. Language Arts often used humor to respond to kids' emotional needs. During the interview, he told a story about one student who was so meticulous and always wanted to do things exactly right. In an essay about Magellan, he wrote that he "circumcised the world" instead of "circumscribe." Mr. Language Arts made a joke out of it and responded with, "Boy, he must have really had a sharp knife" (p. 5). His purpose in approaching the mistake in this lighthearted manner was to help this student get over mistakes easily and to not take it so seriously. He was addressing an emotional 
obstacle this student has with making mistakes. He spoke a lot during the interview about hidden lessons to adapt to his middle schoolers emotional blocks to learning. "If you tell them things like 'today's lesson will be the objective' I mean please they are right away going to turn you out. You want to let them know what they're doing, I understand research, but you can make it so antiseptic that there's no feeling to it anymore and there's no passion. Learning is passion" (p. 6).

Similar to Ms. Third A adapting her discipline methods to the student needs, Mr. Language Arts talked about how he dealt with discipline problems differently over the years, which reflected his keen awareness of his middle school student's psyche. Rather than send students to the principal's office as is school policy for certain infarctions, he would tell his student, "I am not going to send you to the office, you have to deal with me" (Interview, p. 7). He believes that this makes a student reflect, "Wait a minute, this guy is not trying to kick me out of the room," which is adapting discipline to address an emotional need of his student. It is about building a connection with the student and saying indirectly that he will not give up on them. Furthermore, rather than put the student's name on the board for not paying attention, he comes up with gimmicks like coughing up phlegm. In the interview he spoke about a conversation with his students where he explained this particular coughing gimmick, "I need your attention, I can either yell at you, count or put your name on the board and I still need your attention....or I could just cough up phlegm and then you all look at me" (p. 9).

Mr. Language Arts would create bizarre frameworks to communicate feedback to his students in non-threatening ways. One lesson he described during the interview was a totally invented hierarchy of life forms. He would write the hierarchy on the board, have 
the students copy it, and test them on this bogus information. Then throughout the year, he would use this hierarchy as a feedback tool to let middle school kids know when they are doing a good job or need to improve by saying to them, for example, "Yesterday, you were acting like a golden retriever for a couple of minutes and that was so cool, but the second someone took something of yours, you're right down there with slime. What's with that?" (Interview, p. 12). He said that the intent was "to send a message but you don't want to threaten them. So how do you tell the kid that you like what they are doing today without them sounding like a teacher's pet?" (Interview, p. 12).

Physical. Physical adaptations incorporate adjustments to the environment to accommodate student needs. The gum bank discussed under curriculum adaptation was initially created as a physical adaptation to remedy an ongoing administrative complaint that made this trivial matter become an obstacle to learning. Mr. Language Arts transformed the scenario into a satisfactory solution for the administration, a gimmick to keep the students' interest, and a learning tool for a math displacement lesson.

\section{Teaching Methods}

Experiential. "History is a story and I just have them do things and I involve them" (Interview, p. 3). One example he spoke about is the Civil War reenactment he had his students do, marching outside around the school. They had two drummers from the band and the students holding broom handles as guns. He even has the drummers learn a couple of different cadences to demonstrate how the army would give orders for shooting or lining up (Interview, p. 4). The gum bank mentioned earlier is another example of experiential teaching as are the many gimmicks that are mentioned throughout Mr. Language Arts' discussion here-all experiential teaching with a hidden lesson. 
Teacher guide. Mr. Language Arts emulates this idea of a teacher being a guide in so many instances. He does not lecture or give answers. He has a very clear objective, but guides his students to it through stories and questions. This is distinct from the new style of teacher explorer in that Mr. Language Arts seems to always have a clear destination in his mind, even though he rarely reveals it. He allows his students to provide direction, but he skillfully brings them to his intended conclusion. When he taught history, for example, he said, "The give and take of social studies and being able to discuss things was more appealing. The discussion aspect and verbal aspect appeal to me. There is less rote memorization because when I taught history, I didn't teach it from a rote memorization." (Interview, p. 2). The first lesson of the year in his history classes sheds light on Mr. Language Arts' teaching methods. He begins with a definition of history, prefacing it with "here is one of the very few definitions you will ever get from me" (Interview, p. 13). The definition, hardly an antiseptic academic one, is, "History is basically people doing people things and other people writing about it" (p. 12). Then he would proceed with a brainstorming session about what "people things" are. He would fill up the board and he said, "If I do it a certain way long enough, I'm going to get what it is that I want to see up on the board and as soon as I get what I want to see, I stop it" (p. 13).

Even though the students feel that they are leading this lesson, he sees himself as knowing more than they do and guiding them to knowledge indirectly. Mr. Language Arts talked about this concept of "controlled choice" where he allows students the choice, but he guides them to the subject he intends to discuss. He said in the interview, "So the kid feels they have some skin in the game and it works real well at middle school" (p. 8). He frequently refers to this intentionality in hiding the lesson with middle school 
students. He tells a story that provides a framework to talk about substantial lesson without calling it a lesson. For example, at the end of that history brainstorming session discussed above, he brought the students to the conclusion that people only fight about one or a combination of power, money, and beliefs. He used this framework the rest of the year to discuss all history lessons in the book and said during the interview, "And so for a few minutes we could talk about Gandhi or Nelson Mandela and it would let you talk about those guys without specifically calling it a lesson" (p. 16).

Group size. During the observations, Mr. Language Arts began his class with whole group instruction. The students frequently worked individually on writing tasks and reading quizzes. He also had them working in teams to create some sort of presentation using his laptop. They approached him for one-on-one feedback regularly as well, although this was usually quick and done while standing. Generally, Mr. Language Arts' class functioned as whole group, individual, or teams.

\section{Ways of Connecting to Students}

Humor. Humor is a primary way Mr. Language Arts connects to his students. He interacts with his students through sarcastic jabs much the same way middle schoolers do to one another, such as the circumcision story mentioned earlier. For example, when introducing me during the first observation, Mr. Language Arts told his students that I am working on my $\mathrm{PhD}$ and they were the closest we could find to students. He often made funny voices during lesson to lighten the mood. This could be a differentiation due to the age of the students, because he is dealing with middle schoolers as opposed to elementary. However, he did say that when he taught elementary, he did not "baby" the 
kids (Interview, p. 2). Therefore, it seems that this is more his style regardless of the students' age.

During the interview, Mr. Language Arts said, "If you can break that down and somehow establish that connection and that rapport then learning can take place...if the student likes the teacher and the teacher likes the student, you can cut through a lot of that" (p. 7). Just as many of Ms. Third A's nurturing examples were also related to her adaptations to student needs and growth-oriented mindset, Mr. Language Arts' humorous connection to his students is reflected across all the themes as well. His gimmicks to deliver various messages such as coughing up phlegm, the gum bank, and the toilet are alternatives to punitive consequences that would deteriorate the connection goal.

Listening. Mr. Language Arts discussed during the interview the importance for him to listen to and respond to his students. He said:

If you are my student and I tell you I want to know what you think and you actually take a chance, "Okay, we'll try this old guy, we'll try 'em" and you write down what you think, I damn sure better read it and I better react to it (Interview, p. 22).

His guiding teaching style is indicative of his ability to listen and respond to student input. To guide them to his intended intellectual destination, he has to listen attentively and respond to their current thought. Rather than ask basic knowledge questions, he asks thought-provoking questions that require more than memorization and regurgitation, such as the power, money, and beliefs history lesson discussed earlier. While listening is definitely a part of his effective teaching methods, the intention is clearly connection. $\mathrm{He}$ said during the interview, "It's all about somebody honestly caring about what somebody says or does and taking the time to listen" (p. 22). Therefore, Mr. Language Arts uses 
listening in both ways, as conversation for connection and as observation to inform teaching.

\section{Growth-Oriented Mindset}

Self-reflective. "When I have to become the worksheet, call the parents every night kind of a teacher, I can't do that, I have to quit, I can't do that” (Interview, p. 9). Mr. Language Arts knows himself. He knows what he does and why he does it. Even if he does not readily explain the behind the scenes to everyone, he sometimes reveals it. For example, he eventually told one insistent student why he coughs up phlegm all the time. He knows. In addition, during the interview, I repeatedly asked for the "why" and he continued telling me stories. Finally, towards the end of the interview, he finally said, "Oh you have to get me back to my academics. Okay, I'll tell you. I'm sorry, I'm being obtuse now. It's no secret" (p. 21). He went on to tell me his highest hopes for his students, which is detailed under that theme heading below. The point here, though, is that he understands why he teaches in the way that he does and if he is not answering my questions, he knows.

Fallibility. The students in Mr. Language Arts' class are not watching their every step and when they overstep, he guides them back in non-threatening ways. When discussing discipline issues such as the gum bank, Mr. Language Arts said, "I always try to throw things right back on the students and make it their responsibility without giving them the responsibility lecture" (Interview, p. 8). He tries to solve those sorts of problems without shaming or lecturing the students. At the risk of being repetitive, the coughing phlegm is another gimmick example. This allows for a safe space where students do not feel scrutinized. Whenever he uses a gimmick rather than a consequence, it also serves 
the purpose of creating a safe space for the students to feel free in their expression.

During the interview, he spoke about students having a hard time with his "heavy red pen of correction" and how he reframed it by telling them, "My job is to find their mistakes, your job is to keep me from doing my job, that is the deal" (p. 9). He said that the kids were having a hard time letting things go if they made a mistake. One gimmick solution he came up with was a real toilet in the classroom, saying, "There is something symbolic about flushing something down the toilet" (Interview, p. 10). He used the toilet in many different ways, but one was to have kids throw out their bad drafts. Every morning, the toilet would be emptied and cleaned. He made mistakes fun and easy.

The statement that says it all with regards to Mr. Language Arts' fallibility mindset is: "I tell them you have to be safe and it is more than you not getting pounded over the head, it means you have the right to try something and not be embarrassed for trying" (Interview, p. 14).

Holistic view. Mr. Language Arts spoke in the interview about the distinction people make between teaching being an art or a science. In his mind, the people on the science side think about "teacher-proofing" the curriculum and modules. However, the teachers on the art side of this argument "teach in a much larger, broader sense" (p. 7). He sees himself more of a teacher artist. "If what I was teaching was so important they wouldn't teach it to you again and again until the $11^{\text {th }}$ grade," he tells his students (Interview, p. 5). It's not about teaching specific skills, he wants his students to "get a feel for it, learn that it doesn't have to be boring, and..." that "they could figure most of this stuff out on their own" (Interview, p. 5). He would tell his students, "You will learn a 
lot more important things by paying attention in my class then you will academically and these things you will take with you for the rest of your life" (Interview, p. 11).

From Mr. Language Arts' interview, it is evident that he views the curriculum as a vehicle rather than a destination. It is a framework that he adjusts and adds to as needed to communicate life lessons to the students. The gum bank, for example, indirectly taught important lessons in dealing with life's challenges and finding effective and efficient solutions to problems. Mr. Language Arts' gum bank mitigated the administration's concerns of keeping the classrooms clean while minimizing wasted energy on enforcement and, also, enhancing the main objective of student learning - primarily by improving and at minimum not deteriorating the teacher to student connection and also through silly displacement lessons using the gum board. He uses any unplanned events or comments as a jumping board to a life lesson, even a random comment by the students about hot dogs led him to hang a cafeteria hot dog in the classroom for an entire year as a science experiment. Needless to say knowing that even mold would not touch this hot dog, the students in that class stopped eating hot dogs since (Interview, p. 9). These are all examples that point to Mr. Language Arts' holistic view of students and his growthoriented mindset.

High standards. Even in fun experiential activities, staying true to the knowledge is important. In the Civil War reenactment, he had the drummers learn different cadences for the march to mean different things so the students "get a real feel of what happened in these wars" (Interview, p. 4). During the observations, Mr. Language Arts shared his frustration with the librarian that he wanted the students to have "bells and whistles" on their laptops so they can do more with their projects. He actually gave the students his 
laptop to borrow as a solution (Observation \#1, p. 3). Mr. Language Arts told one student during an observation that his work was "unacceptable" and he would need to start over again, saying, "You decide. You can race and do it five times or you can do it right the first time" (Observation \#1, p. 3). On one occasion, he told a student as he passed out the graded tests, "You quit on anything that makes you think" (Observation \#2, p. 1). When he discussed his "heavy red pen of correction" during the interview, it reflects his high standards for student work. The toilet example also reflects his high standards for student work.

One could argue that all of his creative ways of communicating with the students in non-threatening ways are intended to guide them to a higher standard for produced work. From the outside, an observer may initially think that Mr. Language Arts is just about fun. However, it would not take long to realize that there is a deep-seated purpose that drives his sometimes whacky teaching methods. After repeated attempts during the interview, Mr. Language Arts finally revealed his highest hopes for his students.

\section{Highest Hopes for Students}

Mr. Language Arts' highest hope for his students is for each one of them to become him/herself. He finally said in the interview, describing what he hopes for his students, "I want you to be the best you (that) you can be" (p. 21). This is why he is funny and creates gimmicks. Because he wants his students to love learning so that they become life-long learners (Interview, p. 5). This is the core. He said that he does not want his students to become another him and they need to learn to think so they can guard against that tendency to become someone else. This is the reason Mr. Language Arts listens to his students, because he believes by allowing them that space to freely explore 
their own thoughts, they will grow into them and become themselves. This is selfactualization as the highest hope for his students.

\section{Connecting Themes Through Teachers}

After completing the qualitative data analysis and describing each of the 10 cases in detail, a few overarching themes were threaded throughout the chapter. In this section, I will integrate some of the greatest lesson learned from the teachers.

\section{The World Beyond the Book}

While many of the teachers adapt the curriculum to some degree, such as increasing the difficulty and quantity of work for high-achieving students (Ms. Second) or lowering expectations (Ms. First), some teachers view the book as a guide not a prescription. The world is bigger than one text and the goal is greater than a score. Ms. Science expressed this idea that teaching is "changing the life of an individual" and "to be able to bring a sound and capable child to the community" (Interview, p. 2). She frequently incorporated more challenging information when her students were open to it. Ms. K incorporated social activism into her national parks lessons. Mr. Language Arts used the history text as a resource to explore self and relationships with others, the social world and humanity. All of these attributes contribute to an education for democracy: guiding students to their own excellence, exposing them to various perspectives and world views, and teaching them directly about change-makers. An implication for practice is for teachers to educate for democracy by incorporating the world beyond the book. 


\section{Wherever it May Lead}

No answers and a lot of time leads to student-created knowledge. Ms. Second is the most prominent example of thinking time, the silence is hard to bear at times. During the interview, she expressed her desire for students to create their own inferences using the resources they have. What is learning if it is not building on prior knowledge and implementing that knowledge in useful ways? All the teachers except one guided students to discover knowledge as opposed to lecturing them. The more experienced teachers, like Mr. Language Arts, can take a student from any starting point to exactly where he wants them at the end without the student even realizing he is on a predestined journey. Some of the teachers, namely Ms. K and Ms. Fifth, guided discussions where the destination was not predetermined. Teaching students to think and problem-solve is education for democracy. Trusting reason to guide learning is education for democracy. It can be hard to imagine the level of trust it takes in the thinking process to willingly embark on a thinking journey without knowing the destination, wherever it may lead.

\section{Learning with Heart and Mind}

The way teachers understood and handled emotional obstacles to learning was interesting. Emotions matter and teachers who expressed that taught differently. For example, Ms. Third B has a goal to help her students accept guidance from others, yet the limit of her lesson stops at the limit of her student's self-esteem. Ms. Third A's nurturing demeanor makes her students feel safe and loved. Ms. K talks about security and selfworth as prerequisites to learning. Ms. Math makes sure her students feel trusted. Mr. Language Arts makes sure he responds to student work because if they feel heard, they will communicate more. Ms. Science makes an intentional effort to validate her students' 
thoughts, comments, and questions to create a safe space for learning. Feeling safe is freedom to be your own diverse self and to take risks in learning and growing. Therefore, feeling safe to take risks is a prerequisite for progress. Listening emerged as an important concept and teachers listened differently. Some listened with their heart, to connect emotionally to their students. Others listened with their mind, to help their students in practical ways. True listening is a heart and mind endeavor. Mr. Language Arts, Ms. K, Ms. Social Studies, and Ms. Math all used humor regularly in their interactions with students. Humor was a way to keep things light and allow for students to be fallible and have fun learning. Fallibility is at the core of growth and progress. These teaching styles reflect an understanding that students learn with heart and mind.

\section{Inward, Onward, and Upward}

Emerging during the qualitative data analysis were a variety of ways teachers grow and promote growth in their students. As discussed throughout, Mill (1859/1991) argues for the unique growth of each individual in a democracy increases the diversity of viewpoints, which results in the greatest outcome. During the interviews, many teachers revealed their self-reflective tendencies and how that has impacted their teaching. For example, Ms. Third A is a prime example of a teacher who is always looking inward and constantly improving herself. When reflecting on a lesson gone wrong, she did not blame the students for not understanding, instead Ms. Third A examined her teaching, observed the students closer, and adapted her methods. Similarly, Ms. Science expressed this same personal accountability and self-reflection, such as noticing when her emotional state impacts her teaching. Many of the teachers spoke about professional development activities and connecting to other experienced teachers as a way to grow. Promoting this 
concept of being a life-long learner was evident in several teaching styles. For example, Mr. Language Arts wanted his students to love learning so he used humor and gimmicks to make the classroom fun and create a safe space for mistakes. Many of the teachers expressed future hopes for their students around life, not just academics. This focus on the students' life skills is evident in teaching styles as well. Mr. Language Arts does not focus on the facts learned, telling the students that they will be exposed to this information again. His focus is the lessons they can learn about life, using these facts as a framework. His goal is for his students to be their best selves, which is self-actualization as expressed as highest hopes by half of the teachers. What is self-actualization if it is not the unique growth encouraged by Mill (1859/1991)? Modeling growth and promoting growth in their students follows this cycle-inward, onward, and upward.

\section{Fallibility, Growth, and Democracy}

The inability of students to accept their own mistakes seemed to be a school-wide phenomenon because several of the teachers brought this up as a significant obstacle to learning. Is it particular to this school or is it particular to any school with similar student populations? Several teachers mentioned the role of parents, some mentioning that this may be an unintended consequence of attentive and involved parents that hold high expectations for their children's success. The teachers approached this problem differently. Mr. Language Arts, for example, made jokes out of it. Ms. Third B had candid conversations about it. Ms. Third A modeled making, correcting, and accepting mistakes easily. She also responded to student mistakes with a sense of ease and casualty.

This particular theme has emerged as a theoretically significant obstacle to the democratic living the present study intends to promote. Generally, one thinks of 
empowered citizens as having strong wills and strong minds - people that stand up to injustice and powerfully organize to protect liberty. One would expect such an empowered citizen to have tremendous confidence in their own ideas and an iron-clad will to withstand tremendous social pressure to conform. However, such a citizen must also have the humility to know his or her ideas may have portions of "untruths," as Mill (1859/1991) describes it. A citizen who is unwilling to see their own fallibility would be unable to hear the ideas of others, especially if they contradict their own. A person who is unable to hear the ideas of others cannot co-create a world, which is the essence of democratic processes. This is reflected in the critical thinking disposition of openmindedness and truth-seeking, which are central to the present study as important qualities for democratic citizens. As discussed previously, an open-minded individual listens to others' thoughts, even when they disagree. A truth-seeking individual listens with an ear searching for the truth, even if such truths contradict their own ideas. Therefore, if a person is blocked from even listening to different ideas, this prevents the democratic discourse needed to build, maintain, and promote a democracy.

Aside from not being able to effectively deliberate, a person who is uncomfortable with his own fallibility will not easily grow. Mill (1859/1991) describes the wisest of men as those who listen to criticism and use it to improve. A lack of fallibility can create obstacles to listening to criticism, let alone using it for improvement. The importance of human development for a democracy is clearly stated by Mill (1859/1991) and the importance of democracy for human development is clearly stated by Maslow (1943/2013). The data around fallibility in the present study raised important questions with regard to developing students for democratic life. 
Presumably, there may be different reasons a person is unable to sit with their own fallibility. Humility was mentioned here, but it may be a perfectionist personality as well. Understanding the various obstacles to this construct is beyond the scope of the present study. However, emerging as a significant obstacle to student-learning, it is an important area of exploration for future research hoping to improve student learning in general or geared towards developing necessary qualities for democratic citizens specifically.

\section{Summary}

In this chapter, the qualitative data, namely observations and interviews, were analyzed and five teaching style themes emerged: adaptability, teaching methods, ways of connecting, growth-oriented teaching, and highest hopes. While all 10 teachers expressed these 5 themes, they did so differently. Therefore, the themes are broad enough to include the various teaching styles. Within each theme, 25 teaching styles initially emerged. Three more teaching styles were added after the second phase of analysis because they emerged as significant distinctions in the cross-case analyses - curriculum expansion as distinct from curriculum adaptability, teacher explorer as distinct from teacher guide, and observational listening as distinct from conversational listening. For each teacher, the teaching styles were discussed in this chapter and evidence was provided from the data. The result of the qualitative data analysis was a preliminary framework for teaching styles that can be used in future research. 


\section{CHAPTER FIVE}

\section{CROSS-CASE ANALYSES}

"Were all instructors to realize that the quality of mental process, not the production of correct answers, is the measure of educative growth something hardly less than a revolution in teaching would be worked" (p. 207).

\section{John Dewey, Education and Democracy, 1916}

In the previous chapter, the teaching styles of each teacher were described in detail. The present study sought to explore the relationship between each teacher's critical thinking dispositions and his/her teaching styles. The critical thinking dispositions of each teacher were measured using a scale called the CCTDI, as was described in the Methodology chapter. Table 7 below shows each teacher's scores on the CCTDI, including the seven subscales and a total score. In this chapter, the results of the CCTDI are described and observations within and across teachers are discussed.

Table 7

CCTDI Scores for the Teachers

\begin{tabular}{lcccccccccc}
\hline CCTDI & $\mathrm{K}$ & $1^{\text {st }}$ & $2^{\text {nd }}$ & $\begin{array}{l}3^{\text {rd }} \\
\mathrm{A}\end{array}$ & $\begin{array}{l}3^{\text {rd }} \\
\text { B }\end{array}$ & $5^{\text {th }}$ & Sci & Soc & Ma & LA \\
\hline Truth-seeking & 39 & 38 & 37 & 41 & 37 & 48 & 43 & 35 & 38 & 36 \\
Open-mindedness & 33 & 38 & 45 & 43 & 38 & 52 & 42 & 37 & 38 & 40 \\
Inquisitiveness & 49 & 51 & 44 & 47 & 47 & 55 & 58 & 53 & 58 & 49 \\
Analyticity & 51 & 47 & 36 & 45 & 43 & 46 & 52 & 49 & 53 & 45 \\
Systematicity & 47 & 48 & 31 & 42 & 46 & 43 & 54 & 50 & 51 & 38 \\
Confidence in Reasoning & 49 & 50 & 38 & 36 & 46 & 43 & 52 & 53 & 48 & 52 \\
Maturity of Judgment & 48 & 43 & 50 & 46 & 38 & 46 & 43 & 32 & 36 & 35 \\
TOTAL & 317 & 316 & 281 & 299 & 295 & 333 & 344 & 309 & 322 & 295 \\
\hline
\end{tabular}

${ }^{*}$ Sci $=$ Ms. Science, Soc $=$ Ms. Social Studies, Ma = Ms. Math, LA = Mr. Language Arts 
In trying to understand these CCTDI scores, sampling the extreme cases for each disposition revealed important distinctions in teaching styles. Extreme groups for each disposition were created by sampling from both the extremes from within each disposition (across teachers) and across the dispositions (within teachers). First, Table 8 below shows the highest and lowest scores for each disposition as well as the mean and median of the scores within each disposition. Figure 3 follows with a visual of the highest and lowest score for each disposition subscale. I called these teachers the anchors because they became the point of comparing teaching styles while the remaining teachers in the extreme groups were utilized for supporting evidence.

Table 8

Highest and Lowest Scores, Mean, and Median for Critical Thinking Dispositions

\begin{tabular}{lllll}
\hline CCTDI & Highest & Lowest & Mean & Median \\
\hline Truth-seeking & 48 (Fifth) & 35 (Social Studies) & 39.2 & 38 \\
Open-mindedness & 52 (Fifth) & 33 (Kindergarten) & 40.6 & 39 \\
Inquisitiveness & 58 (Science, Math) & 44 (Second) & 51.1 & 50 \\
Analyticity & 53 (Math) & 36 (Second) & 46.7 & 45.5 \\
Systematicity & 54 (Science) & 31 (Second) & 45 & 46.5 \\
Confidence in Reasoning & 53 (Social Studies) & 36 (Third A) & 46.7 & 48.5 \\
& & & & \\
Maturity of Judgment & 50 (Second) & 32 (Social Studies) & 41.7 & 43 \\
\hline
\end{tabular}


The Highest and Lowest Scores for Each CCTDI Subscale

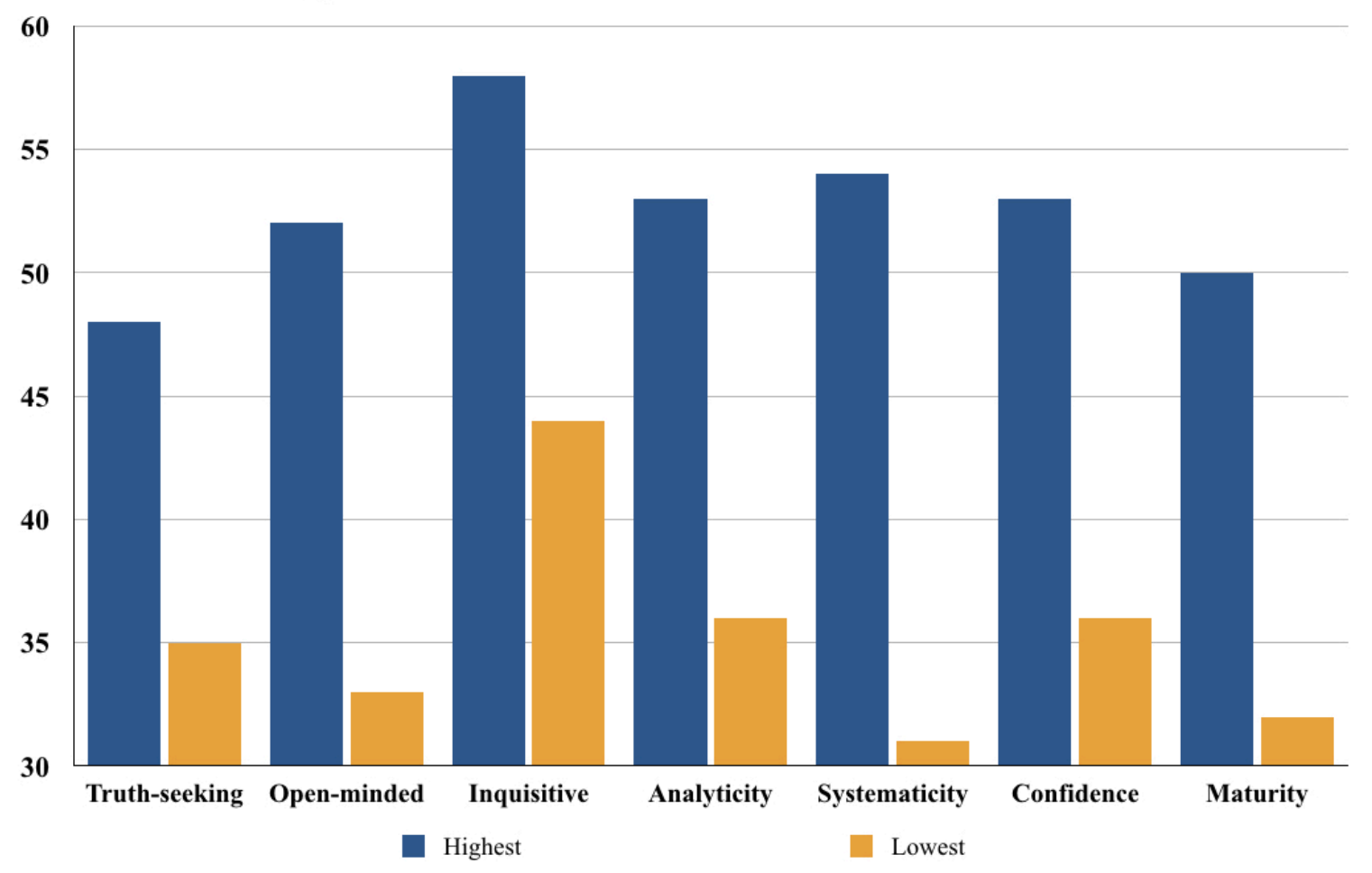

Figure 3

The Highest and Lowest Scores for Each CCTDI Subscale

Next, to support the distinctions in teaching styles between the anchors, the extreme group included the highest $5 \%$ and lowest $5 \%$ scoring teachers for each disposition subscale. By so doing, the differences in teaching styles that are corroborated by more teachers reflect stronger relationships with the critical thinking disposition. When all the high-scoring teachers in systematicity, for example, also consistently exhibited a nurturing teaching style, it strengthened the validity of this relationship as opposed to only looking at the one highest- versus the one lowest-scoring teacher. Table 9 below shows the highest 5\% and lowest 5\% for each disposition across all 10 teachers. Thus, these two categories of extremes show the teachers who scored at the top and bottom for each disposition. 
Table 9

Highest 5\% and Lowest 5\% of Each Critical Thinking Disposition

\begin{tabular}{|c|c|c|}
\hline & Highest $5 \%$ & Lowest $5 \%$ \\
\hline Truth-seeking & Fifth (48) & $\begin{array}{l}\text { Social Studies (35) } \\
\text { Language Arts (36) } \\
\text { Second (37) } \\
\text { Third B (37) }\end{array}$ \\
\hline Open-mindedness & Fifth (52) & Kindergarten (33) \\
\hline Inquisitiveness & $\begin{array}{l}\text { Science (58) } \\
\text { Math (58) } \\
\text { Fifth (55) }\end{array}$ & Second (44) \\
\hline Analyticity & $\begin{array}{l}\text { Math (53) } \\
\text { Science (52) } \\
\text { Kindergarten (51) }\end{array}$ & Second (36) \\
\hline Systematicity & $\begin{array}{l}\text { Science (54) } \\
\text { Math (51) }\end{array}$ & Second (31) \\
\hline Confidence in Reasoning & $\begin{array}{l}\text { Social Studies (53) } \\
\text { Language Arts (52) } \\
\text { Science (52) } \\
\text { First (50) }\end{array}$ & $\begin{array}{l}\text { Third A (36) } \\
\text { Second (38) }\end{array}$ \\
\hline Maturity of Judgment & $\begin{array}{l}\text { Second }(50) \\
\text { Kindergarten (48) }\end{array}$ & Social Studies (32) \\
\hline
\end{tabular}

Sometimes a teacher's top score was not one of the highest scores for that disposition. For example, Ms. Social Studies' top score on the entire CCTDI was in inquisitiveness (53), yet this was not even in the highest $5 \%$ of scores for inquisitiveness when compared to the other teachers (see Table 9). If the extreme group only included the highest and lowest scores for the disposition, cases like Ms. Social Studies would not be represented. However, it was important to include the extremes within teachers as well 
because of the potential influence on teaching styles. While a statistical analysis of interaction effects was not possible with the current sample size and research design, which is a limitation discussed in the subsequent chapter, incorporating the within teacher scores provided insight for future research. Therefore, Table 10 displays each teacher's highest $5 \%$ and lowest $5 \%$ scores.

\section{Table 10}

Highest 5\% and Lowest 5\% of Each Teacher's CCTDI Scores

\begin{tabular}{|c|c|c|}
\hline & Highest $5 \%$ & Lowest 5\% \\
\hline K & $\begin{array}{l}\text { Inquisitiveness (49) } \\
\text { Analyticity (51) } \\
\text { Confidence in Reasoning (49) } \\
\text { Maturity of Judgment (48) } \\
\end{array}$ & Open-mindedness (33) \\
\hline $1^{\text {st }}$ & $\begin{array}{l}\text { Inquisitiveness (51) } \\
\text { Systematicity (48) } \\
\text { Confidence in Reasoning (50) }\end{array}$ & Truth-seeking (38) \\
\hline $2^{\text {nd }}$ & Maturity of Judgment (50) & Systematicity (31) \\
\hline $3^{\text {rd }} \mathrm{A}$ & $\begin{array}{l}\text { Inquisitiveness (47) } \\
\text { Analyticity (45) } \\
\text { Maturity of Judgment (46) }\end{array}$ & Confidence in Reasoning (36) \\
\hline $3^{\text {rd }} B$ & $\begin{array}{l}\text { Inquisitiveness (47) } \\
\text { Systematicity (46) } \\
\text { Confidence in Reasoning (46) }\end{array}$ & $\begin{array}{l}\text { Truth-seeking (37) } \\
\text { Open-mindedness (38) } \\
\text { Maturity of Judgment (38) }\end{array}$ \\
\hline $5^{\text {th }}$ & $\begin{array}{l}\text { Open-Mindedness (52) } \\
\text { Inquisitiveness (55) }\end{array}$ & $\begin{array}{l}\text { Systematicity ( } 43 \text { ) } \\
\text { Confidence in Reasoning ( } 43 \text { ) }\end{array}$ \\
\hline Science & Inquisitiveness (58) & $\begin{array}{l}\text { Truth-seeking (43) } \\
\text { Open-mindedness (42) } \\
\text { Maturity of Judgment (43) }\end{array}$ \\
\hline Social Studies & $\begin{array}{l}\text { Inquisitiveness (53) } \\
\text { Confidence in Reasoning (53) }\end{array}$ & Maturity of Judgment (32) \\
\hline Math & Inquisitiveness (58) & $\begin{array}{l}\text { Truth-seeking (38) } \\
\text { Open-mindedness (38) } \\
\text { Maturity of Judgment (36) }\end{array}$ \\
\hline Language Arts & $\begin{array}{l}\text { Inquisitiveness (49) } \\
\text { Confidence in Reasoning (52) }\end{array}$ & $\begin{array}{l}\text { Truth-seeking (36) } \\
\text { Systematicity (38) } \\
\text { Maturity of Judgment (35) }\end{array}$ \\
\hline
\end{tabular}


In this chapter, eight cross-case analyses are presented, one for the extreme total scores of the CCTDI and seven for the extreme scores on each of the disposition subscales. For each cross-case analysis, a summary of the extreme cases sampled is followed by a systematic comparison of the teaching styles. A Venn diagram for each cross-case analysis is presented to represent the synthesis followed by a qualitative discussion. At the end of the chapter, the conclusion summarizes the consistent findings from all cross-case analyses.

\section{Total CCTDI Highest and Lowest}

The total scores offer a perspective that incorporates the interaction of dispositions and the holistic view of teaching style. Figure 4 below is a bar graph showing the total CCTDI scores by teacher.

\section{Total CCTDI Score for Each Teacher}

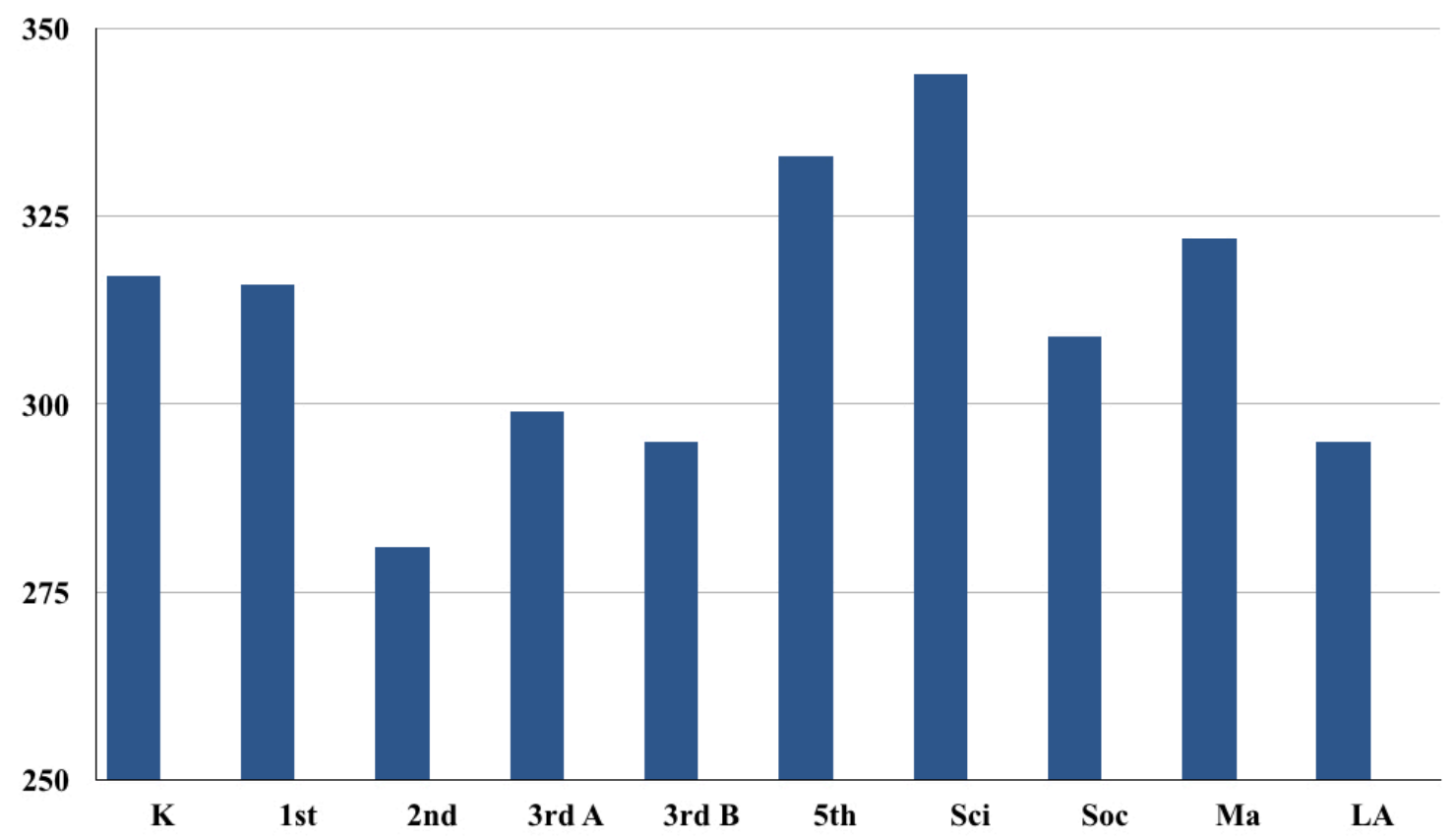

Figure 4

Total CCTDI Score for Each Teacher 
Scores. Ms. Science scored the highest total on the CCTDI (344), while Ms. Second scored the lowest on the CCTDI (281). The mean total CCTDI score for all teachers is 311.1 , which is almost in the middle of the highest and lowest score.

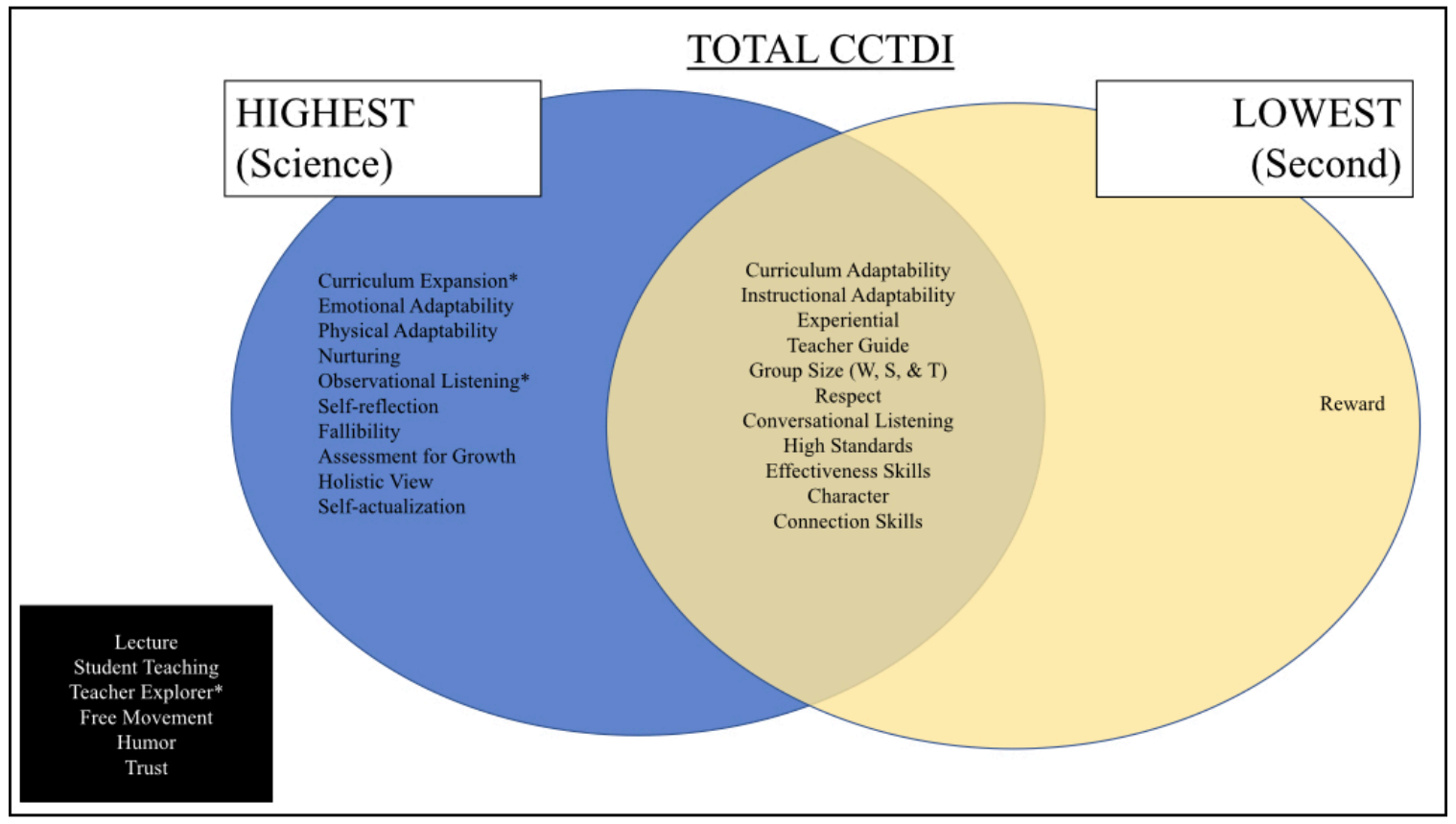

Figure 5

Total CCTDI Cross-Case Synthesis of Teaching Styles

Teaching Styles. Figure 5 above summarizes the findings from the cross-case analysis of teaching styles between the highest and lowest scoring teacher on the total CCTDI. Ms. Science (high) adapts in all four ways to student needs including the emotional and physical needs, while Ms. Second (low) only adapts the curriculum and instruction. Teaching methods were similar in the guiding and experiential learning. Ms. Science (high) connected to students through nurturing while Ms. Second (low) utilized rewards. They both listened to students, but Ms. Science (high) listened in a deeper and broader sense, the later developed style called observational listening. Ms. Science (high) exhibited a self-reflective disposition, viewed assessment as a tool for growth, promoted 
a positive relationship with fallibility while maintaining high standards, and viewed teaching more holistically. Ms. Second (low) maintained high standards, but did not express any of the other growth-oriented teaching styles. Finally, Ms. Science (high) expressed all four highest hopes for her students - effectiveness skills, connection skills, character, and self-actualization —-whereas Ms. Second (low) expressed the first three only. Six teaching styles were absent from both teachers: lecturing, student teaching, teacher explorer, free movement, humor, and trust.

\section{Disposition \#1: Truth-seeking Highest and Lowest}

Truth-seeking is the tendency to seek the best understanding, following evidence even in the face of one's own biases. Figure 6 below summarizes the teachers' scores on the truth-seeking disposition subscale of the CCTDI. Table 11 shows the extreme groups.

\section{Truth-seeking Score for Each Teacher}

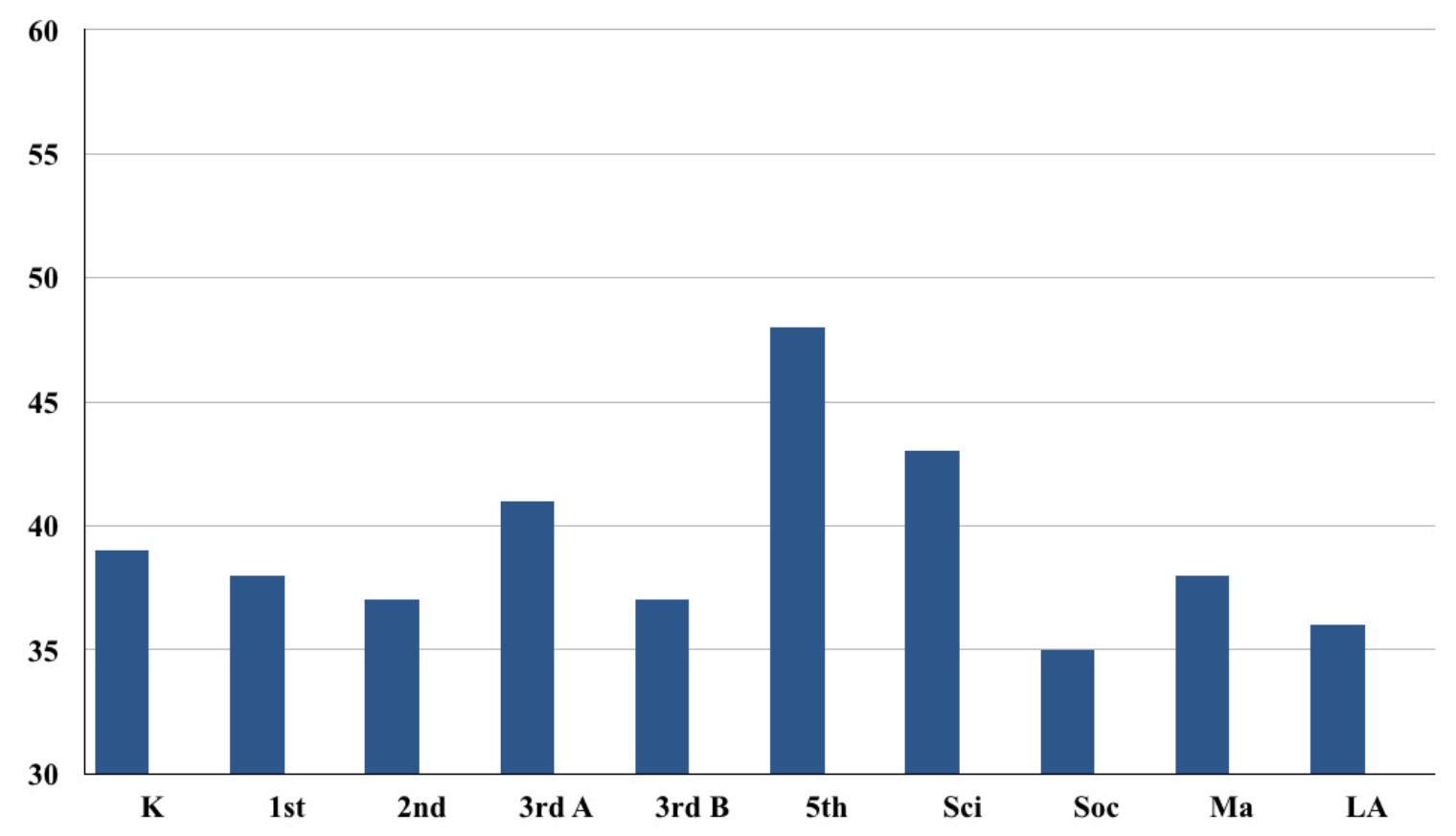

Figure 6

Truth-seeking Score for Each Teacher 
Table 11

Truth-seeking Extreme Groups

\begin{tabular}{|c|c|c|}
\hline & Highest & Lowest \\
\hline $\begin{array}{l}\text { Within Truth-seeking } \\
\text { (Anchors) }\end{array}$ & Fifth (48) & Social Studies (35) \\
\hline Within 5\% & Fifth (48) & $\begin{array}{l}\text { Social Studies (35) } \\
\text { Language Arts (36) } \\
\text { Second (37) } \\
\text { Third B (37) } \\
\end{array}$ \\
\hline $\begin{array}{l}\text { Across Dispositions } \\
\text { (Within 5\% of Teacher's } \\
\text { Highest and Lowest) }\end{array}$ & & $\begin{array}{l}\text { Language Arts (36) } \\
\text { Third B (37) } \\
\text { First (38) } \\
\text { Math (38) } \\
\text { Science (43) }\end{array}$ \\
\hline $\begin{array}{l}\text { Consolidated } \\
\text { (Anchors + Support) }\end{array}$ & Fifth (48) & $\begin{array}{l}\text { Social Studies (35) } \\
\text { Language Arts (36) } \\
\text { Second (37) } \\
\text { Third B (37) }\end{array}$ \\
\hline
\end{tabular}

Scores. The mean for truth-seeking among the teachers is 39.2 and the median is 38. Ms. Fifth scored the highest truth-seeking (48) score even though it is not one of her top 5\% scores. Ms. Fifth, consequently, scored 37.1\% higher on truth-seeking than Ms. Social Studies and 21.7\% above the mean. Ms. Social Studies scored the lowest on truthseeking (35) of all the teachers, which is only slightly (4.2\%) below the mean. It is her second lowest score even though it does not fall within the lowest $5 \%$ of her scores. Ms. Fifth is the anchor for high-scoring, while Ms. Social Studies is the anchor for lowscoring. There are no other high scoring teachers in truth-seeking, but there are three supporting teachers for the low extreme group: Mr. Language Arts (36), Ms. Second (37), and Ms. Third B (37). Table 11 above summarizes the information for truth-seeking from the previous tables. The anchors are distinguished in the first row and are bolded throughout the table. The final row summarizes truth-seeking's extreme groups used for 
comparison. As indicated in the Methodology chapter previously, any score within 5\% of the mean was crossed off, and any low-score above the mean or high-score below the mean was also crossed off.

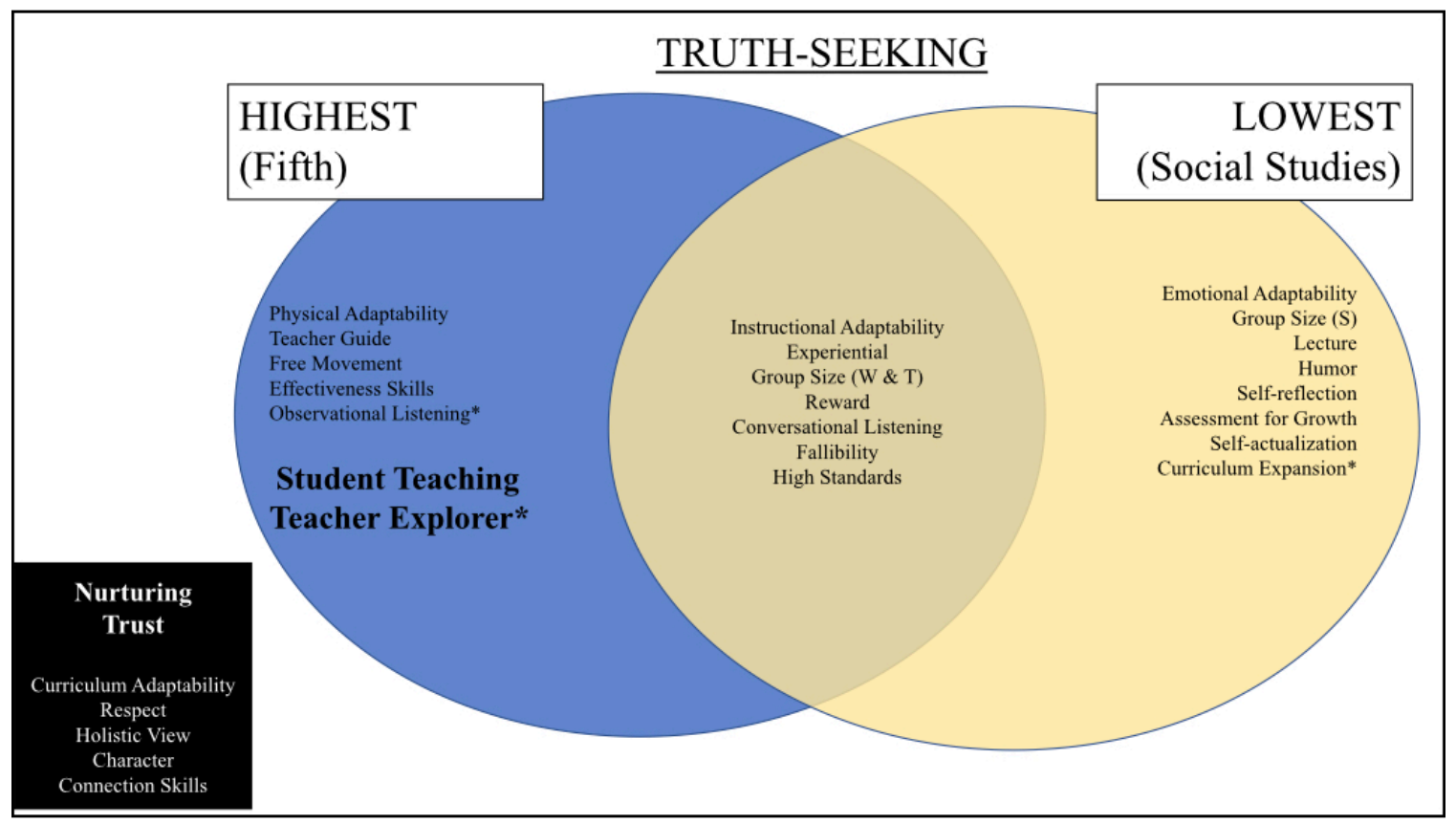

Figure 7

Truth-seeking Cross-Case Synthesis of Teaching Styles

Teaching style. Figure 7 above summarizes the results of the cross-case analysis between teaching styles of the extreme groups for truth-seeking. The teaching styles in bold indicate the consistent relationships that are unanimously supported by all teachers in the high extreme group and not contradicted by any of the teachers in the low extreme group, namely the high truth-seeking teachers consistently utilize student teaching and teacher explorer styles. The other teaching styles are distinctions and similarities between the anchors that are not consistently and unanimously supported by the other teachers in the extreme groups. The black box on the lower left of the figure indicates the teaching styles that were absent from both anchors for truth-seeking. The styles in bold in the 
black box, namely nurturing and trust, were consistently absent from all the teachers in both extreme groups.

In terms of adaptability to student needs, while both anchor teachers (Ms. Fifth and Ms. Social Studies) adapt instruction, Ms. Social Studies (low) also accounts for the emotional needs of her students. Two out of the three supporting low-scoring teachers adapted to the emotional needs of students (Ms. Third B and Mr. Language Arts). Ms. Fifth (high), on the other hand, adapts to the physical needs of students, while Ms. Social Studies (low) did not show evidence of that. There was one contradiction to this where a low-scoring support teacher also adapted to the physical needs of students (Ms. Third B). Initially, curriculum adaptation was defined as a teacher who varies the difficulty of work, quantity of work, expectations, and incorporates outside sources. According to that definition, all the low scoring teachers adapted the curriculum. However, it became evident that the teachers who incorporated outside sources were expanding the curriculum in a way that was distinct from merely adjusting to the achievement level of students. After re-analyzing the qualitative data, the curriculum adaptation was no longer a consistent result. Rather, Ms. Social Studies (low) expanded the curriculum along with two out of the three supporting teachers (Mr. Language Arts and Ms. Third B) and none of the anchors adapted the curriculum in the basic way for achievement.

In terms of teaching methods, both anchor teachers incorporate hands-on activities in their lessons. However, Ms. Social Studies' (low) hands-on activities are generally artistic renditions with clear instruction that support the lesson, while Ms. Fifth's (high) hands-on activities are sometimes artistic and other times experimental where the end is not predetermined. While it could fit under teacher guide strategies, it 
was significant to distinguish this specific style of not having a clear end to the lesson as a new category. Therefore, this emerged as a new teaching style that was not designated during the initial qualitative data analysis-teacher explorer.

Consequently, there is a stark difference between Ms. Fifth's (high) guiding style and Ms. Social Studies (low) lecturing style. Ms. Social Studies (low) was the only teacher participating in the present study who lectured. Even though none of the lowscoring set can support this teaching style, it was a significant aspect of Ms. Social Studies teaching and for that reason was included in the summary of teaching styles to explore in relation to low truth-seeking disposition. While both teachers configured their classrooms in whole group lessons or teamwork, Ms. Social Studies (low) also showed evidence of small group instruction while Ms. Fifth (high) did not. One teacher for lowscoring also showed evidence of small group instruction as well (Ms. Second). Ms. Social Studies (low) was not the only teacher where free movement was absent from her classroom, but she was the only one to express her extreme dislike of free movement. On the other hand, free movement was a part of Ms. Fifth's (high) classroom. However, one of the low-scoring set contradicted with Ms. Social Studies (low) regarding freemovement (Ms. Third B). Finally, Ms. Fifth (high) was the only teacher in the present study who showed evidence of student teaching.

In terms of ways the teachers connect to the students, Ms. Social Studies (low) and Ms. Fifth (high) both listen and use rewards. However, Ms. Fifth (high) listened with the purpose of informing the lesson, which emerged as an important distinction in this second phase of the analysis—observational listening. Ms. Social Studies (low), on the other hand, listened conversationally to connect and build rapport with the students. Ms. 
Social Studies (low) expressed humor in interacting with her students, while Ms. Fifth (high) had a more serious demeanor. Mr. Language Arts (low supporting) also expressed humor.

In terms of growth-oriented teaching, both Ms. Fifth (high) and Ms. Social Studies (low) promoted a positive relationship with fallibility and maintained high standards. Ms. Social Studies (low), however, also expressed self-reflective tendencies and used assessment as a tool for growth. While one other low-scoring teacher (Mr. Language Arts) also expressed self-reflective tendencies, none of the other low-scoring teachers showed evidence of using assessment as a tool for growth. None of the anchor teachers (Ms. Fifth and Ms. Social Studies) showed evidence of the holistic view towards students.

Finally, in terms of highest hopes for students, Ms. Social Studies (low) only expressed self-actualization, while Ms. Fifth (high) only expressed effectiveness skills. Mr. Language Arts (low supporting) also expressed self-actualization, while Ms. First, Ms. Second (low supporting) and Ms. Third B (low supporting) aligned with Ms. Fifth's (high) effectiveness skills. None of these two anchor teachers expressed character or connection skills as a highest hope.

\section{Disposition \#2: Open-mindedness Highest and Lowest}

Open-mindedness is defined as the tendency to listen to other people's opinions, even when contradicting your own. Figure 8 below shows the teachers' scores on the open-mindedness subscale of the CCTDI. Table 12 shows the extreme groups. 


\section{Open-mindedness Score for Each Teacher}

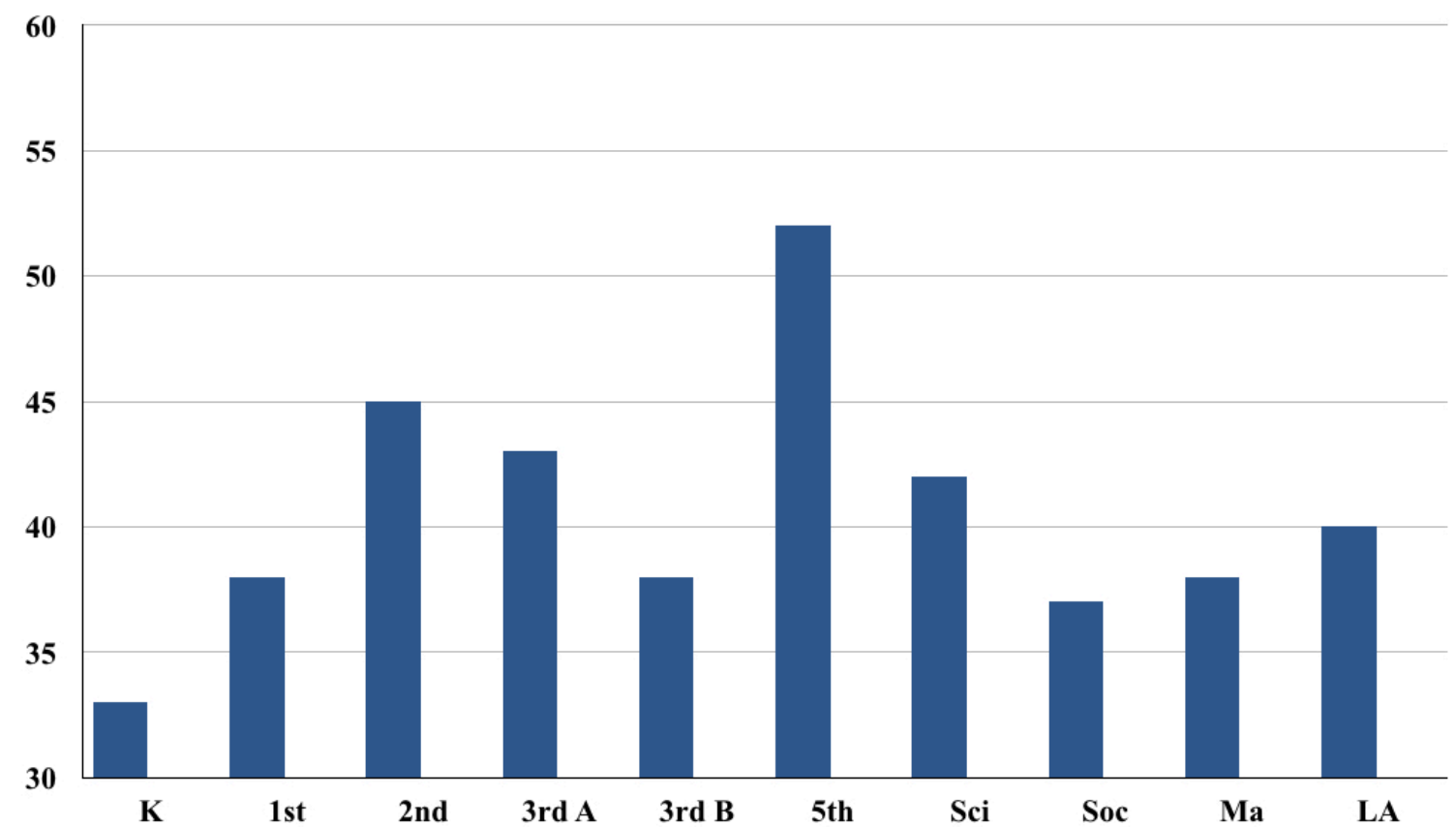

Figure 8

Open-mindedness Score for Each Teacher

Table 12

Open-mindedness Extreme Groups

\begin{tabular}{lll}
\hline & Highest & Lowest \\
\hline Within Open-mindedness & Fifth (52) & Kindergarten (33) \\
(Anchors) & Fifth (52) & Kindergarten (33) \\
\hline Within 5\% & & Kindergarten (33) \\
& & $\begin{array}{l}\text { First (38) } \\
\text { Third B (38) }\end{array}$ \\
Across Dispositions & Fifth (52) & $\begin{array}{l}\text { Math (38) } \\
\text { Seience (42) }\end{array}$ \\
(Within 5\% of Teacher's & & Kindergarten (33) \\
Highest and Lowest) & & $\begin{array}{l}\text { First (38) } \\
\text { Third B (38) } \\
\text { Consolidated }\end{array}$ \\
(Anchors + Support) & Fifth (52) & Math) \\
\hline
\end{tabular}


Scores. The mean for open-mindedness scores is 40.6 , while the median is 39 . Ms. K has the lowest open-mindedness score (33) of all the teachers. Open-mindedness is also her lowest score, about $32 \%$ lower than the average of her top five scores and $18 \%$ below the mean. Five out of the ten teachers scored in their lowest $5 \%$ on openmindedness: Ms. K (33), Ms. First (38), Ms. Third B (38), Ms. Science (42), and Ms. Math (38). Ms. Science's score is above the mean (40.6) even though it is one of her lowest, and therefore, she has been removed from the low-scoring group. Ms. First, Ms. Third B, and Ms. Math scored only $6.4 \%$ below the mean. Ms. Fifth (52) has the only high score in open-mindedness, which is both one of her high scores as well as the highest open-mindedness score among all the teachers. Ms. Fifth's score (52) is $28.6 \%$ above the mean score (40.6) for open-mindedness among all the teachers. No other teacher has open-mindedness as a high score compared to their other scores. Therefore, the anchors for open-mindedness, bolded throughout Table 12, are Ms. Fifth (high) and Ms. K (low) with three teachers as supporting evidence in the low-scoring group: Ms. First, Ms. Third B, and Ms. Math. 


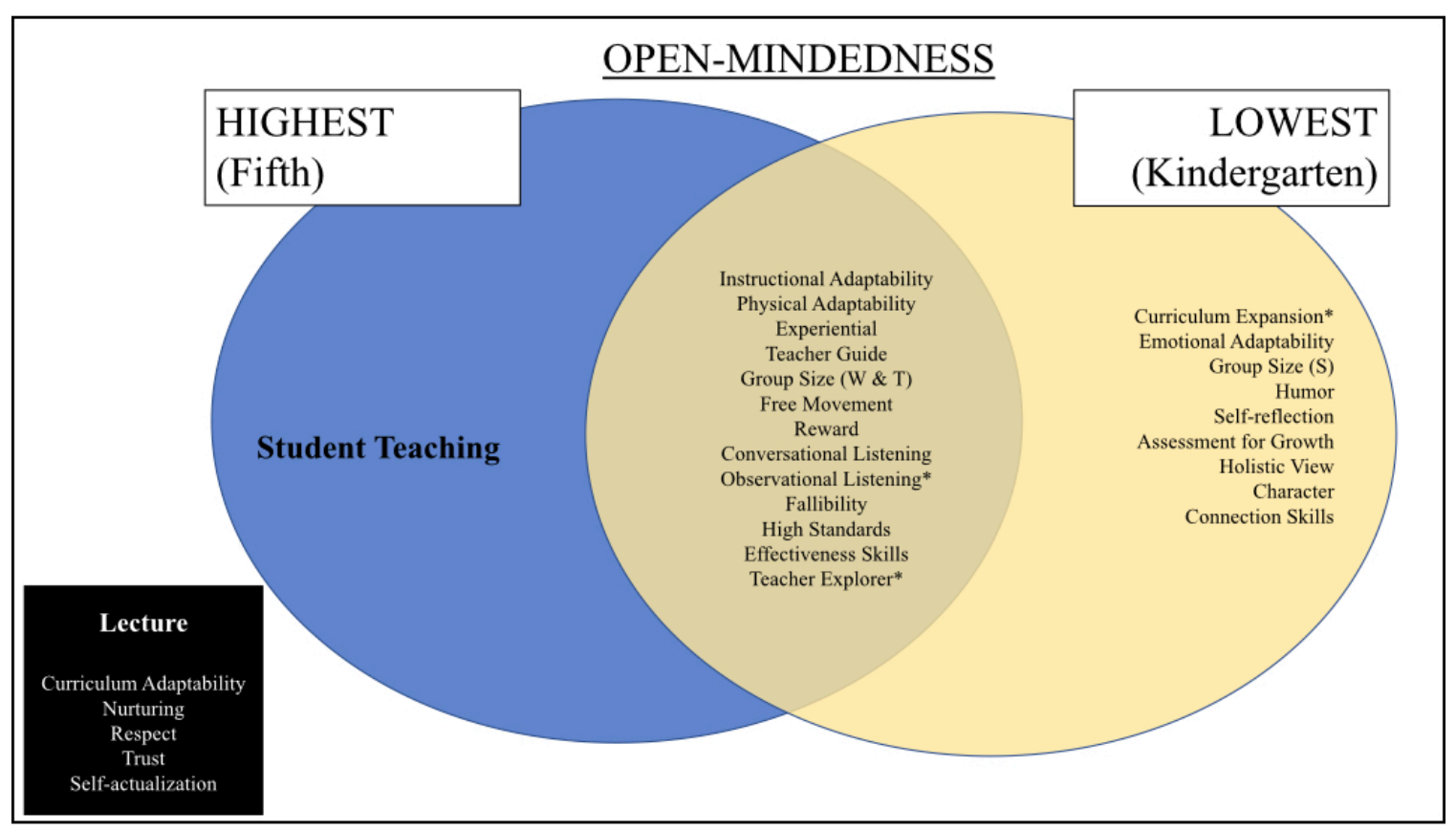

Figure 9

Open-mindedness Cross-Case Synthesis of Teaching Styles

Teaching style. Figure 9 above summarizes the similarities and differences in teaching styles between the anchors for open-mindedness. In comparing the teaching style themes emerging from the qualitative data analysis between Ms. Fifth (high) and Ms. K (low), Ms. K had all the teaching styles that Ms. Fifth had except student teaching. As indicated by the bold font in Figure 9, the high-scoring teacher exhibited student teaching while all four low-scoring teachers did not. Therefore, this is the only consistent relationship emerging from the cross-case analysis for open-mindedness: high openmindedness related to student teaching. While both adapted instruction and adapted to the physical needs of their students, Ms. K (low) expanded the curriculum, (the new distinction made during the cross-case analysis) and adapted to the emotional needs of her students as well. Two of the three supporting teachers for the low-scoring group also 
expanded the curriculum (Ms. First and Ms. Third B) and adapted to the emotional needs of students (Ms. Third B and Ms. Math). Ms. K (low) along with one supporting teacher (Ms. First) showed evidence of small group instruction, where Ms. Fifth (high) did not. They both utilized experiential teaching strategies, guided students, and had free movement in their classrooms. In terms of connecting to their students, they both utilized rewards and listening, but Ms. K (low) and one supporting teacher (Ms. Math) also used humor. With regard to growth-oriented teaching, both teachers expressed positive relationships with fallibility and maintained high standards. Ms. K (low) also showed evidence of self-reflection, assessment for growth, and maintaining a holistic view of her students. One supporting teacher showed evidence of a holistic view as well (Ms. Third B). Finally, both teachers expressed effectiveness skills as a highest hope. However, Ms. $\mathrm{K}$ (low) expressed character and connection skills as well. Two of the three supporting teachers also expressed character and connection (Ms. First and Ms. Math). Indicated in the black box on the bottom left of Figure 9, there was no evidence of the following styles for both extreme anchors for open-mindedness: lecturing, basic curriculum adaptation, nurturing, respect, trust, or hopes of self-actualization.

Even though Ms. K's open-mindedness score is the lowest, she exhibited behaviors in the classroom that seemed to be consistent with an open-minded disposition. She listened to her students even in off-topic conversations, such as the examples provided from the observation data where she responded to the "UK" comment or engaged in a discussion about the timing of another student's family trip. She encouraged them to participate in unique ways, such as the triangle nose comment or the boy who demonstrated over the cones in a unique way. She did not follow the prescribed 
curriculum, but rather integrated new ideas into lessons, such as integrating Marjorie Stoneman Douglas and alligator safety into the Everglades lesson. She often adapted the directions on worksheets to fulfill the needs of her students. Interestingly, Ms. K was probably the one teacher that spoke most about intentionally integrating multicultural perspectives, not to say the other teachers did not, but they did not necessarily emphasize it in the interview. These are all teaching activities that I anticipated to reflect openmindedness, yet Ms. K scored the lowest on this disposition that she emphasized the most.

Emerging from the qualitative data, Ms. Fifth is the teacher that had the most hands-on lessons in the entire school as mentioned previously, followed by Ms. Social Studies. This was an obvious distinction in the interview and observations as well as her reputation among the administrators. Additionally, during the observations it was evident that Ms. Fifth never responded to a student's question with the answer, but rather guided students with questions and resources. Ms. Fifth and Ms. K were actually the only two teachers who engaged students in a discussion without having the final answer clearly mapped out in their own minds. Therefore, Ms. K and Ms. Fifth are the only two teachers who guide in this deeper way, which was distinguished as teacher explorer. 


\section{Disposition \#3: Inquisitiveness Highest and Lowest}

Inquisitiveness is defined as intellectual curiosity even if the desired knowledge is not immediately relevant. Figure 10 displays the teachers' scores on the inquisitive subscale of the CCTDI. Table 13 displays the process for determining the extreme groups for inquisitiveness.

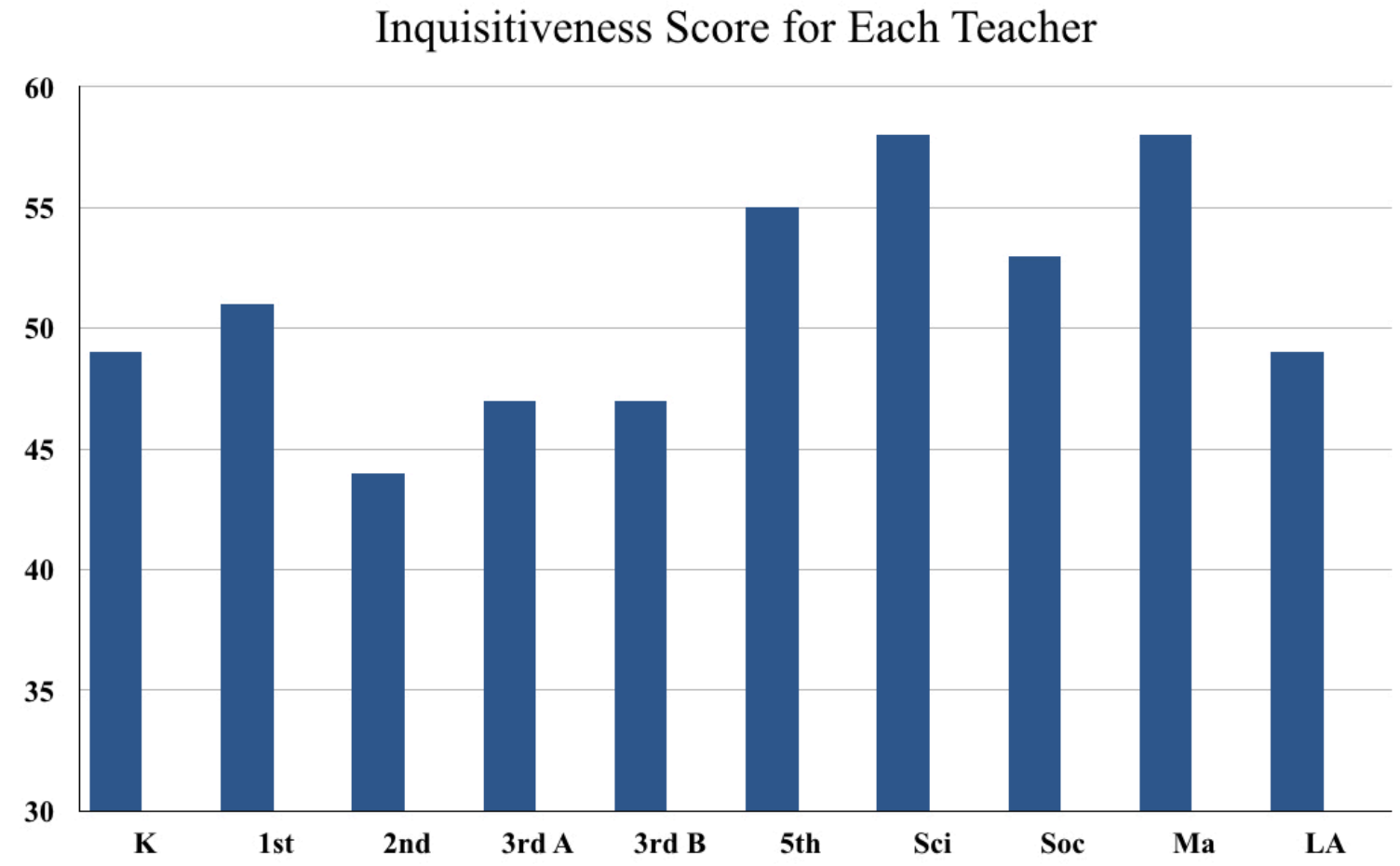

Figure 10

Inquisitiveness Score for Each Teacher 
Table 13

Inquisitiveness Extreme Groups

\begin{tabular}{|c|c|c|}
\hline & Highest & Lowest \\
\hline $\begin{array}{l}\text { Within Inquisitiveness } \\
\text { (Anchors) }\end{array}$ & $\begin{array}{l}\text { Science (58) } \\
\text { Math (58) }\end{array}$ & Second (44) \\
\hline Within 5\% & $\begin{array}{l}\text { Science (58) } \\
\text { Math (58) } \\
\text { Fifth }(55)\end{array}$ & Second (44) \\
\hline $\begin{array}{l}\text { Across Dispositions } \\
\text { (Within } 5 \% \text { of Teacher's } \\
\text { Highest and Lowest) }\end{array}$ & $\begin{array}{l}\text { Science (58) } \\
\text { Math (58) } \\
\text { Fifth (55) } \\
\text { Social Studies (53) } \\
\text { First (51) } \\
\text { Kindergarten (49) } \\
\text { Language Arts (49) } \\
\text { Third A (47) } \\
\text { Fhird B (47) } \\
\end{array}$ & \\
\hline $\begin{array}{l}\text { Consolidated } \\
\text { (Anchors + Support) }\end{array}$ & $\begin{array}{l}\text { Science (58) } \\
\text { Math (58) } \\
\text { Fifth (55) } \\
\text { Social Studies (53) }\end{array}$ & Second (44) \\
\hline
\end{tabular}

Scores. The mean of all inquisitiveness scores was 51.1 and the median was 50 , higher than the rest of the dispositions. Consequently, all the teachers except Ms. Second (44) had inquisitiveness within 5\% of their highest scores, with it being the highest score for 7 of those 9 teachers. Both Ms. Science and Ms. Math scored the highest in inquisitiveness (58) within their own scores and across teachers, which was $13.5 \%$ above the mean. Ms. Second's inquisitiveness score (44) was the lowest across teachers and below the mean by $13.9 \%$, yet it was above both her individual mean (40) and median (41) and did not fall within 5\% of her lowest score. Therefore, the mean for inquisitiveness (51.1) lies almost exactly between the highest scores of Ms. Science and Ms. Math (58) and the lowest score of Ms. Second (44). Four of the nine teachers in the 
high-scoring group were removed because their score was below the mean (Ms.

Kindergarten, Mr. Language Arts, Ms. Third A, and Ms. Third B), and one removed (Ms.

First) because her score was within 5\% of the mean. Therefore, the high-scoring anchors are Ms. Science and Ms. Math, with two supporting teachers (Ms. Fifth and Ms. Social Studies). The low-scoring anchor is Ms. Second.

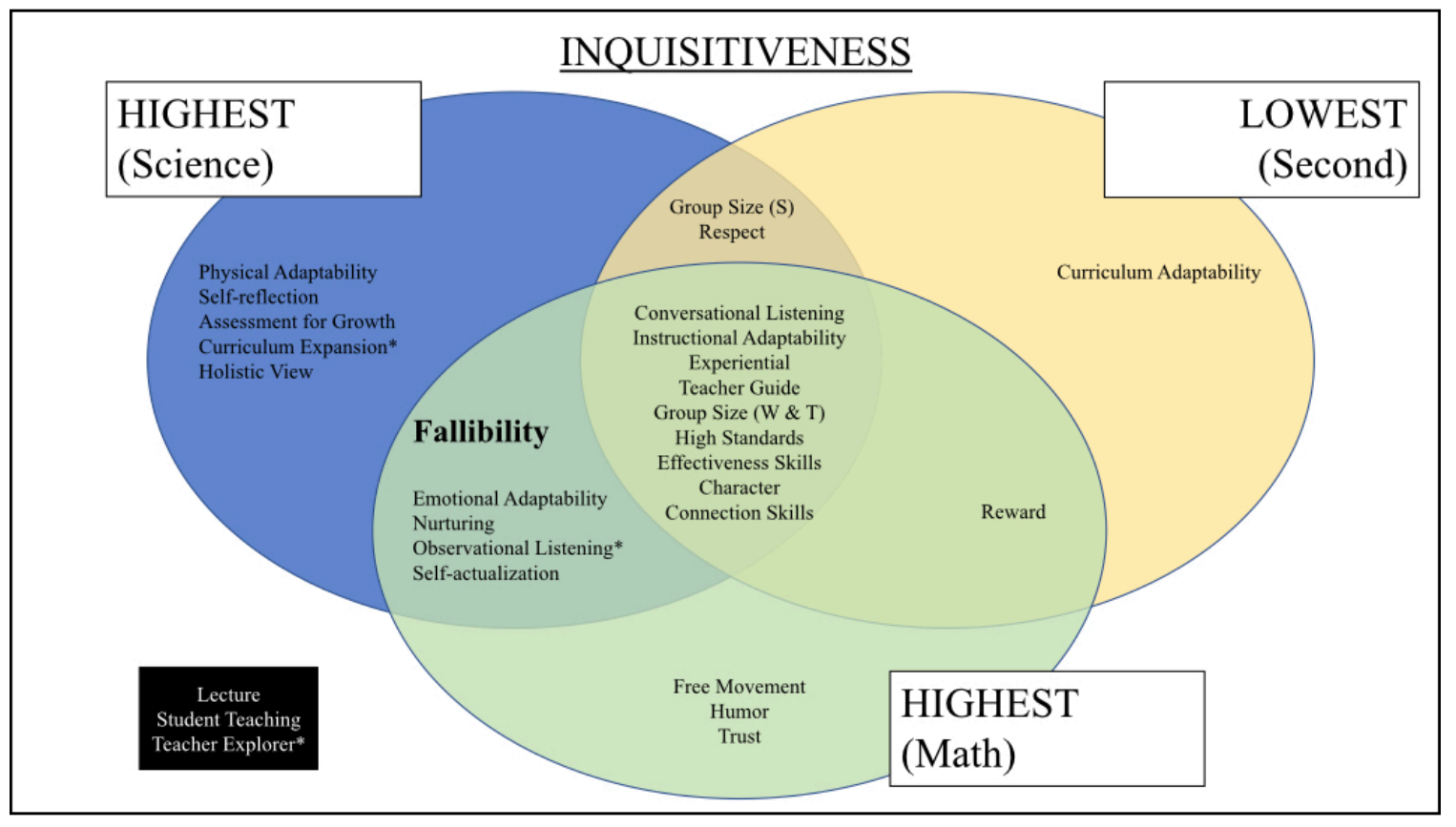

Figure 11

Inquisitiveness Cross-Case Synthesis of Teaching Styles

Teaching style. Figure 11 above summarizes the similarities and differences in teaching styles between the anchors. Because there are two high-scoring anchors (Ms. Science and Ms. Math) for inquisitiveness, I included the teaching styles that both shared and were different from the low-scoring anchor (Ms. Second). Both Ms. Science (high) and Ms. Math (high) adapted to the emotional needs of their students, connected in nurturing ways, listened in a deeper sense, expressed fallibility positively, and expressed 
self-actualization as a highest hope. Fallibility had support from all high-scoring teachers (Ms. Fifth, and Ms. Social Studies) and, as indicated in bold in Figure 11, it is one of the consistent relationships resulting from the present study. Self-actualization was also exhibited by the high-scoring anchors (Ms. Science and Ms. Math), but only supported by one of the two support teachers (Ms. Social Studies). Ms. Second (low) did not express any of these teaching style categories except listening.

However, there was a clear distinction in the way Ms. Second (low) listened compared to the way Ms. Science (high) and Ms. Math (high) listened. Ms. Second (low) approached listening as a strategy to connect with the students (conversational listening), whereas Ms. Math and Ms. Science expressed an additional intention of using listening as a strategy to gain information that guides teaching. One of the most striking features of Ms. Science's teaching style is her observation of her students. While most teachers observe their students, Ms. Science's observation is that of a trained scientist, looking for clues in comments, work, and behaviors. She adapts her teaching and the curriculum accordingly, whether it be for a specific class or an individual student, adapting intellectually or emotionally. Remember her statement:

"Observing is key...I mean you really could just go in and teach and then step out, but you would never be successful that way, you would just be a regular teacher. You're not going to be able to connect or bond with the children" (Interview, p. 5).

Similarly, Ms. Math spoke about listening to her students, saying during the interview, "You have to listen to them sometimes they tell you what you're doing they dislike and there is another way" (p. 12). For Ms. Science and Ms. Math, this is an intentional 
listening to adapt, which emerged as a new teaching style during the cross-case analysis phase—observational listening.

There are eight teaching style themes that Ms. Second (low) did not express, but one of the high-scoring teachers (Ms. Science and Ms. Math) did express. Ms. Science (high) showed evidence of adapting to the physical needs of her students, expanding the curriculum, self-reflecting, using assessment for growth, and maintaining a holistic view of students. While Ms. Math (high) did not align in those four teaching styles, she did express free movement, humor, and trust. Ms. Second (low) aligned with only one of the two high-scoring teachers (Ms. Science or Ms. Math) on three teaching styles; small group instruction and respect aligned with Ms. Science, while reward aligned with Ms. Math. Ms. Second (low) adapted the curriculum in the more basic way by varying the amount of work or the difficulty level for her students based on their achievement level. There were three teaching styles indicated in the black box in Figure 11 that were absent from all the anchors for inquisitiveness: lecturing, student teaching, and teacher explorer.

\section{Disposition \#4: Analyticity Highest and Lowest}

Analyticity is the tendency to anticipate potential outcomes. Figure 12 displays the teachers' scores on the analyticity subscale of the CCTDI. Table 14 shows the extreme groups for analyticity that were used to compare teaching styles. The high extreme group is led by the anchor, Ms. Math, and supported by Ms. Science and Ms. K. The low extreme anchor is Ms. Second with no supporting teachers. 


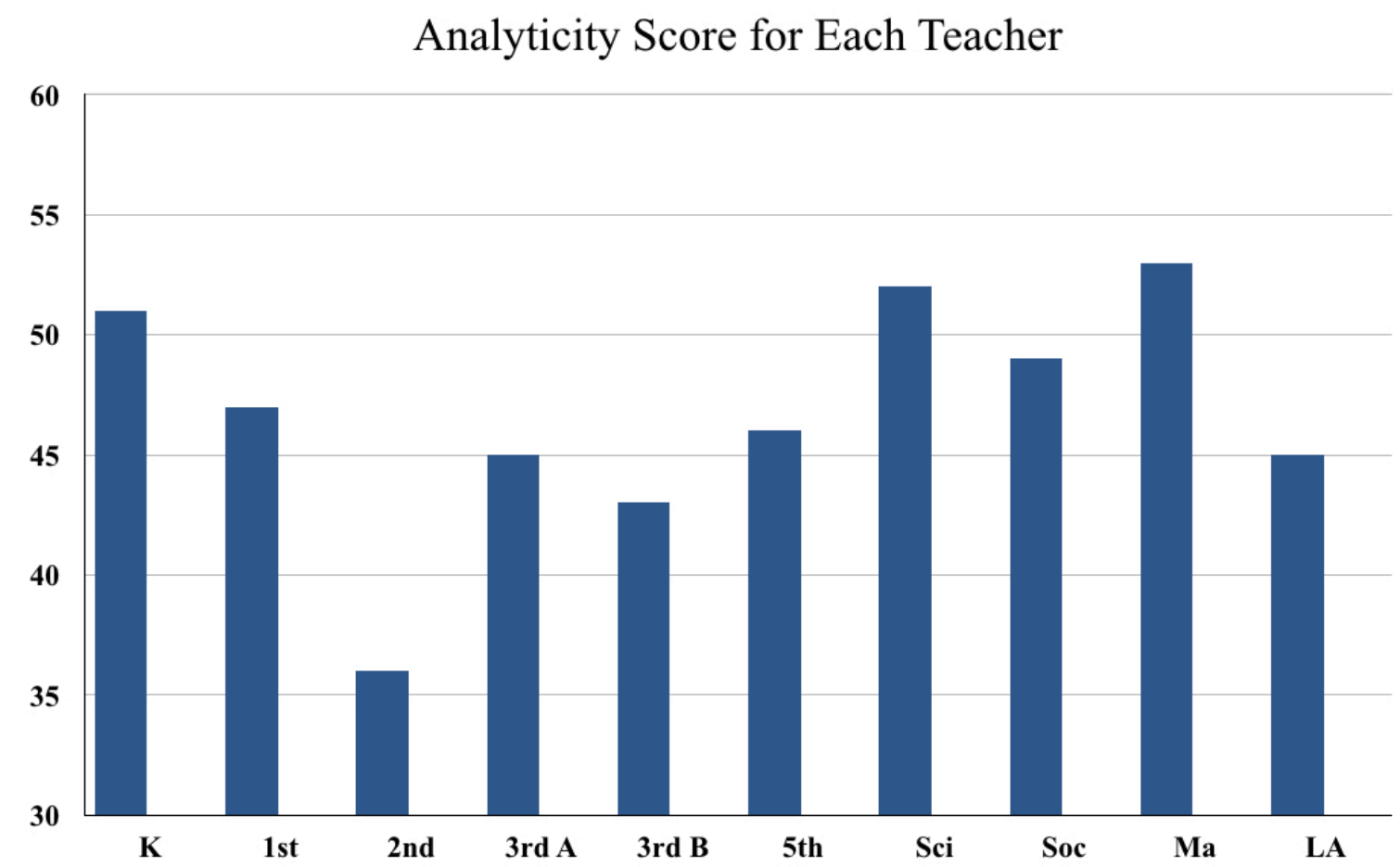

Figure 12

Analyticity Score for Each Teacher

Table 14

Analyticity Extreme Groups

\begin{tabular}{lll}
\hline & Highest & Lowest \\
\hline Within Analyticity & Math (53) & Second (36) \\
(Anchors) & $\begin{array}{l}\text { Math (53) } \\
\text { Science (52) } \\
\text { Kindergarten (51) }\end{array}$ & Second (36) \\
Within 5\% & $\begin{array}{l}\text { Kindergarten (51) } \\
\text { Third } \text { A (45) }\end{array}$ & \\
\hline Across Dispositions & Math (53) & \\
(Within 5\% of Teacher's & $\begin{array}{l}\text { Science (52) } \\
\text { Kindergarten (51) }\end{array}$ & Second (36) \\
\hline Consolidated & & \\
\hline (Anchors + Support) & &
\end{tabular}


Scores. The mean of the teachers' analyticity scores is 46.7 and the median is 45.5. Ms. Math has the highest analyticity score (53), above the mean by $13.5 \%$, with Ms. Science following with the second highest analyticity score (52). However, analyticity is not their highest individual scores. It is Ms. K's highest individual score (51) and one of Ms. Third A's top 5\% scores (45). Even though analyticity is one of Ms. Third A's top scores, her score of 45 is slightly below the mean score of 46.7. Therefore, Ms. Third A was removed from the high-scoring group on analyticity. None of the teachers have analyticity in the lowest $5 \%$ of their scores, but Ms. Second scored the lowest (36) on analyticity of all the teachers. This analyticity score is below the mean by $22.9 \%$ and below her individual mean (40) and median (41) as well. The anchors are Ms. Math (high) and Ms. Second (low), as indicated by bold on Table 14.

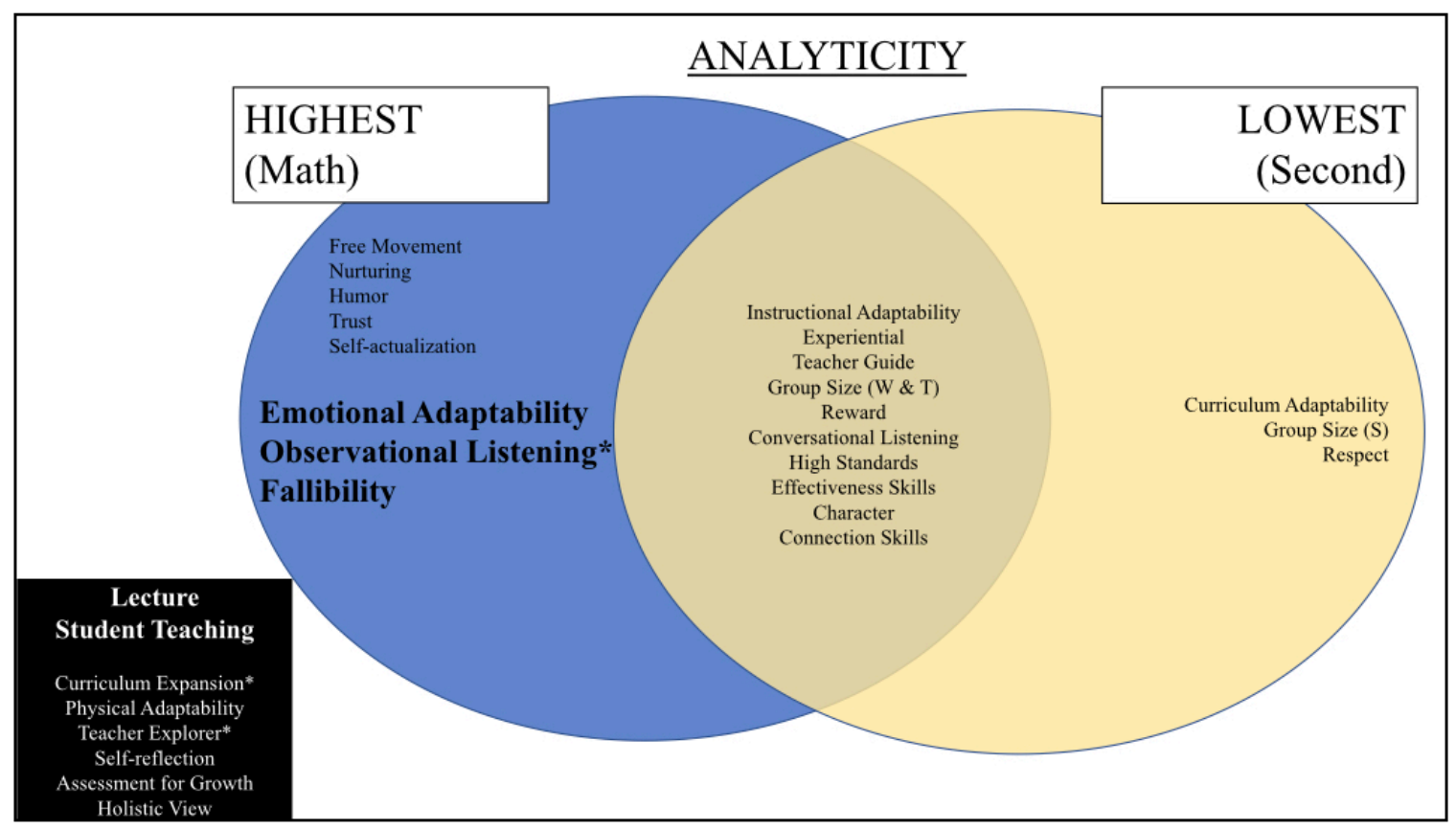

\section{Figure 13}

Analyticity Cross-Case Synthesis of Teaching Styles 
Teaching style. Similar to inquisitiveness, Ms. Math (high) is on the opposite side of the analyticity score from Ms. Second (low). The three consistent findings for analyticity, as indicated by the bold font on Figure 13, are: emotional adaptation, observational listening, and fallibility. Therefore, the cross-case analysis for analyticity indicates that all the teachers who scored high consistently exhibited these three styles, while none of the low-scoring teachers exhibited these three styles.

In comparing the anchors with regard to the teaching style theme of adaptability, Ms. Second (low) showed evidence for basic curriculum adaptations. While Ms. Math (high) did not adapt the curriculum, the other teachers in the high extreme group for analyticity expanded the curriculum (Ms. K and Ms. Science). In terms of teaching methods, all teachers in both extreme groups exhibited experiential learning, teaching guide techniques, whole group instruction, and teamwork. However, while Ms. Second (low), Ms. K (high), and Ms. Science (supporting high) showed evidence of small group instruction, Ms. Math (high) did not. Regarding ways of connecting, Ms. Math (high) expressed nurturing as did one supporting teacher (Ms. Science), humor as did one supporting teacher (Ms. K), observational listening as did both supporting teachers (Ms. Science and Ms. K), and trust. Both supporting teachers listened in the same deep way that Ms. Math (high) did, to gain information for student learning. As discussed previously, Ms. Second (low) also listened, but it was intended as a way to connect to students emotionally as opposed to an observational technique to inform instruction. In terms of growth-oriented teaching, Ms. Math (high) and both high-scoring support teachers expressed fallibility while Ms. Second did not. Finally, in expressing highest hopes for students, both high and low groups expressed effectiveness skills, character, 
and connection skills. However, Ms. Math (high) also expressed self-actualization along with Ms. Science (supporting high).

Two styles were consistently absent from both extreme groups, lecturing and student teaching. As indicated by the black box on the lower let of Figure 13, six more styles were absent from both anchors for analyticity: curriculum expansion, physical adaptation, teacher explorer, self-reflection, assessment for growth, and holistic view of students.

In terms of specific behaviors that may align with analyticity, Ms. Math (high), for example, spoke about how she imagines utilizing suggested instructional methods with her class and decides if it will be effective. This is analyticity because she anticipates potential outcomes based on current plans. During the interview, she gave an example of an "A" student who was not preparing for an upcoming exam. She warned him, but eventually let him fail because he was not heeding her warnings. She taught him analyticity by allowing him to fail. Ms. Math spoke about the importance of math for developing systematic thinking and step-by step problem-solving. This is an important component of analyticity, to anticipate a future outcome and create a plan that yields a desired result.

Ms. Science (supporting high) realized with some experience that if she followed the prescribed curriculum in order, her students would not be prepared for aspects of the SAT. However, if she merely rearranged the order of the chapters, she could simultaneously teach the curriculum and prepare the students for this exam without added stress or rush. This was a clear distinction from many of the other teachers' preparation methods which included a complete month of SAT practice before the exam. It makes 
sense that she scored high on analyticity, because analyticity is exactly this ability to anticipate the outcome from current actions.

Ms. K (supporting high) also scoring highly on analyticity exhibited some behaviors that seem to be linked to this disposition. For example, in creating her lesson plans, Ms. K writes only a broad outline and adjusts her teaching according to student learning. She, first, knows herself enough to create an effective planning strategy that works with her style. It is her analyticity that allows her to know if she creates a detailed plan, she will not complete it and she will be emotionally discouraged by not completing it. It is also her high disposition towards analyticity that probably enables her to quickly adapt her teaching to help her students reach desired outcomes. For example, she assesses her students' needs and changes the directions on prescribed curriculum to meet their needs or utilizes her deep knowledge of each individual students to adapt her instruction.

Ms. Second (low) scored the lowest on analyticity. In her teaching, a few factors were evident. She did not adapt her teaching in many ways, only by quantity of work, quantity of time, and difficulty of work. Evident in the observations and in the interviews was the amount of thinking time she provided students. During the interview, it was clear that this idea of making correct and timely decisions was extremely important for her. She felt that one of her goals as a teacher was to help her students learn how to make the right decisions at the right time and that the consequences of wrong decisions could be life-altering. The ability to make right decisions is connected to analyticity in terms of being able to imagine the outcomes based on current circumstances. Therefore, Ms. Second focused so much on this concept in which she scored the lowest. 


\section{Disposition \#5: Systematicity Highest and Lowest}

Systematicity is defined as the tendency to approach problems in an orderly way.

Figure 14 below displays the teachers' scores on the systematicity subscale of the CCTDI. Table 15 presents the extreme groups.

\section{Systematicity Score for Each Teacher}

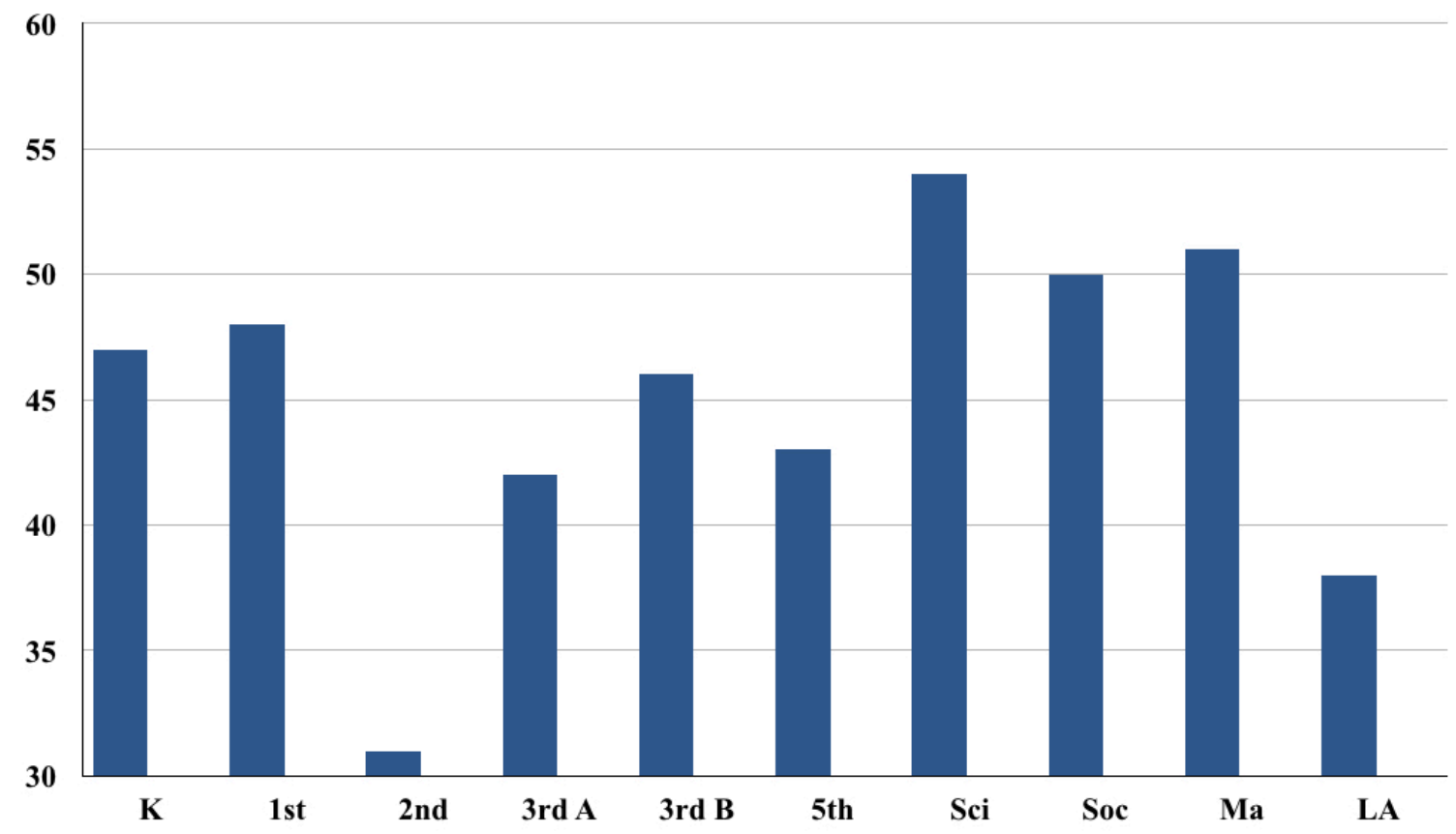

Figure 14

Systematicity Score for Each Teacher 
Table 15

Systematicity Extreme Groups

\begin{tabular}{|c|c|c|}
\hline & Highest & Lowest \\
\hline $\begin{array}{l}\text { Within Systematicity } \\
\text { (Anchors) }\end{array}$ & Science (54) & Second (31) \\
\hline Within 5\% & $\begin{array}{l}\text { Science (54) } \\
\text { Math (51) }\end{array}$ & Second (31) \\
\hline $\begin{array}{l}\text { Across Dispositions } \\
\text { (Within 5\% of Teacher's } \\
\text { Highest and Lowest) }\end{array}$ & $\begin{array}{l}\text { First (48) } \\
\text { Third B (46) }\end{array}$ & $\begin{array}{l}\text { Second (31) } \\
\text { Language Arts (38) } \\
\text { Fifth (43) }\end{array}$ \\
\hline $\begin{array}{l}\text { Consolidated } \\
\text { (Anchors + Support) }\end{array}$ & $\begin{array}{l}\text { Science (54) } \\
\text { Math (51) } \\
\text { First (48) }\end{array}$ & $\begin{array}{l}\text { Second (31) } \\
\text { Language Arts (38) } \\
\text { Fifth (43) }\end{array}$ \\
\hline
\end{tabular}

Scores. The mean for systematicity is 45 and the median is 46.5 . Ms. Science scored the top score in systematicity (54) making her the high anchor for systematicity; even though this is $20 \%$ above the mean, it is not one of her top scores. Ms. Math (51) scored within the highest $5 \%$ of all systematicity scores and systematicity is in the top 5\% of Ms. First (48) and Ms. Third B's (46) scores. However, because Ms. Third B's score is within $5 \%$ of the mean for systematicity, she is removed from the high-scoring group. Therefore, Ms. Math and Ms. First are the supporting teachers for the high-scoring anchor, Ms. Science. Ms. Second scored the lowest (31) of all the teachers on systematicity and it was also her lowest score and $31 \%$ below the mean, thus making her the low anchor for systematicity. Systematicity was also in the lowest $5 \%$ of Ms. Fifth (43) and Mr. Language Arts (38), thus they are Ms. Second's supporting teachers. 


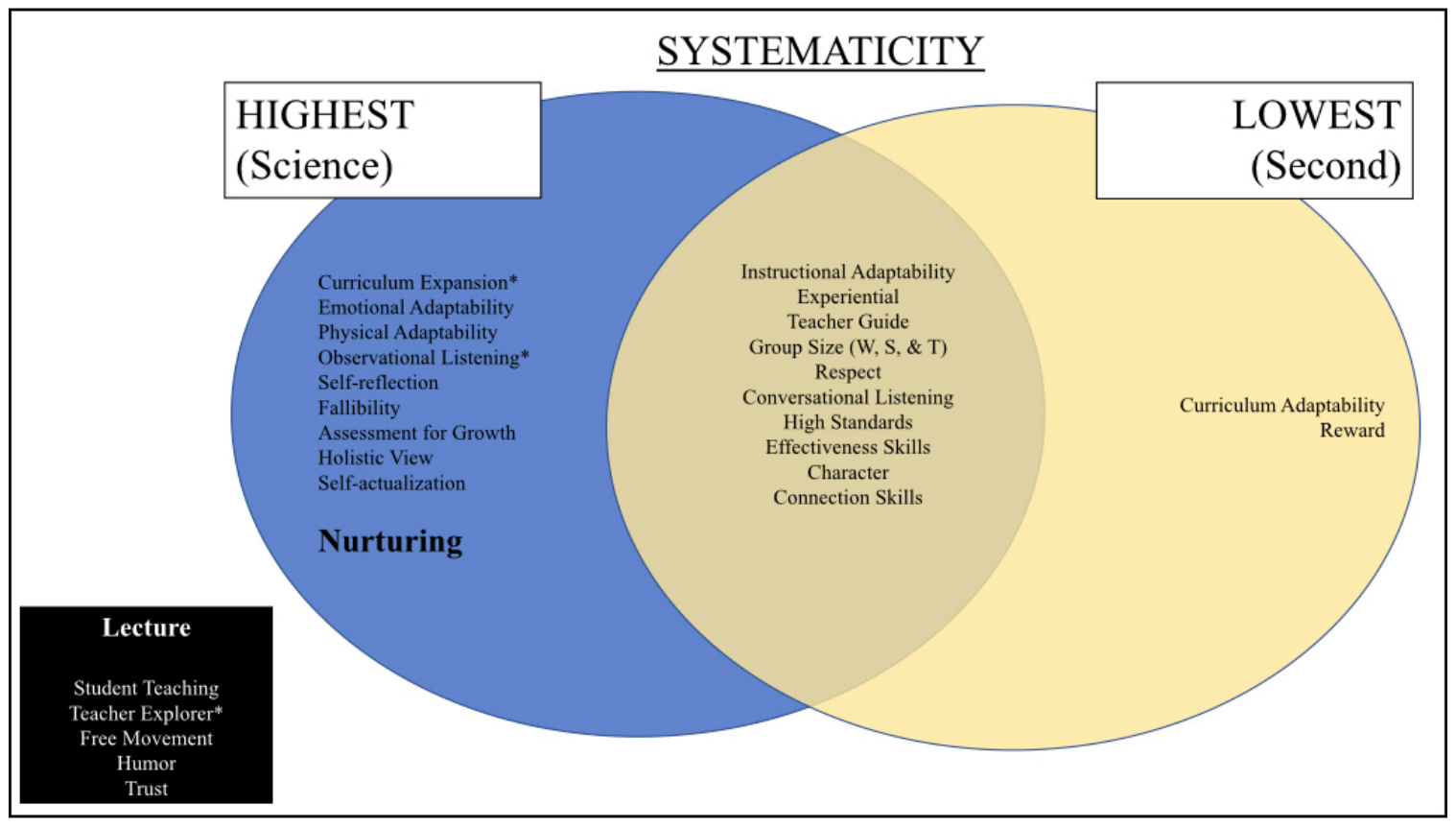

Figure 15

Systematicity Cross-Case Synthesis of Teaching Styles

Teaching style. Figure 15 above summarizes the results from the cross-case analysis for systematicity, with the consistent relationships indicated by the bold font. Ms. Science (high) and Ms. Second (low) are again on opposite score ends for systematicity, just as they were for inquisitiveness and analyticity. Previously, the distinction in emotional adaptability was noted where Ms. Science (high) exhibited this teaching style while Ms. Second (low) did not. One of the two supporting teachers for the high-scoring group on systematicity also exhibited emotional adaptability (Mr. Language Arts). Ms. Science (high) also exhibited physical adaptations whereas Ms. Second (low) did not. In contradiction, one supporting low teacher (Ms. Fifth) also exhibited physical adaptations. Ms. Science (high) exhibited nurturing ways to connect to her students. This finding was supported by all teachers in the high extreme group and not contradicted by 
any of the teachers in the low extreme group. Therefore, a consistent relationship between high systematicity and nurturing was found. Ms. Second (low) exhibited reward as a way to connect while Ms. Science (high) did not. Both exhibited respect and listening. As previously discussed, the way they exhibited listening differed in that Ms. Science (high) listened with an observer's ears to gain information to guide her teaching, whereas Ms. Second (low) listened as a way to be approachable and connect to her students emotionally. In addition, Ms. Science (high) expressed all themes of growthoriented teaching whereas Ms. Second (low) exhibited only high standards. Of the growth-oriented teaching styles, fallibility was also expressed by all two supporting teachers for the high group and all two supporting teachers for the low group. Finally, Ms. Science (high) expressed all the highest hopes themes while Ms. Second (low) expressed all except self-actualization.

As indicated by the black box on the bottom left of Figure 15, six teaching styles were absent from both anchors for systematicity: lecturing, student teaching, teacher explorer, free movement, humor, and trust. Lecturing was consistently absent from all teachers in both extreme groups, as indicated by the bold font.

In terms of classroom management, which seems to be the aspect of teaching most relevant to systematicity, Ms. Second (low) was one of the most structured and organized teachers even though she scored the lowest on systematicity, which is defined as being disciplined, orderly, and organized. She had clear discipline systems in place, the students all knew what they were to do and when, and her classroom was orderly in every aspect of the word. Ms. First's (supporting high) classroom management and structure was very similar to Ms. Second (low). Ms. First (supporting high) and Ms. 
Second (low) were also similar in their level of adaptability to their students' needs, which was less than Ms. Science's (high) more comprehensive adaptability. Ms. Fifth (supporting low) and Ms. Science's (high) classroom management was less stringent than Ms. First (supporting high) and Ms. Second (low), but still organized and focused. Students had a clear understanding of expectations and there was no ambiguity about the task; however, there was a level of comfortable conversation that was not there with Ms. Second (low) and Ms. First's (supporting high) class. Mr. Language Arts (supporting low) had more of an organic organization where it all flowed into the appropriate area, but it was not as structured as Ms. Second's (low) and Ms. First's (supporting high). There was more give and take, where students needed frequent reminders to be on task.

Ms. Science (high) seemed to demonstrate her systematicity in her arrangement of the curriculum for SAT preparation, as discussed as an example of analyticity as well. She also demonstrated systematicity in the way she approached student problems. For example, when Ms. Science (high) was trying to understand why one student repeatedly asked for help on certain questions, she observed for patterns. She eventually guided this student to learning in a systematic, orderly way. Therefore, it seems that Ms. Science (high) demonstrated teaching that aligned with systematicity when she adapted to her students' needs. 


\section{Disposition \#6: Confidence in Reasoning Highest and Lowest}

Confidence in reasoning is a tendency to trust reflective thinking and the reason.

Figure 16 below shows the teachers' scores on the confidence in reasoning subscale of the CCTDI. Table 16 shows the extreme groups.

\section{Confidence in Reasoning Score for Each Teacher}

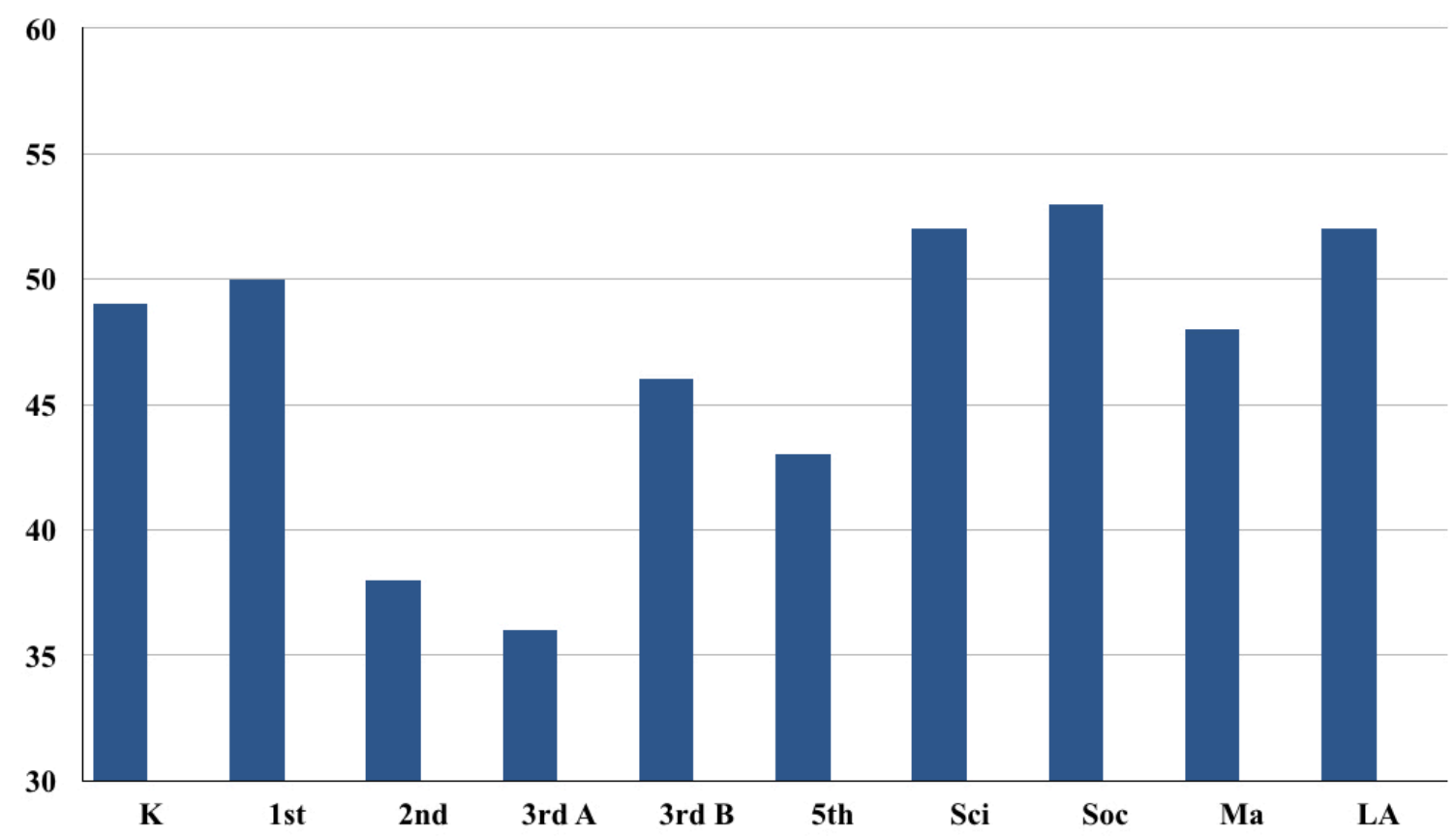

Figure 16

Confidence in Reasoning Score for Each Teacher 
Table 16

Confidence in Reasoning Extreme Groups

\begin{tabular}{|c|c|c|}
\hline & Highest & Lowest \\
\hline $\begin{array}{l}\text { Within } \\
\text { Confidence in Reasoning } \\
\text { (Anchors) }\end{array}$ & Social Studies (53) & Third A (36) \\
\hline Within 5\% & $\begin{array}{l}\text { Social Studies (53) } \\
\text { Language Arts (52) } \\
\text { Science (52) } \\
\text { First (50) } \\
\end{array}$ & $\begin{array}{l}\text { Third A (36) } \\
\text { Second (38) }\end{array}$ \\
\hline $\begin{array}{l}\text { Across Dispositions } \\
\text { (Within 5\% of Teacher's } \\
\text { Highest and Lowest) }\end{array}$ & $\begin{array}{l}\text { Social Studies (53) } \\
\text { Language Arts (52) } \\
\text { First (50) } \\
\text { Kindergarten (49) } \\
\text { Third B (46) } \\
\end{array}$ & $\begin{array}{l}\text { Third A (36) } \\
\text { Fifth (43) }\end{array}$ \\
\hline $\begin{array}{l}\text { Consolidated } \\
\text { (Anchors + Support) }\end{array}$ & $\begin{array}{l}\text { Social Studies (53) } \\
\text { Language Arts (52) } \\
\text { Science (52) } \\
\text { First (50) }\end{array}$ & $\begin{array}{l}\text { Third A (36) } \\
\text { Second (38) } \\
\text { Fifth (43) }\end{array}$ \\
\hline
\end{tabular}

Scores. The mean of all the teachers' confidence in reasoning scores is 46.7 and

the median is 48.5 . Table 16 summarizes the process of forming the extreme groups, with the anchors in bold and the final row showing the extreme groups. Confidence in reasoning was both Ms. Social Studies' highest score (53) and the highest confidence in reasoning score among all the teachers, scoring $13.5 \%$ above the mean. Confidence in reasoning was also Mr. Language Arts' highest score (52), trailing Ms. Social Studies by only one point. There were five teachers who had confidence in reasoning in the top 5\% of their scores: Ms. K (49), Ms. First (50), Ms. Third B (46), Ms. Social Studies (53), and Mr. Language Arts (52). Because Ms. Third B and Ms. K's scores are within 5\% of the mean, they are removed from the high-scoring group. Therefore, the high-scoring anchor is Ms. Social Studies with three supporting teachers (Mr. Language Arts, Ms. Science, 
and Ms. First). There were two teachers who had confidence in reasoning in the lowest 5\% of their scores: Ms. Third A (36) and Ms. Fifth (43), with Ms. Third A's score (36) being the lowest among all the teachers, $22.9 \%$ below the mean. Ms. Second (38) scored within $5 \%$ of the lowest score on confidence in reasoning. Therefore, Ms. Third A is the anchor for the low-scoring group with Ms. Second and Ms. Fifth as supporting teachers.

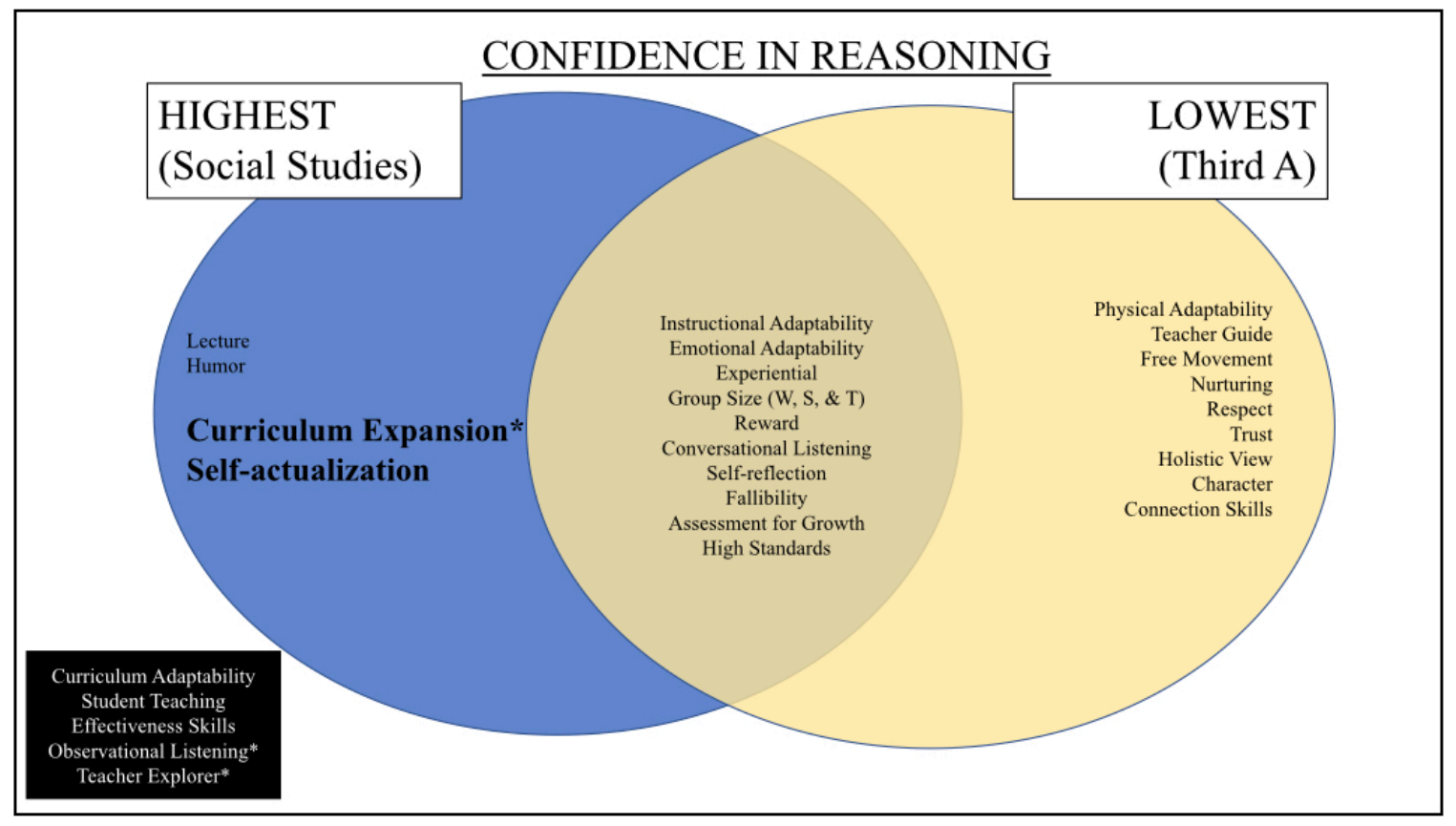

Figure 17

Confidence in Reasoning Cross-Case Synthesis of Teaching Styles

Teaching style. Figure 17 above displays the summary of teaching style

distinctions resulting from the cross-case analysis for confidence in reasoning. Ms. Social Studies (high) and Ms. Third A (low) had many differences in teaching style. While both teachers adapted instruction and adapted to the emotional needs of students, Ms. Social Studies (high) also expanded the curriculum. All of the high-scoring supporting teachers also expanded the curriculum in similar ways while the low-scoring teachers did not; thus, curriculum expansion's relationship to high confidence in reasoning was a 
consistent finding as indicated by the bold font in Figure 17. While Ms. Second, a lowscoring support teacher, also adapts the curriculum, she does so on a more superficial level than all of the high-scoring teachers by simply adjusting the difficulty level and expectations based on student achievement. Another distinction in adaptability, Ms. Third A (low) adapted to the physical needs of students, for example she allowed doodling because it helps some students concentrate. This was supported by one other low-scoring teacher (Ms. Fifth) and one high-scoring teacher (Ms. Science).

In terms of teaching methods, Ms. Social Studies (high) and Ms. Third A (low) used experiential techniques and configured the classroom in whole group, small group, and teams. However, Ms. Social Studies (high) lectured rather than guided like Ms. Third A (low). In addition, Ms. Social Studies (high) detested student movement in the class, unlike Ms. Third A, who allowed her students to move around freely. One other lowscoring teacher supported Ms. Third A's free movement (Ms. Fifth).

While both teachers utilized rewards and conversational listening to connect to students, Ms. Third A (low) was nurturing with her students and exhibited trust and respect in interacting with them. Ms. Social Studies (high), on the other hand, used humor to connect to students. Ms. Third A (low) also exhibited more holistic views of her students, while both teachers maintained all other categories of the growth-oriented teaching styles (self-reflection, fallibility, assessment for growth, and high standards).

Probably the most significant distinction is in their expressions of highest hopes for their students, Ms. Social Studies (high) along with all the high-scoring group expressed self-actualization, while Ms. Third A (low) expressed character and connection skills. Therefore, in Figure 17, self-actualization is the second teaching style in bold, 
showing that it was supported by all teachers of the high-scoring group with no contradictions from the low-scoring group. Both anchors did not exhibit basic curriculum adaptations, student teaching as a method, teacher explorer methods, observational listening, and effectiveness skills as a highest hope as indicated by the black box in the lower left of Figure 17.

\section{Disposition \#7: Maturity of Judgment Highest and Lowest}

Maturity of judgment is the tendency to see the complexity of issues, yet still strive to make timely decisions. Figure 18 presents the teachers' scores on the maturity of judgment subscale of the CCTDI. Table 17 shows the extreme groups.

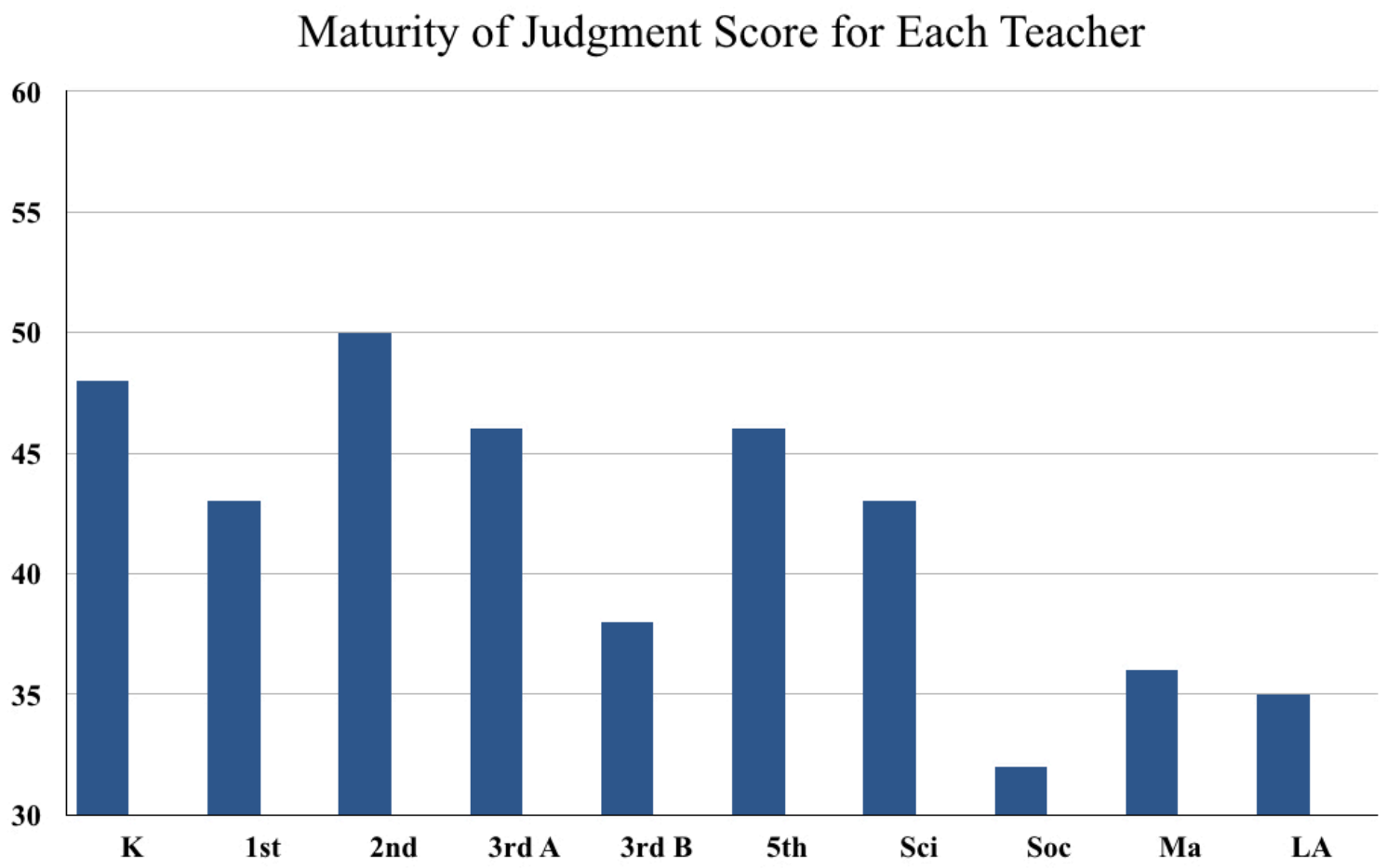

Figure 18

Maturity of Judgment Score for Each Teacher 
Table 17

Maturity of Judgment Extreme Groups

\begin{tabular}{|c|c|c|}
\hline & Highest & Lowest \\
\hline $\begin{array}{l}\text { Within } \\
\text { Maturity of Judgment } \\
\text { (Anchors) }\end{array}$ & Second (50) & Social Studies (32) \\
\hline Within 5\% & $\begin{array}{l}\text { Second (50) } \\
\text { Kindergarten (48) }\end{array}$ & Social Studies (32) \\
\hline $\begin{array}{l}\text { Across Dispositions } \\
\text { (Within } 5 \% \text { of Teacher's } \\
\text { Highest and Lowest) }\end{array}$ & $\begin{array}{l}\text { Second (50) } \\
\text { Kindergarten (48) } \\
\text { Third A (46) }\end{array}$ & $\begin{array}{l}\text { Social Studies (32) } \\
\text { Language Arts (35) } \\
\text { Math (36) } \\
\text { Third B (38) } \\
\text { Seience (43) }\end{array}$ \\
\hline $\begin{array}{l}\text { Consolidated } \\
\text { (Anchors + Support) }\end{array}$ & $\begin{array}{l}\text { Second (50) } \\
\text { Kindergarten (48) } \\
\text { Third A (46) }\end{array}$ & $\begin{array}{l}\text { Social Studies (32) } \\
\text { Language Arts (35) } \\
\text { Math (36) } \\
\text { Third B (38) }\end{array}$ \\
\hline
\end{tabular}

Scores. The mean score for maturity of judgment is 41.7 and the median is 43 .

Ms. Second scored the highest on maturity of judgment (50) both within her individual scores and among the teachers' scores, which is $19.9 \%$ above the mean. While not their highest score or the highest score for maturity of judgment, Ms. K (48) and Ms. Third A (46) had maturity of judgment in their highest $5 \%$ scores. Therefore, Ms. Second is the high-scoring anchor with two supporting teachers (Ms. K and Ms. Third A). Ms. Social Studies scored the lowest on maturity of judgment (32) both within her own scores and among the teachers scores, which is $23.3 \%$ below the mean. Interestingly, all four middle school teachers scored in their lowest $5 \%$ on the maturity of judgment scale-Ms.

Science (43), Ms. Social Studies (32), Ms. Math (36), Mr. Language Arts (35). This is Ms. Math (36) and Mr. Language Arts' (35) lowest score as well. For Ms. Math, her 
maturity of judgment score (36) is $37.9 \%$ lower than her highest score in inquisitiveness (58). For Mr. Language Arts, his maturity of judgment score (35) is $32.7 \%$ lower than his highest score in confidence in reasoning (52). Aside from the middle school teachers, only one other teacher has maturity of judgment in her lowest $5 \%$ of scores-Ms. Third B (38). Although among her lowest scores, Ms. Science's 43 is above the mean of all teacher scores on the maturity of judgment scale, therefore she is removed from the lowest-scoring teachers' group. Therefore, the anchor for a low maturity of judgment score is Ms. Social Studies with three supporting teachers (Mr. Language Arts, Ms. Math, and Ms. Third B). Table 17 above summarizes the process of creating the extreme groups for maturity of judgment, with the anchors in bold font and the final row showing the consolidated extreme groups formed for comparing teaching styles.

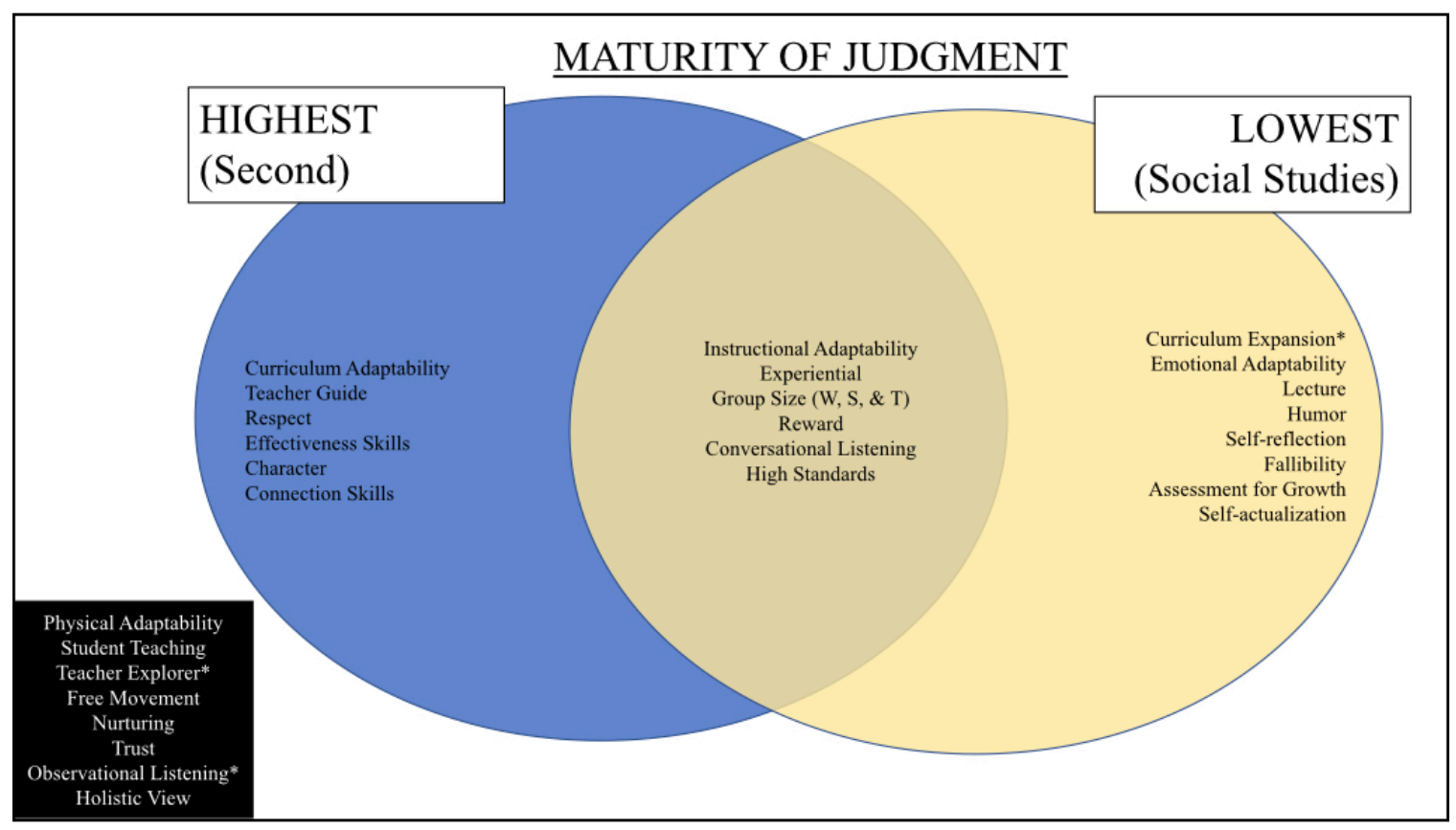

Figure 19

Maturity of Judgment Cross-Case Synthesis of Teaching Styles 
Teaching style. Figure 19 above summarizes the cross-case analysis for teaching styles between the anchors for maturity of judgment, Ms. Second (high) and Ms. Social Studies (low). In terms of adaptability, they both adapt instruction; however, Ms. Social Studies (low) also adapts to the emotional needs of her students and expands the curriculum while Ms. Second (high) adapts the curriculum in the basic way discussed previously. Even though all the low-scoring teachers adapted to the emotional needs of their students like the low-scoring anchor (Ms. Social Studies), all of the high-scoring support teachers (Ms. K and Ms. Third A) also adapted to the emotional needs of their students. Therefore, emotional adaptation was not a consistent distinction between Ms. Social Studies (low) and Ms. Second (high). Ms. Social Studies (low) was the only teacher participant who lectured; therefore, it is no surprise that this arose as a distinction between her teaching style and Ms. Second's (high) guiding style. Ms. Social Studies (low) along with two of the three supporting teachers (Ms. Math and Mr. Language Arts) used humor to connect to their students. Interestingly, the one low-scoring teacher who did not use humor, Ms. Third B, was the only one who is not a middle school teacher. On the other hand, Ms. Second (high) spoke a lot about respect as a way to connect with her students. This was supported by one other high-scoring teacher (Ms. Third A) and a lowscoring teacher (Ms. Third B). In comparing the growth-oriented teaching styles, while both teachers exhibited high standards, Ms. Social Studies (low) also expressed selfreflection, promoted fallibility, and used assessment for growth. These were partially supported by her low-scoring support teachers, but fully supported by the two highscoring support teachers. Possibly the most interesting finding, none of the high-scoring group expressed self-actualization as a highest hope for their students, yet the three 
lowest scoring teachers expressed self-actualization. Actually, Ms. Social Studies (low) only expressed self-actualization, whereas Ms. Second (high) expressed all highest hopes except for self-actualization. Because Ms. Third B (supporting low) did not express selfactualization like the other three teachers in the low extreme group, it is not listed as one of the consistent findings. However, because it was very close, it is a promising question for future research.

In looking at the teaching style framework emerging from the qualitative data analysis, there were four highest hopes teachers expressed: effectiveness skills, character, connection skills, and self-actualization. The most tangible ones that seem easier to measure are effectiveness skills and connection skills. It is harder to measure or to see evidence for self-actualization in students. Maybe the highest scoring teachers all exhibited effectiveness and connection because maturity of judgment is a practical and action-oriented critical thinking disposition that calls for timely decision-making in the face of complex and incomplete information. Meanwhile, the lowest scoring teachers exhibited the more abstract and harder to measure self-actualization. There were no consistent relationships in the present study between maturity of judgment and these highest hopes because the teachers in the extreme groups that were closer to the mean did not follow this pattern. The inability to see this relationship may be due to the small sample size and nature of the research design.

Previously Ms. Second's teaching style was compared to Ms. K's style when discussing inquisitiveness and analyticity where they were on opposite ends of the scores. For maturity of judgment, however, they both scored high. Teacher guide strategies were evident extensively in the high extreme group's (Ms. Second, Ms. K, and Ms. Third A) 
teaching styles. Ms. Second (high) never answered a student question, but rather ensured that students understand the given information and then gave them ample thinking time. Ms. K (supporting high) dialogued with her students to encourage critical thinking. She would even self-dialogue, pretending to be both student and teacher, to show students the process. Ms. Third A (supporting high) would direct students to the area of the text where they would find their answers. All three teachers who scored high on maturity of judgment guided students with questions rather than providing direct answers.

As mentioned earlier, Ms. Second (high) emphasized during the interview the importance of making the right decision at the right time. This is very much aligned with maturity of judgment, which means the disposition to see the complexity of issues and striving to make timely decisions. Ms. Second scored low on analyticity, which means that she scored low on the tendency to see the outcome of current actions or plans. Essentially, Ms. Second's scores reflect that she knows issues are complex, wants to make decisions in a timely manner, yet may not appropriately anticipate the outcome. When asked how she prepares her students to make these timely and accurate decisions later in life, Ms. Second responded with a few of her teaching style methods. First, she provides the students with the information they need to solve problems. Then, she gives them time. During the observations, it was clear that Ms. Second does not answer student questions in the way Ms. Fifth did not either. The thinking time, as mentioned previously was a striking feature in her classroom and in our interview conversation.

Interestingly, Ms. Social Studies, who scored the lowest on maturity of judgment (32), was the only teacher who did not exhibit teacher guide strategies. Rather, she lectured and answered questions directly. During the observations, she would ask 
knowledge-based questions and call on students to provide the answer, moving on to other students when the answers were not readily produced. The lecturing style and knowledge-based questions is aligned with lower tendencies to see the complexity of issues, namely maturity of judgment.

Maturity of judgment was also Ms. Math (36) and Mr. Language Arts' (35) lowest score. Ms. Math's strongest disposition is inquisitiveness (58), while Mr. Language Arts' strongest disposition is confidence in reasoning (52). Both inquisitiveness and confidence in reasoning are theoretically opposite to maturity of judgment. Inquisitiveness is the disposition of asking questions and seeking knowledge that is not obviously relevant now. Because maturity of judgment is one of the practical critical thinking dispositions that support timely decision-making, inquisitiveness can interfere with that timely component. Confidence in reasoning is the trust in reflective processes as opposed to an aversion to careful reasoning. The same distinction occurs between confidence in reasoning and maturity of judgment, where too much reflective thinking interferes with the timely decision-making, whereas someone who does not have a strong disposition towards confidence in reasoning would make a quick and careless decision.

In terms of teaching style, Ms. Math (supporting low) spoke extensively about adapting teaching to student needs. She said that she does not give up and she changes the way she gives the information until each student understands. Sometimes that means solving a problem five different ways. She also integrates real-life examples and handson lessons to help students learn without realizing they are learning. For example, she had them bring in receipts from their family's recent purchases to learn about percentages. 
They calculated the sales and the taxes. On another occasion, she had them bring in items to sell to their classmates. During the interview, Ms. Math said that they were doing three or four step problems without even feeling it. While her teaching style is engaging and adaptable, such activities take time. Ms. Math mentioned how they reworked the schedule to allow two periods of math on some days of the week because she was not getting through the curriculum. After seeing her low maturity of judgment score in relation to her other scores, I wonder if her need for extra time and her engaging activities are reflections of this weaker critical thinking disposition.

Mr. Language Arts (supporting low) similarly had an interesting take on timeliness. He would engage in discussions that seem in line with his strong confidence in reasoning and simultaneously in line with his weaker maturity of judgment. Even though confidence in reasoning, which was his strongest disposition, is a trust in reflective process, Mr. Language Arts spoke repeatedly about getting his students to learn without realizing it, almost like he intentionally sneaks in the lessons. It feels like a big public relations campaign in Mr. Language Arts' class, where he uses gimmicks to reach objectives without informing the students of his end goal and he creates a sense of control using "controlled choice" where he allows them to choose between already approved options. Mr. Language Arts' methods do not seem in line with a trust in reflective processes if it is tricking the students into believing they are thinking on their own and choosing the direction of the conversation. Consequently, the hidden lessons and controlled choice methods incite questions about democratic norms of openness and publicity. Even if his purpose is beneficial to the students, is it not their right to be informed? While interesting to note, exploring the impact of these teaching styles on the 
democratic values of students was beyond the scope of the present study and is an important question for future research.

\section{Cross-Case Syntheses}

The 7 cross-case analyses ( 1 for each critical thinking disposition) resulted in 10 distinctions, 6 absent styles, and 6 similarities in teaching styles between the extreme groups for each critical thinking dispositions. Figure 20 below illustrates the 10 consistent distinctions in teaching styles for all high-scoring teachers. These were the teaching styles that were bolded in the Venn diagrams throughout this chapter.

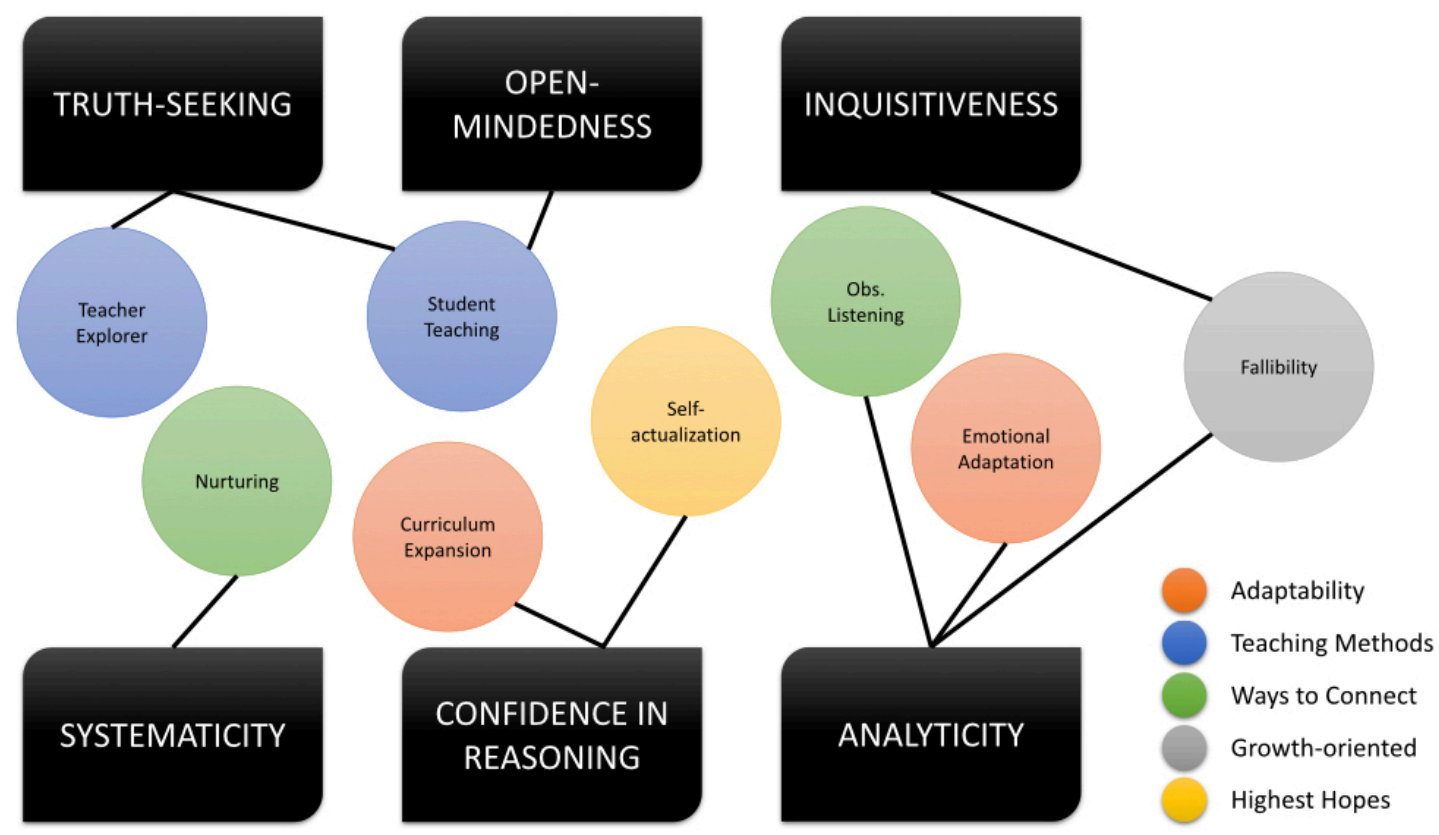

Figure 20

Relationships of Critical Thinking Dispositions to Teaching Styles

The critical thinking disposition of maturity of judgment did not result in a consistent finding, and therefore, is not in the above graphic. The 10 consistent distinctions were: 
1. Truth-seeking and Teacher Explorer

2. Truth-seeking and Student Teaching

3. Open-mindedness and Student Teaching

4. Inquisitiveness and Fallibility

5. Analyticity and Fallibility

6. Analyticity and Emotional Adaptability

7. Analyticity and Observational Listening

8. Confidence in Reasoning and Curriculum Expansion

9. Confidence in Reasoning and Self-actualization

10. Systematicity and Nurturing

The teaching styles emerging from the first phase of analysis (Chapter Four) were categorized under five themes. The key on the bottom right of Figure 20 indicates the color coding of the teaching styles for each theme. Truth-seeking and open-mindedness were only associated with teaching styles in the "teaching methods" theme.

Inquisitiveness was only associated with a teaching style in the "growth-oriented" theme. Systematicity was only associated with a teaching style in the "ways to connect" theme. Meanwhile, confidence in reasoning showed consistent relationship with styles from the "adaptability" and "highest hopes" themes. Finally, analyticity was consistently related to "adaptability," "ways to connect," and "growth-oriented" themes.

Besides the 10 consistent findings relating strong critical thinking dispositions to teaching styles, the cross-case analyses also indicated 6 teaching styles that were consistently absent from both high and low scoring teachers on some of the dispositions. 
Figure 21 below illustrates the missing teaching styles for each disposition from all teachers of both extreme groups - high and low, anchors and supporting.
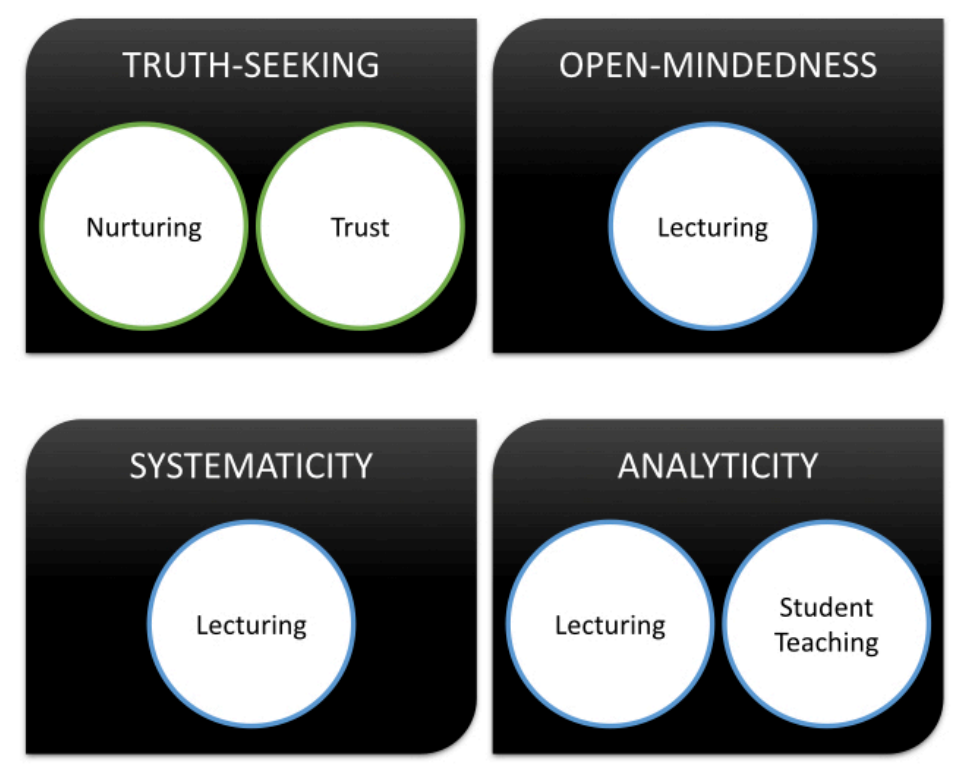

Teaching Methods Ways to Connect

Figure 21

Absent Styles Between Critical Thinking Dispositions and Teaching Styles

The same color coding from Figure 20 applies to Figure 21. Interestingly, there was a consistency to the teaching style theme absent from each disposition. For example, neither high-scoring nor low-scoring teachers on truth-seeking utilized two teaching styles falling under the same theme, "ways to connect." Similarly, the extreme cases for open-mindedness, systematicity, and analyticity did not utilize teaching styles from the same theme_- "teaching methods.” Only one teacher exhibited lecturing (Ms. Social Studies) and one teacher exhibited student teaching (Ms. Fifth). Therefore, the consistently absent results for analyticity merely indicates that neither Ms. Fifth nor Ms. Social Studies had extreme scores for this disposition. Similarly, the consistently absent result of lecturing style for systematicity and open-mindedness indicates that Ms. Social 
Studies did not score high or low on these disposition subscales. Due to the small sample size, lecturing and student teaching were only represented by one teacher each and point to a limitation of the present study that can be mitigated by future research.

Finally, the cross-case analyses also indicated six teaching styles that were consistently similar between all the anchors for each critical thinking disposition. In other words, there were six teaching styles listed on the overlap in every single Venn diagram. These six teaching styles were: instructional adaptability, group size whole, group size team, experiential teaching methods, conversational listening, and high standards. All of these teaching styles were exhibited by the majority of teachers, some were even unanimously exhibited by all 10 teachers; accordingly, the five recurring styles were always a similarity between the anchors of the extreme groups, yet not unanimously supported by all teachers within the extreme group.

\section{Summary}

The CCTDI scores for the 10 case studies were described in detail. Extreme case sampling of the case studies resulted in two groups for each of the seven dispositions (high-scoring and low-scoring), which was then used to perform a cross-case analysis of teaching styles. The results of the seven cross-case analyses were 10 unanimous distinctions, 6 unanimous voids, and 6 similarities in teaching styles between the extreme scoring groups. These findings are summarized under the final section of this chapter labeled "cross-case syntheses." The limitations and implications of these findings is discussed in the subsequent chapter. 


\section{CHAPTER SIX}

\section{DISCUSSION}

"The day they decided that Sneetches are Sneetches And no kind of Sneetch is the best on the beaches.

That day, all the Sneetches forgot about stars And whether they had one, or not, upon thars" (p. 19).

Dr. Seuss, The Sneetches, 1961

Through the review of the literature, the present study asserted that critical thinking dispositions are important for democracy (Gutmann \& Thompson, 2004; Habermas, 1998; Mill, 1859/1991) and schools must be tasked with developing future citizens of our democracy (Barber, 1997; Westbrook, 1996). It was also asserted that critical thinking dispositions can be taught through interactions that promote them as opposed to limiting it to direct instruction or certain subjects. Rather, critical thinking should be infused throughout all academic subjects at all grade levels (Facione, 1990). Therefore, the purpose of the present study was to explore the relationship between critical thinking dispositions and teaching styles. Through cross-case analyses of multiple mixed methods case studies, the following consistent findings relating critical thinking to teaching styles emerged: 10 distinctions, 6 absent styles, and 6 similarities. This chapter outlines the results, limitations, recommendations for future research, the implications for research, the implications for theory, and the implications for practice.

\section{Results: Distinctions}

Emerging from the cross-case analyses, 10 distinctions in teaching styles were consistent between extreme scoring teachers on the critical thinking dispositions. Each distinction is discussed in detail below and organized in the following way: definition of 
critical thinking disposition, connection of the concepts to education for democracy, alignment of the finding with the hypotheses, and possible explanations for the finding.

\section{Distinction \#1: Truth-seeking and Teacher Explorer}

Emerging from the cross-case analysis was a new teaching style category, teacher explorer. While initially viewed as teacher guiding methods, it became evident that distinguishing the explorer was important in comparing teaching styles based on highand low-scores in critical thinking dispositions. Teacher explorer was defined as a teacher who engages in discourse with students without having a predetermined outcome, but rather develops the learning outcome in collaboration with the students. The findings of the present study indicated that the teachers with a strong disposition towards truthseeking consistently exhibited the teacher explorer style. A truth-seeking disposition is defined according to the CCTDI as:

...the habit of always desiring the best possible understanding of any given situation; it is following reasons and evidence where ever they may lead, even if they lead one to question cherished beliefs. Truth-seekers ask hard, sometimes even frightening questions; they do not ignore relevant details; they strive not to let bias or preconception color their search for knowledge and truth. The opposite of truth-seeking [sic] is bias which ignores good reasons and relevant evidence in order not to have to face difficult ideas (Insight Assessment website).

As discussed in the early chapters, democracy is co-creating our society through open dialogue accessible to all citizens. Habermas' (1998) criteria for judging the validity of arguments reflect the importance of truth-seeking for open democratic discourse.

Similarly, Westheimer and Kahne (2004) assert that the justice-oriented citizen, their interpretation of the "good citizen," should consider "the evidence of experts" (p. 243). Thus, through the review of the literature, the importance of a truth-seeking disposition was established. It is also evident that a teacher explorer models this co-creating of 
outcomes that democratic living requires. In the discussions that teacher explorers encourage, they expect students to support their contributions with reason and evidence. This is again in line with Habermas (1998). Teacher explorer is about leading students in a discussion without intentionally guiding them to a specific thought, but rather only guiding the methods of discussing. Similarly, Mill's (1859/1991) assertion is that the interaction of diverse ideas leads to the greatest truth and this leads society to progress, thus the justification for freedom and democracy.

The expectations prior to data collection for strong truth-seeking teachers, as outlined in the review of the literature, were as follows:

1. Expose students to competing points of view or various methods of reaching a solution

2. Ask discussion-promoting questions

3. Allow lively debates between competing viewpoints

4. Uphold criteria for creating valid arguments, relying on facts as opposed to opinions

5. Guide students to research a topic

6. Model self-reflective practices

The findings supported my hypotheses. A teacher explorer incorporates the six hypotheses expressed.

In trying to understand why a teacher with a strong disposition towards truthseeking also uses teacher explorer methods, a look at truth-seeking's definition provides great insight: "following reasons and evidence where ever they may lead" (Insight Assessment website). Consequently, a teacher explorer is following the reasons and 
evidence produced by students wherever they may lead. It is reasonable to hypothesize from this finding that teacher explorer methods may potentially develop truth-seeking tendencies in students.

\section{Distinction \#2: Truth-seeking and Student Teaching}

Through the cross-case analysis, there was a positive relationship between truthseeking and student teaching. Similar to teacher explorer, student teaching allows the students to lead the conversation on a given topic. The students in Ms. Fifth's class frequently presented. During one observation, they were tasked with doing their own research from reputable sources and presenting the material requested. The teacher asked for the sources and how they know they can trust their sources. This process is aligned to education for democracy in several aspects. First, the emphasis on trustworthy sources is in line with two of Habermas' (1998) criteria for assessing the validity of an argumenttruthfulness and justifiability. Students are expected to make truthful statements supported by evidence. Next, practicing presenting information in front of the class is in line with a third of Habermas' (1998) criteria - intelligibility. Therefore, student teaching develops important qualities necessary for democratic living. Consequently, a teacher who has a strong disposition towards truth-seeking would promote her students to follow reasons and evidence, as the definition for truth-seeking above states and as Habermas (1998) asserts as necessary for proper deliberation in a democracy.

In addition to incorporating competing points of view and leading discussion, my expectations for teaching that promoted truth-seeking also included teachers expecting students to uphold certain criteria for creating valid arguments, similar to Habermas' (1998) validity claims, such that students cannot be dishonest or make claims without 
supporting evidence. This may, thus, require the teacher to guide students to research a topic. Consequently, a teacher who models self-reflective practices would theoretically be teaching students to examine their own biases, not unlike quality qualitative research (Merriam, 2002), and uphold a standard of relying on facts rather than opinions. Accordingly, the finding that student teaching was related to a high truth-seeking disposition supports my hypotheses.

Exploring possible reasons for this finding, it is not hard to see the connection between a teacher with a strong tendency to follow facts and a teacher who incorporates student teaching in the way Ms. Fifth did. Not only did she assign them to research and follow the evidence, she also asked them to explain the validity of their information and sources. This finding sheds light on a teaching style that, if implemented well, may be clearly connected to developing truth-seeking in students, thus forming a hypothesis for future research.

\section{Distinction \#3: Open-mindedness and Student Teaching}

The results of the cross-case analysis supported a positive association between

open-mindedness and student teaching. Open-mindedness is defined below as:

...the tendency to allow others to voice views with which one may not agree. Open-minded people act with tolerance toward the opinions of others, knowing that often we all hold beliefs which make sense only from our own perspectives. Open-mindedness, as used here, is important for harmony in a pluralistic and complex society where people approach issues from different religious, political, social, family, cultural, and personal backgrounds. The opposite of openmindedness is intolerance (Insight Assessment website).

The link between open-mindedness and democracy was discussed in the review of the literature. As Mill (1859/1991) contends, even an outrageous opinion is valuable to a society because it challenges others to strengthen their arguments and, as a result, their 
convictions and resolve. For someone to be willing to even hear an outrageous opinion, let alone a valid different opinion, he/she must possess this disposition towards openmindedness. Meanwhile, the qualities of student teaching and promoting important qualities for democracy were discussed in the latter section for the second distinction, namely that student teaching implemented well is in line with Habermas' (1998) validity claims.

My hypotheses for teaching styles of teachers with strong open-mindedness were as follows:

\section{Listening}

2. Allowing all opinions and ideas generated by students

3. Allowing expression of uncommon perspectives in text or spoken by students, even if the teacher disagrees

4. Responding against intolerance by students towards idea or others

5. Having implicit or explicit rules for civil discourse such as listening carefully as others speak and disagreeing using validity claims (not intolerant opinions)

Student teaching may incorporate many of my hypotheses, but not necessarily. Student teaching is essentially the teacher sitting and listening to the students presenting. It is also a platform for students to express themselves; however, it depends on the teacher. Does the teacher allow for a free expression of ideas or restrict students with a prescribed formula for presenting? For example, Ms. Fifth allowed the students to research a topic they select from sources they select. Some teachers allow students to teach the class, but only from the classroom text. Ms. Fifth's student teaching style does align with my hypothesis, whereas the latter hypothetical example would not. Similarly, the final 
hypotheses stated describe most teachers' rules with regard to listening carefully to

fellow classmates presenting and disagreeing civilly with supporting evidence. However, it is not a necessary component of student teaching. Therefore, detailing conditions for effective student teaching that promotes open-mindedness may be helpful. Similar to its relationship with truth-seeking, this finding generated a hypothesis of effective student teaching developing open-mindedness in students.

\section{Distinction \#4: Inquisitiveness and Fallibility}

The fourth distinction emerging consistently in the cross-case analysis was between high inquisitiveness and fallibility. Inquisitiveness was defined as:

...intellectual curiosity. It is the tendency to want to know things, even if they are not immediately or obviously useful. It is being curious and eager to acquire new knowledge and to learn the explanations for things even when the applications of that new learning are not immediately apparent. The opposite of inquisitiveness is indifference (Insight Assessment website).

As established previously, inquisitiveness is important for Millian (1859/1991)

democracy because inquisitiveness is the disposition that leads to innovative ideas.

Inquisitiveness is the human condition that leads to diverse ways of living, which is what Mill contends is conducive to the greatest societal progress.

Fallibility emerged as a teaching style during the qualitative data analysis. It was defined as the teachers' openness in sharing their own mistakes with students. It was also evident in the intentionality in creating a safe space for student mistakes and an emphasis on effort over results. Consequently, the fallibility teaching style indicated an important trait for democratic living. Fallibility presented itself in various ways throughout the data. First, students who were unable to sit with their own mistakes lacked the initiative to try. This obviously leads to constricted growth, but for a democratic society, this leads to a 
lack of innovation and progress. As Mill (1859/1991) quotes Wilhelm von Humboldt, "The end of man...is the highest and most harmonious development of his powers to a complete and consistent whole" and therefore, every human being must direct his efforts on "the individuality of power and development" (p. 61). Second, some students were so confident in their own positions that they were unable and unwilling to hear guidance from anyone, even the teacher. One student would not even believe his teacher when she told him that there are carrots in carrot cake. This lack of openness to their own fallibility translated into a lack of openness to grow personally and a lack of openness to any different viewpoints. For democracy, if one individual does not grow, the entire society loses out on their potential contribution to progress. Meanwhile, if an individual lacks the open-mindedness necessary for democratic discourse, the interchange of ideas that build upon one another is compromised.

Prior to data collection, I detailed my expectations for teaching styles that would develop inquisitiveness, which included:

1. Making students feel comfortable and safe to ask questions

2. Not demeaning or insulting a student for asking "irrelevant" questions

3. Responding positively to behaviors that exhibit inquisitiveness even if the teacher cannot engage it currently

4. Encouraging students to research topics of interest and share with the class

5. Following student-led questions sometimes

The findings from the present study support the first three hypotheses because fallibility was defined as a teacher who intentionally created a safe space. I did expect more 
teaching styles to relate to inquisitiveness such as student teaching or curriculum

expansion; however, those other relationships were not consistent.

Possible explanations for this relationship may be related to the experiences of someone who has a strong inquisitive disposition. This person, theoretically, explores ideas and asks questions that are not immediately relevant. Therefore, there is a great possibility of often reaching intellectual dead ends or ending up somewhere unexpected. That experience of walking an intellectual path while not knowing the end, having to adapt, and potentially turning back is parallel to fallibility. Consequently, there is an overlapping experience between an inquisitive person and a person who accepts fallibility. This distinction generated a hypothesis for future research about a teacher who promotes a positive relationship with fallibility developing inquisitiveness tendencies in students, such as taking intellectual risks and exploring ideas freely.

\section{Distinction \#5: Analyticity and Fallibility}

Analyticity and fallibility emerged as another consistent positive relationship in

the cross-case analysis. Analyticity is defined below as:

...the tendency to be alert to what happens next. This is the habit of striving to anticipate both the good and the bad potential consequences or outcomes of situations, choices, proposals, and plans. The opposite of analyticity is being heedless of consequences, not attending to what happens next when one makes choices or accepts ideas uncritically (Insight Assessment website).

Because Mill's (1859/1991) goal is societal change or progress, analyticity is very important. Free discourse is a means to developing ideas and plans for future possibilities. Therefore, the potential consequences of ideas must always be considered. Free discourse without analyticity is incomplete because it would mean passing around ideas without considering the real-life practical impact of implementing these ideas. 
Hence, analyticity should guide discussions and while people may disagree about possible outcomes of decisions, a consideration of outcomes is necessary. Similarly, Westheimer and Kahne's (2004) justice-oriented citizen is one who analyzes past causes for current conditions and proposes solutions for future resolution; therefore, a strong disposition towards analyticity is necessary for such analysis and planning.

Fallibility was truly a surprising teaching style that emerged through the qualitative data analysis, and even more so, its connection to education for democracy. Fallibility is about a person's perception and reaction to their own mistakes and the mistakes of others. In a liberal deliberative democratic society, citizens are expected to appreciate diversity and openly engage with diversity with the intention of improving plans and decisions. Mill (1859/1991) contends that even an outrageous idea is beneficial to democratic discourse because it allows others to solidify their own arguments. However, he ultimately argues that all ideas have some useful parts (which he calls truths) and the combination of these parts can ultimately develop an idea with greater benefit. Why is fallibility relevant? Fallibility creates a safe space for people to explore diverse ideas and share those explorations without fear of being ostracized or shamed. Mill (1859/1991) contends that wise men have made a habit of listening to criticism and correcting themselves. A positive relationship with fallibility is essential for this type of intellectual growth and maturity. Thus, fallibility makes personal growth possible, which has been repeatedly established as important for democracy throughout the present study, and makes sharing the benefits of personal growth possible (Mill, 1859/1991).

A person who is strong in analyticity can not only anticipate possible outcomes, but can also reflect on the impact of his/her past actions. This type of thinking is more 
empowering than someone who does not have the tendency to connect actions to outcomes. It is possible that individuals with weaker analyticity attribute mishaps to outside forces beyond their control. Therefore, acknowledging one's own past mistakes (fallibility) creates a sense of empowerment because the individual can change outcomes by changing actions. This is in line with a democratic ideology that the people have the power to govern themselves.

Prior to data collection, I outlined in the review of the literature my expectations of possible teaching styles that may emerge for teachers with a stronger disposition towards analyticity as follows:

1. Discussing connection between policy and results (history)

2. Discussing possible alternative outcomes based on changes to policy decisions

3. Entertaining solution outcomes using different methods (math)

4. Asking students to anticipate the outcome of a story (literature)

5. Imagining various endings to the same story (literature)

6. Producing their own story

7. Following through on classroom rules and consequences

Consequently, this result of analyticity relating to fallibility did not support my hypotheses. The only minor connection to my hypotheses is a teacher looking at historical mistakes and outcomes; however, fallibility was about personal mistakes currently occurring, not societal mistakes over time.

What possible reasons would teachers who have a strong disposition towards striving to anticipate "both the good and the bad potential consequences" also have a positive relationship with fallibility and accepting mistakes from themselves and their 
students? It may be that in anticipating outcomes, these teachers already see the possibility of making mistakes. Therefore, it is not a surprise when it occurs. If someone has the tendency to do this, they become accustomed to sometimes missing the mark. Rather, if someone always expects perfect results, having a lower disposition towards analyticity, then mistakes always disappoint. Accordingly, a teacher with a strong disposition towards analyticity would also see the potential outcomes of students who get stuck on mistakes and stop growing versus students who take it lightly and try again.

\section{Distinction \#6: Analyticity and Emotional Adaptability}

The cross-case analysis indicated a consistent relationship between analyticity and teachers adapting to the emotional needs of the students. Analyticity's importance for democracy was established in the latter section.

How is emotional adaptability relevant to democracy? Referring back to Mill's (1859/1991) reliance on Wilhelm von Humboldt's discussion about people reaching their potential, emotional obstacles can hinder that development process. Accordingly, the entire society loses when any member does not fully develop to their own potential. Thus, adapting to the emotional needs of oneself and of others is a beneficial ability in citizens of a democracy. By so doing, the hope is improving each other's access to effective democratic processes and increasing the equality of opportunity. Emotional adaptability is at its essence acknowledging the benefit of emotions as guides to important and relevant human needs. To acknowledge another's emotions as important sends a strong message of inclusion and a strong message of the high value of every human being, which is an important notion for a democratic society. A democratic society that values individual liberty and diversity would ideally listen deeply to all members and care about 
each person's contribution because the greater the diversity, the closer to truth, and greater progress we all make (Mill, 1859/1991).

Referring to the hypotheses stated for analyticity in the latter section, this finding that teachers with strong analyticity tendencies are consistently emotionally adaptive did not support my hypotheses. However, in looking closer at the high-scoring teachers, some of their observed teaching styles did support my hypotheses. For example, Ms. K did have her students anticipate the next event as she read the class a story. Ms. Math demonstrated several methods to solve the same problem and, also, supported students' attempts to use unique methods.

In terms of understanding analyticity's connection to an emotionally adaptive teaching style, a teacher must first notice the emotional state of her students to then adapt to improve it. Analyticity is aligned with adapting because the teacher must anticipate the possible outcome of maintaining current plans and, also, anticipate the outcome of implementing a different plan. This, however, could theoretically apply to any form of teacher adaptability. Maybe the reason emotional adaptability showed this consistent relationship with analyticity as opposed to other adaptable teaching styles is because it takes a stronger disposition towards analyticity to anticipate emotional outcomes as opposed to academic or physical ones.

The results of the present study seem to say nothing about the possibility that emotional adaptability would in any way promote analyticity in students. However, a teacher who does adapt to the emotional needs of students is making an important implicit statement about the importance of that human being to the classroom 
community. The teacher who adapts is listening and caring deeply about each student and modeling qualities important for a vibrant and healthy democratic society.

\section{Distinction \#7: Analyticity and Observational Listening}

The seventh consistent distinction emerging from the cross-case analysis was between a high disposition for analyticity and observational listening. As discussed previously, listening was divided into observational and conversational listening after the cross-case analysis. In the qualitative analysis phase, these two concepts were merged. However, after analyzing teaching styles based on CCTDI subscale scores, observational listening surfaced as an important distinction in listening. Observational listening is deeper and broader, not limited to only conversational listening for interpersonal connection to students. Teachers who used observational listening looked and listened for clues about their students to adapt to their particular needs.

This type of listening is aligned with the democratic discourse outlined in the present study because its goal is progress (achievement), not just community-building. This is aligned with Mill's (1859/1991) discussion about people whose judgment is deserving of more confidence than others because they have done more internal "building." Mill contends that it is because these individuals have been open-minded and accepting of criticism. These individuals have made a habit of listening to whatever others with various opinions have said against them and made a habit of "correcting and completing" their own opinions. "No wise man ever acquired his wisdom in any mode but this; nor is it in the nature of human intellect to become wise in any other manner" (Mill, 1859/1991, p. 25). This individual example is the building block of progress for society. Great ideas that led to societal progress originated from an individual or a 
combination of individual contributions to a field. Improving the quality and value of an individual's opinions and ideas requires certain habits of mind, openness to diverse opinions (open-mindedness) and openness to criticism of oneself (fallibility). Similarly, a teacher who is listening with the intention of adapting her current teaching is following the same example. She is open to her own fallibility as a teacher and is willing to adjust to become more effective.

In looking at my pre-data collection expectations for teaching styles that would emerge for teachers who scored high in analyticity, this finding did not support those hypotheses. Trying to understand this relationship, a teacher who has a strong disposition for analyticity would theoretically have an understanding that her current actions as a teacher will yield different student results, and therefore, to improve the outcomes, adjustments to current actions should be based on data. Observational listening is essentially data collection for teachers. While observational listening potentially changes student outcomes, it is unclear how observational listening would develop analyticity in students. Therefore, this distinction that teachers strong in analyticity consistently listen for observation does not seem to generate a reverse hypothesis for students developing analyticity because of observational listening.

\section{Distinction \#8: Systematicity and Nurturing}

One of the more surprising relationships that emerged is that teachers who scored high on systematicity consistently exhibited a nurturing teaching style. Systematicity was defined in the CCTDI as: 
...the tendency or habit of striving to approach problems in a disciplined, orderly, and systematic way. The habit of being disorganized is the opposite tendency. The person who is strong in systematicity may not know of a given approach, or may not be skilled at using a given strategy of problem solving, but that person has the desire and tendency to try to approach questions and issues in an organized and orderly way (Insight Assessment website).

As established in the review of the literature, deliberative democracy (Gutmann \& Thompson, 2004; Habermas, 1998) is an example of applying systematicity to Mill's (1859/1991) theoretical notions of liberal democracy. For example, Habermas (1998) outlined tenets for deliberation, such as the validity claims. These are structures to approach democratic deliberation in an orderly and systematic way.

Through the qualitative data analysis, nurturing emerged as a teaching style where teachers showed care for the students' needs and used endearing terms such as "honey" or "sweetie." While using endearing terms is not necessary for effective democratic discourse, the terms were merely a reflection of the nurturing nature and essentially, nurturing is a reflection of care for others. Consequently, caring for others is an important component of democratic living. While America is generally considered a liberal democracy, it also has components of a republican democracy such as homogeneity and solidarity (Plattner, 1998; Tocqueville, 2002; Smith, 1993). And while liberal democratic thought values individual liberty above all, republican democratic thought, on the other hand, focuses more on the collective. Schmitter and Karl (1991) contend that applying either conception to the extreme could undermine democracy. Nurturing is in line with the collective concepts of republican democratic thought. This discussion can also be applied to the emotional adaptability teaching style. 
While I would initially assume that nurturing may be related to a strong openmindedness disposition, systematicity was an unexpected result. My hypotheses for teaching styles that would reflect or develop strong systematicity were:

1. Structured classroom processes

2. Approaching questions in an orderly way

3. Clear steps for writing essays

4. Clear criteria for quality

Therefore, my hypotheses were not supported by this result.

The teachers in the present study all expressed a deep care for their students' wellbeing, even though they did not all express it in nurturing interactions with their students. One explanation is that a strong disposition towards systematicity means that classroom management probably comes easier for this teacher. Better classroom management means easier flow, and if creating those systems occurs with ease, then the teacher has a greater capacity for nurturing. On the other hand, a low systematicity score may indicate that classroom management is a difficult task. This could mean that there is poor classroom management, which translates into increased stress for the teacher. It could also mean that while a teacher maintains good classroom management, it is harder and does not come so naturally, which again translates into greater stress. Therefore, classroom management may cause more stress for the low-scoring teacher, thus compromising on the nurturing. For example, Ms. Second, the lowest scoring teacher on systematicity, had one of the most orderly classrooms; however, her interactions with the students lacked in nurturing. This explanation can explain why a nurturing person who has a weak disposition towards systematicity may not exhibit nurturing due to stress. However, there 
is an assumption that there is a capacity for nurturing that is merely not expressed.

Another perspective, the nurturing teachers may see the orderliness and structure as a gesture of care for their students' well-being. Interestingly, in their research entitled, “Growing a Nurturing Classroom,” Boorn, Dunn, and Page (2010) describe, “A nurturing classroom has a planned routine to provide a predictable, reliable structure in which the children feel safe and cared for, so that they begin to trust the adults, to explore and to learn" (p. 312).

It is unclear how nurturing teaching styles would develop systematicity in students; therefore, is harder to grasp. Initially, nurturing teaching styles seem unlikely to develop systematicity. Rather, it seems that the benefit of this finding may be to understand conditions conducive for nurturing styles to be expressed. However, after seeing the research about growing a nurturing classroom, it seems plausible that creating that time of orderly classroom environment creates a predictable environment and aids in developing trust. The classroom is an extension of a healthy home environment. Therefore, this level of nurturing may theoretically develop dispositions towards systematicity.

\section{Distinction \#9: Confidence in Reasoning and Curriculum Expansion}

Teachers who scored high in confidence in reasoning consistently expanded the curriculum. The definition of confidence in reasoning is as follows: 
...the habitual tendency to trust reflective thinking to solve problems and to make decisions. As with the other attributes measured here, confidence in reasoning applies to individuals and to groups. A family, team, office, community, or society can be trustful of reasoned judgment as the means of solving problems and reaching goals. The opposite habit is mistrust of reasoning, often manifested as aversion to the use of careful reason and reflection when making decisions or deciding what to believe or do (Insight Assessment website).

A foundation of freedom is the trust of human intellect and ability to make decisions. In a free society where power is in the hands of the people, confidence in reasoning is essential. Mill (1859/1991) warns about the dangers of basing decisions on opinions and whims and the potential for the pitfall of the tyranny of the majority as a result. Therefore, I contend that having citizens with a disposition towards reasoning is a safeguard against tyranny of the majority. Consequently, Westheimer and Kahne (2004) describe the justice-oriented citizen as "considering the evidence of experts, the analysis of government leaders... with the varied opinions and arguments...” (p. 243). McDevitt and Kiousis (2006) contend that having a truly open discourse that produces new ideas requires citizens to have confidence in the process, because in the process they must be willing to take risks and potentially be wrong. This is supported by Gutmann and Thompson's (2004) assertion that decisions in a deliberative democracy are provisional, thus allowing for revision of incorrect actions. Aligning with a confidence in reasoning disposition, Biesta (2006) asserts that citizens of a democracy must have a deep appreciation and understanding of democratic values, much so that they will not abandon reflective thinking and reasoned judgments because it is difficult or time-consuming. Rather, democratic people know the value of this process and trust the outcome as the best means to solving societal problems and achieving goals. 
Curriculum expansion was one of the three new styles that emerged from the second phase of data analysis. Initially a component of curriculum adaptation, it became evident that curriculum expansion was quite different in intent and potential outcome for student learning. Curriculum adaptation was defined as teachers who varied difficulty level, quantity, and expectations based on student achievement levels. However, curriculum expansion was indicated by a teacher who would integrate new information and go beyond the books to follow student interests or abilities. Curriculum expansion may relate to two aspects of Mill's (1859/1991) notions of democracy: the interaction of diverse viewpoints and the development of individuals. A teacher who integrates new perspectives on the content is exposing students to a variety of viewpoints and expanding their understanding around a topic. Ms. Science, the second highest scoring teacher on confidence in reasoning, expanded the curriculum by introducing higher level concepts to students because they were ready. Rather than stick to a prescribed curriculum based on general age recommendations, Ms. Science assessed her students' readiness for a concept and focused on their growth.

My hypotheses for teaching styles that would potentially develop or reflect confidence in reasoning were:

1. Encouraging students to think through a problem

2. Providing reasoning for decisions

3. Not providing answers, but rather offering information and guiding questions These hypotheses were not supported by this result. It seems possible that curriculum expansion teaching styles would develop confidence in reasoning dispositions in students; therefore, this is a possible hypothesis generated by this finding. It also seems 
possible that curriculum expansion styles may develop an inquisitiveness disposition in students. These are possible areas for future research.

\section{Distinction \#10: Confidence in Reasoning and Hope of Self-actualization}

Teachers who scored high in the CCTDI confidence in reasoning subscale consistently expressed self-actualization as one of their highest hopes for their students.

Self-actualization emerged as a teaching style across several teachers. Teachers who expressed self-actualization as a highest hope spoke about their students becoming their best selves and mastering their chosen field. As mentioned previously, Mill (1859/1991) quotes Wilhelm von Humboldt about human development. If each citizen of a democracy reaches self-actualization in their own unique way, progressing individually, then society will progress. The corollary is asserted by Maslow $(1943 / 2013)$ in that a democratic society ensuring individual liberty is a necessary condition for selfactualization to occur. Democratic discourse between people who have grown as individuals is more productive than democratic discourse between people who lack knowledge, experience, or wisdom.

My hypotheses for confidence in reasoning, stated in the latter distinction, were not supported by this finding as well. My hypotheses seem to all revolve around teaching guide styles, not necessarily self-actualization hopes. However, there is a clear theoretical link between the guiding teaching styles outlined in my hypotheses that train students to think through problems and being able to navigate life's challenges in discovering themselves. Nevertheless, it is unclear if having hopes of self-actualization for students would develop a confidence in reasoning unless those translated into teacher guide strategies. 


\section{Results: Absent Teaching Styles}

While the initial focus of the cross-case analyses was the distinctions in teaching styles between high- and low-scoring teachers on each disposition, I noticed six consistently absent relationships and began to question their importance.

\section{Absent Teaching Style \#1-2: Truth-seeking, Nurturing, and Trust}

Why was it that the extreme groups in truth-seeking consistently did not exhibit nurturing or trust? Teachers who had an average truth-seeking score exhibited nurturing and trust, yet the extremes consistently did not. One possibility may have to do with the fact that nurturing and trust are both ways of connecting to students. When one thinks of a truth-seeking individual who follows evidence wherever it may lead, trying to gain the best understanding of a given situation, the focus is not connecting to others. Maybe teachers who are high truth-seekers are focused on the intellectual pursuit, whereas nurturing is an emotional pursuit. The low truth-seeking individuals, on the other hand, do not follow evidence or seek greater understanding, but rather seeks to support their own biases. It may be possible that biases are an obstacle to connection. The findings do not say that truth-seeking individuals are not nurturing; rather, the findings say that the high truth-seeking and low truth-seeking teachers did not exhibit nurturing styles in the classroom. This is an area for future research.

\section{Absent Teaching Style \#3: Open-mindedness and Lecturing}

The extreme groups in open-mindedness, both high and low, did not lecture.

Lecturing does not seem to align with a highly open-minded teacher because lecturing is a one-way teaching style that does not engage the students in the same way discussionoriented styles do. Therefore, it theoretically makes sense that the high-scoring teachers 
on open-mindedness did not lecture. However, why did the low-scoring teachers not lecture? Ms. K was the lowest-scoring teacher on open-mindedness, which surprised me. She engaged in discussions with her students, listening carefully to their input. She incorporated multicultural perspectives throughout the year, teaching students about holidays from around the world even when not explicitly planned in the curriculum. She regularly integrated new material that expanded the curriculum. All of these teaching styles seemed to point to a high open-mindedness disposition.

One possible explanation for Ms. K is Adler's Compensation Theory, which states that people overcompensate for their weaknesses through hard work and focused effort until the weaknesses become super strengths (Vaughan, 1927). However, this does not explain why it was a consistent finding absent for all low-scoring teachers. Another explanation may be related to the small sample size. Only one teacher exhibited lecturing among the 10 case studies. Therefore, it would be less likely to see lecturing as opposed to other styles such as experiential teaching or teacher guide that were almost unanimous among the 10 teachers. Finally, another explanation may be that current trends in teacher training encourage teacher guide styles. Therefore, regardless of personal dispositions, lecturing is not as prevalent.

\section{Absent Teaching Style \#4: Systematicity and Lecturing}

The extreme groups in systematicity did not exhibit lecturing styles. The expectation was the contrary to open-mindedness in that a highly systematic person seems aligned with the lecturing style. However, the highest score in systematicity led her class in lively discussions. On the other hand, I would have expected a low-scoring teacher on systematicity to lecture. Still, Ms. Second, the lowest scoring teacher on 
systematicity, gave students the most thinking time of any other teacher and routinely guided students to discover answers on their own as opposed to providing them the answers. Is this relationship a product of the small sample size and the lack of examples of teachers who lecture? Or is this pointing to the teacher training trends towards guiding methods and thinking time?

\section{Absent Teaching Style \#5-6: Analyticity, Lecturing, and Student Teaching}

The extreme groups in analyticity did not lecture and did not have students teach. The findings of the present study are not conclusive and similarly cannot explain this relationship. However, there may be some insight in looking at teaching styles of the extreme scoring teachers for analyticity. The highest scoring teachers on analyticity were Ms. Math, Ms. Science, and Ms. K. It is not as prevalent to have students teach in a Math class or a kindergarten class. Therefore, the small sample size and lack of variability may be the reason for this finding.

On the other hand, Ms. Second was the lowest scoring teacher in analyticity, which I think may be related to her emphasis on thinking time for students. She focused a lot of the interview time on the importance of making the right decision at the right time. Maybe this points to Adler's Compensation Theory because she senses a weakness (analyticity) and is working to strengthen it. Thinking time is a teaching guide method as opposed to a lecturing style. While generalizations are beyond the scope of the present study, Ms. Second's data may be pointing to a relationship between a weak score that relates to a teaching style that works against that weakness for the benefit of students. This type of relationship was echoed by Ms. K's open-mindedness and Ms. Second's systematicity. 


\section{Results: Similarities}

There were six teaching styles that were listed in the overlap section of every Venn diagram. In other words, the high and low anchors for each of the seven dispositions' cross-case analysis exhibited these six teaching styles. Unlike the other two sets of results, these similarities are only reflected among the anchors, not the entire extreme groups. Thus, these similarities are not unanimous findings among all high- and low-scoring teachers, merely the highest and lowest on each disposition score.

The six similar styles were: instructional adaptability, experiential methods, group size whole, group size team, conversational listening, and high standards. Instructional adaptability, team group size, and high standards were exhibited by 9 out of the 10 cases. Whole group size, experiential teaching methods, and conversational listening were exhibited by all 10 teacher cases. Consequently, these teaching styles were very likely to be consistently similar between anchors. The more interesting question, however, is whether these teaching style similarities are related to the small sample size of the present study or to a trend in teacher education and school administration focusing on these styles? Then the more relevant question to the present study becomes, how do these teaching styles align with an education for democracy? Do they develop important qualities for a democratic people?

While these questions are an area for future research, a theoretical inquiry into the alignment with an education for democracy is possible here. The experiential methods and group size styles both fit under instructional adaptations, which are merely different ways to teach the material to improve student learning. Adapting instruction to match the 
needs of a diverse student population is aligned with an appreciation and accommodation for diversity.

The conversational listening leads to the discussion about the link between connection and democracy (refer back to "Distinction \#6: Analyticity and Emotional Adaptability). Democracy is essentially a social system. In On the Social Contract, Rousseau (1762/1978) engages readers in a thought experiment about the origin of man being solitary and in constant need of defending oneself. In this thought experiment, the strongest would simply take what they want. As a result, like-minded individuals form societies and create rules that safeguard the greater good. While Mill (1859/1991) does not contend that individuals should adhere to a homogeneous outcome, but rather must remain diverse and propose diverse ideas, there must be some level of community to keep a society together (Plattner, 1998; Tocqueville, 2002; Smith, 1993). Schmitter and Karl (1991) contend that applying either conception, republican or liberal, to the extreme could undermine democracy. Conversational listening falls into this area in terms of its importance for education for democracy.

Finally, the last of the similar teaching styles, high standards are important for democracy because of the value of each individual. Mill (1859/1991) asserts that each person should develop themselves fully. A teacher who maintains high standards is a teacher looking for results and growth. It is important to keep in mind that not balancing the high standards teaching style can result in a suppression of non-measured qualities also important for democracy, such as artistic abilities. However, a teacher who has a holistic view of students and is adaptable to their emotional as well as intellectual states 
can maintain high standards without suppressing greatness in unorthodox or diverse areas.

\section{Limitations and Recommendations for Future Research}

While measures were taken for the trustworthiness of the qualitative data and for the reliability and validity of the quantitative data, any research study has its limitations. The limitations I am aware of are listed here along with recommendations for remedying those limitations in future research.

First, the teaching style categories may not accurately represent all nuance of teaching style. While a fairly comprehensive teaching style framework emerged through the iterative qualitative process, important distinctions arose during the next phase of cross-case analyses. For example, a new teaching style category emerged for Ms. Fifth and Ms. K of teacher explorer. In addition, the difference in listening style of Ms. Science and Ms. Math compared to Ms. Second was important for several dispositions. Similarly, teachers who adapted the curriculum did so in different ways and in one comparison between Ms. Second and Ms. Social Studies, that distinction was important. These are the examples that presented themselves in the cross-case analysis; however, a clear limitation is that other nuanced distinctions may exist in the current coding system and not yet evident. A recommendation for future research is to refine the teaching style categories through a mixed methods approach of qualitative observations and interviews followed by an analysis using the current framework as a quantitative rubric for coding.

Second, the extra-curricular teachers were delimited from the sample in the present study. As mentioned in the methodology chapter, the physical education teacher was observed having important life conversations with the middle school teachers during 
break time. The methods of the present study did not lend themselves to capture these out of the classroom interactions that could yield important implications about the relationships teachers form with their students and the teaching styles that may emerge. A recommendation for future research is to account for out of the classroom interactions with students and include extra-curricular teachers.

Third, a number of limitations arose due to the small sample size. The mixed methods cross-case analysis did not account for the relationship between interactions of critical thinking dispositions and teaching style. In other words, if a teacher scored high on inquisitiveness and maturity of judgment, does her teaching look different than a teacher who scored low on one of these or both of these? Theoretically, each teacher has a critical thinking dispositions profile and the interaction of those strengths and weaknesses may present in teaching styles differently. A recommendation for future research is to develop a methodology to explore the interaction effects of critical thinking dispositions on teaching styles. With a greater sample size, the interaction effects would be possible to capture statistically using the General Linear Model. A practical suggestion for a research design is to use the teaching style framework to quantitatively observe and analyze data, thus making the increased sample size practical.

Similarly, because of the small sample size, the extreme groups were not always so extreme. The research design of the present study created extreme groups from the sample after their scores were accounted for. Therefore, the extreme was relative to the scores of all the other teachers as opposed to being relative to the highest possible score of 60 or the lowest possible score of 0 . This limitation may be why a consistent distinction between maturity of judgment and self-actualization was not discernable in 
the present study. The more extreme cases within the groups reflected this consistent distinction, but it was negated by the less extreme cases (closer to the mean). This limitation can be remedied in future research by increasing the sample size and reversing the research design by first creating more extreme groups based on scores and then gathering the qualitative data on teaching styles. To safeguard against researcher bias during the qualitative phase, a research design may develop a way to keep the research blind from the scores of the teachers until after analysis.

Consequently, the present study was delimited to one school in an attempt to reduce spurious variables related to school culture and administration interactions. However, there are also limitations to having a sample from one school such as the participants not being representative of the general teacher population at public schools. A recommendation for future research is to increase the variability of the sample by replicating the research at other types of schools or selecting teachers from various types of schools.

Finally, critical thinking dispositions were measured using the CCTDI. While some of the subscales showed above average reliability and validity, there are limitations to this instrument. Firstly, it is costly. Even with a dissertation discount, the CCTDI cost about $\$ 600$ for 50 tests, the minimum quantity for the discount. To use this instrument post-doc is cost prohibitive. Secondly, the construct validity published does not provide evidence to support if the instrument measures what it says it measures, namely critical thinking dispositions. Determining that some of the scales correlate to scales that measure different constructs is not especially helpful. Specifically, the publishers claim that all seven subscales are correlated to ego resiliency, defined as adaptable and flexible. Does 
this mean that the CCTDI is measuring the adaptability of individuals rather than their critical thinking dispositions? Had they shown evidence of the truth-seeking subscale scores correlating to a different truth-seeking survey, then the validity evidence of the instrument would be stronger. Thirdly, the publisher is the one who scores the CCTDI and researchers are not given access to the participants' answers on specific items. There are 75 questions and 7 dispositions. This raised concerns around how many items are there for each subscale because 75 divided by 7 is not a whole number. Similarly, each subscale maximum score is 60 points. Are different items given different weight? If so, it would be tremendously beneficial for data analysis purposes to know the participants' answers and the items that matter more. Therefore, a recommendation for future research is to use additional measures for critical thinking dispositions to further support the findings of the CCTDI. A possibility is to utilized qualitative measures along with the published critical thinking dispositions framework from the CCTDI.

\section{Implications for Research}

The present study generated several areas for future research. The implications for research, therefore, are in one of the following categories: same research question, specific questions around results, questions around theory, and questions around teaching styles.

First, the most basic possibility is a new study taking into account the limitations stated above. The greater sample size would increase the variability of the teachers and could offer support for findings consistent with the present study. That variability can be in terms of teacher attributes and school contexts. Ideally, the increase in sample and the variability of the teachers will result in greater variability in the critical thinking 
disposition scores (greater extremes). This will allow for consistent results to be substantiated and inconsistent results to be further explored. A further implication can be a statistical analysis of interaction effects of critical thinking dispositions on teaching styles. Similarly, exploring the same question utilizing a different research design is also possible. For example, a reversal of phases may be a way to ensure a greater extreme sampling for the qualitative data collection. In other words, the research can start with a greater number of participants who take the CCTDI and then sample the extreme scores on each subscale before observing and interviewing for teaching styles. A corollary to the present study's research purpose may be to train teachers on the critical thinking dispositions and observe if teaching styles change in any way.

A second line of inquiry generated by the present study has to do with one assumption that was stated in the introduction, namely that the teachers' critical thinking dispositions would translate in their teaching and develop correspondingly strong dispositions in their students. Therefore, a future area of inquiry is to study how the teaching styles develop important qualities for democracy in students. Some of the findings generated hypotheses in line with this question. Specifically, the findings around teacher explorer, student teaching, and fallibility generated hypotheses about developing truth-seeking, open-mindedness, and inquisitiveness in students. In general, many of the teaching styles theoretically align with democratic values and an implication for research is studies that explore the student outcomes in relation to the teaching styles with regards to democratic qualities.

A third implication for research is an exploration of the teaching styles consistently absent for truth-seeking, open-mindedness, systematicity, and analyticity. 
Why is it that extremely high truth-seeking teachers and extremely low truth-seeking teachers did not exhibit nurturing or trusting teaching styles? Were these findings due to limitations of the present study or were they valid?

A fourth line of inquiry can be the teaching styles that were consistently similar between all anchor teachers. Are these similarities due to the small sample size and limited school context or can they be generalized to most of America's teachers? Are these teaching styles more emphasized in current teacher education programs? If so, how does this impact our education system? Are these teaching styles developing in students the important qualities for democratic life?

\section{Implications for Theory}

An interesting phenomenon observed a few times throughout the data is a teacher exhibiting behaviors of a strong critical thinking disposition while scoring the lowest in that disposition. For example, the lowest open-mindedness score was Ms. K's, yet her teaching style reflected a high level of open-mindedness. Similarly, the lowest systematicity score was Ms. Second's, but her classroom was one of the most systematic, organized, and planned classrooms. Ms. Second scored the lowest on analyticity yet was the one who most emphasized anticipating the outcomes of current decisions. Alfred Adler's Compensation Theory states that people strive to overcome their inherent limitations, often building the inferior aspects to supernormal strengths (Vaughan, 1927). The implication for theory is that teachers may compensate for their weaknesses by focusing on them in their teaching, thus not pass them on to their students.

A second implication for theory is the integrated discussion linking teaching styles and critical thinking dispositions to an education for democracy. While exploring 
the impact of teaching styles on students' development of democratic qualities was beyond the scope of the present study, the theoretical connections made throughout can be a basis for future exploration.

Possibly the present study's most important contribution to the field is the teaching style framework that emerged from the qualitative data analysis. The present research was intended as an exploration of this relationship between teaching styles and critical thinking dispositions. Five teaching style themes summarize the teaching styles: adaptability to student needs, teaching methods, ways of connecting to students, growthoriented teaching, and highest hopes for students. Table 18 below is copied from Chapter Four and displays the themes that emerged along with the corresponding teaching styles, incorporating the adjustments after the cross-case analysis.

Table 18

Teaching Style Framework

\begin{tabular}{|c|c|c|c|c|}
\hline Adaptability & Methods & Connecting & Growth-Oriented & Highest Hopes \\
\hline Curriculum & Experiential & Nurturing & Self-reflective & Effectiveness \\
\hline $\begin{array}{c}\text { Curriculum } \\
\text { Expansion }\end{array}$ & Teacher Guide & Humor & Fallibility & Character \\
\hline Instruction & Teacher Explorer & Reward & Assessment & Connection \\
\hline Emotional & Lecture & Respect & Holistic View & Self-Actualization \\
\hline Physical & $\begin{array}{c}\text { Student Teacher } \\
\text { Group Size } \\
\text { (Whole, Small, } \\
\text { Teams })\end{array}$ & $\begin{array}{c}\text { Conversational } \\
\text { Listening } \\
\text { Listening }\end{array}$ & High Standards & \\
\hline & $\begin{array}{c}\text { Free Movement } \\
\text { Trust }\end{array}$ & & \\
\hline
\end{tabular}




\section{Implications for Practice}

The greatest implications for practice are for teacher education programs. While the findings of the present study cannot make any conclusions about student outcomes, they point to eight teaching styles that were consistent with high critical thinking dispositions. Some of these styles may be emphasized more than others in current teacher education programs. The eight teaching styles are:

1. Curriculum expansion

2. Emotional adaptability

3. Teacher explorer

4. Student teaching

5. Nurturing

6. Observational listening

7. Fallibility

8. Self-actualization

Teacher education programs can develop these styles in future teachers in a number of ways. First, it is important to discuss with future teachers the theoretical implications of each teaching style on student outcomes and on society at large. Second, training teachers on methods of integrating these styles into their teaching is essential. This includes providing possibilities and resources for maneuvering around the administrative restraints that can hinder certain teaching styles. Third, in line with the latter, teacher education programs can develop the underlying critical thinking dispositions associated with each teaching style. In this way, it is not an artificial addition to a repertoire of methods, but rather a holistically ingrained way of being with students. The results are a more balanced 
and centered teacher who is empowered deeply and a profound learning experience for the students.

\section{Curriculum Expansion}

Curriculum expansion was defined as teachers going beyond the prescribed curriculum, integrating outside sources, and following students' lead in abilities and interests. The first task of teacher education programs should be discussing the theoretical implications of curriculum expansion. As established throughout the present study, curriculum expansion can be a way to give voice to other perspectives and achieve two important goals. One is allowing students to be exposed to and appreciate the diversity of knowledge (Mill, 1859/1991); the second goal is providing the diverse student population of a pluralistic liberal democracy the opportunity to hear their own voice legitimated by the curriculum (Aronowitz \& Giroux, 1991). Both of these goals are closely aligned with and education for democracy. Curriculum expansion can also be a way to adapt to student needs and growth capacities. Similarly aligning to an education for democracy, the importance of human development for Mill's (1859/1991) notions of democracy has been established thoroughly.

The second recommendation for teacher education programs is to train teachers on integrating curriculum expansion, taking into account current policy restraints. Specific recommendations based on the age of students and the subject matter can be developed. An emphasis should be placed on easy and time efficient methods of integrating curriculum expansion. For example, a simple method may be giving students the opportunity to research and share perspectives that speak to them. While general methods are beneficial, teacher education programs must be aware of the specific 
restraints in local schools and teach methods to mitigate those restraints. For example, if the chosen curriculum for the county has areas that are especially restricted, teacher education programs can use those lessons as examples in methods to expand the curriculum. Similarly, teacher education programs must know the student population in their geographic region and train teachers on integrating voices that may speak to those students.

The third task of teacher education programs can potentially be to develop in future teachers the critical thinking disposition related to curriculum expansion. While more research is needed to generalize on the findings of the present study, I will mention this area for future implications. Confidence in reasoning was the critical thinking disposition related to curriculum expansion in the present study. Therefore, an emphasis on developing confidence in reasoning in future teachers can potentially translate into a more natural expression of curriculum expansion. The results of the present study did not indicate how to develop confidence in reasoning, rather they only indicated how a strong confidence in reasoning disposition is expressed in teaching. Theoretically, however, it is possible to develop a confidence in reasoning by modeling the reflective thinking process in class interactions. Jason Baehr, associate professor of philosophy at Loyola Marymount, says he stops "a lot to think and wonder with students, to ask questions and get to why" (Berrett, 2012).

\section{Emotional Adaptability}

Emotional adaptability was adapting to the emotional needs of students. This required teachers to be observant and come up with possible solutions. The first recommendation for teacher education programs is to discuss the theoretical implications 
of emotionally adaptive teaching on students and on society at large. Scott (2008)

discusses how a shift in the West towards a more emotional perspective as opposed to the established individualism has impacted education. She cites the changes in the 1941 edition of the Encyclopedia of Educational Research as compared to the 1991 edition, where affect education has replaced character education as a topic. Her conclusion is that emotions moved from being an area for teachers to observe to a subject of intervention. This is precisely where the emotional adaptability teaching style fits in the conversation.

What does this shift mean for democracy? As previously established, understanding and helping our students overcome emotional obstacles to development can be beneficial to Mill's (1859/1991) ideal of individuals developing to their potential, thus having ideas worthy of more respect. Aside from being more beneficial contributors to society, an emotionally healthy individual will be less likely to harm others as Honess and Hunter (2014) discuss results from an affective education curriculum shown to reduce aggressive student behaviors by $32 \%$. Therefore, affective education programs are a preventive measure in line with Mill's (1859/1991) Harm Principle, namely that the limit of individual liberty is when actions harm others.

The second recommendation for teacher education is to teach methods of emotional adaptability. There are a number of curricular programs that explicitly teach students about emotions, often called affective education, such as the Developing Understanding of Self and Others Activities Kit (Rabinovitz, 1985) and Promoting Alternative Thinking Strategies curriculum (Honess \& Hunter, 2014). However, emotional adaptability is not a curriculum; it is a teaching style, a way the teacher responds to students' emotions with the clear purpose of mitigating obstacles to learning 
and growth. Therefore, possibly implementing the affective education programs as a part of teacher education could develop in future teachers the abilities required for an emotionally adaptive style such as emotional awareness and emotional literacy for self and others.

The third recommendation with regard to emotional adaptability is to develop the critical thinking disposition of analyticity in teachers. While more research is needed to establish the reliability of the present study's findings connecting analyticity to emotional adaptive teaching, there is potential benefit and as such is mentioned here. Ingrained in a strong disposition towards analyticity is an ability to accurately assess obstacles and to appropriately develop plans to improve outcomes. The question is if developing the general analyticity abilities would naturally carry over to the emotional domain as well. Holma (2012) asserts that there has been an established dichotomy between emotions and cognition throughout the history of Western philosophy and an excessive fear of "psychologization" in educational theories. "Psychologization" is referring to a fear of either blaming the victims of structural inequalities or blaming the psychological problems of the oppressors. These phenomena have resulted in the neglect of emotions in educational philosophy. Holma (2012) argues for the importance of emotions in "citizenship education" to develop tolerance towards others (p. 407). Some of the findings from the present study point to the nexus between cognition and emotion that Holma (2012) is arguing for in education, for example analyticity related to emotional adaptability and fallibility. 


\section{Teacher Explorer}

The societal shift to an emotional focus, Scott (2008) argues, has impacted the way teachers interact with students and knowledge, no longer being "the sage on the stage," but instead adopting "the guide by your side" philosophy (p. 554). As a result, there is an emphasis in current educational trends on student-centered learning and student-created knowledge. Accordingly, the teacher explorer style was defined as a collaborative effort between teacher and students to develop a learning outcome where the teacher has no predetermined end in mind and the focus is on the process.

The first recommendation is to integrate in teacher education programs a theoretical understanding of teacher explorer methods specifically, or student-centered styles in general, on the students and society at large. In other words, how does this teaching style prepare students for the current world and for democratic living? In the previous discussion about curriculum expansion, the concept of incorporating students' voices and legitimating other sources of knowledge applies to teacher explorer styles as well. More specifically, teacher explorer methods are one way of expanding the curriculum and one benefit is including and legitimating the voices of a diverse student population. In so doing, the teacher also emotionally validates students, thus mitigating significant obstacles to growth. The implications for a liberal democracy are a future citizenry that are welcomed and capable of participating fully in democratic life.

The second recommendation with regards to teacher explorer styles is to train future teachers on the methods. How can a teacher, given all the current policy, administrative, or curricular constraints, integrate teacher explorer methods in the classroom? What does a teacher explorer look like in various subjects throughout various 
grade levels? After establishing the legitimacy of student voice, teaching how to integrate student voice is essential. One suggestion comes from Wiggins and McTighe's (2005) suggestions for essential questions. There are intentionally no answers to essential questions because the purpose is to inspire students to think. Questions with no end open the way for teaching with no end, which is a teacher explorer. They offer examples for all subject matter and teachers can adapt questions to the age level of students. For example, "To what extent is DNA destiny?" or "Must a story have a beginning, a middle, and an end?" (pp. 105-106).

The final recommendation for developing teacher explorer methods in pre-service teachers is to develop the critical thinking disposition of truth-seeking that was found to be consistently related in the present study. Truth-seeking is the tendency to follow evidence wherever it may lead, even if against one's own cherished beliefs. Therefore, the theoretical connection to teacher explorer is quite easy to follow. A strong truthseeking teacher would theoretically be open to student input as long as they are supported by reason and a strong truth-seeking teacher would follow the discussion wherever it may lead without a predetermined end. How can teacher education programs develop truthseeking dispositions in future teachers? The academic world of research and literature reviews develops truth-seeking dispositions, therefore, extending that graduate-type work to teacher education may be beneficial.

\section{Student Teaching}

The first recommendation for teacher education programs is to provide the theoretical implications of student teaching. It is important for pre-service teachers to understand the connections between student teaching, student development, and 
democracy. The theoretical conversation earlier tying teacher explorer to the educational shift to student-centered philosophies applies to student teaching as well. Just as teacher explorer methods expand the curriculum and incorporate diverse student voices, student teaching can be used with the same purposes in mind. In addition, student teaching allows students to practice important skills for democratic life such as media literacy, citing reliable sources, and expressing oneself in an intelligible way (Habermas, 1998).

The second recommendation for teacher education programs is to teach effective methods to incorporate student teaching. Touched upon in the previous discussion, student teaching with rigid guidelines as to content and presentation is quite different than student teaching with freedom to express and expand upon the curriculum. In other words, if a teacher assigns a student to present chapter five from the text, this is restricting content. However, a teacher who assigns a general area of topics for students to research and prepare is expanding the curriculum. Teacher education programs must make the distinction between student teaching that restricts versus student teaching that expands. Rather than provide explicit guidelines for the outcome of student-led presentations, teachers can provide students with explicit rules for the process to ensure reliable information. Advocating for media literacy in schools, Hobbs (2017) states,

Of all the types of misleading news listed in the EAVI (European Association for Viewers' Interests) chart, propaganda is perhaps the most difficult for students to understand. Propaganda, which is generally defined as strategic communication designed to activate strong emotions, bypass critical thinking, and shape attitudes and behaviors, has long been an important form of social power (p. 28).

Training future citizens to critically analyze news and information, which is in line with Habermas' (1998) validity claims, is a safeguard against Mill's (1859/1991) fear of the tyranny of the majority. 
Finally, a third recommendation is for teacher education programs to develop the critical thinking dispositions connected to student teaching styles, namely truth-seeking and open-mindedness. Truth-seeking was addressed in the latter discussion with the recommendation of integrating some graduate level academic expectations such as literature reviews and research protocol. It seems that one of the prime ways to develop an open-minded disposition is to expose students' biases by intentionally provoking them with bold positions. Barry Schwartz, a professor of social theory and social action at Swarthmore College, utilizes this technique with his students to move them away from “intellectual rigidity" (Berret, 2012). Professor Clifton Conrad at the University of Wisconsin argues that faculty are not leading by example because they often choose safe intellectual positions out of fear of tenure prospects and also out of a desire to appear learned rather than learning (Berret, 2012). In terms of teacher education aimed at developing intellectual habits of mind, faculty must be models.

\section{Nurturing}

Nurturing was defined in the present study as a teacher's parent-like demeanor with students, engaging in actions that reflect care. The theoretical importance of nurturing styles in connection to democratic life have been discussed. Nurturing's importance is in line with emotional adaptive teaching and student-centered teaching methods. A nurturing teacher sends a clear message to students that they are each valuable and important. Future citizens of a democracy must believe in their own value to the society and likewise the value of each member of society. As Mill (1859/1991) contends, each diverse viewpoint contributes positively to the democratic discourse, even if it is an outrageous opinion that forces citizens to strengthen their own arguments. 
The second recommendation to teacher education programs is to develop in teachers an empathic perspective of their future students. My conviction is that if teachers maintain a more holistic view of their students, the nurturing style will naturally be expressed. Boorn, Dunn, and Page (2010) describe a training program entitled, Growing A Nurturing Classroom, that focuses on teachers taking a holistic approach to education, based on the notion that emotional well-being is central to learning.

Because the present study found that teachers who scored high in systematicity expressed nurturing teaching styles, teacher education programs may find beneficial outcomes in developing systematicity in pre-service teachers. While classroom management is generally incorporated in teacher education programs, it is from a theoretical perspective. New teachers often become disheartened when faced with the reality of balancing all the moving parts of a classroom (Roache \& Lewis, 2011 as cited in Eisenman, Edwards, \& Cushman, 2015) and often blame their teacher education for not adequately preparing them with real-life practical methods to solve classroom challenges (Steward-Wells, 2000 as cited in Eisenman, Edwards, \& Cushman, 2015). Eisenman, Edwards, and Cushman (2015) assert that teacher education programs must emphasize classroom management and teach it explicitly much the same way they approach reading instruction; however, most teacher preparation programs dedicate only one course to classroom management. The authors also advocate for a change in perspective on classroom management from a way to control student behavior to a way of improving learning outcomes. The focus should be, they contend, on students managing their own behaviors and learning. This shift in defining classroom management seems more aligned with democratic life where citizens are empowered to govern themselves. 
Eisenman, Edwards, and Cushman (2015) offer five practical activities they use in their classroom management courses: movie study, microteaching, animated video or comic strip, observational protocol, and personal management system. These five activities incorporate self-reflection, role play and real world observations that yield a personal customized management plan upon graduation.

\section{Observational Listening}

Initially, listening emerged as one teaching style category, but during the crosscase analyses it became evident that some teachers did more than engage in conversations with students. Observational listening was when a teacher listened with an intentionality to observe students to inform teaching. This was different than a teacher who used regular assessments such as tests to assess student progress. A teacher who engaged in observational listening was always looking for clues where students did not understand or even clues pointing to emotional obstacles to learning. Observational listening is different than active listening, which is essentially about accurately understanding the speaker and reflecting back that understanding. Observational listening may not be listening with ears, but it is observing any student expression that reveals obstacles to learning. This is a term that was created to reflect the style emerging in the present study.

The theoretical significance of a teacher who listens in this way to students is profound. Not only is it reflective of a holistic view of student growth, it is reflective of an accountable teacher who is constantly adjusting to student needs as they arise. The traditional testing model and labeling students with achievement levels gives a different feel to the classroom. The observational listening is about growth, the testing is about labeling. Observational listening is in line with an education for democracy; the 
individualized view of students nurtures diversity and the emphasis on growth improves the contribution each member makes to society. Thus, observational listening can be another path to expanding the curriculum and emotionally adaptive teaching.

How can teacher preparation programs teach observational listening? Programs in active listening or listening skills will not be beneficial here. Observational listening is more about teachers perceiving clues from student expressions in all forms. While not targeted to teacher education, one research study explores the benefit of utilizing a variety of activities to teach medical students to pick up on patients' contextual clues (Thompson et al., 2010). The authors developed a program called "Context and Healing" that combined direct instructional methods along with video simulations and reflective activities. Similar programs to train pre-service teachers to pick up on student contextual clues can be beneficial.

Finally, observational listening was exhibited by teachers in the present study who scored high on analyticity. Therefore, teacher education programs may find it beneficial to develop pre-service teachers' dispositions towards analyticity. Some suggested areas theoretically linked to analyticity may be decision-making and strategic planning. However, as mentioned previously, this relationship may be pointing to that nexus between cognition and emotion in education, which Holma (2012) believes is essential.

\section{Fallibility}

Fallibility is a teaching style under the growth-oriented theme defined as a teacher creating a safe space for student mistakes and promoting a positive perspective of fallibility. While not the only way, teachers in the present study did this by modeling an acceptance of their own mistakes and encouraging student effort over results. While 
unaware of the connection prior to my research, I realized during the qualitative phase that fallibility is a necessary prerequisite to effective democratic deliberation. I am convinced that citizens who are unable to accept their own fallibility will not be able to hear opposing viewpoints with an open-mind and will be unwavering in adhering to their own positions. Supporting my statement, Holma (2012) asserts in an article aptly named, "Fallibilist Pluralism and Education for Shared Citizenship" that "taking a tolerant and dialogical attitude toward different others requires tolerance toward one's own fallibility and vulnerability" (p. 398).

Consequently, it is important to provide future educators the training to implement fallibility as a teaching style. Engaging in and modeling for students selfreflective practices is beneficial. This type of teaching challenges "the sage on the stage" philosophy and asks teachers to be vulnerable in front of their students to open a space for students to do the same. Aside from modeling fallibility, future teachers can benefit from methods to create safe learning spaces for students. Some of the examples from the present study were quite unique. Mr. Language Arts brought a toilet in his classroom and used it as a gimmick to flush bad work. He made it fun and funny to make mistakes. He also made sure to respond to students sharing their thoughts and ideas, seeing it as a display of vulnerability and an important chance for him to validate their opinions. Other teachers like Ms. Third B spoke about perfectionism with her students openly and directly. Exploring these methods and integrating this conversation in teacher education programs is a vital safeguard for our democracy.

Fallibility, like emotional adaptability and observational listening, were expressed by teachers who scored high on analyticity. Referring back to those discussions, teacher 
education programs can look into possible ways to improve future teachers' dispositions towards analyticity. They can also consider the connection between emotion vulnerability and intellectual development.

\section{Self-actualization}

Self-actualization emerged as a teaching style theme expressing teachers' highest hopes for their students. Teachers who expressed self-actualization hopes wanted their students to reach their potential and master an area of their choosing. The term was borrowed from Maslow's (1943/1991) hierarchy of needs and was theoretically connected to democracy. Maslow (1943/1991) argues that individual liberties are a necessary condition for self-actualization to occur. On the other hand, Mill (1859/1991) argues that self-actualized individuals (not his term) are important for a vibrant, deliberative democracy because they contribute to societal progress.

One recommendation is for teacher education programs to develop that theoretical link between self-actualization and democracy. A second recommendation is for teacher education programs to train pre-service teachers on practical ways to teach with selfactualization in mind. How can teachers help students along their self-actualization paths? In an article about self-actualization in science education, Bencze (2000) discusses the contradictory messages the curriculum and teachers send students. There is a desire for students to become independent thinkers, yet teachers continuously guide towards the "correct" construction of knowledge. Reading this article shed light on Mr. Language Arts' teaching styles. Bencze (2000) argues that constructivist teaching can be misused as a subversive activity where teachers attack students' free construction of knowledge in three ways: referring to student ideas with derogatory terms such as "naïve," limiting 
student access to content or procedures, and regulating student conclusions. Mr. Language Arts did not treat his students' ideas with disrespect; however, he did regulate their conclusions and said so in the interview. Therefore, the result is a teacher-controlled classroom with a student-centered façade (Fensham et al., 1994 as cited in Bencze, 2000). Therefore, this research points to freedom in constructing knowledge as the path to selfactualization. Accordingly, liberation psychotherapy, an umbrella term including fields such as Humanistic psychology, states that human beings are naturally "good" and all dysfunction can be blamed on some sort of damage from authority figures in early life. The solution is to free damaged individuals to pursue self-actualization (Rice, 1996 as cited in Scott, 2008).

The present study found that teachers who scored high on confidence in reasoning unanimously expressed self-actualization as a highest hope. It seems that a confidence in reasoning disposition, or a tendency to trust reflective and reasoned thinking, can be developed by constructivist pedagogy. Constructivist pedagogy is "a theory that knowledge is built up by combining information with existing cognitive structures" (Bencze, 2000, p. 847). In other words, knowledge is built and it requires reflective thought. Consequently, when implemented with fidelity, constructivist pedagogy supports self-actualization because it allows for innovative ideas to be formed (Bencze, 2000). Therefore, a recommendation for teacher education programs is to teach utilizing constructivist pedagogical methods and train future educators to implement those methods in their classrooms. 


\section{Summary}

In this chapter, I discussed the results of the present study, including the 10 distinctions, 6 absent styles, and 6 similarities. Limitations and recommendations for future research were discussed. Implications for theory included: a conversation about Adler's Compensation Theory; the links formed between critical thinking dispositions, teaching styles, and democracy; and the teaching style framework. Implications for research discussed some of the possibilities generated by the present study. Finally, the implications for practice discussed possible ways teacher education programs can train future educators on the eight teaching styles presented in the findings, linking the findings of the present study to relevant research in various fields.

\section{Conclusion}

Imagine a world where people co-create and grow — a world that includes every human being in the decision-making processes that impact their lives. Imagine a world where human beings are treated with the dignity that is declared in so many world documents, yet contradicted in so many world events throughout history. Imagine a world that values the diversity within humanity rather than uses it as a means of oppression and tyranny. Democracy does not automatically maintain itself by prescribed constitutions and procedural codes (Dewey, 1939), but rather its citizens must have certain dispositions to protect and strengthen it (Biesta, 2006).

Education for democracy formed the foundation of this work. How can schools cultivate in our children the qualities they need for democratic living and the qualities that will ensure they work hard to maintain and improve upon our most valuable democracy? The focus in the present study was critical thinking dispositions as necessary 
qualities for future citizens. Critical thinking is not only a necessary tool for fully engaging in democratic discourse, but it is a safeguard against any level of exclusionary practices, or the "tyranny of the majority" (Mill, 1859/1991). Developing critical thinking dispositions in our future citizenry would provide all members of our society access to the dialogue. The assumptions laid out at the beginning of the present study stated that if teachers have critical thinking dispositions, they will presumably teach differently and students will develop these qualities organically.

The purpose of the present study, therefore, was an initial step in this line of inquiry — to explore the relationship between teachers' critical thinking dispositions and their teaching styles. How do the teachers' critical thinking dispositions differentiate between teaching styles? Through multiple-case studies of 10 teachers, a framework for teaching styles was developed. The CCTDI provided a score profile of seven critical thinking dispositions for each teacher. Cross-case analyses provided the framework to compare teaching styles based on distinctions in critical thinking dispositions. The resulting cross-case syntheses produced analytic generalizations (Yin, 2013), which can form the foundation for future research. In addition, the rich qualitative descriptions incorporated throughout the entire study provide insight that can similarly support future research. The hope is that the present study contributes to and continues a line of inquiry that serves the purpose of protecting and strengthening our democracy. 


\section{REFERENCES}

American Civil Liberties Union. End mass surveillance under the PATRIOT Act. Retrieved November 30, 2017, from https://www.aclu.org/issues/nationalsecurity/privacy-and-surveillance/end-mass-surveillance-under-patriotact? redirect $=$ node $/ 29187$

Apple, M. W., \& Beane, J. A. (2007). Democratic schools: Lessons in powerful education $\left(2^{\text {nd }}\right.$ ed.). Portsmouth, NH: Heinemann.

Aronowitz, S. \& Giroux, H. A. (1991). Postmodern education: Politics, culture, and social criticism. Minneapolis, MN: University of Minnesota Press.

$\mathrm{Au}, \mathrm{W}$. (2007). High-stakes testing and curricular control: A qualitative metasynthesis. Educational Researcher, 36, 258-257.

Barber, B. R. (1997). Public schooling: Education for democracy. In J. I. Goodlad \& T. J. McMannon (Eds.), The public purpose of education and schooling (pp. 21-32). San Francisco, CA: Jossey-Bass.

Bencze, J. L. (2000). Democratic constructivist science education: enabling egalitarian literacy and self-actualization. Journal of Curriculum Studies, 32, 847-865.

Benjamin, M. (2011, June 24). New Patriot Act controversy: Is Washington collecting your cell phone data? Time. Retrieved November 30, 2017, from http://content.time.com/time/nation/article/0,8599,2079666,00.html

Berrett, D. (2012). Habits of mind: Lessons for the long term. Chronicle of Higher Education, 59 (7), A1-A6.

Bloom, B. S. (1984). Taxonomy of educational objectives ( $2^{\text {nd }}$ ed.). New York, NY: Longman.

Blumenthal, M. (Jul 19, 2013). People, power, or propaganda? Unraveling the Egyptian opposition. Al-Jazeera English. Retrieved November 30, 2017, from http://www.aljazeera.com/indepth/opinion/2013/07/2013717115756410917.html

Biesta, G. (2006). Beyond learning: Democratic education for a human future. London: Paradigm Publishers.

Biesta, G. (2007). Education and the democratic person: Towards a political conception of democratic education. Teachers College Record, 109, 740-769. 
Bogdan, R. C., \& Biklen, S. K. (2007). Qualitative Research for Education: An Introduction to Theory and Methods ( $5^{\text {th }}$ ed.). New York, NY: Pearson.

Boorn, C., Dunn, P. H., \& Page, C. (2010). Growing a nurturing classroom. Emotional and Behavioural Difficulties, 14, 311-321.

Campbell, D. E. (2005). Voice in the classroom: How an open classroom environment facilitates adolescents' civic development. (Working Paper). The Center for Information and Research on Civic Learning and Engagement.

Carle, E. (1987). A house for hermit crab. Saxonville, MA: Picture Book Studio.

Chaddock, G. R. (May 27, 2011). Patriot Act: Three controversial provisions that Congress voted to keep. The Christian Science Monitor. Retrieved November 30, 2017, from https://www.csmonitor.com/USA/Politics/2011/0527/Patriot-Actthree-controversial-provisions-that-Congress-voted-to-keep

Collie, R. J., \& Martin, A. J. (March 2016). Adaptability: An important capacity for effective teachers. Educational Practice and Theory, 38, 27-39.

Dewey, J. (1916). Democracy and education: An introduction to the philosophy of education. New York, NY: The Free Press.

Dewey, J. (1939). Freedom and culture. New York, NY: Putnam.

Eisenman, G., Edwards, S., \& Cushman, C. A. (2015). Bringing reality to classroom management in teacher education. Professional Educator, 39, 1-12.

Facione, P. A. (1990). Critical thinking: A statement of expert consensus for purposes of educational assessment and instruction (The Delphi Report Executive Summary). California Academic Press. Retrieved November 30, 2017, from https://www.insightassessment.com/Resources/Importance-of-CriticalThinking/Expert-Consensus-on-Critical-Thinking/Delphi-Consensus-ReportExecutive-Summary-PDF

Facione, P. A. (2011). Critical thinking: What it is and why it counts. Insight Assessment. Retrieved November 30, 2017, from https://www.insightassessment.com/Resources/Importance-of-CriticalThinking/Critical-Thinking-What-It-Is-and-Why-It-Counts/Critical-ThinkingWhat-It-Is-and-Why-It-Counts-PDF 
Facione, P. A., \& Facione, N. C. (2007, Mar/Apr). Talking critical thinking. Change, 3944.

Foster, K. A. (2005). The unfinished business of building a democratic middle school (Doctoral dissertation). Retrieved from Dissertation Abstracts International. (UMI No. 3168023).

Goodlad, J. I., Mantle-Bromley, C., \& Goodlad, S. J. (2004). Education for everyone: Agenda for education in a democracy. San Francisco, CA: Jossey-Bass.

Greene, M. (1993). Diversity and inclusion: Towards a curriculum for human beings. Teachers College Record, 95, 211-221.

Gutmann, A. (1987). Democratic education. Princeton, NJ: Princeton University Press.

Gutmann, A. and Thompson, D. (2004). Why deliberative democracy? Princeton, NJ: Princeton University Press.

Habermas, J. (1998). Between facts and norms: Contributions to a discourse theory of law and democracy, (trans. W. Rehg). Cambridge, MA: The MIT Press.

Hobbs, R. (2017). Teaching and learning in a post-truth world: It's time for schools to upgrade and reinvest in media literacy lessons. Educational Leadership, 75 (3), 26-31.

Holma, K. (2012). Fallibilist pluralism and education for shared citizenship. Educational Theory, 62, 397-409.

Human Rights Watch. (2004, February 27). France: Headscarf ban violates religious freedom. Retrieved November 30, 2017, from https://www.hrw.org/news/2004/02/26/france-headscarf-ban-violates-religiousfreedom

Insight Assessment. (2010). Test manual: California critical thinking disposition inventory.

International Association for the Evaluation of Educational Achievement (IEA). Civic Education Study. Retrieved November 30, 2017, from http://www.terpconnect.umd.edu/ jtpurta/

Josephson Institute. The six pillars of character. Retrieved November 30, 2017, from http://charactercounts.org/sixpillars.html 
Kozol, J. (2005). The shame of the nation: The restoration of apartheid schooling in America. New York: Crown Publishers.

Loewen, J. W. (2007). Lies my teacher told me: Everything your American history textbook got wrong. New York, NY: Touchstone.

Madaus, G. F. (1988). The distortion of teaching and testing: High-stakes testing and instruction. Peabody Journal of Education, 65, 29-46.

Maslow, A. H. (1943/2013). A theory of human motivation. Mansfield Centre, CT: Martino Publishing.

McDevitt, M. \& Kiousis, S. (2006). Deliberative learning: An evaluative approach to interactive civic education. Communication Education, 55, 247-264.

McNeil, K., Newman, I., \& Frass, J. W. (2011). Designing general linear models to test research hypotheses. Lanham, MD: University Press of America.

Merriam, S. B. (2002). Qualitative research in practice. San Francisco, CA: Jossey-Bass.

Mill, J. S. (1859/1991). On liberty and other essays, ed. John Gray. Oxford, England: Oxford University Press.

Newman, I. \& Hitchcock, J. (2014). Considering the purpose of research when identifying qualitative and quantitative commonalities. Paper presented at the Eastern Education Research Association, Jacksonville, FL.

Newman, I. \& McNeil, K. (1998). Conducting survey research in the social sciences. New York, NY: University Press of America.

No Child Left Behind Act, 20 U.S.C. § 6301 (2002). Retrieved November 30, 2017, from http://www.ed.gov/policy/elsec/leg/esea02/index.html

Plattner, M. F. (1998, Mar/Apr). Liberalism and democracy: Can't have one without the other. Foreign Affairs, 77, 171-180.

Rabinovitz, J. (June 1985). Affective education: It's as Easy as D-U-S-O. The Journal of Adlerian Theory, Research, and Practice, 41, 215-221.

RAND Corporation. Delphi method. Retrieved November 30, 2017, from http://www.rand.org/topics/delphi-method.html 
Rawls, J. (1996). Political liberalism. New York, NY: Columbia University Press.

Rogan, R. P. (2006). Voices and empowerment in a democratically-constructed elementary school classroom: A participatory action research study of our beliefs. Retrieved from Dissertation Abstracts International.

Roosevelt, F. D. (September 27, 1938). Message for American education week. Online by Gerhard Peters and John T. Woolley, The American Presidency Project. Retrieved November 30, 2017, from http://www.presidency.ucsb.edu/ws/?pid=15545

Rousseau, J. J. (1762/1978). On the social contract with Geneva manuscript and political economy, (trans. J. R. Masters), (Ed.) R. D. Masters. New York, NY: St. Martin's Press, Inc.

Rubin, H. J., \& Rubin, I. S. (2005). Qualitative interviewing: The art of hearing data $\left(2^{\text {nd }}\right.$ ed.). Thousand Oaks, CA: Sage Publications.

Schmitter, P., \& Karl, T. L. (Summer 1991). What democracy is... and is not. Journal of Democracy, 2 (3), 75-88.

Schumpeter, J. (1943). Capitalism, socialism, and democracy. London, England: George Allen and Unwin.

Scott, C. (2008). Teaching as therapy. Educational Philosophy and Theory, 40, 545-556.

Seuss, Dr. (1961). The sneetches. New York: Random House.

Soder, R. (1996). Democracy, education, and the schools. San Francisco, CA; JosseyBass, Inc.

Soder, R. (2001). Education for democracy: The foundation for democratic character. In R. Soder, J. I. Goodlad, \& T. J. McMannon (Eds.), Developing democratic character in the young (pp. 182-205). San Francisco, CA: Jossey-Bass.

Soder, R., Goodlad, J. I., \& McMannon, T. J. (2001) Developing democratic character in the young. San Francisco, CA: Jossey-Bass, Inc.

Spears-Bunton, L. A. \& Powell, R. (Eds.). (2009). Toward a literacy of promise. New York, NY: Routledge Taylor \& Francis Group. 
Smith, R. (Sept. 1993). Beyond Tocqueville, Myrdal, and Hartz: The multiple traditions in America. The American Political Science Review, 87, 549-566.

Stronge, J. H., Thomas, J., \& Grant, L. W. (2011). What makes good teachers good? A cross-case analysis of the connection between teacher effectiveness and student achievement. Journal of Teacher Education, 62, 339-355.

Tashakkori, A. \& Newman, I. (2010). Mixed methods. In P. Peterson, E. Baker, \& B. McGaw (Eds.), International Encyclopedia of Education ( $3^{\text {rd }}$ ed.) (Volume 6) (pp. 514-520). New York, NY: Elsevier.

Teddlie, C. \& Tashakkori, A. (2012). Common "core" characteristics of mixed methods research: A review of critical issues and call for greater convergence. American Behavioral Scientist, 56, 774-788.

Thompson, B. M., Teal, C. R., Scott, S. M., Manning, S. N., Greenfield, E. Shada, R., \& Haidet, P. Following the clues: Teaching medical students to explore patients' contexts. Patient Education and Counseling, 80, 345-350.

Tocqueville, A. (2002). Democracy in America. Chicago, IL: The University of Chicago Press.

Torney-Purta, J. \& Barber, C. (2007). Latino adolescents' civic development in the United States: Research results from the IEA Civic Education Study. Journal of Youth Adolescence, 36, 111-125.

Vaughan, W. F. (1927). The psychology of Alfred Adler. The Journal of Abnormal and Social Psychology, 21, 358-371.

Vogler, K. (2003, September/October). Where does social studies fit in a high-stakes testing environment? The Social Studies, 94, 207-211.

Westbrook, R. B. (1996). Public schooling and the American democracy. In R. Soder (Ed.), Democracy, education, and the schools (Chapter 5). San Francisco, CA: Jossey-Bass.

Westheimer, J. (2008). What kind of citizen? Democratic dialogues in education. Education Canada, 48, 6-10.

Westheimer, J., \& Kahne, J. (Summer 2004). What kind of citizen? The politics of educating for democracy. American Educational Research Journal, 41), 237-269. 
Wiggins, G. \& McTighe, J. Understanding by design. Alexandria, VA: Association for Supervision and Curriculum Development.

Yin, R. K. (2013). Case study research: Design and methods $\left(5^{\text {th }}\right.$ ed.). Washington, DC: Sage.

Zinn, H. (2003). A people's history of the United States: 1492 to present. New York, NY: HarperCollins Publishers, Inc. 
APPENDICES 


\section{APPENDIX A: PARTICIPANT AGREEMENT LETTER}

Dear Participant,

My name is Maram Behairy and I am a student at Florida International University in the College of Education under the supervision of Dr. Thomas Reio. You are invited to participate in my dissertation research project about different teaching styles as they relate to your personal dispositions.

There are no identified risks for participating in this study. Participation is completely voluntary and you may refuse without consequence. Participation entails taking a questionnaire that should take you about 20 minutes to complete, allowing me to observe your classroom a few times, and sitting down to an interview with me at your convenience. You will receive no compensation for your participation in this research.

Further information about this research can be obtained from me (PHONE NUMBER EMAIL) or my faculty advisor, Dr. Thomas Reio (Thomas.Reio@fiu.edu). If you would like further information about your rights as a research participant, you can contact the FIU Office of Research Integrity at 305-348-2494 or by email at ori@fiu.edu.

Thank you for your consideration and your help is greatly appreciated. By signing below, you acknowledge that you have read the above letter and agree to participate in my research project.

Printed Name

Signature Date 


\section{APPENDIX B: OBSERVATION GUIDE}

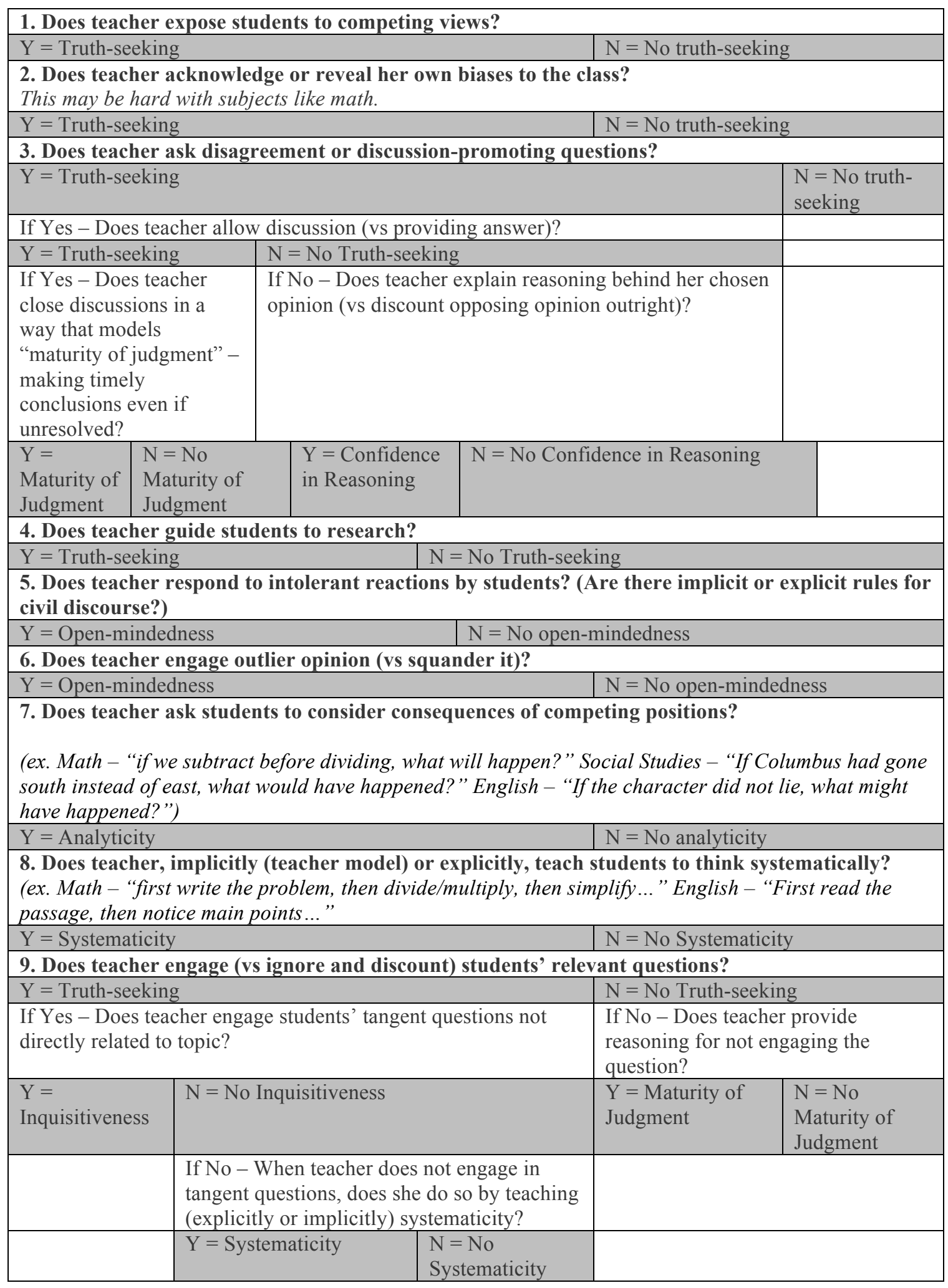




\section{APPENDIX C: INTERVIEW GUIDE}

1. How do you interact with the students?

a. What do you want to give your students?

b. If our school could produce the greatest graduate, what would that look like and what can a teacher do in the classroom to develop that?

c. What do you do when a student asks an outrageous question?

2. How do you interact with the content?

a. Well, how do you prepare your lessons?

b. How do you decide what material to teach?

c. How do you deal with topics with more than one opinion (history)? 


\section{APPENDIX D: RESEARCHER REFLECTIONS}

My interest in this topic stems from my own personal experiences as a student and a minority in the US. My most memorable moments as a student are with teachers who appreciated my questions and different approaches to content. I had an Algebra II teacher who would entertain my ideas on finding solutions in a different way than was prescribed in the text. She followed the path until it was either confirmed or disconfirmed. She taught me how to test my theories and allowed me the space to think, rather than ask me to be quiet or not waste class time. I had an AP Calculus teacher who had an unwavering belief in me and an ethics teacher who was not impressed by rote memorization of what others said about a topic. For the most part, however, it was relatively easy to get through the years with minimal work and some impressive memorizing. I realized that a teacher is really key in developing a disposition towards thinking rather than memorizing. The way some of my teachers interacted with the content and I allowed me to develop a deep appreciation for free discourse, creativity, and critical thinking. Other teachers, on the other hand, just fade in the background of my memory.

My interest in preserving democracy probably stems from my fear of the tyranny of the majority as Mill (1859/1991) talks about. When I read about what we, Americans, accepted to do to the Japanese, putting entire families in concentration camps, it terrifies me of the tyrannical possibilities of human beings - even in a democracy! When I remember the blacklists of the communist era, I wonder what can we do to prevent democracies from committing such violations against individual liberty? I really feel what Dewey (1916) asserts that democracy is not maintained by constitutions and procedural codes, but it requires people to stand up for freedom and liberty even for those they don't agree with or personally like. 
APPENDIX E: PRE-ANALYSIS REFLECTIONS

\begin{tabular}{|c|c|c|}
\hline CCTDI & Highest & Lowest \\
\hline Truth-seeking & $\begin{array}{l}\text { Adapt curriculum (research) } \\
\text { Adapt everything? } \\
\text { Listening } \\
\text { Self-reflective } \\
\text { fallibility }\end{array}$ & \\
\hline Open-mindedness & $\begin{array}{l}\text { Adapt curriculum (research) } \\
\text { Listening } \\
\text { Connection skills } \\
\text { Holistic view } \\
\text { nurturing }\end{array}$ & $\begin{array}{l}\text { Adapt curriculum (expectation } \\
\text { of quality, difficulty level, } \\
\text { quantity) } \\
\text { Lecture }\end{array}$ \\
\hline Inquisitiveness & $\begin{array}{l}\text { Adapt curriculum } \\
\text { Experiential } \\
\text { Teacher guide } \\
\text { Self-actualization } \\
\text { Free movement }\end{array}$ & \\
\hline Analyticity & $\begin{array}{l}\text { Reward } \\
\text { Effectiveness skills } \\
\text { Fallibility } \\
\text { High standards } \\
\text { Assessment growth } \\
\text { Self-reflective }\end{array}$ & \\
\hline Systematicity & $\begin{array}{l}\text { Adapt instruction (method) } \\
\text { Lecture } \\
\text { Respect } \\
\text { High standards } \\
\text { Effectiveness skills }\end{array}$ & \\
\hline Confidence in Reasoning & $\begin{array}{l}\text { Adapt instruction (thinking time) } \\
\text { Experiential } \\
\text { Teacher guide }\end{array}$ & \\
\hline Maturity of Judgment & $\begin{array}{l}\text { Clear deadlines } \\
\text { Reflects complexity }\end{array}$ & Free movement \\
\hline
\end{tabular}


VITA

MARAM BEHAIRY

\begin{tabular}{|c|c|}
\hline 1993 - 1999 & $\begin{array}{l}\text { High School Diploma } \\
\text { Pine Crest School } \\
\text { Fort Lauderdale, Florida }\end{array}$ \\
\hline $1999-2002$ & $\begin{array}{l}\text { Undergraduate Student (no degree earned) } \\
\text { Florida Atlantic University }\end{array}$ \\
\hline $2000-2002$ & $\begin{array}{l}\text { Administrative Assistant } \\
\text { Alazhar School } \\
\text { Tamarac, Florida }\end{array}$ \\
\hline $2002-2004$ & $\begin{array}{l}\text { B.A., Organizational Leadership } \\
\text { Maryville University } \\
\text { St. Louis, Missouri }\end{array}$ \\
\hline 2003 & $\begin{array}{l}\text { Junior Achievement Business Trainer } \\
\text { Edgewood School } \\
\text { St. Louis, Missouri }\end{array}$ \\
\hline $2003-2004$ & $\begin{array}{l}\text { Leadership Trainer } \\
\text { Innovative Group }\end{array}$ \\
\hline $2004-2007$ & $\begin{array}{l}\text { Curriculum Committee Member } \\
\text { Youth Leadership Advisor } \\
\text { DIS Academy } \\
\text { Dayton, Ohio }\end{array}$ \\
\hline $2007-2011$ & $\begin{array}{l}\text { Graduate Assistant } \\
\text { Florida International University } \\
\text { Miami, Florida }\end{array}$ \\
\hline $2011-2014$ & $\begin{array}{l}\text { Curriculum Committee Member } \\
\text { Oaktree Institute }\end{array}$ \\
\hline $2007-2017$ & $\begin{array}{l}\text { Doctoral Candidate } \\
\text { Florida International University } \\
\text { Miami, Florida }\end{array}$ \\
\hline
\end{tabular}

High School Diploma

Pine Crest School

Undergraduate Student (no degree earned)

Administrative Assistant

Alazhar School

Tamarac, Florida

B.A., Organizational Leadership

Maryville University

Junior Achievement Business Trainer

Edgewood School

St. Louis, Missouri

Leadership Trainer

Curriculum Committee Member

Youth Leadership Advisor

DIS Academy

Dayton, Ohio

Graduate Assistan

Florida International University

Curriculum Committee Member

Oaktree Institute

Doctoral Candidate

Miami, Florida 